
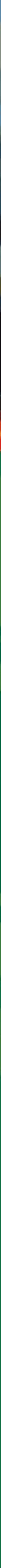


\section{Communities living with hazards}

\section{Editors}

\section{David King and Alison Cottrell}

Centre for Disaster Studies

James Cook University 
Published in 2007 by the Centre for Disaster Studies, J ames Cook University, Townsville and Cairns, Queensland, Australia.

Copyright (c) Centre for Disaster Studies, J ames Cook University.

All rights reserved. Apart from any fair dealing for the purposes of private study, research, criticism or review, as permitted under the Copyright Act, no part of this publication may be reproduced by any process whatsoever with out the written permission of the editors and the publisher.

National Library of Australia

Cataloguing-in-Publication data

Communities living with hazards

Editors David King and Alison Cottrell

Bibliography.

Includes index

ISBN 0864437528

Emergency management - Queensland

Hazardous geographic environments - Queensland

Natural disasters - Queensland

Printed in Australia by LogicMedia at J ames Cook University

Cover design by Verve Design, Blackwood Street Townsville

Warning: Aboriginal and Torres Strait Islander readers are advised that the book may contain images and stories of deceased persons. 


\section{Acknowledgements}

Adella Edwards: cartography and graphics

J ordahna Haig and David Lowe: editorial and coordination

Tropical Cyclone Coastal Impacts Program

Cairns City Council

Terry Hart and Linda Anderson-Berry, Australian Bureau of Meteorology and the Australian Research Council

The Indigenous communities and residents of:

Wujal Wujal, Mornington Island, Torres Strait islands of Thursday and Horn Islands, Injinoo, New Mapoon, Umagico, Seisia, Bamaga, Palm Island, Ringer Soak, Mulan, Balgo Hills, Billiluna, Halls Creek, Oombulgurri, Kalumburu, Old Mapoon, Yarrabah, Normanton, Lake

Nash, Pormpuraaw and Kowanyama

Queensland Fire and Rescue Service

Queensland Department of Emergency Services

Bushfire Cooperative Research Centre

Australian Fire Authorities Council

Bali Organisations: Parum Samigita, Bali SOS, Bali Recovery Group

Informants in Bali

Kowanyama Land and Natural Resource Management Office

Tamborine Mountain Fire Brigades

Thuringowa Fire Brigades

Queensland Parks and Wildlife Service

Beaudesert/ Gold Coast/ Thuringowa Councils

Tamborine Mountain communities

Thuringowa communities

School of Indigenous Australian Studies, J ames Cook University

\section{The Center for Disaster Studies is sponsored by the Queensland Department of Emergency Services}

\section{Disclaimer}

The State of Queensland, acting through the Department of Emergency Services makes no representations about the suitability of the information contained in this publication for any purpose. In no event shall the State of Queensland be liable for any special, indirect or consequential damages or any damages whatsoever arising out of or in connection with the use of information available in this publication. The views included in this document may not necessarily reflect the views held by the State of Queensland. 


\section{Contents}

\begin{tabular}{|c|c|c|c|}
\hline Chapter & $\begin{array}{l}\text { Title } \\
\text { Acknowledgements } \\
\text { List of Tables } \\
\text { List of Figures }\end{array}$ & Author & $\begin{array}{l}\text { Page } \\
\text { ii } \\
\text { iv } \\
\text { iv-vi }\end{array}$ \\
\hline Introduction & Communities living with hazards & $\begin{array}{l}\text { David King and } \\
\text { Alison Cottrell }\end{array}$ & 1 \\
\hline 1 & $\begin{array}{l}\text { What is this thing called } \\
\text { 'community'?: An example in far } \\
\text { north Queensland }\end{array}$ & Alison Cottrell & 6 \\
\hline 2 & $\begin{array}{l}\text { Government, non-government and } \\
\text { community organisations in } \\
\text { disasters }\end{array}$ & David King & 18 \\
\hline 3 & $\begin{array}{l}\text { Enhancing resilience and reducing } \\
\text { vulnerability: Lessons learned from } \\
\text { past disasters }\end{array}$ & David King & 33 \\
\hline 4 & Transport and evacuation planning & Douglas Goudie & 48 \\
\hline 5 & $\begin{array}{l}\text { Tourism, disasters and } \\
\text { vulnerability }\end{array}$ & Scott K. Cunliffe & 63 \\
\hline 6 & $\begin{array}{l}\text { Tourism crisis: Management and } \\
\text { recovery in tourist-reliant } \\
\text { destinations }\end{array}$ & Yetta Gurtner & 82 \\
\hline 7 & $\begin{array}{l}\text { Oral histories about weather } \\
\text { hazards in northern Australia }\end{array}$ & Douglas Goudie & 102 \\
\hline 8 & $\begin{array}{l}\text { Lardil weather stories and } \\
\text { experiences from Mornington } \\
\text { Island }\end{array}$ & Eddie McLachlan & 126 \\
\hline 9 & $\begin{array}{l}\text { Fire risk in Aboriginal peri-urban } \\
\text { landscapes in northern Australia: } \\
\text { Case studies from western Cape } \\
\text { York Peninsula }\end{array}$ & Jim Monaghan & 156 \\
\hline 10 & $\begin{array}{l}\text { Bushfires at the urban-rural } \\
\text { interface }\end{array}$ & $\begin{array}{l}\text { Luke J. } \\
\text { Balcombe }\end{array}$ & 193 \\
\hline 11 & $\begin{array}{l}\text { Living with bushfires: What do } \\
\text { people expect? }\end{array}$ & $\begin{array}{l}\text { Sally Bushnell } \\
\text { and Alison } \\
\text { Cottrell }\end{array}$ & 215 \\
\hline References & & & 254 \\
\hline Contributors & & & 282 \\
\hline $\begin{array}{l}\text { Glossary } \\
\text { Index }\end{array}$ & & & 285 \\
\hline Index & & & 286 \\
\hline
\end{tabular}




\section{Tables and Figures}

Table 1.1

Table 2.1

Table 3.1

Table 3.2

Table 4.1

Table 5.1

Table 5.2

Table 6.1

Table 9.1

Table 9.2

Figure 1.1

Figure 2.1

Figure 2.2

Figure 2.3

Figure 2.4

Figure 3.1

Figure 3.2

Figure 3.3

Figure 4.1

Figure 4.2

Figure 4.3

Figure 4.4

Figure 4.5

Figure 4.6

Figure 4.7

Figure 4.8

Figure 5.1

Figure 5.2

Figure 5.3
A classification of selected definitions of community

Organisations involved in Emergency Management

Post Disaster Studies Carried out by the Centre for Disaster Studies, 1997-2006

Hazard Awareness Targets

Evacuation matrix of safety responses

Hazards to tourism in tropical coastal areas

Community costs of catastrophic events

Direct foreign tourist arrivals in Bali 2001-2005

Bushfire risk treatment options in Pormpuraaw

Fire management in Kowanyama

The Bloomfield River region, Queensland, Australia

The Integrated Emergency Management System

Mitigation, Response and Recovery in Space and Time

Organisation and Membership of Organisations

A Matrix of Types of Organisations

Cyclone Tessi damaged Townsville's Strand in 2000, just after reconstruction had been completed following severe damage caused in 1998 floods

Damage to Black River settlement in Thuringowa following floods in 1998

Storm surge damage at Tikopia Solomon Islands, and tsunami damage at Phuket Thailand

Lessons learned by Cloncurry flood victims

Cloncurry resident showing height of flood waters through a ruined storage shed

Force of the Townsville flood, 1998

Main flood points in the Cairns road network

Cairns building near foreshore during spring tide

Detail of land-based flooding in the Cairns northern beach roads

Detail of temporary coast lines and 'dry' inner Cairns exit routes

Kewarra Beach at 1, 2 and 5m (above HAT) surge

'Great' natural disasters 1950-1999

Economic and insured losses for 'great' natural

catastrophes

Community assets and vulnerability 
Figure 5.4

Figure 5.5

Figure 5.6

Figure 6.1

Figure 6.2

Figure 6.3

Figure 6.4

Figure 7.1

Figure 7.2

Figure 7.3

Figure 7.4

Figure 7.5

Figure 7.6

Figure 7.7

Figure 8.1

Figure 8.2

Figure 8.2

Figure 9.1

Figure 9.2

Figure 9.3

Figure 9.4

Figure 9.5

Figure 9.6

Figure 9.7

Figure 9.8

Figure 9.9

Figure 9.10

Figure 9.11

Figure 9.12

Figure 9.13

Figure9.14

Figure 9.15

Figure 9.16
The contribution of the Travel and Tourism sector to GDP in APEC countries

Disaster losses in Asian LDCs

Disaster losses, total and as share of GDP

The Crisis Management Continuum

Location of the terrorist attacks in Kuta, Bali, 12 October 2002

Aerial view of the damage caused by the explosions at Paddy's Bar and the Sari Club

Tourism crisis - a deserted hotel pool-side in Kuta, J anuary 2003

Cloud in the Kimberley

Two dingoes - the story of the great flood of the Sturt Creek

Sturt Creek

Main settlement, Palm Island

The Kimberley region of north-west Australia

Forrest River landscape at Oombulgurri in the Kimberley

Boab trees in Oombulgurri in the Kimberley

Lardil clan boundaries

The old mission house, now guest house, Mornington Island

The wharf and channel at Gununa, Mornington Island

Western Cape York Peninsula

Magkara Lagoon is a popular dry season fishing place in the Kowanyama hinterland

Open fire cooking

Tending to a kup murri pit

A dry season camp site

Carrying water and supplies to a dry season camp site

An outstation in Kokoberra country

An outstation in Kokoberra/Yir Thangedl country

An outstation in Yir Thangedl country

An outstation in Yir Thangedl/ Yir Yoront country

An outstation in Kuuk Thaayore country

Early Dry Season Fire Frequency 1999 - 2002

Late dry season fire frequency: 1999 - 2002

Entire dry season fire frequency: 1999 - 2002

Outstation sites and fire frequency in 2001 in the Pormpuraaw DOGIT and Strathgordon pastoral property

Fire scars in the vicinity of the Pormpuraaw township 
Figure 10.1 Interface condition - Tamborine Mountain, Queensland Figure 10.2 Intermix condition - Tamborine Mountain, Queensland Figure 10.3 Occluded condition

Figure 10.4 Rural condition - Tamborine Mountain, Queensland

Figure 10.5 Type 1i-Zone

Figure 10.6 Type 2 i-Zone

Figure 10.7 Mount Tamborine

Figure 10.8 Northern Gold Coast

Figure 10.9 Canberra bushfires, J anuary 2003

Figure 10.10 Canberra bushfires, J anuary 2003

Figure 10.11 Canberra bushfires, J anuary 2003

Figure 11.1 Rural Fire Brigade member and cohesiveness 


\title{
Introduction
}

\section{Communities living with hazards}

\author{
David King and Alison Cottrell
}

This book, Communities Living with Hazards, is a celebration of the twentyfifth anniversary of the establishment of the Centre for Disaster Studies. The Centre was formally established by resolution of the Council of James Cook University on 5 April 1979. Staff and researchers with the Centre in 2004 contributed papers that encapsulated their areas of disaster research in order to present a summary of the diversity and orientation of the Centre after 25 years.

Disaster and hazard research at J ames Cook University was given impetus following the devastation of Townsville in 1971 by Cyclone Althea. A group of geographers and engineers, led by J ohn Oliver and Hugh Trollope built up expertise in cyclones that enabled them to contribute significantly to the analysis of Cyclone Tracy's destruction of Darwin in 1974. The engineers established the Cyclone Testing Station in 1977, while Oliver continued research on the physical and social impacts of cyclones and other natural hazards. This research was given focus by the establishment of the Centre in order to improve understanding of both hazards and their impact on people and communities. The social impact was given stronger emphasis by the developing needs of emergency managers and subsequently the International Decade for Natural Disaster Reduction throughout the 1990s. By 2005 the emphasis of research in the Centre had become primarily social and community in orientation, but was not restricted to natural hazards. J ust as emergency managers have been forced to pay greater attention to human induced catastrophes, so also have researchers in the Centre become involved in the impact of terrorism and complex human disasters.

The social emphasis of research in the Centre is focussed on communities. The term is used to cover a range of quite different groupings and places, such that Alison Cottrell starts the book with a discussion of the complexity of the concept of communities. The term hazards is used to be inclusive of the variety of hazards that particularly face communities in Australia, and also the human generated hazards of terrorism and war outside Australia which increasingly involve Australians, as victims and as responders.

Much of the Centre's research over the past decade has focussed on the vulnerability of people and communities to hazards. The practical aim of this 
research has been to contribute to a reduction of that vulnerability through partnerships with local, state and federal government organisations, nongovernment organisations (NGOs) and community and business groups. However, in working with this wide range of communities and organisations, and witnessing a significant number of disasters and their impacts, constantly recurring themes of risk and resilience shaped the ideas of vulnerability. Tackling vulnerability tends to emphasise the weaknesses and problems of communities, whereas recognising and building on characteristics of resilience emphasises the strengths and positive characteristics of society.

Alongside these aspects of communities there is the reality of many different priorities in people's lives competing with the need to prepare for a potential hazard. People, communities, and organisations accept risk in varying degrees, which they balance against their other activities and priorities. This balancing of risk alongside vulnerability and resilience is brought together in the idea of "living with" hazards.

Because people live and work in the tropical north of Australia the communities and hazards have a strong northern flavour, with small cities and towns and remote outback communities in a vast landscape that is regularly impacted upon by cyclones, floods, droughts and bushfire. However, the local lessons learned are applicable nationally and internationally. The commonality of living with hazards, and the practical steps that people must take to reduce the risk they face from predictable regular hazards transcends culture and geography. The book consequently begins with the larger picture of communities, organisations and a range of hazards and responses, through to the itinerant communities of our visitors. From the Indigenous communities that are a significant feature of the northern landscape, case studies of communities and places lead from cyclone, flood and isolation into the bushfire threat and back to the expanding cities and urban sprawl.

In the first chapter Alison Cottrell challenges definitions of community. Communities are complex, dynamic and frequently not geographical in nature, although that is the most common planning view of a community. An example is presented of the isolated Bloomfield community north of the Daintree rainforest as a complex, culturally mixed remote community that tackles its vulnerability to extreme wet seasons and floods through resilient endurance and self-reliance.

David King's chapter on organisations extends the definition of communities to the range of organisations and networks that play a role in mitigation of hazard impact, and response and recovery from a disaster. This began as an 
analysis of the part played by non-government organisations (NGOs) in disasters. As NGOs were defined, their links to other types of organisations, government and non-government, became difficult to isolate within the overlapping roles and responsibilities of mitigation, response and recovery. The chapter reviews the complexity and diversity of government, non government and community organisations and their changing roles in the disaster situation.

Early research began with a response to Cyclone Althea and developed as a Centre after Cyclone Tracy. Undertaking post-disaster studies has always been core business in the Centre. The events of specific disasters are historical milestones that shape local and national history. Learning from each crisis continues to be a critical role of researchers in the Centre. David King also examines in chapter 3 the experiences learned from disasters that have involved research on fieldwork, and examines these experiences against those of other centres and researchers.

In chapter 4 Douglas Goudie examines issues of transport and infrastructure as they constrain evacuation planning. Evacuation of actual risk populations is an option throughout Australia, but authorities tend to give advice and leave people to make their own arrangements in advance of the onset of the natural hazard. This puts responsibility on individual households to practice self-reliance and to evaluate risk and probability. Such an expectation requires detailed knowledge of hazards, likely impacts and safe evacuation routes. Goudie's work is directed towards the practical needs of warnings, education, hazard and route mapping, and anticipation of constructions and bottlenecks. The use of Geographical Information Systems (GIS) is both as an organisational planning and a community educational tool.

Scott Cunliffe's review of hazard risk in international tourism widens the scope of communities. Northern Australia, in particular, derives significant income and employment from the world's largest industry, tourism. Cunliffe looks at the problems of risk, insurers' issues and the reliance of tourism destinations on the sustainable flow and consequent safety of visitors. Emphasis is also extended beyond Australia to the less developed countries of the surrounding region, both as destinations for Australian and other OECD country tourists, as well as their specific vulnerability and sustainability.

In chapter 6, Yetta Gurtner focuses on the post-disaster recovery of two destinations which are popular for Australian tourists. The Bali bombing devastated the tourist industry of an island, with its slow recovery further affected by subsequent terrorist attacks. The Bali bombing of 2002 was also one of Australia's worst disasters in terms of Australian lives lost. 
The impact of the Indian Ocean tsunami in December 2004 was utterly catastrophic and researchers in the Centre, along with other colleagues, conducted research in four of the stricken countries in a variety of impact studies. Gurtner concentrated on the tourist resort of Phuket and was able to compare and contrast the recovery experiences of Bali and Phuket. Attention is also drawn to the impact on the destinations, the host communities, and by extension the lessons that may be learned for Australian tourist destinations and their sustainability.

Chapter 7 provided details of research from some of the more remote communities in northern Australia. The Bloomfield region case study, introduced by Alison Cottrell in chapter 1, began as part of a series of postdisaster studies following Cyclone Rona in 1999, when the Indigenous community of Wujal Wujal was isolated for many weeks. Non-indigenous residents in the same area, who were equally dependent on Wujal Wujal's facilities and lifelines, requested a community hazard vulnerability study, but drew the attention of organisations such as the Bureau of Meteorology and Queensland Department of Emergency Services to the specific circumstances of remote and especially Indigenous communities. The Centre worked with the Bureau of Meteorology in the area of the weather warnings to Indigenous communities throughout remote northern Australia. Douglas Goudie has summarised a portion of that knowledge in chapter 7, drawing on published Indigenous stories and weather knowledge, and oral traditions from fieldwork conducted by several members of the Centre alongside counterparts from the Bureau of Meteorology.

In chapter 8, Eddie McLachlan presents some details of fieldwork experiences of Indigenous weather knowledge from Mornington Island in the Gulf of Carpentaria. Transcripts of some of the interviews provide the authentic voice and indicate the resilience of Aboriginal elders on Mornington Island. Their stories are both cultural and historical, representing the experiences of people grounded deeply in an environment that they know intimately.

In chapter $9 \mathrm{Jim}$ Monaghan shares detailed knowledge of the Pormpuraaw and Kowanyama communities on the western side of the Cape York Peninsula, concentrating on the risk of bushfire to the outstations which are established intermittently by each community. This research was carried out as a specific hazard mitigation planning tool. Jim Monaghan has worked in these communities for most of the last decade; mapping the lands, communities and resources of Pormpuraaw and Kowanyama. The extensive Land Information System contributed to the development of a Natural Disaster Risk Management plan for Pormpuraaw and all-hazard mapping for 
each community. The strength of this work is seen in the complete integration of people, community, culture, land and meaning.

The risk of wildfires at the urban-rural interface is the focus of chapter 10 by Luke Balcombe. The complexity of settlement patterns and the relationship to hazardous bushfire environments is identified. The reasons which support the need for community engagement and education are also identified. Finally, preferred strategies for community education are then proposed.

Chapter 11 is a review of community perceptions and expectations of bushfire/wildfire experiences by Sally Bushnell and Alison Cottrell. This review provides the basis for understanding the variability between and among communities, leading the authors to conclude that locality remains important and that effective methods and models for community engagement need to be developed for application at the local level.

The need for research on communities and their experiences of hazards is unlikely to decline. The material covered by this book indicates some of the many different approaches that might be taken in addressing these issues. Current trends indicate a particular concern for understanding the strengths and limitations of post-disaster impact assessments and the associated methodologies. In particular, there are concerns to ensure that the impacts of hazards and disasters are not to the greatest disadvantage of the few. One consequence is a current trend for a focus on community development approaches to response, recovery and mitigation for the Centre for Disaster Studies and more broadly. 


\title{
1 \\ What is this thing called 'community'?: An example in far north Queensland
}

\begin{abstract}
Alison Cottrell
The Bloomfield River region lies in tropical north Queensland, Australia (see Figure 1.1). It is a mountainous area adjacent to the coast and bordered by the Wet Tropics World Heritage Area. The catchment is vulnerable to flooding, bushfires and tropical cyclones. In the process of conducting an appraisal of community awareness and preparedness for natural hazards (Cottrell et al., 2001), it became apparent that it was necessary to ask the question: what is a community, and what are the implications for hazard studies and practice?

The people who live in the Bloomfield River region are a mix of indigenous and non-indigenous residents estimated to amount to approximately 2,000 people, depending on the time of the year. Most income is from social security payments and government employment. There is an Aboriginal community at Wujal Wujal; cattle properties; tourist ventures which range from inexpensive camping to the very expensive; 'eco-tourism' resorts; people who have retired on independent incomes; those working for the public sector; and those who have 'opted out' of mainstream living, some of whom hold very strong views about conservation. Major industries include retail, tourism, grazing and horticulture.
\end{abstract}

\section{The Bloomfield River Region}

The Bloomfield River region is the traditional country of the Kuku-Yalangi people. Many of the people have homes in the township area of Wujal Wujal, the township of Ayton and/ or have seasonal camps in other parts of the region or live on outstations in the region. The diversity of the Aboriginal residents at Bloomfield was documented by Anderson (1984), and appears to have maintained its diversity. In particular there are two main families of political significance, between whom governance of the Aboriginal community fluctuates. 

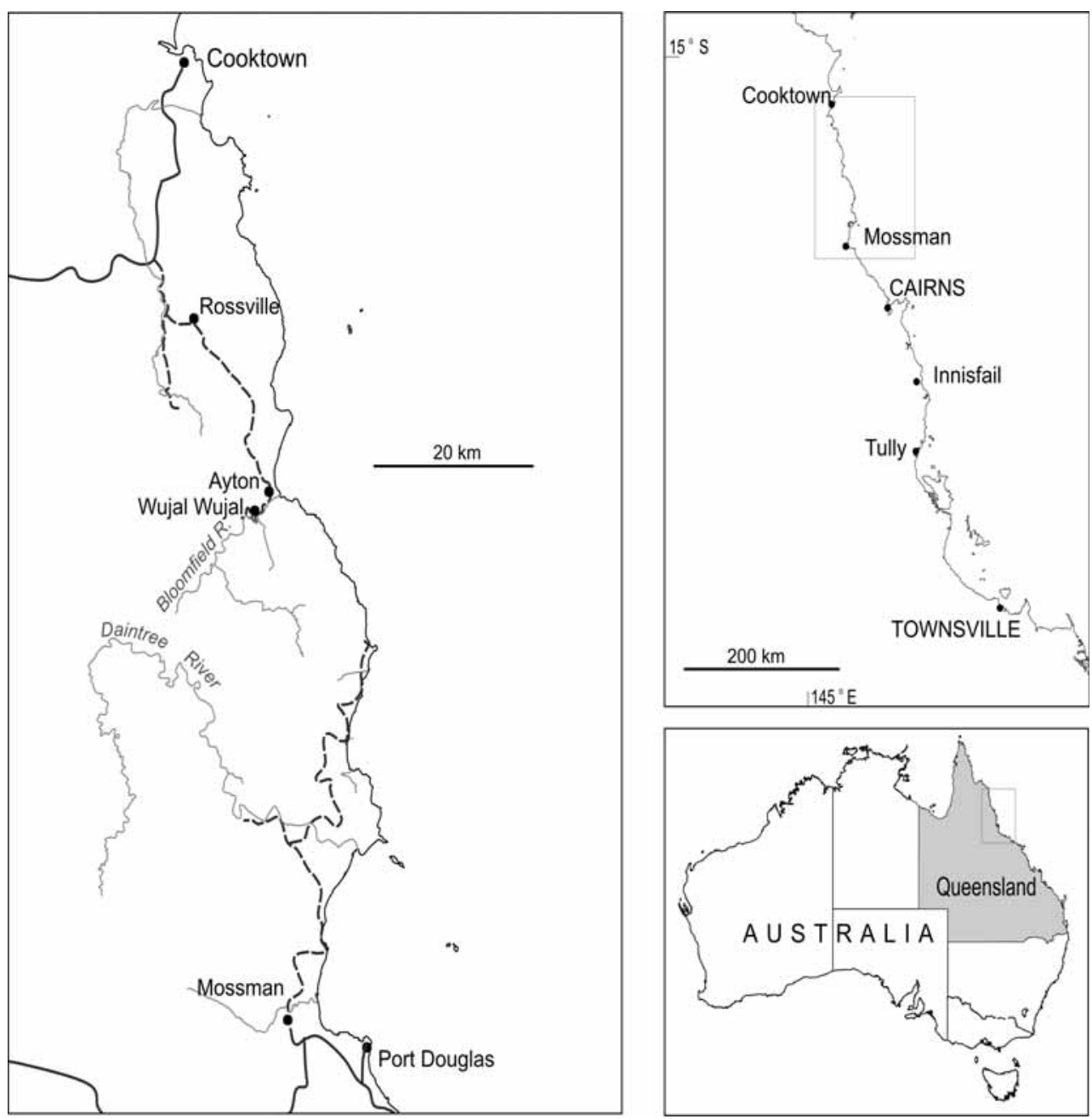

Figure 1.1 The Bloomfield River region, Queensland, Australia

The remainder of the residents in the region have a variable, but in some cases lengthy, history (Anderson, 1983) depending on the sector with which they are involved. For example, there are some families associated with grazing who have been there for several generations. There are also those who have had tourism related businesses for a decade or more. Some people came with the establishment of hippy colonies in the 1970s, bought properties and stayed. More recently, a number of retirees have settled, as well as a group the locals referred to as 'ferals' who live in makeshift 
dwellings in the forest areas. ${ }^{1}$ There are also an unpredictable, and unmonitored, number of tourists who move through the area.

Leaving aside the issue of tourists, there appears to be quite a lot of mobility in the region. Residents regularly travel to Cairns or Cooktown to shop, seek medical and other professional services, board at schools and visit relatives, be they Aboriginal or non Aboriginal.

There are three local governments involved in the region. The area physically covered by the Wujal Wujal Aboriginal Shire Council is that area relating to what was previously a mission and then a Deed of Grant in Trust (DOGIT) community. The social responsibility of this council extends beyond the physical boundaries to meet the needs of the Aboriginal community in the broader region. Cook Shire is technically responsible for the residents to the north of the Bloomfield River and has a local representative who reports to the council in Cooktown. The Douglas Shire, which is based in Mossman, is responsible for the residents south of the Bloomfield River but has no local representative. While there is a sealed road from Mossman through the tourist destination Daintree region, this terminates at Cape Tribulation, after which an unsealed motor-able track traverses the next 30 to 40 kilometres through the Daintree National Park. Environmentalists have campaigned vigorously for the closure of this road, and subsequently due to lower levels of maintenance it is impassable for extensive periods of the wet season. This and the lower level of political support from Douglas Shire led to feelings that residents north of the river were better served than those to the south. However, networks of relationships appear to readily cross the river.

There are a number of community groups operating in the area, some of which are highly active in community development and planning: the Bloomfield/Yalangi Catchment Committee (representing 26 interest groups); the Bloomfield River District Residents Association; the Bloomfield Sports Association; the Bloomfield River District Residents Association; a State Emergency Services (SES) group being established to be based at Wujal Wujal but involving the whole catchment; a well-established health centre is located at Wujal Wujal and serves the whole region; and a Home and Community Care group servicing the needs of the elderly and those with disabilities at Wujal Wujal and Ayton; There is a Community Economic Development Program (CEDP) at Wujal Wujal and Rossville, and a District Citizens Association at Bloomfield River.

\footnotetext{
${ }^{1}$ Interestingly, there is a component of retired hippies who refer to young people who have opted for the simple lifestyle as 'ferals'. This would make an interesting research topic as to whether this relates merely to length of residence, or to ownership of property vis a vis Hall, Thorns and Willmott, (1984),

Community class and kinship - bases for collective action within localities.
} 
The people who live in the region are quite diverse. Those who have moved into the area have done so for a variety of reasons, sometimes leading to conflicts in aspirations for the region. For example, many of the retirees have aspirations for greater access to infrastructure and services, there are also those with strong conservation values, and the Aboriginal community has a desire for increased services while maintaining traditional control. It is clear then, that there is variation in the level of horizontal integration between and within segments of the community. As well, the level of vertical integration is also varied (Warren, 1963; Martinez-Brawley, 1990). For example, representatives and administrators for the Wujal Wujal Council have strong linkages to other levels of government and services and many members of the non-Aboriginal community use the Internet extensively as well as having linkages to government agencies and other support networks.

The fact that the area becomes isolated so quickly in the wet season, combined with the fact that three local government bodies are required to act to meet community needs and do so to varying degrees essentially means that the community is left to deal with its problems on its own. This raises the issue of community based disaster or hazard response planning, and consequently, coming to grips with the issue of what is a community, and what are the implications for hazard studies and practice? This question needs to be addressed because there seems to be an assumption that rural and/or remote communities approach the ideal 'gemeinschaft' (i.e. community) (Cahnman \& Heberle, 1971). However, from the above description it is clear that in the Bloomfield River region, this may not be an accurate description.

\section{Defining Community}

To some extent the issue of defining community in Australia, in the context of hazards, has been addressed by Marsh and Buckle (2001), Buckle (1999) and Sullivan (2003). The discussion centred on the two issues of the complexity of community and the need to be clear about defining community. However, it is not merely the defining of community that is the issue here, but also whether it is ideology that is being discussed. It is important to move the discussion forward by elaborating on how the ideas/definitions/theories of community have developed over time. A detailed discussion of the diversity of perceptions of community within sociology is covered by Bell and Newby (1971) who built on Hillery's (1955) analysis of community definitions. Although Hillery was pessimistic about clarity because of the 94 definitions identified, Bell and Newby built on that analysis to find some common threads (see Table 1.1 below). They conclude that a "majority of definitions include, in increasing importance for each element, the following components of community: area, common ties and 
social interaction" (Bell \& Newby, 1971, p. 29). They then proceed to introduce the notion that conceptualising community as networks may be a productive strategy. This view of community is pursued with great vigour by Wellman (1988, 2001).

Wellman (1988) argues that the evidence that communities exist beyond location is clearly apparent. Wellman also suggests that by focussing on community as network allows the endurance of social relationships to be evidenced and that conceptualising community as networks allows linkages between small and large scale phenomena in a seamless manner.

Table 1.1 A classification of selected definitions of community (after Hillery)

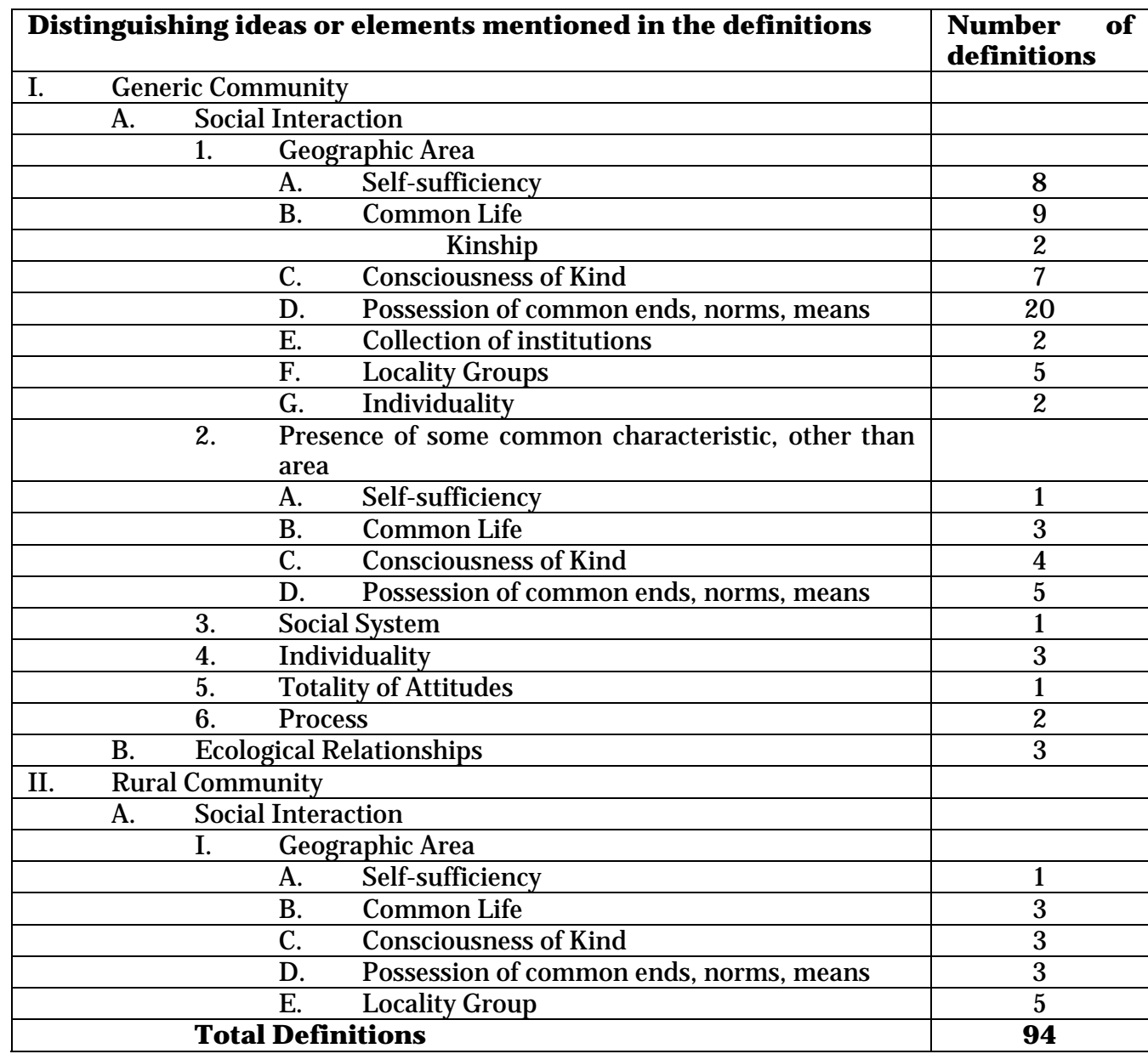

Source: Bell and Newby, (1971), pp. 28-29 


\section{History of Ideas about Community}

Nisbet (1970), Bell and Newby (1971) and Wellman (1988) all remind us of the long history of intellectual traditions which inform our debates about what is community. For Nisbet, there is a 'rediscovery of community' in the nineteenth century. Nisbet identified the nineteenth century concerns with community as a reaction to the concept of contract, rationalism and modernism of the sixteenth to eighteenth centuries (which in itself was a reaction to community as embedded in feudal relations). It is not unusual in social theory to find that at any point in time there are various views held about social phenomena, but that at a particular point in time certain approaches/views dominate. In the $19^{\text {th }}$ century various levels of scale are used about the notion of community. That is community as nation, community as town or city, community as a geographical location. These remain with us, as do strong feelings about what constitutes community, for example Nisbet states:

By community I mean something that goes far beyond mere local community. The word, as we find it in much nineteenth- and twentieth-century thought encompasses all forms of relationship which are characterized by a high degree of personal intimacy, emotional depth, moral commitment, social cohesion, and continuity in time. Community is founded on man (sic) conceived in his wholeness rather than in one or another of the roles, taken separately, that he may hold in a social order. It draws its psychological strength from levels of motivation deeper than those of mere volition or interest, and it achieves its fulfilment in a submergence of individual will that is not possible in unions of mere convenience or rational assent. Community is a fusion of feeling and thought, of tradition and commitment, of membership and volition. It may be found in, or be given symbolic expression by, locality, religion, nation, race, occupation or crusade. Its archetype, both historically and symbolically is the family, and in almost every type of genuine community the nomenclature of family is prominent. Fundamental to the strength of the bond of community is the real or imagined antithesis formed in the same social setting by the non-communal relations of competition or conflict, utility or contractual assent. These, by their relative impersonality and anonymity, highlight the close personal ties of community (Nisbet, 1970, pp. 47-48).

In Nisbet's (1974) view community is central to sociology: community and conflict in relation to the military, political, religious, revolutionary, ecological, and plural communities are discussed at some length. 
Nisbet (1970) and Bell and Newby (1971) both structure their discussions of community in ways that offer us mechanisms for a clearer understanding of the matter. Both discussions refer to Community as Typology or Types; Community as Methodology or Study Method; and Community a Microcosm, or the Molecular Community. Nisbet (1970) also discusses the Empirical Community and the Moral Community while Bell and Newby (1971) expand on Ecological Approaches; Community as Organisations; and Community, Locality and Network.

For this discussion: types, methods, the empirical and the moral community deserve some attention.

\section{Community as Methodology}

Durkhiem is identified by Nisbet as the key figure in the use of community as a methodology for understanding four major themes in human behaviour: morality; analysis of contract; the study of suicide; and the nature of 'man' (sic) (Nisbet, 1970, pp. 82-97). Bell and Newby (1971) include a series of community studies which illustrate this approach quite extensively.

\section{Community and Typology}

It is difficult to imagine a discussion on 'community' which does not refer to Toennies. Cahnman and Heberle (1971) discuss clearly the influence of the Romantic Period and in particular the influence of Comte and Hobbes on Toennies. It is also apparent that from very early on Toennies had to defend this position with other academics of the time; it was necessary to make it clear the position was not idealising gemeinschaft (community) and demonising gesellschaft (society), as Cahnman and Heberle state:

By "community," the reader must not understand a territorial or administrative entity, but what is held in common, what makes for cohesion, what provides bond among men (sic). Occasionally, the meaning of the word "community" comes near to the one of "communion," as in intimate friendship and similar relations that are beyond question. ... We (the editors) have translated Gesellschaft as "association" rather than as "society, "because in the word "association" the meaning of choice and purpose comes clearly to the fore...(Cahnman \& Heberle, 1971, p. xx).

It is necessary to also view the social relations of both ideal types as having positive and negative characteristics, particularly to avoid the trap of resorting to ideology and rhetoric. 
Toennies clarified this position:

I have not considered it as an "ideal", but as an ideal, or constructional, type. ...I do not know of any condition of culture or society in which elements of Gemeinschaft and elements of Gesellschaft are not simultaneously present, that is, mixed (Cahnman \& Heberle, 1971, pp. 9-10).

Clearly then, Toennies differentiates between heuristic devices and what might be described as 'reality' or praxis. As well, the need for clarification is already apparent. The debate about what constitutes 'community' clearly: "has entertained social scientists for almost as long as there has been societies to study" (Sullivan, 2003, p. 19).

This need to distinguish between heuristic devices and 'reality' brings us clearly to the door of ideology. It also brings to the fore the notion of the moral community which will be discussed later. Whilst the distinction between theory and ideology can sometimes appear blurred, Neuman (1997, pp. 37-38) provides a useful clarification. Cohen (1985) verges on accusing theorists of ideology when examining the dichotomies that were historically present in theories of community. Toennies' gemeinschaft versus gesellschaft; Durkeim's mechanical versus organic solidarity; Redfield's folk versus urban society was another 'imagined entity' (Bell \& Newby, 1971, p. 43) and the Chicago School of urban scholars who dealt with urban development in particular. The dichotomy was extended to include postindustrial society by Richmond to further a developmental view of social relationships with an implication that the more urban and (post) industrial tended to be more sophisticated and have more advanced social relations.

In critiquing these ideal types of simple versus complex, Cohen (1985) identifies three 'myths' about 'community' which seem to prevail: the myths of simplicity, egalitarianism and inevitable conformity. In terms of simplicity, Cohen suggests that there are no simple relationships in any community. In urban communities there may be a greater number of roles encountered by individuals, but even in small societies, relationships are complex. Cohen suggests that in some cases, living in large communities makes it easier to withdraw from difficult situations, particularly if dealing with a stranger. Whereas in a small community, often financial and other activities are conducted by people who are in contact with each other on a regular basis. This regular contact requires much more careful social transactions if amiable relations are to be maintained. In large communities it is possible to have relations conducted with strangers and with people who are contacted on a regular basis. Therefore there are few social relations 
which are 'simple', and face to face, and intimate relations occur in all societies.

Cohen also suggests that egalitarianism should be questioned as to whether it is: "ideology ('we should all be equal here')...rhetoric ('we are all equal here').. and...pragmatism ('we behave as if we were all equal here')..." (Cohen, 1985, p. 33). None of these, Cohen suggests, should be confused with the social reality of egalitarianism.

The myth of inevitable conformity is the view that small scale, isolated communities will become overwhelmed by the dominant culture of the large urban centres and lose any identity they may have had. Cohen suggests that these views: "Assume that people can have their culture stripped away, leaving them quite void, then to be refilled by some imported superculture. They assume, in other words, that people are somehow passive in relation to culture: they receive it, transmit it, but do not create it" (Cohen, 1985, p. 36). Community, Cohen suggests, is a socially constructed, symbolic phenomenon. As social change occurs, social and physical boundaries may be lost, but the symbolic socially constructed boundaries are not lost.

However, this shared sense of community which is symbolic may not have exactly the same meaning for each member of the community. For instance, community members may use similar words to describe their community and its activities, but when pressed to describe what these definitions actually mean to them, differences become apparent.

Similarly, Milofsky (1988) indicates: "Communities and their organizations are hard to study.. because they exist primarily in the minds of people. Each member perceives a different community, as roles, geographic location, cultural background, occupation, and a host of other factors vary. 'Community' also has a background factor in the lives of most people" (Milofsky, 1988, p. 4). This brings us to the idea of the moral community.

\section{The Moral community}

Nisbet (1970), in discussing the centrality of the idea of community to sociology, introduces the significance of Comte's views on the notion of the "community lost, community to be gained" (Nisbet, 1970, p. 56). This is a theme well recognised by those who consider the issue of community. Not only do researchers and lay people alike have ideas about what community is, but researchers and lay people may also hold views about the moral worth of community. Again, this can be reflected in those continua of oppositional typologies. Depending on the viewer, urban and complex may be sophisticated and contemporary or the small and simple may be the 'truer' 
community to be valued and preserved or lamented in its passing. Similarly, Wellman (1988) argues:

Contemporary urbanites perversely flatter themselves by remarking how stressful are modern times. They fear that communities have fallen apart, with loneliness and alienation leading to a war of all against all. They are sure that their pre-industrial ancestors led charmed lives when they could bathe in the warmth of true solidarity community... Paradoxically, few urbanites will confess to living lives of lonely desperation. They know they have supportive communities, and that their friends, neighbors, kin and co-workers have them as well...At the same time, nostalgia for the perfect pastoral past dims awareness of the powerful stresses and cleavages that have always pervaded human society (Wellman, 1988, p. 81).

It is the 'loss of community' lament that is most problematic for researchers because some get caught up with what people want community to be, rather than what more objective observations might reveal, that is, what might be described as the empirical community.

\section{The Empirical Community}

For Nisbet (1970) the study of small communities to make what might be described as 'scientific' generalizations about social relations clearly began with Le Play's study of kinship and community in The European Working Classes where he compared 45 families from all over Europe (see also Périer, 1998). Bell and Newby (1971) provide a useful summary of American and European studies of community, with the wry observation that despite the fact there is so much trouble defining community, community studies are none-the-less conducted. The methods used to study communities are varied, but the authors identify some generalizations. Participant observation is one method, but one which despite the richness of the outcome is often criticized for being overly sympathetic to the object of study. Survey techniques may appear attractive for larger population areas, but there is the warning that surveys target individuals not communities, and that unless these are offset with other information could be quite misleading. Researchers are also reminded that there are other forms of data, specifically organisational and other records that might be interrogated to provide information. Above all, Bell and Newby (1971) insist that social interaction is what is sought within the notion of studying community. This by necessity requires identification of organizations and their interactions, class and other status relations which might influence involvement, and power and conflict relations. Bell and Newby also include the use of ecological approaches and network analysis. The merits of network analysis in 
community studies are exemplified particularly in Wellman (1988) and Tindall and Wellman (2001).

\section{Implications for Community studies in the context of Hazards}

Clearly, there is a need to understand in general terms, what is meant when people refer to 'community'. Are they lamenting the loss of the (moral) community' in times of high levels of urbanisation, population mobility and social change? If it is an individual speaking, it is important to remember it is their view of what constitutes community which may differ from other views. What are people implying when they talk about community, is it a locality or is it the networks of relationships that occur at that locality? It cannot be assumed that communities are homogenous entities for which planning is easily undertaken. Communities are also not static, geographically, in terms of membership and in terms of ideology or beliefs. In particular researchers should not be concerned with discovering, or wishing to discover, imaginary idealised social structures. When using 'community' as a methodology, however, there can be a danger of developing a series of case studies that are atheoretical.

Some authors suggest there is no such thing as community, or that community has come to be meaningless and that the term should not be used. Bell and Newby (1971) warn against semantic sleights of hand by merely choosing another word. However, it is highly unlikely that in the short term community will be lost from our vocabulary, and as Nisbet (1970) quotes Durkheim: "If the idea of society were extinguished in individual minds, and the beliefs, traditions and aspirations of the group were no longer felt and shared by individuals, society would die. We can say of it what we..said of divinity: it is real only insofar as it has a place in the human consciousness..." (Nisbet, 1970, p. 95). For Wellman (2001) the notion of community is well and truly alive, even in, or perhaps especially because of, the age of the Internet.

\section{Conclusion}

In the context of hazards, and the Bloomfield River region is an example, geographic location remains of importance, because the types of hazards to which people may be exposed are to a large extent determined by location. In the context of the discussion of what might constitute community in the context of hazards, there are some clear conclusions to be made. What was sought was an empirical view of community, that would allow a more effective approach to hazard mitigation. What was found was clearly a location with at least two primary community networks within which social status and power relations figure strongly, and do vary. Within the 
Aboriginal community 2 there were two politically strong families and within the non-Aboriginal community, a range of networking options, with some people clearly having very little influence. These networks are of prime importance to a situation where hazard planning and mitigation are intended. It can be understood that the networks may be able to provide mutual support in the context of a natural hazard.

It is also clear that because of networks outside the geographical location, resources such as weather information are more readily available than might have been assumed. The benefits of community studies to hazard mitigation and planning clearly remains useful, but it must be acknowledged that each community will be different and that this needs to be understood by service providers.

\footnotetext{
2 It is interesting to note the Aboriginal community was referred to as 'community' while the mainstream community was referred to as 'residents', by Aboriginal people and mainstream people alike.
} 


\section{Government, non-government and community organisations in disasters}

\section{David King}

In the event of a disaster, communities become the targets of specialist organizations and undergo a concentration of activities. The complex unstructured activities and routines of daily life are disrupted and even totally overwhelmed by a single catastrophic event that requires a redirection of priorities, resources and people, to deal with all aspects of the disaster impact as rapidly as possible. The whole community must be mobilised to restore functions and meet needs, to return to the normality of the predisaster state. This latter purpose is least likely to be achieved, as the destroyed community can seldom rebuild to the same complex, but randomly haphazard state that existed before the disaster.

To mobilise the whole community to a single purpose of recovery, requires a high level of organisation. Response to a disaster demands that there be purposeful organisations ready to provide leadership and action. Emergency Management is predicated on the existence of such purposeful organisations. However, while organisations are at the core of Emergency Management Response and Recovery they are by no means simple or singular. Disaster generates the activities of a plethora of organisations, which interact with the community, rather than simply organising disaster response. The community also organises itself, re-assigning priorities and using existing organisations and networks.

\section{The Emergency Management Organisational Environment}

This chapter examines the range and roles of organisations that are involved in all aspects of disaster. The organisations are the structure of disaster Preparedness, Prevention, Response and Recovery, but the community and its citizens are the core of the effects of the disaster itself. In recognition of this Emergency Management has shifted its roles from a concentration on the traditional phases of Preparedness, Prevention, Response and Recovery to a much more community centred approach (Cronstedt, 2002). However, professional emergency managers, who have the greatest knowledge of such 
shifts in approaches and the reasons behind them, are only employed in some of the organisations that are involved in disasters. While the professional emergency managers may provide the most direct leadership and integrative structure to the tasks of dealing with disaster (Britton, 2001), the numerous other organisations that become involved have formerly existed to provide other kinds of services and functions which must be subsumed to deal with the immediate needs of a disaster. Thus although professional emergency managers in mainstream hazard oriented organisations may be aware of the complexity of the management and leadership roles that they are practising, this does not necessarily transfer to the managers and leaders of other organisations.

The traditional Emergency Management structure of Preparedness, Prevention, Response and Recovery (or its variant acronyms) is presented in Figure 2.1 below. These four processes structure the tasks of planning for likely disaster scenarios and for responding, and then reconstructing society and community in the event of a disaster occurring.

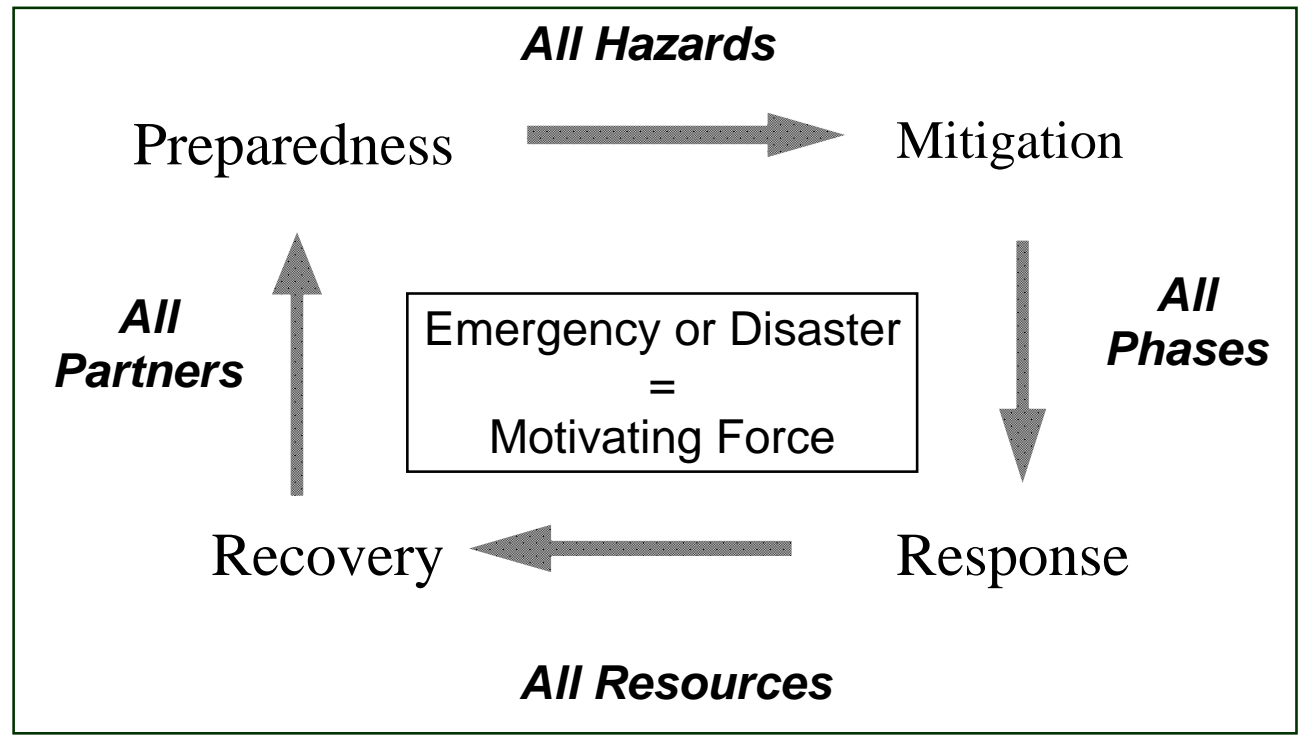

Figure 2.1 Integrated Emergency Management System (source: EMD, 2000)

Increasingly Emergency Management is using the term Mitigation as a larger group of activities that subsume both Preparedness and Prevention. The US Federal Emergency Management Agency (FEMA) uses preparedness and mitigation as separate stages. Emergency Management Australia (EMA) defines mitigation as "measures taken in advance of a disaster aimed at decreasing or eliminating its impact on society and the environment. See also prevention." (EMA, 1998, p. 76). 
Preparedness is defined as "arrangements to ensure that, should an emergency occur, all those resources and services which are needed to cope with the effects can be efficiently mobilised and deployed. Measures to ensure that, should an emergency occur, communications, resources and services are capable of coping with the effects" (EMA, 1998, p. 88). As a disaster is an event that is "beyond the day to day capacity of the prescribed statutory authorities and which requires special mobilising and organising of resources other than those normally available to these authorities" (EMA, 1998, pp. 32-33) the implication is that preparation is entirely contingent upon the scale of the disaster, which is presumably affected by preventive measures that have been put in place. The activities cannot exist separately. Preparing for a disaster will most likely initiate the process, but from then onwards both sets of activities are inextricably linked, reinforcing and complementary. As Emergency Management stakeholders have been using mitigation as an inclusive concept that subsumes preparedness and prevention, it has been used in that sense in Figure 2.1 above, partly in order to simplify a diagram that attempts to express the complexity of the stages of Emergency Management. However, it is irresponsible for any agency to prepare for a disaster without instigating preventive measures, even if these are as basic as information and warnings. The Emergency Management structure partially defines organisational roles and responsibilities, but has tended to portray them as steps or as a linear process, as in Figure 2.1. Many commentators (Cronstedt, 2002; Britton, 2001; Yates, 1999; Comfort et al., 2001) have criticised this linear model of Preparedness, Prevention, Response and Recovery.

These weaknesses and criticisms of the traditional model have led the author to develop a three-dimensional model as presented in Figure 2.2 below.

If the Emergency Management system is simplified into three main groups of activities: Mitigation; Response; and Recovery, there are distinct identifiable roles and responsibilities. Organisations fit into these three broad areas, but not as exclusive processes. Many organisations, both government and non-government, are involved in multiple aspects of disaster mitigation, response and recovery. All these elements are ongoing and interlinked and Figure 2.2 illustrates how these processes may operate simultaneously, interlinking and reinforcing. Mitigation is practised by all organisations and communities to varying degrees, even subconsciously or by seasonal routine. Mitigation of disaster impact is not a process that stops when hazard impact turns into a disaster. The disaster impact is part of the mitigation process in testing, challenging and confronting both the organisations and citizens. A process of learning and direct experience feeds back into mitigation, which grows in potential from the actual experience of the disaster. 


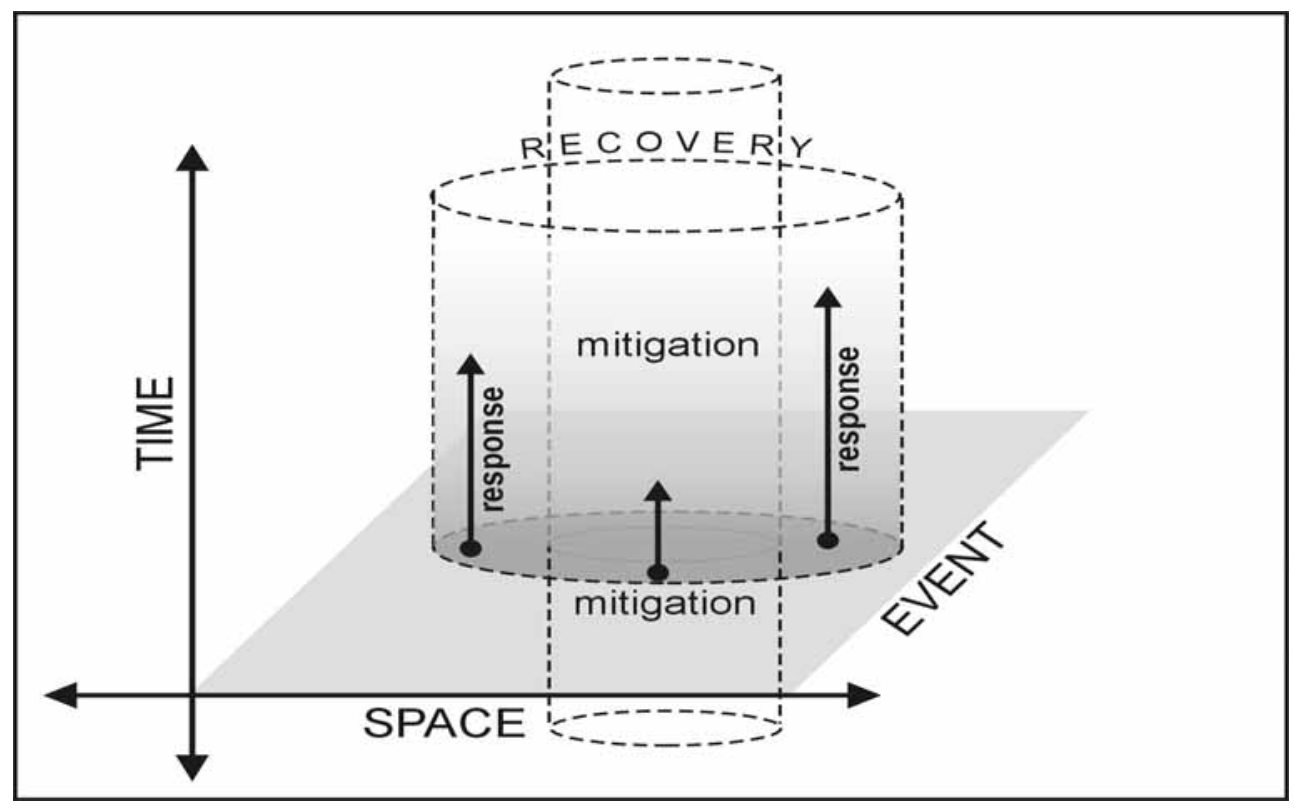

Figure 2.2 Mitigation, Response and Recovery in space and time

Thus mitigation is shown as an iterative and encompassing process. It proceeds through feedback loops, identifying and responding to shortcomings and needs. It can also appear to revert, or go backwards, as obstacles are confronted and mitigation measures fail or are too costly or difficult to implement. Mitigation can be made even more difficult through the contradictory efforts of different agencies. For example, road safety oriented street designs are concerned with traffic calming and a hierarchy of types of streets that reduce and slow local traffic. In flood or storm surge evacuation these design elements can create bottlenecks and congestion and may actually endanger lives. Levees provide short term protection, but in the long term may result in far more serious and widespread flooding. In other locations, flood drainage channels may also exacerbate flooding. The design of roads to act as drainage channels reduces their effectiveness in the event of evacuation.

Response has been typically the Emergency Management focus for a hazard impact or disaster. The reality of a disaster overwhelming the emergency services limits their initial response. The first response is from the impacted community. People who experience the direct effects of a disaster are not passive victims. They are active participants who will work through a range of organisations and networks to deal with the crisis. People may be traumatised, injured and suffering loss, but despite this they are the first 
people on the scene, the first to respond and the first to begin the recovery process. Recovery begins the moment a disaster happens (Sullivan, 2003).

The event also triggers a response in those organisations that have a responsibility or a role in the disaster. Preparation for a predictable and probable hazard is beyond being just mitigation, it is part of the response. Decisions have been made before the event that determine who will do what when the event happens. As citizens take shelter and carry out final precautions and preparations, the emergency organisations also position themselves to deal with the impact. Post-disaster studies in northern Australia (King, 2002) have shown that people leave a significant amount of preparation until the last minute, when the impact of the hazard is certain (or at least the probability is very high). All of the post disaster studies undertaken by the author in northern Australia have been floods and tropical cyclones, or both, which can be predicted to such an extent that people can feel confident in carrying out late preparations. The media refers to panic buying and last minute panic preparations, but observations of people and communities have not portrayed panic. In the immediate few hours before impact people are calm and purposeful in their behaviour, although most will express emotions that principally include concern, excitement and some degree of nervousness. In the tropical north of Australia people are advised to clear up potential debris at the beginning of the cyclone season, and to prepare an emergency kit. The fact that they delay this preparation until a cyclone or flood is inevitable, is a behavioural response that is mirrored by most organisations. Mental preparation and planning notes what needs to be done, but scarce resources cannot be allocated to the hazard response until it happens. Thus actions which are expected as preparations, are in reality postponed to become part of the response; a pre-disaster response. The response is therefore a direct outcome of mitigations and begins immediately before the hazard hits. The completely unexpected and extreme disaster has probably not been prepared for or mitigated against. Response and Recovery in such an event will begin immediately after it has happened.

Recovery is triggered by the response. It begins immediately after the disaster has occurred, but it is not a linear process (Sullivan, 2003; Cronstedt, 2002). The response to the disaster involves many different organisations, government and non government, each of which has separate roles, responsibilities and agendas. They carry out different tasks, at separate times and places, as well as overlapping and even sometimes competing with one another. In the ideal world all of these organisations would be coordinated by a single authority. In the developing world especially, this is frequently not the case.

A coordinating authority may exist, but it is frequently under-funded, poorly resourced, and even ignored by non-government organisations (NGOs), 
other government departments and politicians. This happened on a large scale in Papua New Guinea (PNG) following the Sissano Lagoon Tsunami disaster in 1998. To a lesser degree, coordination of the response to the impact of Cyclone Zoe on Tikopia and Anuta in the Solomon Islands in 2003 was constrained by a collapse of governance in that country, with the consequent inability of coordinating authorities to initiate a rapid response without outside assistance. Thus response is contingent upon the wealth of a nation, not just in terms of its physical capability, but more importantly in terms of governance.

The response phase can easily be poorly coordinated or chaotic. Even in the best of circumstances, the devastating impact of a disaster means that responses will come in pulses of activities that will inevitably occur separately in time and space. As response cannot be equal, recovery is most certainly not equal or linear. Recovery is also community initiated as well as developing from the organisational response. Community and organisational Response and Recovery efforts may proceed in parallel, virtually independent of one another. Again, this process of parallel recovery is far more likely to occur in developing countries, where a lack of pre-disaster infrastructure exacerbates problems of Response and Recovery.

Recovery proceeds in unequal pulses that involve a series of feedback loops as well as setbacks and secondary crises, such as public health emergencies that emanate from the initial disaster and redirect resources and efforts, thereby slowing the recovery process, and adding fresh impacts and trauma to the afflicted community. Recovery is an iterative process that develops opportunities as well encountering constraints.

\section{The Organisations}

It is within these complex interlinking phases of Emergency Management that organisations operate. Primary Emergency Management is generally practised by governments, with citizens reasonably expecting that emergency organisations will come to their aid in a disaster. Their expectations include a response from the army or defence force. The reality of a disaster is that the local emergency services and the civil functions of local government organisations are unable to cope, and the army does not necessarily have an Emergency Management role. Some countries use their defence forces to a greater extent than Australia, with civil defence having a much stronger relationship to military defence. Until 2001 Australia's peak Emergency Management body, EMA, came under the Department of Defence, although it was not answerable to the military, nor they to EMA, although EMA is a civil defence organisation in the event of war. However, it remains a misconception of many citizens that the defence forces will automatically be 
involved in a major disaster. On many occasions they have been involved, especially in such massive disasters as Cyclone Tracy in 1974 and 1975, but they only participate on request from civil authorities. This also applies to overseas relief operations, where the decision to use the defence forces is made by central government.

Emergency Management is therefore primarily a civil government activity, coordinated from the local level through state or provincial governments, up to a central government response depending upon the severity of the disaster (Douglas, 1999; Norman \& Coles, 2003). In developing nations a lack of resources, as well as traditions of military involvement in government, may result in a stronger reliance on military intervention in disasters. There are many developing nations that have a small or even no defence force, especially in the Pacific where only PNG and Fiji have armies. Although PNG has experienced a long civil war on Bougainville, its colonial and development experience put strong emphasis on its police and civil authorities, such that it's defence force continues to take a secondary role in disaster response.

Emergency Management is structured through laws that apportion responsibility for preparedness and prevention, and for response and recovery. For example in Queensland the Disaster Management Act 2003 (Queensland Government, 2003) specifies arrangements that are primarily carried out at the level of the local government. Local governments vary enormously in size and area. The smallest local government areas in northern Australia have less than 1,000 people and many have land areas in excess of 50,000 square kilometres. Their organisational capacity to deal with disaster is very limited, although the remotest parts of the north cope with floods and cyclones that in more developed parts of Australia would constitute a natural hazard or become a disaster. A similar resilience supports communities in remote parts of developing nations in South-East Asia and the Pacific.

Although legislation puts responsibility on local levels of government to prepare for disaster, the capability to respond adequately is limited. Apart from local government, disaster preparation is a requirement for all other government departments that provide social and welfare services to the community. In a disaster these needs are increased and are more urgent. Emergency Management coordinates the responses of all these government organisations, but they are separate entities answerable to different political masters. Each government department has its own priorities, agendas and needs, even within an atmosphere of cooperation. While many of these organisations have clearly defined, exclusive roles, such as health and police, organisations responsible for specific community members, such as the aged, 
or specific ethnic groups, may end up side by side providing very similar services.

Government is only one of many types of organisations that become involved in disasters. The trend in government has been towards less government and more privatisation. Former government roles in welfare and service provision are now provided by private enterprise. There is a blurred line between companies that are providing services to the public, and the traditional NGOs that began life as charities. At the further end of the business end of this continuum of organisations are companies that are in business to make profits for their shareholders, but which possess plant, machinery and expertise or infrastructure to play a very significant role in community recovery. Some companies are devastated or go out of business in a disaster, but for many others it is an opportunity for expansion, and inevitably profit, although individuals working for these companies may be no less motivated by altruism than members of government and relief organisations. The need to operate profitably does not in any way lessen their commitment to any of the phases of Emergency Management. At the same time they may even be able to provide services more efficiently and at a lower cost. That is often the aim of privatisation.

At the other end of this continuum are charities and humanitarian NGOs whose members are driven principally by beliefs, altruism and often a strong political agenda. However, the humanitarian NGOs have been undergoing quite dramatic changes to their roles. These issues and their impact on Emergency Management, especially in developing countries will be returned to later in this chapter.

On one scale there exists this continuum between altruistic NGOs at one end and purely commercial business operations at the other end. Stretching this scale is a size and spatial continuum that ranges from the international and national government organisations down to community, household and residual leadership. These ideas are expressed in Figure 2.3 in terms of these continua. 


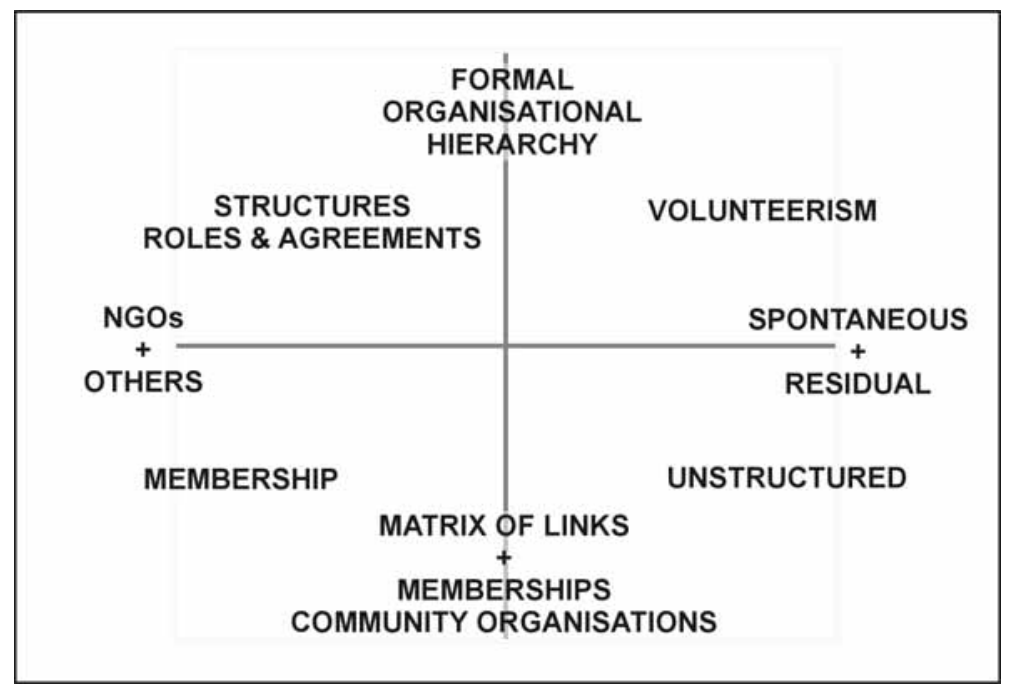

Figure 2.3 Organisation and membership of organisations

Table 2.1 below lists the types of organisations involved in Emergency Management and disaster response and recovery. The model expressed in both Figures 2.1 and 2.2 and listed in Table 2.1, is organisations coming together from diverse backgrounds to focus on a disaster event, within the dimensions of space, time and specialist roles and skills.

Table 2.1 Organisations involved in Emergency Management

\begin{tabular}{|l|l|l|}
\hline \multicolumn{1}{|c|}{ Direct } & \multicolumn{1}{c|}{ Indirect } & \multicolumn{1}{c|}{$\begin{array}{c}\text { Residual \& } \\
\text { Spontaneous }\end{array}$} \\
\hline International & Businesses & Culture \\
\hline $\begin{array}{l}\text { Government } \\
\text { Organisations }\end{array}$ & $\begin{array}{l}\text { Economic } \\
\text { Organisations }\end{array}$ & Community Networks \\
\hline $\begin{array}{l}\text { Non-government } \\
\text { Organisations }\end{array}$ & $\begin{array}{l}\text { Recreational } \\
\text { Organisations }\end{array}$ & Internet \\
\hline Privatised Specialists & $\begin{array}{l}\text { Religious } \\
\text { Organisations }\end{array}$ & Residual Leadership \\
\hline $\begin{array}{l}\text { Grass Roots } \\
\text { Organisations }\end{array}$ & Cultural Groups & Volunteers \\
\hline $\begin{array}{l}\text { Community } \\
\text { Organisations }\end{array}$ & Interest Groups & Fixers \& Tradespersons \\
\hline & Political Groups & Illegal Groups \\
\hline & Media & Family \& Household \\
\hline & & Individuals \& Visitors \\
\hline
\end{tabular}


The organisations directly involved are those that have a primary responsibility for Emergency Management and disaster mitigation. Government organisations include all levels of government as outlined earlier. The NGOs include the traditional relief organisations and charities, but there are also NGOs that would be included in the indirectly involved group of organisations, such as Landcare, the formal organisations of religions, various types of youth groups that provide volunteers and so on. These are separate from organisations like the State Emergency Services (SES), which rely on volunteers, but are sponsored directly by government. However, many groups, including rural fire brigades, surf lifesaving clubs and others, are essentially community organisations. Grass Roots Organisations (GROs) are very definitely local community groups. Within the developing world, many GROs were formed as progress associations for the sake of advancing development, but adapted to relief and recovery in the event of a disaster. In the developed world GROs have often been single issue, but otherwise quite loose organisations. Some of these have responded directly to disasters or the threat of a hazard, as victim support or lobby groups, but there are far more GROs that are indirectly involved in disaster Response and Recovery (Fahey, 2003). They may not have been formed with any thought of hazard or disaster, but once formed they create and maintain community links and networks which may be rapidly used in a crisis.

The indirect group of organisations are those which exist primarily for a purpose other than hazard mitigation, but which contribute resources, personnel, networks and knowledge during and after a disaster. Included here are the media, in all of its forms and roles. The media are primarily a private enterprise industry, but it is crucial to government organisations and emergency managers who depend upon media response to get information, warnings and messages to the community. The media are often the earliest responders to a disaster, providing initial information and immediate impressions. When category five Cyclone Zoe hit the island of Tikopia, a remote and extremely isolated outlier of the Solomon Islands the first outsider to provide any news of the islanders' survival was a freelance journalist who chartered a helicopter from New Zealand. It is interesting that the journalist's initial report of devastation and survival described people fishing. Thus although the media comprised the first outsider, the Tikopians had got on with their own process of survival and recovery.

The media are also extremely powerful in advertising a crisis and prompting political and citizen response. The corollary of this power is the invisibility of unreported, or poorly reported disasters. Disasters are, in part, constructed by the media. They often exaggerate human interest elements, they look for scandals and government ineptitude, assign blame and instigate generous 
relief responses. They self censor some images of suffering, but are also guilty of misusing distressing images to increase the impact of their stories.

Emergency managers have no control over the media and need their positive support at all phases of Emergency Management. All organisations must therefore devote some of their resources to media liaison and must continually work at these networks. NGOs especially, work hard at developing their media image and ensuring media visibility as citizen generosity is a key component of their income.

There also exists a level of informal organisation that can be grouped under residual and spontaneous organisations. These are two quite separate community processes. The spontaneous response and resulting organisation, or community, or network, occurs directly as a consequence of the disaster event. The 'residual organisations' are those elements of civil society that underpin all that people do, the ways in which society is defined and constructed, the traditional, and the informal. Residual organisations are culturally constructed, grounded in community and civil society, representative of the ways people organise and network. This is not necessarily something ancient and 'culturally known', although it certainly includes that part of society, but it also includes all that is immediate and functional.

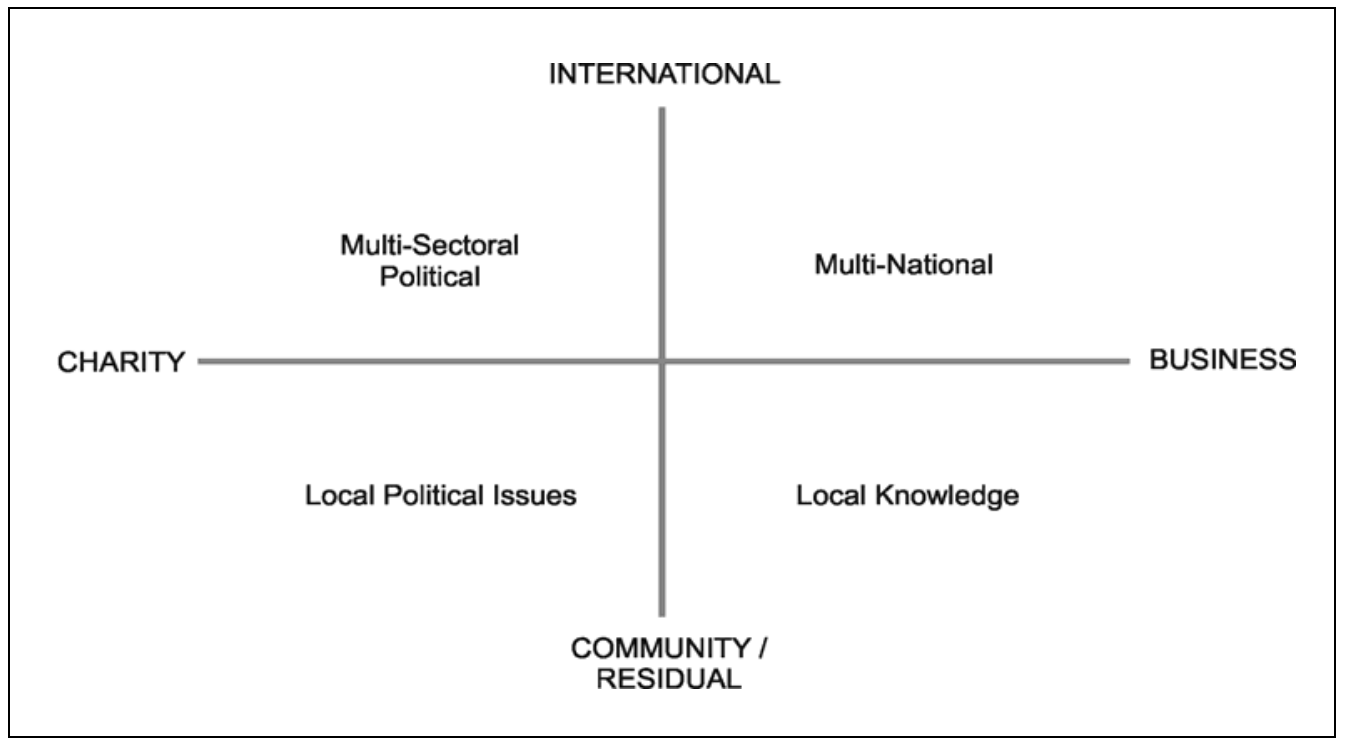

\section{Figure 2.4 A matrix of types of organisations}

The size and numbers of organisations that participate in any disaster vary with the spatial extent, the severity and the population that is involved. 
Obviously, the more organisations that are involved, the more complex is the task of Emergency Management. These organisations bring to the community a wide range of skills and approaches. These variations are illustrated in Figures 2.3 and 2.4.

Figure 2.3 expresses a range in size, organisational structure and scale. No organisation can encompass all of these types, they will sit primarily in one or more sectors. Figure 2.4 illustrates the variety of structures within organisations and the community. The upper left area is structured, the lower right is unstructured. Urban society, in particular, is a highly complex, unstructured matrix of networks and linkages. It is like the structure of the Internet, allowing enormous numbers of groupings and largely informal organisations (Alexander, 1966). This is the community which is managed by formal Emergency Management with its clear cut organisational hierarchy. Cutting across this continuum is a range of organisations from the formally structured NGOs which may include businesses and companies, through to the spontaneous and residual. Where the community initiates and pursues its own Response and Recovery, it is in the lower right area of the model, unstructured but not necessarily disorganised.

Thus it is inevitable in any disaster that problems of organisation and leadership will emerge. The effectiveness with which these issues are resolved will have a powerful influence on the effectiveness of Response and Recovery. Organisations will pursue their own agendas generating both contradiction and complementarity. Communities will pursue their own, often parallel, routes to Response, Recovery and Mitigation (Spillan, 2003; Palmer, 2001; Benini, 1999; J uratowitch et al., 2003; Silberbauer, 2003; Prater \&Wu, 2002; Loosemore \& Hughes, 2001).

\section{NGO Roles in Complex Emergencies}

The roles of NGOs in complex emergencies have been distorted away from needy communities towards the demands of governments and international agencies. Understanding the shift in the roles of NGOs raises issues that may help countries that have experienced a complex disaster, to better coordinate the naturally occurring processes of community recovery and redevelopment within a NGO policy. However, the problems and issues faced by the NGOs themselves are also complex.

Most NGOs involved in development have evolved from a humanitarian liberal and idealistic agenda, but performance in development has been ineffective or patchy, both sectorally and geographically (Edwards \& Hulme, 2002). With local knowledge and local institutional organisation, development NGOs found themselves well placed to intervene in relief when 
states collapsed and conflict emerged (Keen, 1998; Harvey, 1998; Edwards \& Hulme, 2001). Being reliant on donors for funding many NGOs found themselves beneficiaries of increased publicity as wars and associated natural disasters developed. It was easy to shift from development to relief when the budget expanded, although obviously to professionals committed to improvement in the quality of life in developing societies, there was no choice but to become involved in relief.

The accountability of NGOs is both to the donor and to the recipient, upward and downward. The end of the Cold War took many governments, such as the USA and USSR, out of direct aid competition in the developing world. Aid was both relatively reduced and channelled through international agencies and NGOs (Fowler, 2001; Reno, 1997). NGOs became more connected with donors who were bigger and more powerful (Edwards \& Hulme, 2001). Even though developing nation governments may have lost the ability to govern their own countries they have still been able to exert an influence on NGOs. This is acceptable and even necessary where coordination is needed, but it has added another level of accountability upward, to the detriment of downward accountability (Edwards \& Fowler, 2001; Keen, 1998; Edwards \& Hulme a \& b, 2001; Hilhorst, 2002). Thus NGOs are in greater danger of disengaging from direct partnership with disaster affected communities, while they serve instead the needs and agendas of host governments, private donors, donor agencies and Western donor governments.

The concept of political aid and a hierarchy of victims (Fox, 2001) challenge the political naivety of NGO relief efforts that indirectly (or directly through corruption and theft) support combatants and extend or exacerbate the conflict (Fox, 2001; Duffield, 2001; Macrae \& Leader, 2001; Keen, 1998). Thus on one side NGOs have been criticised for supporting corrupt governments by providing outside funded welfare projects, while on another side they undermine those same governments by enabling combatants to stay in business (Woodward, 2001), on yet another side they play into the globalisation agenda by practising privatisation of social services and international aid (Cliffe, 2000; Fowler, 2001; Edwards \& Hulme, 2001) and on the fourth side they have neglected accountability to, and partnership with, the community they exist to serve.

Against this background, the development NGOs have been drawn into increasingly complex conflicts, involving many players, unclear goals, struggles for resources and in some cases associated natural disasters; and all of the outcomes of displacement, medical crises; collapse of government and destruction of infrastructure. These 'new wars' of the new millennium or the twenty-first century, challenge all relief agencies to participate in the 
peace process as actively as the military organisations that are involved. Most of the 'new wars' have taken place in Africa, and they are symptomatic of a collapse of governance and development. Within the Asia Pacific region the East Timor conflict was the last of the 'old wars', a post-colonial struggle for independence, where there were clear goals on both sides. The collapse of governance in the Solomon Islands during 2002 and 2003 was more typical of the new conflicts and the complex humanitarian response. PNG faces the danger of similar disruption, while in Indonesia and the Philippines complex ethnic/political conflicts share many similarities with those of Africa. Of particular significance is the connection between economic setbacks and a slowing of development with the emergence of regional, ethnic and religious conflicts.

Firstly, the 'new wars' involve a dislocation of globalisation and network connections, especially in relation to the trade in cheap arms and the migrations of refugees (Cliffe, 2000). Secondly, these wars create their own political economies. The commonly used term 'warlord economies' (Reno, 1997), describes conflicts as a competition for resources that had formerly been controlled by the patronage system that had developed out of colonialism. Thirdly, the public and private spheres are blurred as combatants change sides, and mercenaries and criminals become involved. Fourthly, there are no significant political goals in these new wars. The 'new wars' are cheap wars (Keen, 1998; Richards, 1996) where terrorism or dominance of the unarmed civilian population is easily achieved, but the capacity to defeat a government is insufficient. The under-funded hand to mouth campaigns of such rebels contributes to their lack of goals.

As international agencies and NGOs move into a humanitarian disaster, alongside or parallel to community activity, the involvement of central government may facilitate or direct redevelopment within a broader political framework and development strategy. A strong civil society that works with NGOs may improve the developmental aspects of relief (Harvey, 1998). Civil society as a concept includes all the positive aspects of community, independent of the state and thereby the grassroots that presents a bottom up approach to development. Civil society is not totally undermined by disaster, but in the face of war or disaster it transforms and re-emerges. It is a rehabilitation model that is downwardly accountable and separate from state and donor politics. Its mechanism for reconstruction is to utilise community or traditional institutions and structures.

\section{Conclusion}

Organisations exist to respond to disasters and to reconstruct places and communities, but the circumstances of each disaster throw up unique problems and sets of complex issues that will stress and constrain even the 
most experienced disaster organisations. Disasters overwhelm. Most governments and government agencies, especially at the local area level that experiences the disaster impact, will have had little previous direct experience of dealing with an actual disaster. Organisations exist primarily to meet other needs and provide regular and routine services. In developed industrialised countries, governments and non-government organisations are overwhelmed by disaster, but when governance is much weaker, especially in the poorer countries of the world, formal organisations are even less likely to be able to respond or even to function at all. Added to weak governance, are issues of cultural pluralism, social and economic divisions, control of the state territory, and thus even the willingness, let alone capacity, of governments to provide aid or assistance to specific groups or locations.

Conventional models of Emergency Management presuppose that government and non-government organisations will proceed through regular processes to respond, aid recovery, and mitigate against future hazards. The reality is that capacity is far more constrained than Emergency Management processes portend. Also underplayed in formal organisational models is the role of virtually everyone else in responding to and recovering from a disaster. Community, business, non-formal organisations and individuals take actions to respond to hazards and recover from disaster without necessarily relating to the roles of formal organisations. Organising the organisational and non-organisational response is part of the process and chaos of any disaster. It is possible to identify all the levels and types of organisations and communities that have been examined in this chapter, but what each would do in the unique disaster event remains as unpredictable as the disaster impact itself. What is essential is the recognition by Emergency Management that it will always deal with the consequences of a disaster in partnership with a plethora of government, business and community organisations each of which has its own priorities, structures and procedures.

A modified version of this chapter was first published as Organisations in disaster, Natural Hazards, 40(3), 657-665 in March 2007. 


\section{Enhancing resilience and reducing vulnerability: Lessons learned from past disasters}

\section{David King}

Learning from the reality of disasters that have been experienced or which have been learned vicariously from the experience of other people and communities, empowers people to reduce their vulnerability and to enhance their resilience in the face of catastrophe. Unfortunately the process of learning is neither as obvious nor as commonsense as the drama and tragedy of an unfolding disaster demands. Lessons are not fully learned, the missing details may become fatal flaws in people's understanding of events, and reconstruction of events from the perspectives of participants, observers and analysts are necessarily piecemeal, driven by drama, economy and politics, un-contextualised and unique. Learning from past disasters is not a simple or obvious process. This chapter begins with reflections on perception; scale; emphasis; and place, in order to understand some of the diversity of disaster learning experiences. Examples of lessons learned from local, regional and distant disasters provide a review in order to identify issues, commonalities (within unique events) and those mitigative actions that may reduce each person's and each community's vulnerability to a range of hazards, and simultaneously enhance their resilience before, during and after a catastrophic event.

Do communities or individuals learn anything from the experience of the disaster? Is vulnerability to future events reduced by direct experience or indirectly experiencing disaster, and/or is resilience enhanced? The Integrated Emergency Management System model of Prevention, Preparedness, Response and Recovery assumes a continual feedback loop. Emergency managers are required to learn from each disaster through debriefing, studies, reorganisation, and redefinition of priorities.

Many lessons learned for communities by emergency managers are passed down to communities through education, warnings, information, mitigation, physical prevention structures, planning and intervention. Emergency managers, as professionals, have a more global view and their job of 
protecting communities is to learn lessons from all disasters in order to improve mitigation and capacity to respond and to aid recovery.

The problem for emergency managers in indirectly learning from other disasters is that experience comes second hand from other participants and must then be processed, redefined, understood and transmitted third hand to communities for which they are responsible. At the same time individuals and communities learn of other disaster experiences primarily through the media, and sort information and structure other people's experiences to fit their own situation and place. This process at community level is much more piecemeal than that of emergency management. However, it is also location and situation specific, whereas the emergency managers' sorting and understanding of others' experiences is directed to responsibility for many communities - the whole state, or nation, or even an international region. Thus at the initial level of learning indirectly from other communities' disasters and experiences, there are two radically different learning experiences. The emergency manager's learned experience is top-down and global, while the community's is bottom-up and personal.

\section{Post-disaster Studies}

The first stages of a disaster response require rapid appraisals to assess needs and response levels. Needs analyses inevitably form part of the briefings and may contribute to deeper reflections and lessons that can be learned, especially at the organisational level. However their primary function is to satisfy immediate needs under pressure. Researchers are often not involved at this initial stage. Researchers usually visit the scene of a disaster within a few days, or up to a week or so, after an event. The aim is to keep out of the way of response teams, and researchers do not enter a declared disaster area until they have been granted permission from the authorities who are primarily involved in response and relief. The aim of the post-disaster research is to record issues, experiences and impacts, while these are fresh in people's minds. These studies are also primarily records of what happened in an event, but they form the first stage of attempting to analyse issues and ultimately to synthesise disaster experiences into more general conclusions that can inform policy.

Enormous numbers of post-disaster studies and reports are available, ranging from measurements of purely physical impacts to records of highly personal human experiences. For tropical cyclones and hurricanes alone, Haig (2004) brought together over 200 studies into a web site International Post Cyclone Database. This database cross references individual studies according to their titles, keywords, survey aims, type, study area, methodology, key findings, events name, date, location, cities, states and 
countries. As further events are added, comparisons of issues impacts and experiences are enhanced.

A review of 130 post-disaster studies (King, 2002) summarised places, events, types of disasters and classified their methods. As the USA and Australia had funding programs for post-disaster surveys, the majority of these reports were written by USA and Australian researchers although because US-based research could obtain funding to examine overseas disasters, many studies of events in other parts of the world had been carried out by US-based researchers. Of the 130 studies that were examined, 29 were cyclones/hurricanes, 21 were floods and 13 earthquakes, with eight bushfires and nine tornadoes. These were the dominant disasters in a list that also covered human induced hazards. These five hazard groups are the major killers, but to an extent are predictable, with appropriate behaviour and preparatory actions that can be taken to reduce vulnerability and impact. As these were all post-disaster studies they were all consequently case studies of specific events, occasionally more than one, but primarily concerned with a single disaster on those issues related to a place and time.

Members of the Centre for Disaster Studies carried out a series of post disaster studies between 1997 and 2006 covering 16 separate disasters in 20 different locations (see Table 3.1). With the exception of the Indian Ocean Tsunami and human induced disasters like the Bali bombing, all were floods and cyclones and in particular the events were concentrated in local communities.

The first event in Table 3.1 below, Cyclone Gillian, was a non event but a warning to the Bureau of Meteorology about the lack of preparation. No warning had been issued to a major Queensland urban area since the beginning of the decade. This category one cyclone dissipated before reaching the coast, however, it occurred in the middle of a working day and the experience illustrated chaos in the manner in which schools and workplaces were closed down as well as a general lack of preparation.

Two much later studies took up a related theme of severe category 5 cyclone warnings in communities that subsequently were spared impact or received much less impact than expected. In 2005 Cyclone Ingrid crossed Cape York Peninsula but missed all the communities it had threatened and in 2006 Cyclone Monica crossed the Peninsula and deepened into a very severe category 5 as it skirted the Northern Territory. Monica weakened to a category 3 when it finally crossed over Darwin. Surveys targeted people's attitudes to preparing for the worst and not going through it, the 'cry wolf' syndrome. Research showed a high level of tolerance for being fully warned. 


\section{A Litany of Disasters}

Table 3.1 Post-disaster studies carried out by the Centre for Disaster Studies, 1997-2006

\begin{tabular}{|c|c|c|c|c|}
\hline Place & Year & Hazard & Name & Research Method \\
\hline Townsville & 1997 & Cyclone & Gillian & $\begin{array}{l}\text { Questionnaire, } \\
\text { warnings \& behaviour }\end{array}$ \\
\hline Cloncurry & 1997 & Flood & & $\begin{array}{l}\text { Questionnaire, } \\
\text { interviews }\end{array}$ \\
\hline Cairns & \multirow{3}{*}{1997} & \multirow{3}{*}{ Cyclone } & \multirow{3}{*}{ Justin } & \multirow{3}{*}{$\begin{array}{l}\text { Longitudinal } \\
\text { questionnaire \& short } \\
\text { survey questionnaire }\end{array}$} \\
\hline Mareeba & & & & \\
\hline Innisfail & & & & \\
\hline Townsville & 1998 & Floods & $\begin{array}{l}\text { (ex-Cyclone } \\
\text { Syd) }\end{array}$ & $\begin{array}{l}\text { Household telephone, } \\
\text { business \& Magnetic } \\
\text { Island surveys } \\
\text { interviews }\end{array}$ \\
\hline Burketown & \multirow{3}{*}{1998} & \multirow{3}{*}{ Floods } & & \multirow{3}{*}{$\begin{array}{l}\text { Questionnaire, } \\
\text { interviews }\end{array}$} \\
\hline Normanton & & & & \\
\hline Karumba & & & & \\
\hline Innisfail & \multirow{4}{*}{1999} & \multirow{4}{*}{ Cyclone } & \multirow{4}{*}{ Rona } & $\begin{array}{l}\text { Flooded buildings } \\
\text { survey }\end{array}$ \\
\hline $\begin{array}{l}\text { Cairns - Barron River } \\
\text { suburbs }\end{array}$ & & & & $\begin{array}{l}\text { Evacuation } \\
\text { questionnaire }\end{array}$ \\
\hline $\begin{array}{l}\text { Port Douglas \& } \\
\text { Mosman }\end{array}$ & & & & $\begin{array}{l}\text { Warnings \& behaviour } \\
\text { questionnaire }\end{array}$ \\
\hline Wujal Wujal & & & & $\begin{array}{l}\text { Warnings \&impact } \\
\text { interviews }\end{array}$ \\
\hline Broome & 2000 & Cyclone & Rosita & $\begin{array}{l}\text { Questionnaire, } \\
\text { interviews }\end{array}$ \\
\hline Cairns & 2000 & Cyclone & Steve & $\begin{array}{l}\text { Longitudinal } \\
\text { questionnaire }\end{array}$ \\
\hline Mornington Island & 2001 & Cyclone & Abigail & $\begin{array}{l}\text { Questionnaire, } \\
\text { interviews }\end{array}$ \\
\hline Sierra Leone & 2002 & Civil War & & $\begin{array}{l}\text { Interviews, meetings, } \\
\text { secondary data }\end{array}$ \\
\hline Bali & 2003 & Terrorism & & $\begin{array}{l}\text { Interviews, meetings, } \\
\text { secondary data }\end{array}$ \\
\hline Tikopia, Solomons & 2003 & Cyclone & Zoe & Basic needs \\
\hline Anuta, Solomons & & & & assessment \\
\hline Phuket, Thailand & 2005 & Tsunami & Indian & Interviews, \\
\hline Maldives & & & tsunami & $\begin{array}{l}\text { observations, field } \\
\text { measurements, } \\
\text { secondary data }\end{array}$ \\
\hline Port Douglas & 2005 & Cyclone & Ingrid & $\begin{array}{l}\text { Interviews, } \\
\text { questionnaire }\end{array}$ \\
\hline $\begin{array}{l}\text { Innisfail \& } \\
\text { communities }\end{array}$ & 2006 & Cyclone & Larry & $\begin{array}{l}\text { Interviews, } \\
\text { questionnaire }\end{array}$ \\
\hline Darwin & 2006 & Cyclone & Monica & Telephone survey \\
\hline
\end{tabular}


Centre for Disaster Studies researcher, Anderson-Berry, focussed on the northern beaches of Cairns during 1996 to measure cyclone awareness and preparedness in a community that had not experienced a cyclone threat for six years. In 1997 the giant Cyclone J ustin, filled the Coral Sea and took a month before finally crossing the Cairns northern beaches coast line as a category 2 . This was an opportunity to resurvey experience and behaviour amongst the same population that had completed the awareness and preparedness survey only six months earlier. Making this a truly longitudinal study, category 2 Cyclone Steve in 2000 passed over the same communities (Anderson-Berry \& King, 2005). A high proportion of residents who had taken part in the earlier surveys were still available to participate in the third study, providing a valuable measure of a small but significant increase in community awareness and preparedness.

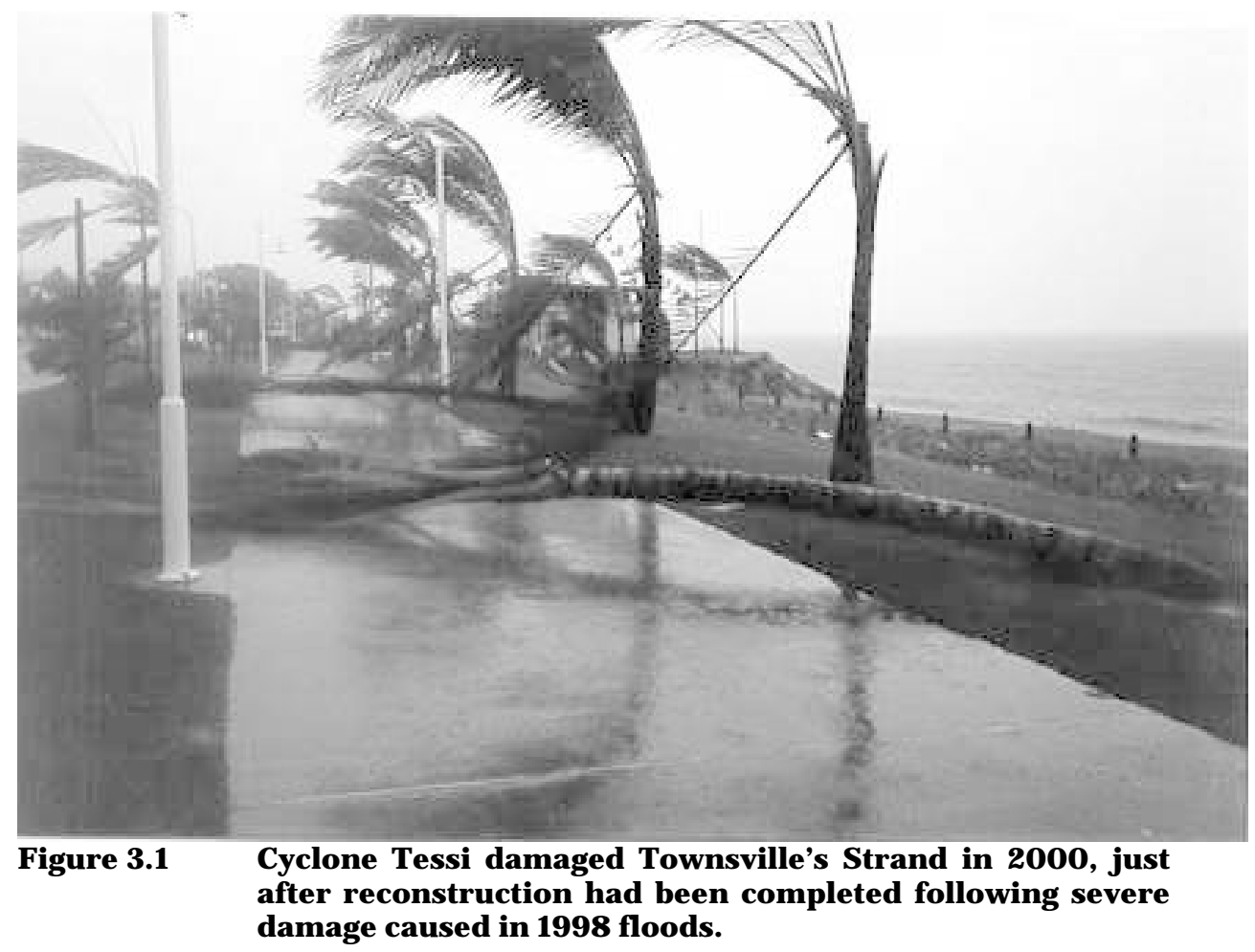

Other cyclones provided further opportunities to pursue awareness and preparedness, but also to examine issues of warnings and hazard perceptions. Cyclone Abigail in 2001 was only a category two, but it passed over a low-lying Indigenous community at Mornington Island, where Eddie McLachlan, a Centre for Disaster Studies researcher was already recording indigenous hazard knowledge. J ust as this study was oriented to a particular emphasis, similarly Cyclone Rosita at Broome in 2000 was an opportunity to 
concentrate on an issue, by looking at the impact on a tourist location. The vulnerability of tourists and tourist destinations has developed as a major research area for the Centre, not just because of its significance on the Queensland coast but principally because of the lack of crisis management in the tourist industry.

In 1999, Cyclone Rona initiated a series of issues. Post-disaster studies following the passage of this exceptionally wet cyclone addressed different issues in locations that were over $200 \mathrm{~km}$ apart. This cyclone was preceded and accompanied by flooding rains and crossed the coast at Cow Bay in the Daintree rainforest. Wujal Wujal and Bloomfield communities to the north (around 1000 Indigenous and Non-indigenous residents) were totally isolated for weeks and failed to notice formal warnings of the close proximity of the cyclone. Anderson-Berry's initial visit to the community was followed by a series of studies as researchers in the Centre directed emphasis to remote and Indigenous communities, examining their vulnerability, resilience and warnings. South of Cyclone Rona's eye, Douglas Shire was fairly well-prepared but the controversial issue was the efficacy of warnings. The post-disaster surveys in Port Douglas and Mosman were concerned with this issue of official warnings and their effectiveness. While the survey at that time showed a satisfactory level of awareness and preparedness, a similar kind of survey was carried out in the same locations in 2005 after category 5 Cyclone Ingrid had passed (ultimately crossing Cape York Peninsula but causing very little damage). In this case the survey was carried out for the opposite purpose of eliciting community response to what the media had termed a 'false alarm'. Community attitudes towards their preparations were positive, as it should be, but the issue of false alarm perceptions remains a concern to emergency managers.

Cyclone Rona's passage dumped vast amounts of rain on the Atherton Tablelands to the west of Cairns, causing the Barron River to flood. This river emerges from the mountain range on to the coastal plain of Cairns adjacent to the suburbs of Lake Placid and Caravonica. As the river rose rapidly, authorities issued an evacuation order to all residents of these two suburbs during the middle of the night. The post-disaster survey in Cairns was therefore a detailed questionnaire issued to all households that had evacuated, to record their problems, perceptions and experiences. Of value to the Cairns City Council, which had not previously conducted an evacuation, the survey also illustrated the controversial issue of pets in evacuation centres. More than $80 \%$ of households took pets with them, from cats and dogs to some truly bizarre creatures. As a consequence the Cairns City Council followed up the pets issue in council surveys that were carried out during 2004. 
The fourth of the Cyclone Rona studies also concentrated on flood experiences in Innisfail, $90 \mathrm{~km}$ south of Cairns, where houses and commercial properties in low-lying areas adjacent to the Johnstone River were inundated. The survey stressed property damage and loss related directly to house type (especially low or high set) and measured precise flood levels on property and within buildings.

Cyclone Larry in March 2006 was in a sense 'the big one' that had been feared for many years, but it just missed a coastal city (either Cairns or Townsville could have been severely impacted upon). Once again it was Innisfail that was the victim along with surrounding small communities and villages on the coastal plain and on the Atherton Tableland. This impact area experienced a category 5 that rapidly weakened to a 4 but remained a severe 4 until it had passed the Tableland. Although a rural area, the affected population of more than 50,000 people was scattered through many small towns and communities. The lesson learned from household surveys was of a well prepared, experienced and knowledgeable community that behaved correctly and consequently experienced no loss of life and few injuries.

Many floods in northern Australia are related to cyclonic weather systems, but there were significant differences in the three sets of post-flood surveys. At Cloncurry in 1997 the Cloncurry River rose rapidly to unprecedented levels, inundating parts of the town, thereby forcing the evacuation of people and property. The Gulf of Carpentaria lowland floods the following year inundated a vast area, as the great rivers that drain into the Gulf coalesced into an inland sea. Towns and communities in the region became islands with problems and issues that emanated from their isolation: lack of food; inundation of septic systems; loss of power and freshwater; a strong risk of secondary disease and infection; and widespread destruction of roads, drainage, bridges and culverts. Most remote cattle stations have traditionally stocked up on provisions for the isolation of the wet season but the predominantly Indigenous small towns and Aboriginal communities lack that capacity. Most households have low incomes, high dependency on welfare and are unable to stockpile supplies. Because of this characteristic of the market, retailers are also restricted in their ability to stock up. Despite these problems these isolated communities were remarkably resilient. The communities endured and made do with what they had available.

Stoic endurance is easily attributed to the social construction of the outback community. Certainly post-disaster studies undertaken by the Centre illustrated many examples of the term 'outback spirit'. However, the same spirit of neighbourliness was equally evident in Townsville during the 1998 flood. This was an extreme rain event (a consequence of a decayed cyclone, in which over $700 \mathrm{~mm}$ of rain fell in less than 24 hours) with creek flash 
flooding causing severe damage in a small number of locations. While carrying out a 1000 household telephone survey in the days following the flood, interviewers recorded many remarkable anecdotes of bravery and selflessness, as well as some of the problems of inappropriate behaviour.

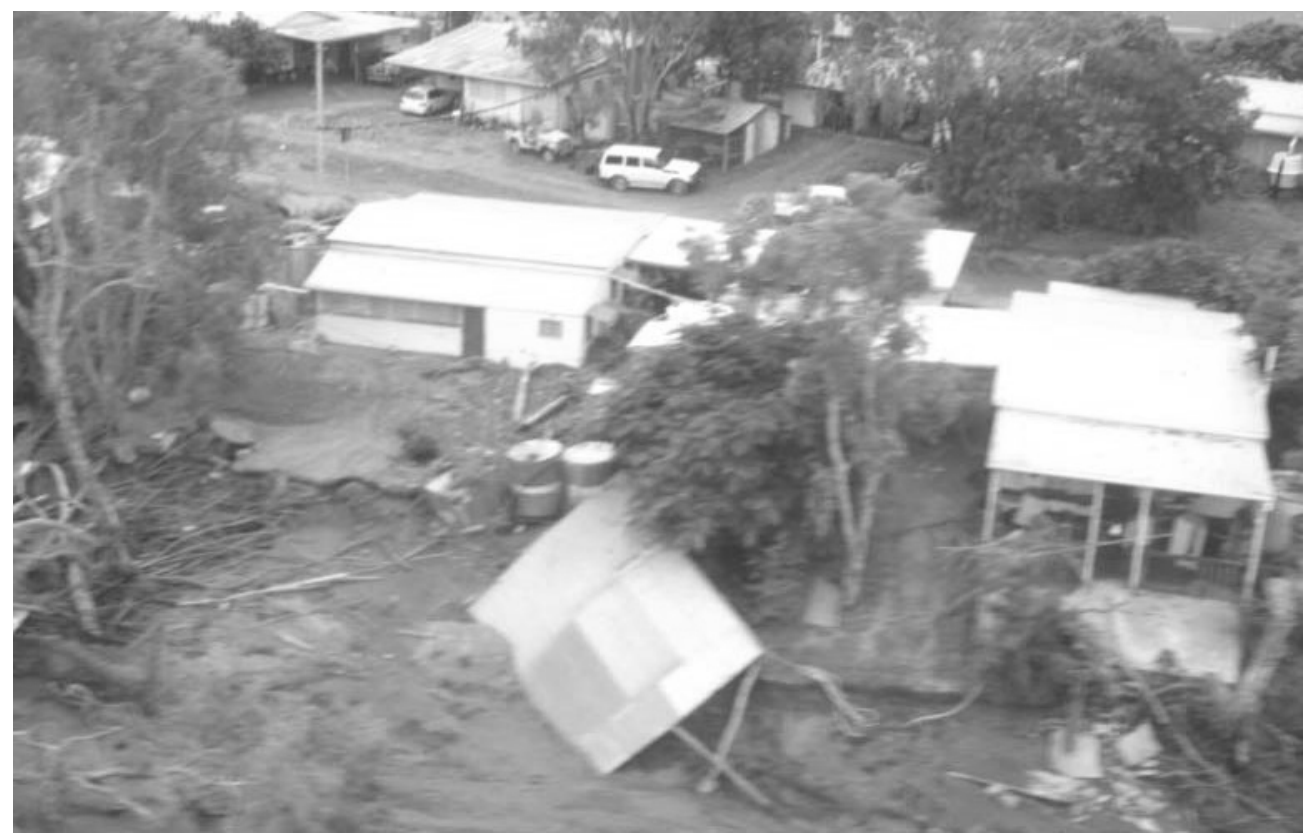

Figure 3.2 Damage to the Black River settlement in Thuringowa following floods in 1998.

Despite having used a variety of research methods and approaches these mainly local events involving predictable and regular hazards of flood and cyclone demonstrated some general trends and impacts.

The following general trends and impacts have been noted:

- unequal distribution of the hazard impact;

- $\quad$ loss of essential services during and for a period after the hazard event;

- $\quad$ lack of expectation in the community of the severity of the impact;

- $\quad$ late or minimal preparation for the hazard;

- response and assistance within the community and between neighbours;

- confusion concerning warnings, and especially the way in which they were portrayed and transmitted by the media;

- a level of resilience which involved acceptance of the hazard and generally a lack of attribution of serious blame. 
This idea of acceptance of natural hazards was expressed by a Thai informant in Phuket during the week following the Indian Ocean Tsunami in 2004 that it was easier in an emotional or psychological sense to deal with natural hazards rather than terror. This sentiment encapsulates an aspect of community resilience that to some extent accepts natural hazards as part of the natural order, something over which little control is possible. War and terror on the other hand undermine people's faith in human nature, threaten all of our humanity and may even be a direct physical threat.

Immediate post-tsunami disaster observations in Thailand also suggested lessons that can be learned from the devastation which could be applied directly to other hazards and other areas, such as coastal Australia (King \& Gurtner, 2005). Tsunami damage resembled many aspects of storm surge damage.

The immediate response to the tsunami in many parts of the world was a transfer and internalisation of the threat. While tsunamis may occur in many parts of the world's plate boundaries, cyclones and hurricanes are much more regular an occurrence, with the storm surge accompanying a severe storm being just as destructive as a tsunami albeit over a longer period of time and with a greater opportunity for evacuation.

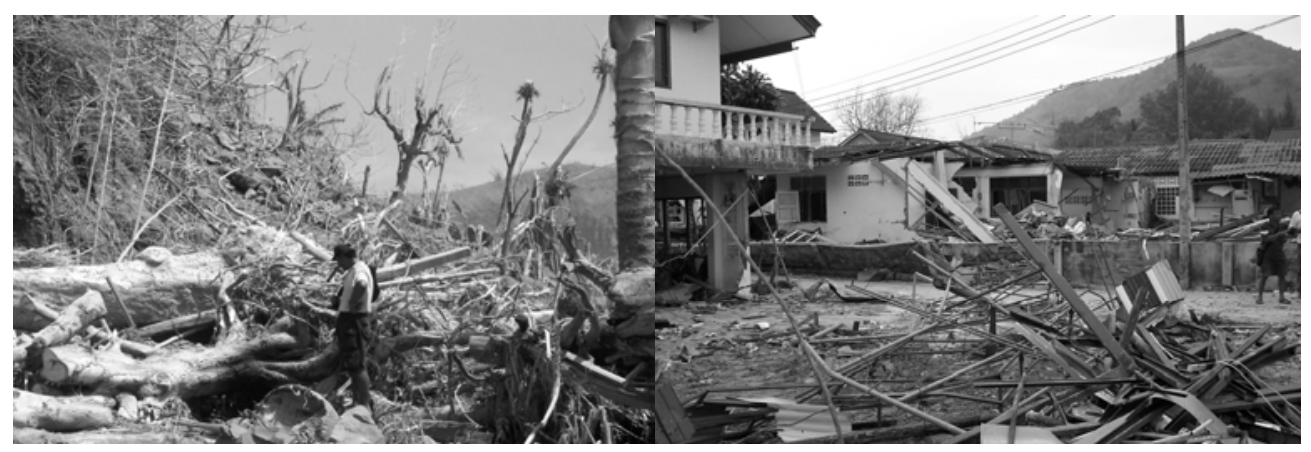

Figure 3.3 Storm surge damage at Tikopia Solomon Islands, left, and tsunami damage at Phuket Thailand, right.

Other significant transfers of the tsunami experience relate to the vulnerability of critical infrastructure and lifelines. Particularly noticeable on Phuket was the lack of damage to significant infrastructure, with response coming from the intact and functioning administrative centre. Recovery was able to progress rapidly despite widespread destruction in the coastal zone. This would probably not be the case in Australian coastal settlements where far too much of the critical infrastructure, economy and services are in low lying or coastal locations. Land use planning and building structure locations were identified as significant issues for post-tsunami mitigation. 
Similarly in Australia there are many people in the community who oppose development along coastal foreshores because of the extreme vulnerability of this zone to storm surge. As the primary tourist resource is the beach and the sea, it is inevitable that pressure for development on the foreshore will continue to come from the tourist industry, whether in Thailand or northern Australia. The Indian Ocean tsunami caused particularly severe damage to small buildings on the foreshore, a lesson that is directly transferable to residential absolute beach frontage.

In Thailand the impact of the tsunami was felt particularly strongly in the tourist industry, tourists themselves and tourist workers. Tourists have often been omitted from community hazard mitigation efforts and yet they are especially vulnerable. The need for hazard education was highlighted by the tsunami. Education needs to be targeted to diverse communities, including tourists and tourism operators as separate identifiable communities. Warning systems for both tsunamis and cyclones can only be effective if communities are educated to understand what the warning means and how to behave.

\section{Hazard Experience and Emergency Management}

There are common themes in emergency managers' and researchers' perspectives on the lessons that can be learned from disasters. There are also common patterns and processes that are identified in similar types of disasters. Yet while a particular level of flood, category of cyclone or scale of earthquake may demonstrate similar processes, the resulting disasters are all different. Location, culture, society, politics, organisation, awareness and many other factors all contribute to the unique features of each disaster. To learn lessons from disasters it is important to recognise commonalities while being aware of that which is unique, or specific to the location. Researchers and emergency managers do this by recognising the special circumstances of each catastrophe and identify those factors as part of the explanation. There are many examples in studies of previous disasters that identify both those factors that are common and those which are unique.

For example Keys (2005), reporting on the 2002 floods in Germany and the Czech Republic identified the dismantling of former warning mechanisms and changing land management systems as an emergency management issue that could be transferred to the Australian experience, but at the same time he was impressed by the scale of the disaster which gave it its unique characteristics. Bankoff's (2003) assessment of flooding in the Philippines also recognises environmental problems, alongside the complexity of social and environmental factors, but he reduces the uniqueness to the social construction of vulnerability. Both writers stress the importance of 
understanding historical changes and processes to understand current hazards, but bring quite different perspectives on the nature of society.

The perspective brought by the researcher to a disaster event configures the lessons that may be learned and transmitted. Emergency managers are particularly involved in organisation and the political system. The limited number of questions and surveys that are available to researchers result in specific selections. Prater and Wu's (2002) study of Taiwan's 1999 earthquake was oriented to analysis of organisational and institutional responses. Similarly Wachtendorf's (2000) study of the Red River flood positively emphasised cross border political arrangements; in this instance the US/ Canada border. Betts (2003) on the other hand found institutional failings in flood warning systems in Victoria. The research perspective was from the bottom-up community level. Wachtendorf's was much more a view from the top down. Where researchers stand, or come from, influences the issues seen and the lessons learnt. This does not mean that one view is wrong and another right. All are real reflections of disastrous events, but the lesson that is learned is perhaps less from the event than from the observer. Pfister's (2002) assessment of Grafton's floods in 2001 identified a poor response to evacuation warnings and concluded a need for better warning education. As an emergency manager, this observation is Pfister's role and the correct view of community. However, community workers in southern India, Thomalla and Schmuck (2004) observed a similar sort of community response in Orissa in 1999 and concluded failures in government and NGO organisations as well as in the communities themselves. However, an overview of two decades of hazard research in southern India by Winchester (2000) concluded that NGOs had been effective but the crucial need was to target the poor who make up the bulk of the victims.

Many post-disaster studies examine post-traumatic stress, most are carried out by psychologists and psychiatrists and are often much more longitudinal in scope. Some emphasise the relief workers, others the victims. Johnes (2000) for example examined the impact of the Aberfan spoil heap collapse over 30 years after the event and Blatt (2001) subsequent to a mine disaster in Austria, both in order to assess failures in government and media that hampered recovery. The lessons learned were organisational although the emphasis was trauma. J onkman and Kelman (2005) identified inappropriate behaviour as a cause of flood deaths, and Gordon (2004), reflecting on a range of emergencies, concluded that social processes and relationships are drained and undermined during and following a disaster. The trauma and grief experienced by victims and survivors is not necessarily just a consequence of the actual hazard, but is constructed or exacerbated by other processes that are equally part of the disaster - organisational and social 
failings, the lopsided construction of the event by the media and a lack of appropriate knowledge.

Because a disaster is a terrible and destructive experience, researchers and emergency managers are invariably driven to find explanations as to why things went wrong in order to mitigate against future disasters. Postdisaster surveys and reflective papers can be expected to identify shortcomings. However, there is a significant category of positive analyses. These may broadly be put into groups of resilience and education. Recent resilience papers cover events of great diversity: destruction of the World Trade Center (Kendra \& Wachtendorf, 2003), recovery and sustainability in Kobe (Shaw \& Goda, 2004), community first aid response after the Northridge earthquake (Kano et al., 2005), social and ecological resilience (Adger et al., 2005), and emotional and psychological response and resilience following the Katherine floods of 1998 (Skertchly \& Skertchly, 2000). Handmer and Hillman (2004) also illustrate the importance of economic recovery in enhancing resilience following a range of Australian disasters.

Resilience is the key to learning from disasters. Studies that find flaws and organisational failings that have contributed to a disaster, stress vulnerability. At the community level when levels of impact and loss are identified it is clear which groups or locations in the community were the most vulnerable in a specific crisis. The outcome should then be a reduction of the vulnerability of those people and places. However, the things that make people vulnerable are often structural social issues. Poverty, ethnic isolation, infrastructural disadvantage, low levels of education, and such factors as complex as cultural practices and beliefs are areas of community vulnerability that are outside the control of the emergency manager.

While identifying factors of vulnerability to a disaster helps in understanding the process, these may not necessarily be the route by which vulnerability is reduced. By building on the resilience of society and strengthening positive factors, vulnerable communities may become more empowered to minimise the impact of future hazard events. Such empowerment mainly involves organisational and social change at the community level. Awareness and preparedness empower people to deal with their own situation and location. The two most direct influences on awareness and preparedness are direct experience and education. Education often begins with media accounts and images of disasters in other places - the news. News accounts initiate awareness, but awareness in itself can run into the arid wastes of fear, unless it is backed up by preparedness behaviour that is based on the strengths, capacity and resilience of communities. The media goes part of the way in taking some responsibility for preparedness by informing people of actions 
they can take, but shortcomings of media coverage are their needs for drama and for stories that are piecemeal and often not at all reflective of the real situation of a disaster. The media also lacks an interest in hazards when there is no immediate threat, unless this can be personalised by events like scientist and politician confrontations.

The greatest advantage of media coverage it is that it is potentially free education. Every other education and awareness campaign costs emergency management organisations money. However, a major inexpensive and highly effective route to awareness and preparedness action is through education in schools (Finnis et al., 2004; Izadkhah \& Hosseini, 2005). The effective cost of hazard education in school is a transfer of attention away from other subjects, but generally hazard modules are well integrated into social and environmental studies education. Apart from well taught hazards education being exciting and interesting to children, it is effective in laying down knowledge and action that may be absorbed by the child for life and which are also communicated to family, relatives and friends in the broader community through homework, projects and explanation.

Beyond the school, public awareness involves complex and costly strategies. O'Neil (2004) illustrates a range of individual social attitudes to hazards that may form the basis for specific targets and approaches of warnings and awareness campaigns. O'Neil's summary table below highlights different attitudes within the community.

\section{Table $3.2 \quad$ Hazard awareness targets}

\begin{tabular}{|l|l|l|}
\hline \multirow{3}{*}{ Risk averse } & $\begin{array}{l}\text { Concerned with the same } \\
\text { hazard as the agency }\end{array}$ & $\begin{array}{l}\text { Target this group with hazard specific } \\
\text { information \& messages \& focus on how } \\
\text { they will manage their response to the risk } \\
\text { (i.e. what to do in a cyclone) }\end{array}$ \\
\cline { 2 - 4 } & $\begin{array}{l}\text { Concerned with different } \\
\text { hazards to the agency }\end{array}$ & $\begin{array}{l}\text { Target this group with non-hazard specific } \\
\text { safety initiatives (What to do in an } \\
\text { emergency) } \\
\text { Agency partnerships }\end{array}$ \\
\hline Risk tolerant & $\begin{array}{l}\text { Ambivalent about the } \\
\text { hazard or the effect upon } \\
\text { them }\end{array}$ & $\begin{array}{l}\text { Target this group with general information } \\
\text { about the hazard. Highlight the risk from } \\
\text { the hazard and how it will affect their } \\
\text { family. }\end{array}$ \\
\hline Risk deniers & $\begin{array}{l}\text { Denies that the hazard will } \\
\text { occur or that it will affect } \\
\text { them. }\end{array}$ & $\begin{array}{l}\text { Target this group with messages that build } \\
\text { the credibility and authority of the agency. }\end{array}$ \\
$\begin{array}{l}\text { Sees a disaster as an } \\
\text { opportunity to become } \\
\text { involved in rescue efforts or } \\
\text { to pursue their interests }\end{array}$ & $\begin{array}{l}\text { During event, warn of dangers \& penalties } \\
\text { for interfering with work of emergency } \\
\text { agencies. After the event target with } \\
\text { specific messages relating to safety for } \\
\text { individuals and families. }\end{array}$ \\
\hline
\end{tabular}

Source: O’Neil, 2004 
Research into disaster impact on communities shows clearly that direct experience of a disaster is a particularly powerful awareness education event (Paton et al., 2001; Comstock \& Mallonee, 2005; Anderson-Berry \& King, 2005). It is common sense to expect hazard impacted communities to have developed greater awareness and to have responded by adopting appropriate preparations. Research shows that this happens as predicted, but not to such a high level as might be expected. The average community response is greater, but direct experience of a disaster does not transform all people into active community emergency managers. Rather, it results in a significant improvement in awareness and preparedness that may reduce, but not eliminate vulnerability to future hazards. Perhaps acceptance of people's limitations and an ability to respond appropriately to a crisis are resilience characteristics that communities rely upon.

\section{Conclusion}

Understanding, constructing and moving on to improved preparation are processes in learning from disasters that are influenced by a kind of distance decay effect. Distance decay is a gravity model (based on Newton's law of gravity) in which the influence of another place upon any given place is contingent upon the size of the other place and its distance away. This influence may be measured in such processes as migration or trade and flow of goods. Disasters outside our local community influence us in the same way. The further away the event is, the bigger it has to be to attract our attention. In distance decay models (used in human geography and economics) there are controlling elements in the formula, such as a factor of distance and a global constant. Qualifying factors are consequently things like the type of disaster, and the information technology. The community that experiences regular flooding or cyclones, pays greater attention to similar events elsewhere because of the commonality of experience, and would be much less interested in earthquakes or volcanoes. Yet, as shown above, the experiences of different disaster types can be transferred in terms of knowledge and experience. The Indian Ocean Tsunami demonstrated impacts that could be transferred to storm surge, as well as the general vulnerability of the coastal zone, tourists, critical infrastructure and buildings. The other qualifying factor, information technology, means that well-connected places are more visible. Researchers learn far more of hurricanes in the southern United States than of cyclones in much closer areas such as India and the Philippines because of the more ubiquitous technology and media of the developed world.

With these qualifying factors modifying the level of knowledge of other disasters, the basic rule is that the further an event is from our location the less is learnt about it or less attention paid, unless it is bigger, more 
spectacular, deadly or destructive. Therefore the following disaster learning problems can be summarised in relation to households and communities:

- There is the lack of transfer of knowledge and awareness between different types of hazards;

- Information technology gives emphasis to places, and events, that are better connected;

- Distant events that are learnt about are the biggest, and in a sense, the easiest to ignore because they are extreme;

- Most information is received on the most local events that, most of the time, are not extreme disasters - thus communities remain unprepared for a truly catastrophic event.

Consequently most communities receive hazard knowledge that reinforces complacency. Most disaster declarations experienced by most communities have not involved absolute devastation. Other local events are similar and communities being essentially resilient, they muddle through, prepare moderately well for survivable events and are further reinforced in their lower-level awareness. This is quite acceptable for the regular and predictable hazards that cause sufficient damage and disruption to warrant a disaster declaration, but do not result in devastation or significant loss of life. Unfortunately the distance decay effect reinforces the community view that terrible things happen a long way away, that our hazards are part of the way of life and the pattern of the seasons, and locals cope reasonably well. Thus until the terrible disaster happens locally, most people learn only selected lessons from other disasters. Communities are completely unprepared for the catastrophic disaster even when, as in New Orleans in 2005, they knew how vulnerable they really were. 


\section{4 \\ Transport and evacuation planning}

\section{Douglas Goudie}

At the conceptual level, disasters can be divided into those with a warning of more than a few hours, and those with a warning of less than a few minutes. This chapter considers disasters with sufficient warning periods to be able to evacuate vulnerable people away from the expected high impact areas. The chapter also develops lessons and recommendations based on actual preparation for a major cyclone storm surge in Cairns, resulting in planning recommendations and conclusions based on ecologically sustainable development (ESD) principles and practicability. All the case studies explored on evacuations are related to community safety and capacity building: involve the community and provide effective information and early warning to the community at risk.

In all disaster risk reduction work, the core goal is to minimise loss of life and injury. Reducing loss of expensive or highly sentimental items is also of some importance. Planning and community involvement can prepare people to minimise loss through precautionary evacuations. Case studies from north Queensland form the basis of recommendations developed here.

A cyclone storm surge and evacuation network modelling project conducted over three years for Cairns in far north Queensland forms one end of the spectrum of study - in the worst case, about 54,000 people in Cairns would need to be evacuated to shelter higher and safer than their own homes, ahead of an extreme cyclone storm surge. However, land-based flooding would block most of the exit roads from the low coastal suburbs.

This chapter considers a range of threats with some warning time, and issues and strategies to maximise the mobilisation of people out of the most severe danger zones.

\section{Threat types}

There are both 'sudden threats' - land slide, earthquake, tsunami; and 'signalled threats' - cyclone, major winds, fire, flood. Threats, with or without warnings, form the basis for the evacuation matrix in Table 4.1 below. 
Table 4.1 Evacuation matrix of safety responses

\begin{tabular}{|l|l|l|l|}
\hline \multicolumn{4}{|c|}{ Sudden Threats: Virtually no warning } \\
\hline & \multicolumn{1}{|c|}{ Land slide } & \multicolumn{1}{c|}{ Earthquake } & Tsunami \\
\hline Safety response & $\begin{array}{l}\text { Stay in strong } \\
\text { structure }\end{array}$ & $\begin{array}{l}\text { Stay in strong } \\
\text { structure }\end{array}$ & $\begin{array}{l}\text { Flee to higher } \\
\text { ground at } \\
\text { outflow of sea }\end{array}$ \\
\hline
\end{tabular}

\begin{tabular}{|l|l|l|l|}
\hline \multicolumn{4}{|c|}{ Signalled Threats: Usually some warning } \\
\hline & $\begin{array}{l}\text { Cyclone/major } \\
\text { wind }\end{array}$ & \multicolumn{1}{|c|}{ Fire } & Flood \\
\hline $\begin{array}{l}\text { Vulnerability of } \\
\text { present } \\
\text { environment }\end{array}$ & $\begin{array}{l}\text { If likely in surge, } \\
\text { must evacuate; if } \\
\text { weak shelter, } \\
\text { must evacuate }\end{array}$ & $\begin{array}{l}\text { House material, } \\
\text { surrounds, water } \\
\text { available. If poor, } \\
\text { leave early. }\end{array}$ & $\begin{array}{l}\text { May be } \\
\text { inundated, } \\
\text { may be cut off }\end{array}$ \\
\hline $\begin{array}{l}\text { Vulnerability of } \\
\text { individuals }\end{array}$ & High = earliest & $\begin{array}{l}\text { Weak and young leave } \\
\text { early }\end{array}$ & $\begin{array}{l}\text { Judgements of } \\
\text { flood height }\end{array}$ \\
\hline $\begin{array}{l}\text { Distance to secure } \\
\text { shelter }\end{array}$ & $\begin{array}{l}\text { The further, the } \\
\text { earlier }\end{array}$ & The further, the earlier & $\begin{array}{l}\text { The further, } \\
\text { the earlier }\end{array}$ \\
\hline $\begin{array}{l}\text { Present safety of } \\
\text { route/vulnerability } \\
\text { en route }\end{array}$ & $\begin{array}{l}\text { Know in } \\
\text { preparation }\end{array}$ & Know in preparation & $\begin{array}{l}\text { Know in } \\
\text { preparation }\end{array}$ \\
\hline $\begin{array}{l}\text { Means of travel } \\
\text { Reliability and } \\
\text { suitability }\end{array}$ & $\begin{array}{l}\text { Reliability and } \\
\text { suitability }\end{array}$ & $\begin{array}{l}\text { Reliability and } \\
\text { suitability }\end{array}$ \\
\hline $\begin{array}{l}\text { Community } \\
\text { Help available }\end{array}$ & Help available & Help available \\
\hline
\end{tabular}

The key issues for disaster planners are the extent of expert warning there may be, and the extent of public warning for a given threat. Also, it is critical to know who is vulnerable, where the safest shelter is and how vulnerable people get to shelter. Disaster managers attempt to balance the politics of calm or panic as it relates to public safety: how much should the public know?

With virtually no warning hazards such as landslides, earthquakes and tsunamis, the Prevention and Preparedness components of the Integrated Emergency Management System model of Prevention, Preparedness, Response and Recovery is to have strong structures in landslide or earthquake areas. In tsunami scenarios, the ideal situation is to have a public education program which advises that if the sea is observed to be withdrawing that this is an immediate signal to escape to high ground in all haste. This discussion considers threats with warnings, making precautionary evacuation possible.

Case studies explored include Cloncurry, Magnetic Island and Cairns. 


\section{Floods}

The following discussion considers some lessons learned from major floods in north Queensland. Flooding and storm surge due to cyclones are signalled threats.

In Cloncurry in March 1997, floodwaters two metres higher than any flood in the hundred years prior were experienced. People did not believe it possible, so tended to under prepare (King \& Goudie, 1998). By interviewing floodaffected people in Cloncurry, it was learned that there was disbelief, support from neighbours, a need for a better warning system, and a need for more public awareness and involvement. People would generally move themselves or their possessions ahead of potential flood damage earlier, if faced with a similar threat (see Figure 4.1 below).

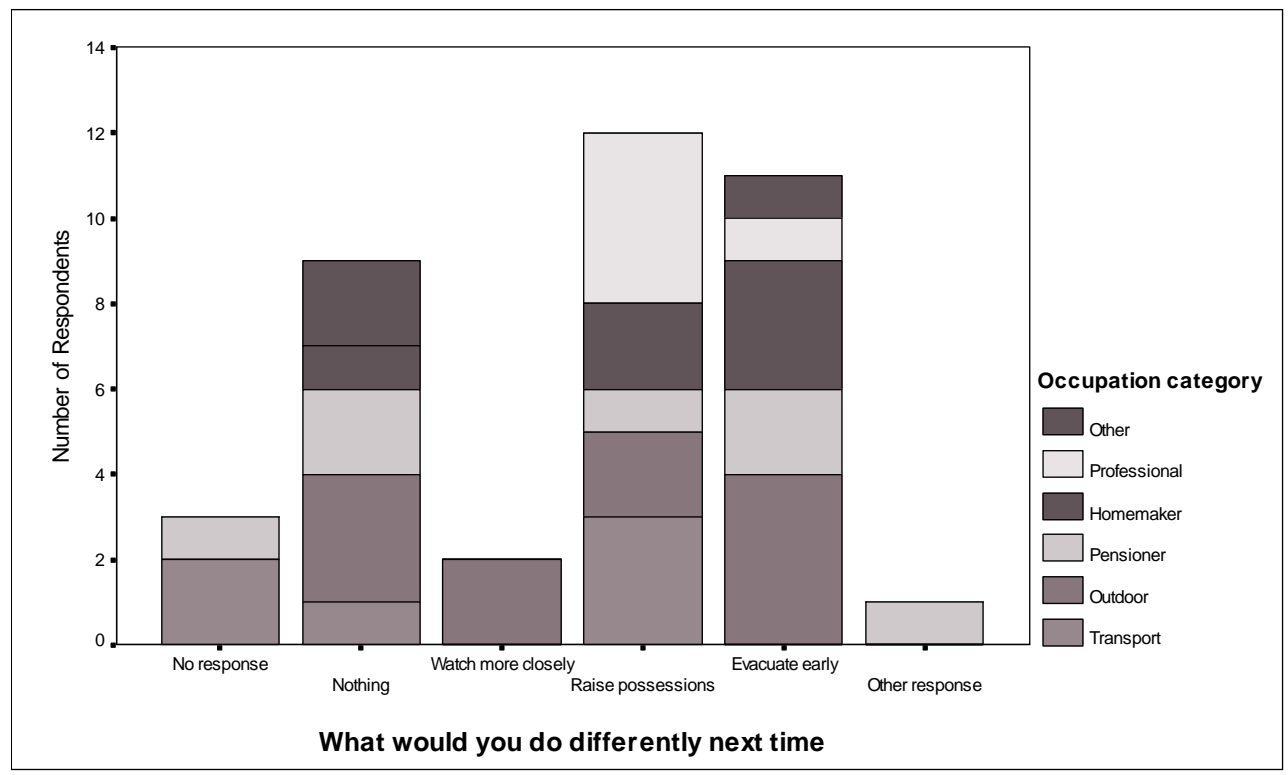

Figure 4.1 Lessons learned by Cloncurry flood victims 


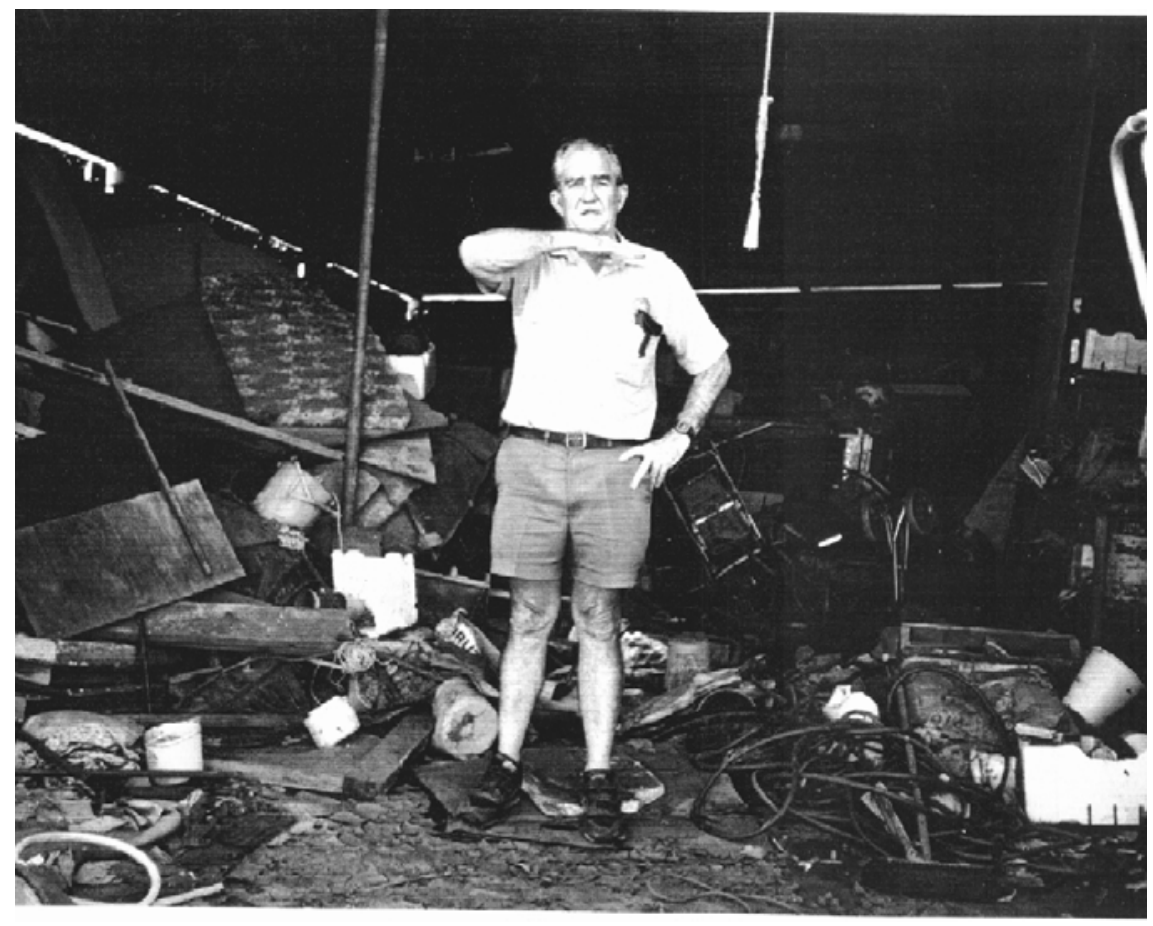

Figure 4.2 Cloncurry resident showing height of flood waters through a ruined storage shed.

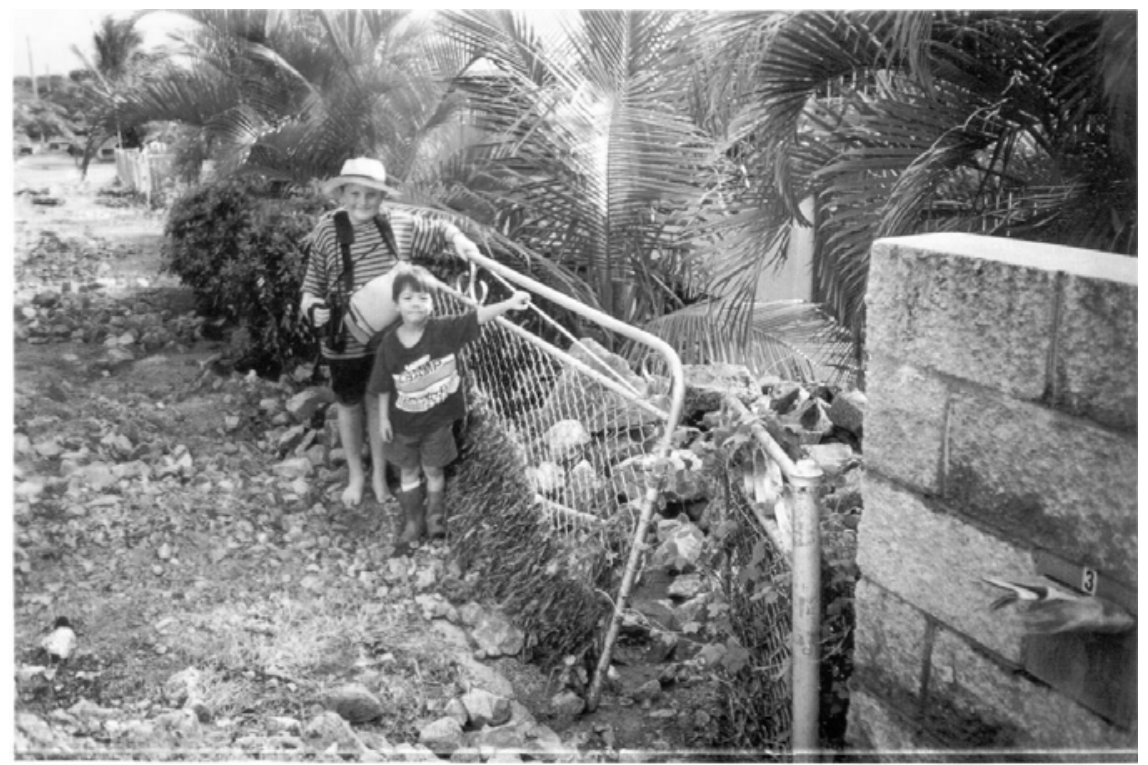

Figure 4.3 Force of the Townsville flood, 1998 
All the rock in Figure 4.3 was transported by high-energy water flow in the January 1998 flood, described as a 1 in 200 year flood. The implied force of the water shows why driving into floodwaters may lead to major safety problems. The experience of fieldwork on Townsville's Magnetic Island showed that well-intended thoughts of travel during heavy rain may not be possible because of flooded roads. Considering land-based flooding ahead of a cyclone and storm surge may be the single most important factor in survival for people in low-lying costal areas which are prone to cyclones.

\section{Cairns, cyclone surge and the road network}

The goal of the three-year study reported below was to define the role and implications for the road network's weak points ahead of a cyclone storm surge in Cairns, and produce recommendations.

The cyclone storm surge research approach was to establish the following:

- The nature of the hazard;

- $\quad$ Public vulnerability and awareness;

- $\quad$ Likely maximum surge height;

- Implications of land-based flooding;

- Who is vulnerable, and where and when they should go;

- $\quad$ Preferred movement of people;

- How the preferred movement could be implemented.

The most obvious weakness is the many flood points in the Cairns road network (indicated by the numbers of stars in Figure 4.4 below). The following sections of this discussion consider the road network flooding in some detail, then strategies to help achieve an early and precautionary evacuation. These strategies, as detailed below, include local inundation maps, definition of a maximum total flood contour, billet brokers, flood spotters and mobile sirens. 


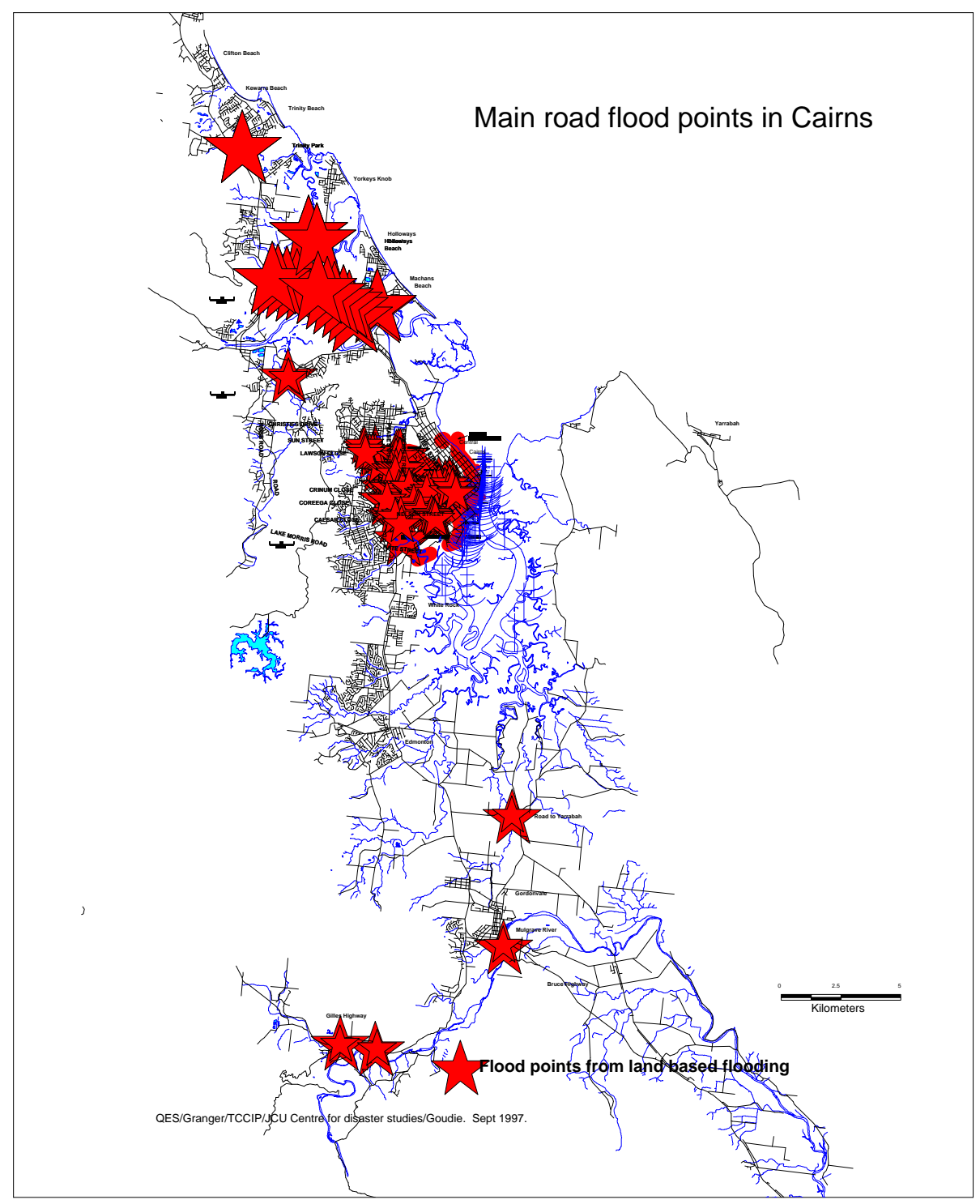

Figure 4.4 Main flood points in the Cairns road network

The proximity of the spring tide to the height above sea level of much of the Cairns central business district shows how vulnerable much of the Cairns central area is to even a small storm surge (figure 4.5 below). 


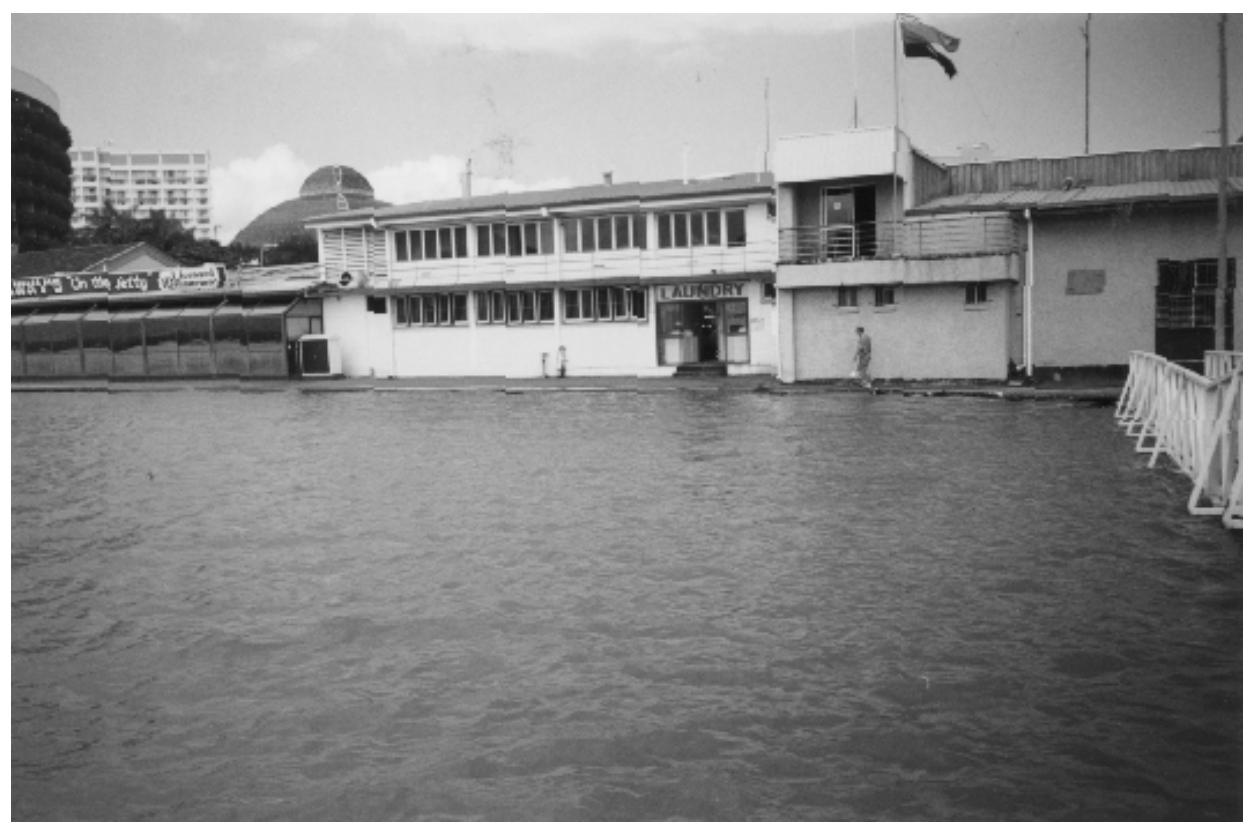

Figure 4.5 Cairns building near foreshore during spring tide

\section{Summary outcomes}

- The road network will impose severe restrictions on last minute evacuations.

- Flood waters may cut evacuation routes days before a cyclone strikes.

- An evacuation spread over many hours to safe local shelter will minimise traffic congestion as the threat heightens.

- Accumulation of vehicles on the 'threatened' side of floodwaters normally garaged in the vulnerable northern beaches will make further arrivals transferring to 'high-clearance' vehicles increasingly chaotic. Hence the need for early departures and marshalling points on highest ground within the vulnerable communities.

- The evacuation procedures developed are likely to form the basis of response in Cairns for many years to come. Consideration of the likely increase in frequency and severity of cyclones caused by the enhanced greenhouse effect should be included (Minnery \& Smith, 1994). Further, sustainable urban development should include explicit cyclone preparation and response strategies in all areas of ongoing urban growth.

- $\quad$ Prior to a surge, about 6,000 vehicles and 25,000 people (ABS, 2002) will be located on the main Cairns floodplain. About 2,000 households in that area do not own cars. 


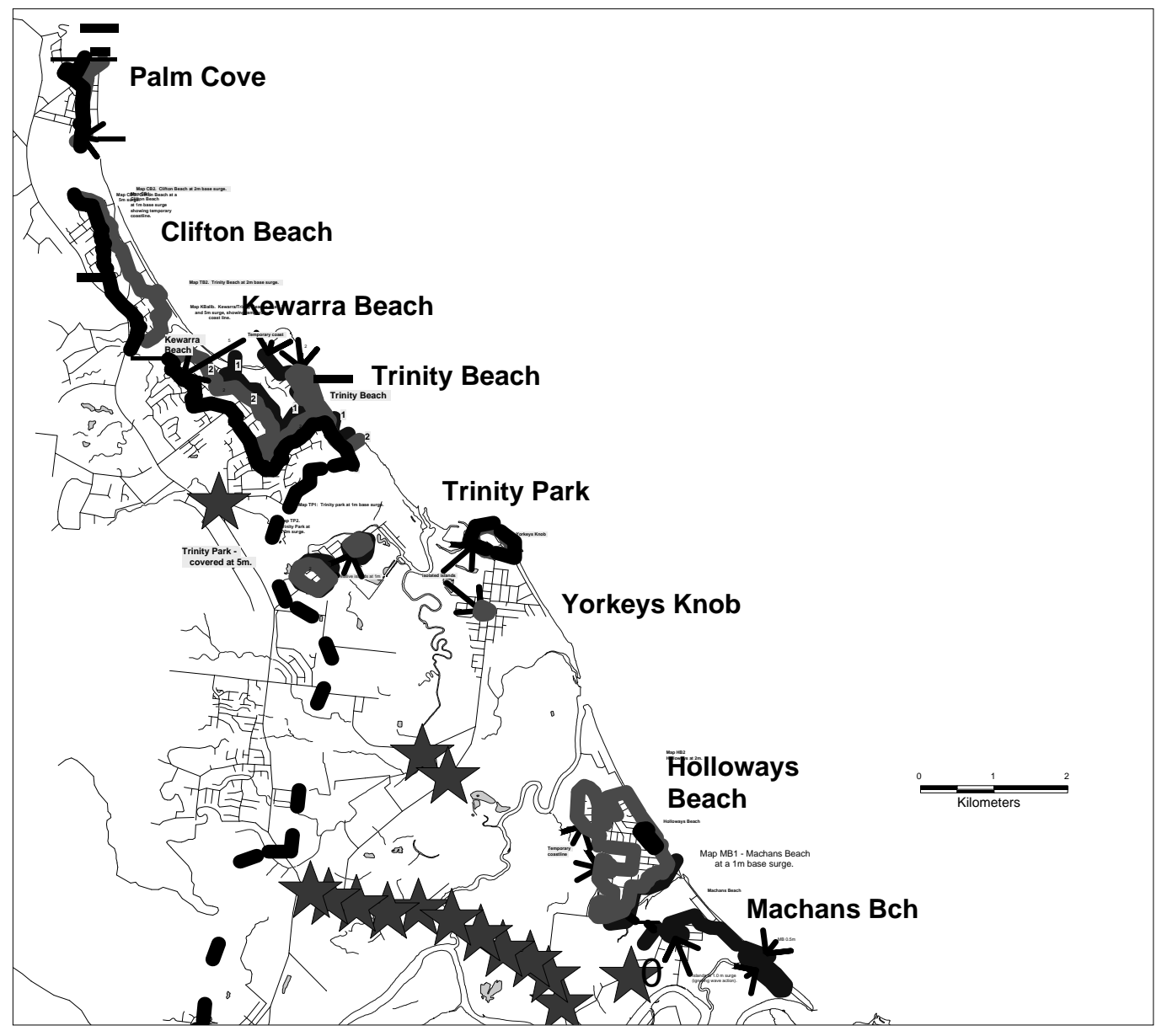

Figure 4.6 Detail of land-based flooding in the Cairns northern beach roads.

In Figure 4.6 the stars indicate the local flood points, the dark lines would be the $5 \mathrm{~m}$ temporary coast and the light lines the $2 \mathrm{~m}$ temporary coast. This figure indicates that early evacuation would be needed in most of the northern beach suburbs.

For the Cairns central area, Figure 4.7 below there are five components: local land-based flood areas; 'dry' exit routes; and three coast line levels at one metre, two metres and five metres. The stars show the local flood areas in central Cairns. This flooding may occur days before the cyclone and storm surge. The dark continuous lines show the 'dry' exit routes around the flooded areas (traffic lights are adjusted to help exit flow). After flooding and evacuation, the heavy dotted lines show the 'temporary coast line' at one 
metre, two metres and five metres surge above Highest Astronomical Tide (HAT - king tide).

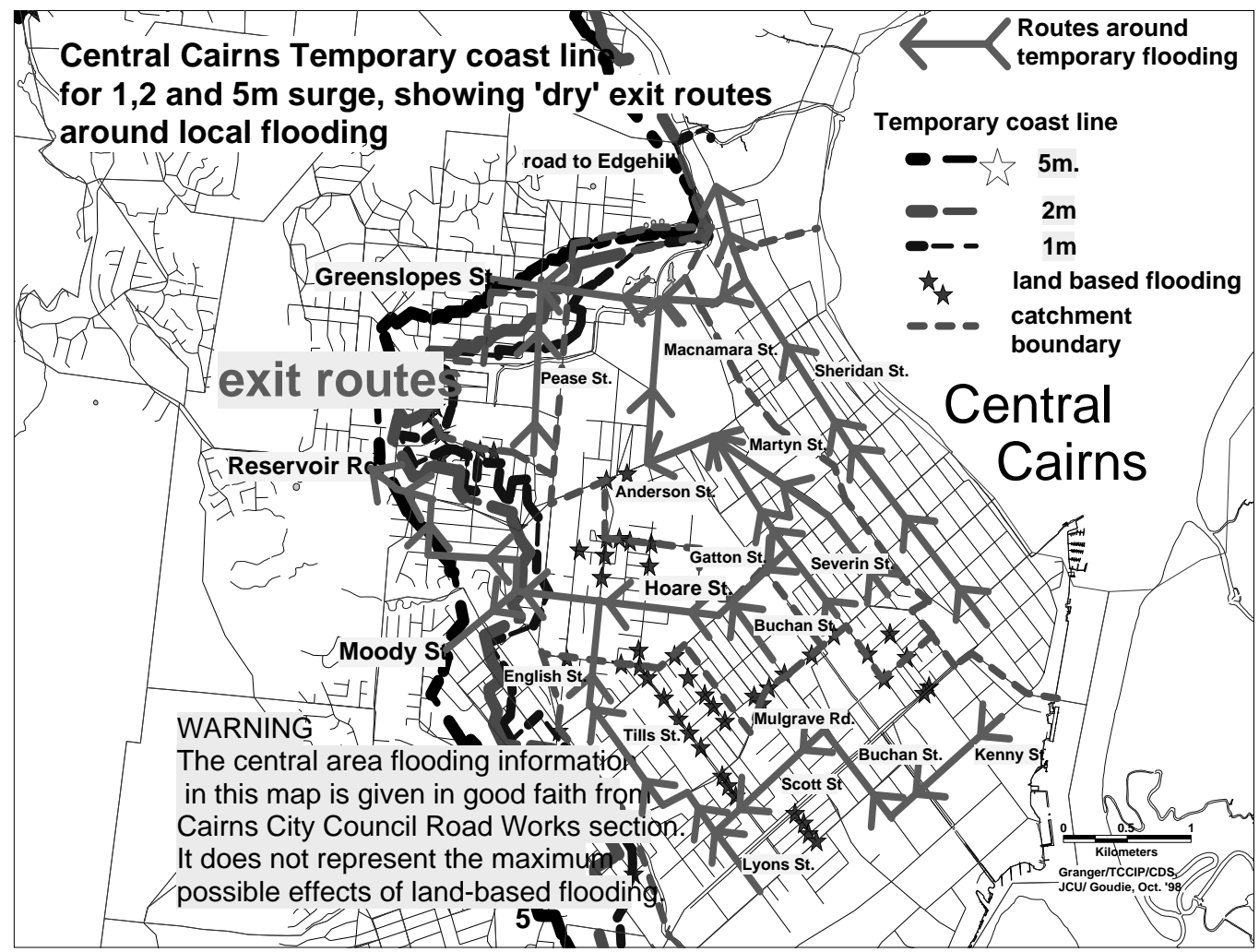

Figure 4.7 Detail of temporary coast lines and 'dry' inner Cairns exit routes.

The temporary coast lines and the following information are all based on a digital elevation model (DEM), with a general accuracy of about $250 \mathrm{~mm}$ for elevations for every building in Cairns. The methods developed through the Tropical Cyclone Coastal Impact Program (TCCIP) process have relied heavily on the DEM. This elevation data has allowed for the mapping of ground contours at $1 / 2$ metre intervals. Transport planning will be successful if no-one is trapped and drowned. Transport planning is fully dependant on an informed public undertaking early and voluntary response.

\section{Evacuation layers}

Generation and study of hundreds of such maps above implies that evacuation should be conducted at the one metre, two metre and five metre extreme surge height (see Figure 4.7), erring on the side of early and precautionary evacuation. 
Examination of Figure 4.7 shows vulnerable buildings on: the coastal edge and low points (to one metre); the broad coastal plain of inner Cairns and lowest parts of all the northern beach suburbs, including Trinity Park (to two metres) and progressively more of the beach suburbs; and a relatively narrow upper edge at the beginning of the mountainous base of the Cairns flood plain. Thus there are three basic evacuation layers.

The Figure 4.8 below provides an example of pockets and areas of one community vulnerable to surge at heights of one metre, two metres and five metres above HAT. These layers were selected because of the shelf-like low coastal topography in the Cairns area.

The only viable evacuation strategy to best minimise loss prior to or during a significant cyclone storm surge in Cairns is early, precautionary 'self evacuation' to relatively safe domestic shelter on higher ground, mainly within Cairns. Precautionary evacuation is recommended because cyclones have erratic paths (Lourensz, 1977), and their effects are not fully predictable (JCUNQ, 1972).

Increased political and community involvement are necessary parts of successful evacuation. Roads to the south and west are likely to be blocked by land-based floodwaters. The primary objective is for vulnerable people to move from low-lying, threatened areas to the homes of friends, relatives or networked contacts living on higher ground. Destination shelters would ideally be strong, and away from large trees and major debris sources, with socially similar households. The whole community should be involved in storm surge preparation. Early public involvement will help clarify community needs and encourage cooperative behaviour. This will minimise direct and formal demands on the disaster response when the next major cyclone threatens Cairns.

The following issues are critical for successful pre-surge road use:

- $\quad$ Knowing the flood areas in the road network;

- $\quad$ Commitment to precautionary evacuation;

- Well known evacuation zones;

- $\quad$ Political support and community preparation;

- $\quad$ Fully pre-arranged private billets.

Loss of life and loss of portable valuables will be minimised by developing the following features:

- $\quad$ Strong political support for public education;

- $\quad$ Sponsorship and public involvement; 
- $\quad$ Local inundation maps in retail outlets;

- $\quad$ Local billet brokers';

- Local 'spotters' placed at known flood points to report as waters rise, their information may trigger evacuations if a large cyclone is in the vicinity;

- Local siren warnings;

- $\quad$ Local maximum urban flood contour;

- $\quad$ Self-organisation in the tourism industry for their staff and guests.

The aim is to encourage early self-evacuation to pre-arranged private shelter on higher ground. Along with work being done by the Cairns Disaster Management Group, this may be best achieved by the following:

- $\quad$ placing maps like Figure 4.8 in every convenience store in the vulnerable areas of Cairns; these maps would be specific to the usual 'catchment' of each store;

- $\quad$ placing maps in shopping mall displays in the Cairns area, which could be organised through sponsors and the displays could be posted from October to March inclusive.

A legend could be developed so that each dot, in Figure 4.8 below, represents a business or house, for example, red dots could mean people must evacuate up to $0.75 \mathrm{~m}$ above floor level; yellow might mean water over property; and white could mean relatively surge free. 


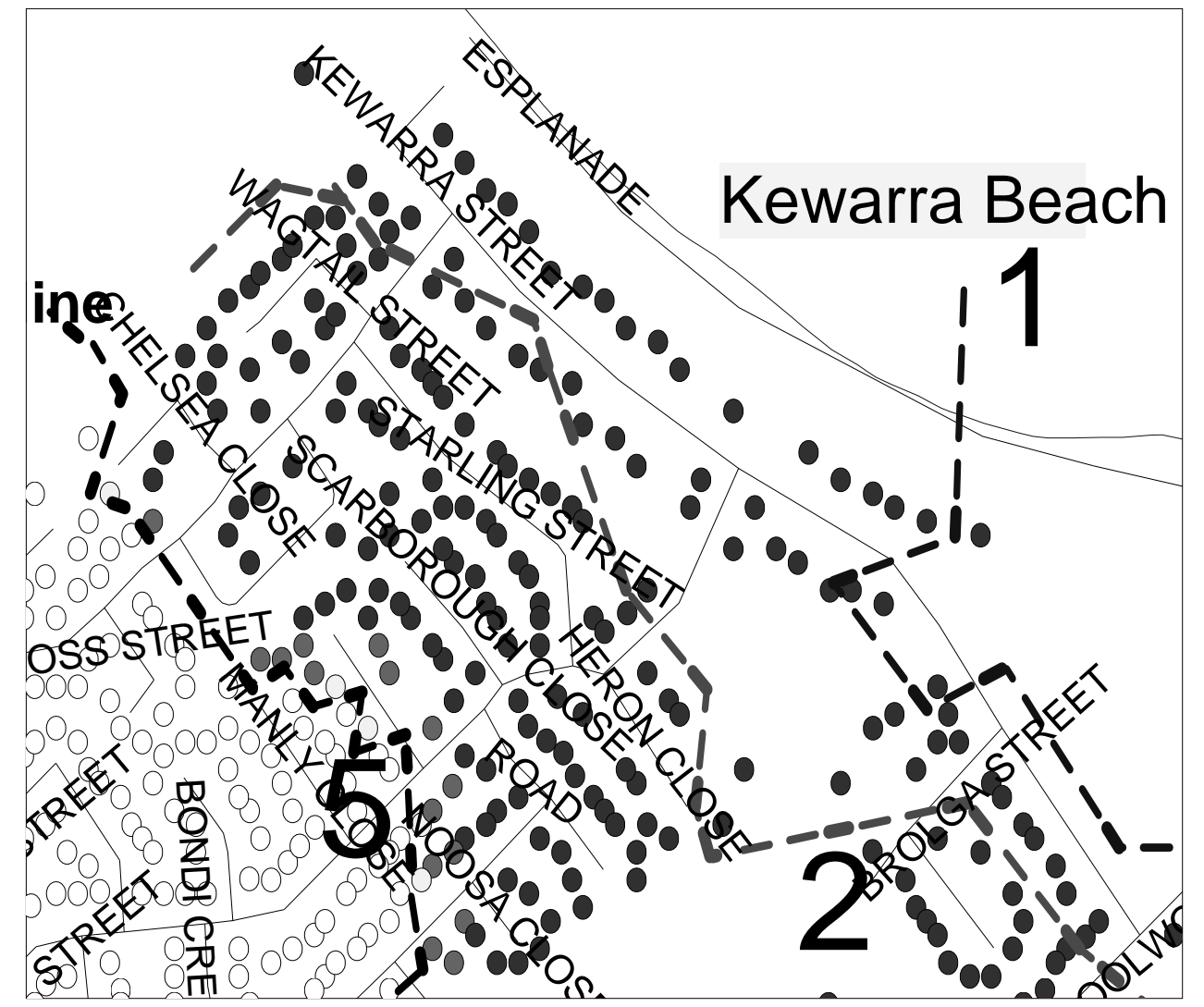

Figure 4.8 Kewarra Beach at a 1, 2 and 5m (above HAT) surge

\section{'Billet broker' details}

For the many residents of low-lying areas of Cairns who do not have their own informal networks to arrange overnight billeting, there is a clear need to have billet brokers' (Goudie, 1996). Interested and active members of various community groups in Cairns could fulfil this role. Such activities would need seed funding to cover phone, newsletter printing and mailing costs, plus, perhaps, a little support for the parent groups involved. In this way, people in the vulnerable, low-lying areas would be facilitated to form a contact with a welcoming household on higher ground, well before landbased flooding or gale-force winds prevent safe passage from lower to higher ground. A major cyclone threat would trigger an early, ad hoc response, engendering an attitude of a 'practice', an 'overnight picnic', rather than a 'false alarm'. These ideas are at the conceptual stage only. 


\section{Mobile or fixed sirens}

Research in Cloncurry and on Magnetic Island found that not enough people listen to the radio and the television information is just not localised or specific enough. Development and implementation of an effective sirenbased public warning system is recommended to avoid people being ignorant of danger which could cost lives. It could be argued that luck played a significant part in saving four people from drowning on Magnetic Island during the 1998 floods. The use of a mobile siren system could be piloted in a small population area like Magnetic Island, and developed for all areas of Queensland which are flood or fire prone.

For sirens to be effective there would need to be widespread information as to what they meant, and what should be the individual responses. Radio and local talks, along with local letter drops would help prepare residents and managers for the practice runs. It is suggested that the siren signals (see below) are sounded at 11 am on the first Sunday of October and November (before the wet season), to familiarise people with the sound, and the preferred response. Further, mobile sirens already exist in the community on police and emergency vehicles, thus the infrastructure costs are near zero.

The sirens could have the following three levels of alarm, and one all clear signal:

- Danger looming, stand by, or respond in a precautionary way (perhaps three short blasts, repeated periodically);

- Respond to danger (equivalent to an order to evacuate, perhaps one short and two long blasts);

- $\quad$ Danger imminent, prepare for impact (perhaps three long blasts);

- An all clear signal may be useful as well (perhaps long, well-spaced blasts).

\section{Selected evacuation details}

To maximise community safety in the ways outlined, it is recommended that seed funding be provided to establish community storm surge groups and billet brokers. To maximise tourist safety, logically the tourism industry should take full responsibility (under the direction of Emergency Services authorities) for the safe relocation of their own staff and guests (Drabek, 1994). The industry has many buses, 'adequate' shelters, and an accurate record of visitors in the area at any given time.

There is a clear need to establish staggered evacuation procedures for all vulnerable people requiring an ambulance. It is suggested that various health authorities provide a mapped database (e.g. MapInfo or Latitude) of people 
in their care who may need special attention (updated each October). If they live in the low lying-areas of the beach suburbs, they will need to be moved before exit routes are compromised.

More vulnerable people: the elderly; the infirm; the disabled; tourists; and those without cars or rides with friends or neighbours in the lowest areas, should be the first to be moved. This should occur in sequence: when a 'recommendation to evacuate' is given, evacuees without use of private transport should board evacuation buses at specified marshalling points within vulnerable communities. It is important to note that people may leave earlier if a strong police anti-looting presence is provided. Local government, guided by federal consistency, should consider the development of appropriate signs to identify routes and destinations. Finally, vertical evacuation utilising sound high-rise commercial buildings, could be designated as 'shelters of last resort' for people trapped in the inner city area (Smith, 1995).

\section{Other general recommendations}

- There is a need for effective communications for SES personnel. For example, many had difficulty contacting each other on Magnetic Island in 1998.

- $\quad$ More detailed public education should be provided about the dynamics of flooding specific to each catchment, and the link roads between catchments.

- In line with current government policy, fully involve the community in 'urban segments' to ensure 'safe' upslope shelter. For example, the golf club rooms in Picnic Bay, or the Sports Club rooms in Horseshoe Bay on Magnetic Island. What extra items are needed? Who will help the infirm?

- In Cairns, debris and weak points in the road network immediately after any cyclone flooding would be identified and checked by Queensland Transport/Main Roads Department/Road Transport Construction Services and Cairns City Council, aiming to allow the maximum number of people to return to their properties as soon as possible. Initially, the Main Roads Department would work on problems north of the Barron River and Cairns City Council to the south.

- Community service television announcements and footage of Cairns road flood-points may help encourage early self-evacuation of vulnerable people to 'safe' shelters. 
- $\quad$ Modelling of a cyclone category 5 storm surge of five metres, with funnelling, wave reach and flooding should be used to define a local contour of safety' - the local maximum flood height, which could be prominently indicated where it crosses major roads. People can be encouraged to negotiate their own billets with friends, relatives, workmates or other contacts above that line, but within their own sector of the city (e.g. discouraging people in low-lying areas in the south waiting until danger is imminent before travelling to friends on high ground in the far north of the city).

- Use the roads early when the decision to evacuate has been made.

- $\quad$ Education, community involvement, billet brokers, mobile sirens and ad hoc precautionary evacuation are likely to minimise the social impacts of major cyclone storm surges in vulnerable coastal centres.

- $\quad$ Research methods which combine computer modelling, interviews, a planning team, literature search and guided by sustainability principles and community involvement may be used widely in preliminary planning.

\section{Conclusion}

Research from other locations in north Queensland illustrate the potential problem to be faced by people in the region and unless lives are to be placed at risk, effective strategies for self-evacuation of households must be developed in cities such as Cairns which is clearly vulnerable to storm surge flooding. 


\section{5 \\ Tourism, disasters and vulnerability}

\section{Scott K. Cunliffe}

“Like a ticking time-bomb, the tourism industry represents an
enormous catastrophic potential” (Drabek, 1994, p. 25).

The main objectives of this chapter are: to describe some of the natural and anthropogenic hazards which have an impact of the tourism industry in tropical coastal areas; and to highlight the importance of vulnerability reduction to assist communities to cope with all potential hazards to their livelihoods. The discussion takes a global view of hazards and vulnerability while pointing out specific aspects of vulnerability and the exposure of tourism destinations in the Asia-Pacific region. The chapter takes a general view of hazards and vulnerability issues related to tourism.

Early on the morning of 17 January 1995 an earthquake centred on Awaji Island, 20 kilometres off the coast of J apan, devastated the city of Kobe and other parts of the densely populated Hanshin region. The quake lasted just fourteen seconds, and there were no warnings. The earthquake was Japan's worst since 1923, claiming more than 6,400 lives and leaving more than 300,000 people homeless. The damage to homes, buildings, and infrastructure in the area was a colossal US\$150 billion. In the longer term tourist visitor numbers were substantially reduced, negatively impacting on the tourism sector (Kippo News, 1996). The government was criticized for its slow response in the aftermath of the earthquake and later acknowledged serious flaws in the country's emergency management system.

This event illustrates the following pertinent points:

- Despite the recognized vulnerability and exposure of many parts of J apan to massive seismic activity, this, one of the most technologically advanced and economically wealthy countries of the world, was poorly equipped to respond to this catastrophe;

- Insured versus total economic losses illustrated an underinsured private market;

- The structural instability of vast areas of ground floor residential accommodation only became evident after the earthquake had killed 
many older residents who favoured ground level access because of their limited physical motor skills, building codes have since undergone significant revision to remedy this failure;

- The preparedness of emergency assistance teams and the coordination of response mechanisms (emergency relief, medical facilities, food, water shelter etc.) were critical to the saving of lives in the immediate aftermath.

The example of the Kobe disaster is used here to illustrate a likely and plausible outcome (conceptually, not literally) of the impact of a major natural hazard in any number of large tropical coastal tourism areas throughout the world. The potential for a major crisis due to a single natural hazard, compounded by anthropogenic inefficiencies, thus causing significant loss of life and property, has a high probability. In the case of Kobe, the long-term response of the Japanese authorities has been to strengthen all aspects of disaster planning and risk management in J apan, not just in vulnerable seismic zones. In addition, community representatives now actively participate in the policy and planning processes.

Unfortunately, human societies have a tendency to act curatively to catastrophic events rather than employing a preventive approach, using disaster as the primary incentive to policy change, rather than proactively planning for future uncertainties. This chapter therefore argues for the substantive strengthening of proactive disaster planning and risk management for tourism in tropical coastal areas.

Disasters for the general observer are usually referenced by location, hazard agent, and time, with the focus on the hazard agent in the case of natural disasters. The perception communicated, and therefore the dominant paradigm, is that disasters are caused by hazards. This has been a traditional geographers' perspective (Salter, 1995). Heathcote (1979) in a description of natural disasters in Australia, focuses on the extreme event, avoiding any mention of vulnerability, and describing risk in terms of the quantification of probability and consequence; “... [disasters are] extreme geophysical events greatly exceeding normal human expectations in terms of their magnitude or frequency, and causing significant material damage to man (sic) and his works with possible loss of life" (Heathcote, 1979, p. 3).

There is a vast range of potential hazards that can have significant negative impacts on communities, tourists, and businesses in coastal tropical areas including those listed in Table 5.1. 
Table 5.1 Hazards to tourism in tropical coastal areas

\begin{tabular}{|l|l|l|l|}
\hline Atmospheric & Earth & Biological & Human \\
\hline Tropical cyclones & Landslides & Human epidemics & Industrial accidents \\
\hline Tornadoes & Earthquakes & Plant epidemics & Transport accidents \\
\hline Storm surges & Tsunamis & Animal epidemics & Crime \\
\hline Floods & Volcanoes & Plagues & Political conflicts \\
\hline Frosts & Erosion & Bush fires & Structure failures \\
\hline Droughts & Ground failure & & Structure fire \\
\hline Severe storms & & & Contamination \\
\hline
\end{tabular}

Source: After Granger (2000, p. 25).

Although the tourism industry represents a disaster vulnerability of catastrophic potential, the situation need not worsen. The industry needs to respond proactively to a rapidly expanding vulnerability, and failure to do so will keep an expanding tourist population at risk (Drabek, 1994). The costs of settling liability costs, together with "the marketing costs of offsetting customer ill will" (Drabek, 1994, p. 88) after a disaster or crisis, are massive compared to the minimal costs of investment in disaster planning and tourism risk management. Recent global crises that have had a massive impact on the tourism industry in virtually all parts of the world have provided impetus for the state of disaster planning and risk management for the tourism industry to improve greatly in the recent past. Clearly, the 'do nothing' scenario is not an option.

Books, articles, media coverage, international meetings, specialist committees and other formal and informal groups representing many aspects of the tourism industry planning and management fraternity, have come to the fore in recent years to support the development of better, more efficient ways of coping with disaster and uncertainty in the future. The World Tourism Organization (WTO), the World Travel and Tourism Council (WTTC) and others at an international level, have led the way in recognizing the need to plan for catastrophe in the tourism industry, now, more than ever before in the history of tourism (WTO, 2001).

\section{Natural and Anthropogenic Disasters}

In our current world of uncertainty, it is all but certain that more disasters will be faced in the future in terms of frequency and impact (Quarantelli, 
1999), due primarily to two worldwide social trends: industrialization and urbanization. Quarantelli argues that if the right policies and measures are put in place, "the future will not be the past revisited nor will it be only the present repeated" (Quarantelli, 1999, p. 9). There exists a very real sense of urgency to ensure much is learnt from recent disasters, and that the threat and impacts of repeat events of an escalating scale will be minimised or even avoided. The tourism industry has responded to this need, including the publication of a variety of disaster and risk management publications (WTO, 2001; Glaesser, 2003; and Wilks \& Moore, 2003).

An important point to understanding why disasters and crises occur is that "it is not only natural events that cause them" (Blaikie et al., 1994, p. 9), but rather, they are also the product of the social, political, and economic environment because of the way in which disasters affect social structures, the people, communities, and their livelihoods that are destroyed or damaged. As Blaikie points out, there is often too much emphasis placed on doing something about the natural hazards themselves, "and not nearly enough on the social environment and its processes" (Blaikie et al., $1994 \mathrm{p}$. 9). Similarly, Mileti (1999) points out that in the United States, short-sighted and narrow conceptions of the human relationship to the natural environment account for the nation's failure to reduce the way in which natural disasters result in major catastrophic events.

Natural disasters are also often thought to be one of the major instruments of catastrophic events. While this is true to some extent, statistically, in the nine decades 1900 to 1990 (using the death toll as an indicator), the ratio of deaths from natural disasters reported was less than $22 \%$ of the total. Civil strife accounted for $48.6 \%$ and famine a further 39.1\% (Office of Foreign Disaster Assistance, 1990). The economic (and insured) costs of natural disasters are continuing to escalate alarmingly. Natural disasters, of which the major proportion was weather-related catastrophes, cost the world over $\$ 60$ billion in 2003, up from around \$55 billion in 2002 (United Nations Environment Program, 2003).

Tourists are generally unfamiliar with many and often all of the places they visit, particularly with respect to potential hazards, and even more particularly with respect to natural hazards (Kuehlbrandt, 2000). The predilection of tourists for potentially hazardous sites, directly on the waterfront, or precipice with the best views or other scenically spectacular locations, resort hotels on the beachfront etc., places tourists amongst the most vulnerable of the entire community, alongside the old and infirm. Neither the tourism businesses nor the host community wish to frighten away visitors, with unnecessary warnings of pending catastrophe. There exists a need and responsibility, shared by local authorities and the goods 
and services providers themselves, to adequately appraise visitors "of both potential dangers [of natural disasters] and appropriate life-saving actions" (Murphy \& Bayley, 1989, p. 38). Safety drills on air and sea transportation services are commonplace, but the dangers of the impacts of extreme weather are not commonly delivered in an organized manner to tourists in tropical coastal areas.

This paradox of not wishing to promote a potential danger for fear of a negative response from visitors (lowering arrivals numbers for instance) while at the same time not wishing to be irresponsible in terms of safety and preparedness, is all too common to tourism service providers in tropical coastal areas. Issuing disaster preparedness and response information to clients does not always have negative connotations. A survey of backpackers undertaken in Cairns, Australia (Kuelhlbrandt, 2000) indicated a high level of interest in these young tourists actually having the opportunity to physically experience the onset of a cyclone, despite an extremely low level of understanding of possible consequences, response actions, evacuation and procedures.

Disasters, or at least potential disasters, can have an 'attraction' value, but this is rarely part of marketing campaigns apart from certain extreme adventure travel experiences designed for a small but important niche market. Murphy and Bayley (1989) go even further, suggesting that natural disasters can be positive free advertising.

Media exposure and consequent public awareness would usually have cost the tourist industry vast sums under normal circumstances, but if it can capitalize on this free, sensational exposure it can increase a flow of visitors and revenue, that, in turn, can facilitate recovery and lead to a better landscape in the aftermath of a disaster (Murphy \& Bayley, 1989, p. 46).

This would surely only occur in the most exceptional of circumstances. 


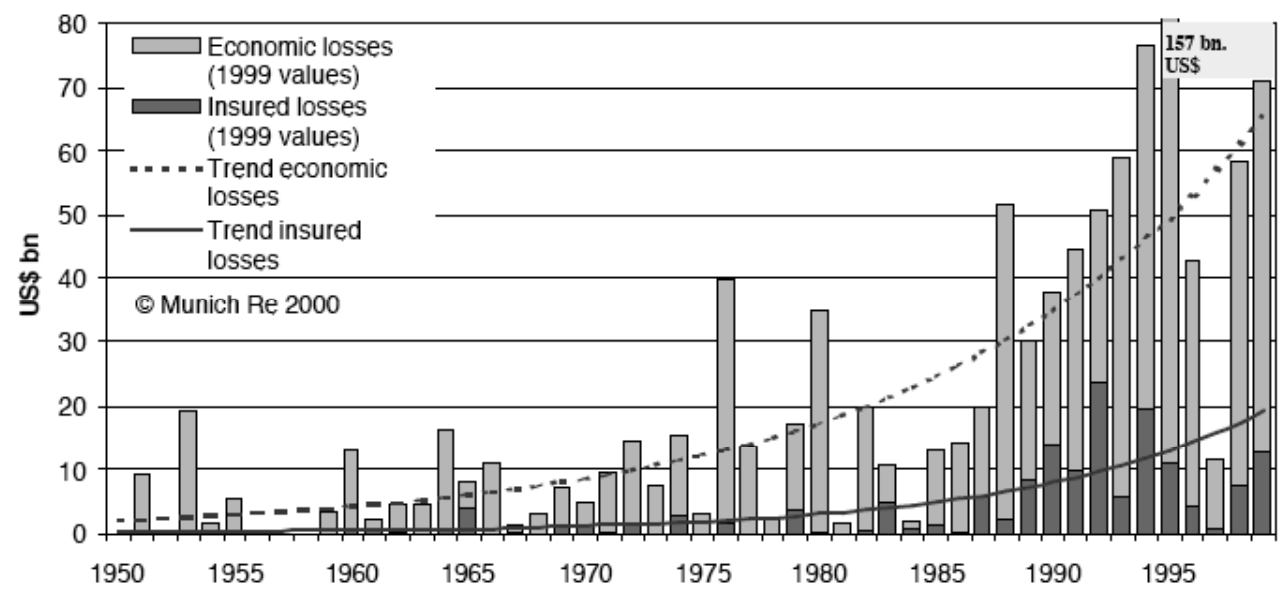

Figure 5.1 'Great' natural disasters 1950-1999

Source: Munich Re, NatCat Service (2000).

Tourism is affected by the largest natural disasters (great natural catastrophes or 'NatCats' as the insurance industry refers to them) even when the impacts are indirect, or the catastrophe occurs in apparently distant geographic locations. Natural catastrophes are classed as great if the ability of the region to help itself is distinctly overtaxed, making interregional or international assistance necessary, or when thousands of people are killed, hundreds of thousands are made homeless, or when a country suffers substantial economic losses. Figures 5.1 and 5.2 present the losses caused by great natural catastrophes since 1950. There are between 500 and 700 loss events registered every year around the world (Guha-Sapir, Hargitt \& Hoyois, 2004). The tables below show only 'great' natural catastrophes, selected based on monetary and human loss. In 2000, there were ten such events. The vast majority of these massive natural catastrophes had direct and indirect impacts on tourism flows.

The trend line on the Figure 5.2 below shows clearly the alarming trend towards rapidly escalating economic losses from these major events. Insured losses are increasing at a much lower rate, reflecting the ability of primary and re-insurers to accept greater risk and greater potential losses. It can be estimated that this general trend is equally applicable to the tourism industry; rapidly increasing economic losses from natural disasters with a much lower level of increase in insured losses.

There were around 11,000 fatalities from natural catastrophes in 2002. The earthquake in Afghanistan claimed some 2000 lives, halting the meagre domestic and international tourist flows in that country for much of the year. 
In 2002, a relatively 'good' year for the insurance industry, insured losses were US $\$ 13.5$ billion, of which US $\$ 11.4$ billion were from natural catastrophes (Swiss Re, 2003). Around 39\% of global insured losses in 2002 were in Europe, even though more than half of the total number of catastrophic events occurred in Asia, which also suffered $48.4 \%$ of total fatalities for 2002 (Swiss Re, 2003).

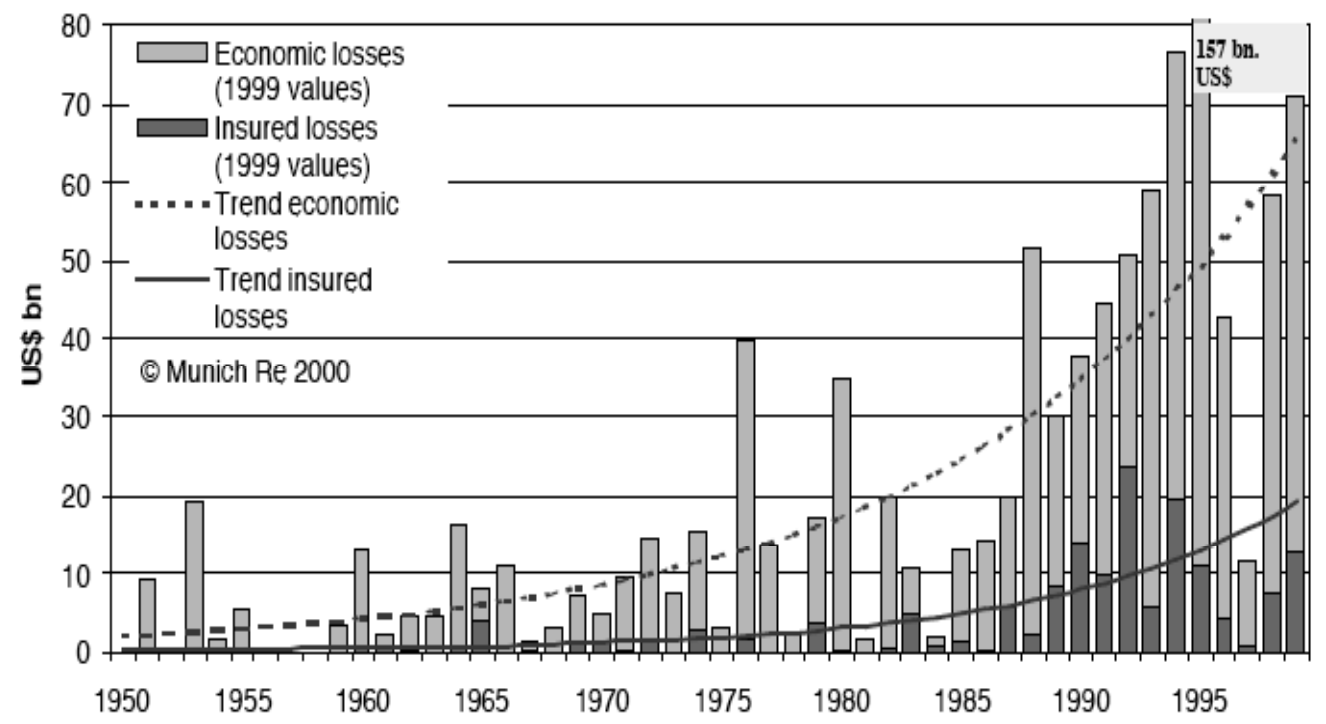

Figure 5.2 Economic and insured losses for 'great' natural catastrophes Source: Munich Re, NatCat Service, 2000.

In September 2001, terrorism took on a new dimension the world over with the aircraft being flown into the World Trade Center buildings. Insurers have responded by minimizing terrorism exposure (reducing policy conditions, increasing premiums and exclusions), changing the scope of coverage for terrorism-related losses. The USA, Germany and France have introduced new forms of terrorism coverage in which the state carries a substantial share of the loss.

In 2002, the insurance industry registered 13,000 fatalities from man-made disasters, including more than 800 fatalities from terrorist attacks. Unlike 2001 insurers did not have to contend with the scale of major losses from terrorism experienced in that year. The direct targeting of tourists in Bali, Indonesia, (claiming 190 lives) and Djerba, Tunisia in 2002 (19 lives) had devastating effects on their respective local and national economies, and indeed on global tourism figures in the immediate aftermath. The arson attack on a train in India in 2002 (59 lives) caused tourism to slow in the short-term only for India and the region. 
Possibly the greatest threat to a stable tourism industry in tropical coastal area in the long-term is the effect of climate change. This phenomenon coupled with the current demographic patterns of change around the world, will have an impact of a dimension that is currently unknown, but is predicted to be significant.

\section{Vulnerability Reduction}

The long-term future of the viability of tourism in tropical coastal areas is dependent upon the active development of vulnerability reduction and mitigation measures. These are broadly accepted as the highest impact and most cost-effective mechanisms to reduce losses from catastrophes, the ensuing reconstruction debt, and other adverse consequences (Evans, 1996). Beachfront tourist resorts are especially prevalent examples of the need for effective vulnerability reduction, as are population centres sited at coastal and seismic-risk locations.

The Asian Development Bank (2002) in its poverty reduction initiatives has recognised the vulnerability of communities to a variety of uncertainties that have a significant impact on the livelihoods of those communities. Figure 5.3 below illustrates the assets of a community and the vulnerabilities at risk.

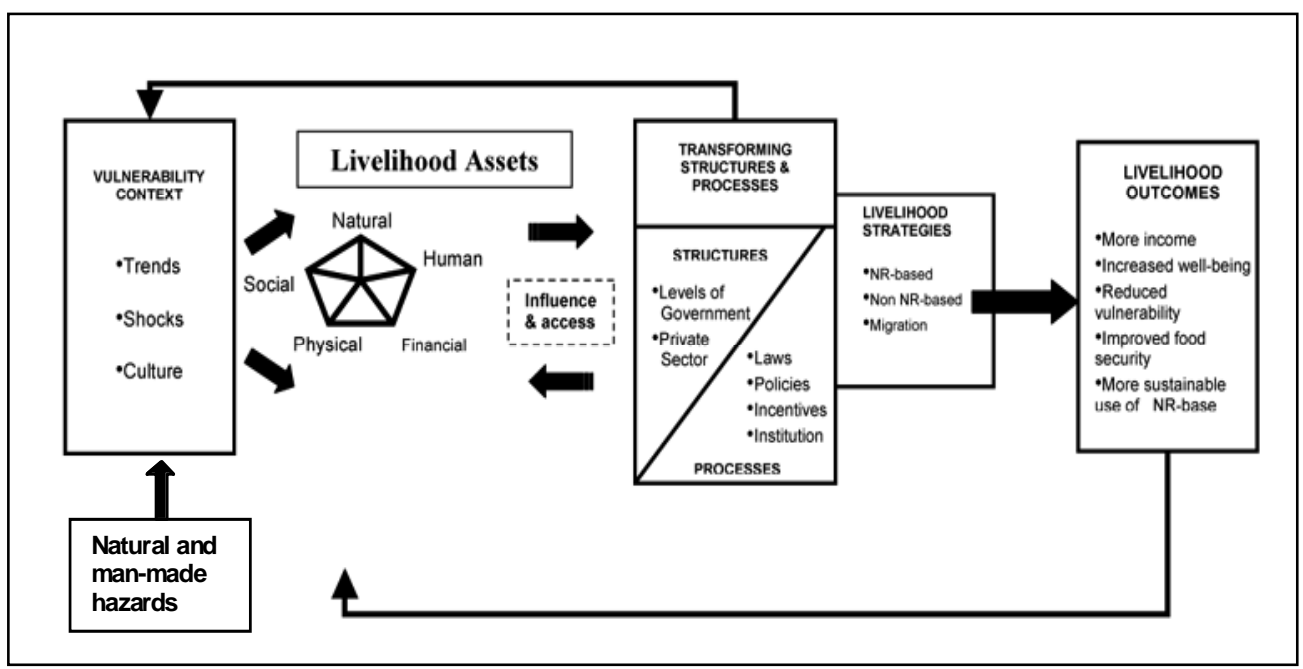

Figure 5.3 Community assets and vulnerability

Source: Adapted from Asian Development Bank 2002

Although the fundamental value of vulnerability reduction to catastropheprone coastal tropical areas is not in dispute, the adoption of an effective policy is hampered by complex behavioural, political, and institutional 
factors. The following basic principles could initiate the process of establishing a vulnerability reduction approach for tourism facilities in coastal tropical areas at a national and regional level:

- A National Strategy: Vulnerability reduction should become a committed national strategy covering not only the tourism sector, but also all sectors of the economy (a long-term and non-partisan strategy).

- $\quad$ Leadership and Partnership: With the tourism ministry as the lead agency (headed by a cabinet-level chairman), the strategy should be institutionalised through the creation of a council of the nation's leaders from all sectors. This office, with technical and financial support from international development funding agencies, could act as a clearing house serving all sectors, providing best practice information, and monitoring and publishing plans, performance criteria, and results of its activities.

- $\quad$ Education and Training: School curricula at all levels should include specific content covering vulnerability reduction and tourism development. Institutions of higher education should be encouraged to establish departments focusing on the advancement of vulnerabilityreduction technology and its effectiveness, in conjunction with natural and anthropogenic hazard mitigation. Tourism schools have a particular responsibility in this regard, but the current situation is not positive. For example, in a recognized authoritative university-level text titled "Tourism Analysis: A Handbook" (Smith, 1995), there is no mention of risk analysis, risk management, disasters, or catastrophic events in the index, and only passing mention of these topics within the text itself.

Any effective strategy to manage disaster risk at tourism destinations must begin with an identification of the hazards and what is vulnerable to them. This involves information on the nature and extent of risk that characterizes a particular location, including information on the nature of particular physical hazards obtained through hazard assessments, as well as information and data on the degree of exposure of businesses, the population, and its infrastructure and built environment to those hazards. In this way, informed decisions can be made on where to invest and how to design sustainable tourism developments that will withstand the impacts of potential disaster events.

Regulatory controls, when developed and implemented with community (stakeholder) approval can protect tourism infrastructure developments and reduce vulnerabilities to natural hazards. Local approval must be stressed. 
Top-down regulations are less likely to succeed than those developed with and for stakeholders (Inskeep, 1998).

Simple regulatory measures seen as capable of encouraging vulnerability reduction can be divided into the following categories:

- $\quad$ Non-Structural:

- Identification of hazard-prone areas and limits on their use;

- Land-use allocation and control, including building-line distances;

- Use of incentives;

- Structural:

- Use of building codes and materials specifications;

- Retrofitting existing structures;

- Use of protective devices.

Communities and the families who comprise those communities are especially vulnerable for reasons indicated in the ADB diagram in Figure 5.3 above.

By vulnerability we mean the characteristics of a person or group in terms of their capacity to anticipate, cope with, resist and recover from the impact of a natural hazard. It involves a combination of factors that determine the degree to which someone's life and livelihood are put at risk by a discrete and identifiable event in nature or in society (Blaikie et al., 1994, p. 48).

Blaikie's definition is important as it describes vulnerability in terms of people's capacity to avoid, cope with and recover from hazard impact. It illustrates two trends in explaining vulnerability that are reflected in the disaster literature.

Firstly, the shift in focus away from the hazard event being the primary cause of loss (with people characterised as victims, passive onlookers that are subordinate to the hazard), towards a focus on the human community and people's living conditions, social and economic resources, livelihood patterns and social power. Secondly, it includes a consideration of resilience, which is a more positive (empowering) concept (Berry, 2002, p. 45).

Recognition of the significance of clearly understanding the vulnerability of a business or community is critical to a thorough and comprehensive risk management process. Table 5.2 below is a list of the potential costs that can 
assist with further defining where the vulnerabilities lie and their potential consequences.

Table 5.2 Community costs of catastrophic events

\begin{tabular}{|l|l|l|}
\hline \multicolumn{3}{|c|}{$\begin{array}{c}\text { Categories of costs to communities of catastrophic events } \\
\text { the list includes direct, indirect, tangible and intangible cost categories) }\end{array}$} \\
\hline Loss of life & Physical suffering & Emotional suffering \\
\hline Damage to property & Reduced productivity & Degraded environment \\
\hline Loss of species and habitat & Damaged infrastructure & Weakened economy \\
\hline Loss of employment & Associated loss to businesses & Increased cost of insurance \\
\hline Reduced quality of life & Destruction of livelihood & Damaged social structures \\
\hline
\end{tabular}

Source: Adapted from Department of Emergency Services 2001, p. 4

The World Bank recognizes the potential dangers of ever-swelling urban populations that create conditions for more and worse environmental and social disasters. Of the estimated 511 mega-cities (with population over 1 million) in 2010, most will be within 100 kilometres of the coast, and for the first time, the majority (51.8\%) of the world's population will be urban (J ones, 1992). The implications for tourism are widespread, particularly given the primacy or dominance of these large urban conurbations as both cultural centres and transportation hubs for travellers.

Vulnerabilities are therefore increasing. There are more built-up areas for natural and man-made disasters to have a negative impact, particularly those tourism areas developed along the coast. Concentrations of population and infrastructure are increasingly vulnerable to the relatively sudden natural and man-made disaster agents such as tropical storms, hurricanes, earthquakes, forest fires, floods and landslides, explosions, transportation accidents, volcanic eruptions, structural failures, avalanches etc. The more slow-moving and insidious disaster agents of famine, drought, toxic poisonings, air and water pollution, epidemics etc., and other crises such as war, terrorism, riots, sabotage, political unrest, and other hostilities (Quarantelli, 1993) also apply to tourism destinations. Vulnerability reduction is therefore at the very heart of the risk management processes for tourism in coastal tropical areas.

Hazard mitigation measures are working tools that can be used to minimise losses through lowering levels of vulnerability, increasing levels of preparedness, response, and recovery mechanisms, and insurance. Some general steps that can be taken are described below. Insurance, however, is not often understood as a mitigation tool, but rather something that is part of disaster preparedness, the value of which comes into effect in the recovery stage. It is also a potentially valuable tool to encourage vulnerable businesses and communities 'to adopt cost effective measures voluntarily" (Kunreuther, 1996, p. 184). Premium reductions, lower deductibles, and higher limits of 
coverage are a few examples where the primary insurers could offer incentives to policyholders. This is an area where surprisingly, given the wealth of information and resources available to insurers and reinsurers, much more could be done by making incentives available to assist businesses and communities help themselves to minimise vulnerability to catastrophic loss.

Steps that can be taken to reduce and weaken the negative effects of the tourism disasters of the future include the following:

- Recognizing disasters as events which affect society with negative social impacts that can be minimized with social policy;

- $\quad$ Moving towards an all-hazards approach away from the distinction between natural and man-made disasters;

- $\quad$ Ensuring that disaster mitigation is given at least equal priority in planning and application as emergency preparedness, response and recovery;

- Integrating disaster planning and risk management strategies to the development planning processes of the social systems involved;

- $\quad$ Addressing both disaster issues and environmental issues concurrently where there are similarities by clarifying their similarities and differences.

For real property (tourism infrastructure, plant and equipment), specific hazard mitigation measures that can be undertaken include the following:

- Hazard mitigation measures and mechanisms such as developing and enforcing building-code regulations;

- Disaster planning through cautious land-use management and the establishment of legal restrictions for building on exposed locations;

- Hazard mapping of vulnerable areas to determine the intensity of risks from all natural hazards (hurricanes, other winds, flooding, earthquakes, etc.), and to use hazard maps to assist in proper land use management;

- $\quad$ For insurers or other hazard experts to conduct (underwriting) assessments of asset and property values, resistance to wind or other hazards, and likelihood of damage (as reflected in probable maximum loss estimates by insurers), based on probability data on the occurrence of such natural disaster events;

- $\quad$ Given the importance of disaster data, additional compilation of event frequencies and estimated probabilities, as well as covariance and correlation studies among regions and between events, to feed into the valuations of property risk. 
The above suggested areas for reducing vulnerability and exposure is not comprehensive, but this view from the insurers provides a useful starting point for recognising that understanding vulnerability and exposure to risk is critical to future business and community sustainability and good business practice.

\section{Natural Disasters in Developing Countries}

A World Bank report describes natural disasters in the following manner:

natural disasters are a tragic interruption to the development process. Lives are lost; social networks are disrupted; and capital investments are destroyed. When development plans are laid and disaster strikes, development funds are diverted to the emergency. Additional aid is directed to relief and reconstruction needs to get the country back on track' toward economic and social development (Kreimer \& Arnold, 2000, p. 12).

In recent years, development agencies including the German bilateral aid organization, Deutsche Gesellschaft für Technische Zusammenarbeit (GTZ) $\mathrm{GmbH}$ and the World Bank have recognized the important links between disasters and development. This was inevitable given the disproportionately high costs that developing countries pay for disasters and their impacts. In addition, natural disasters in developing countries can and often do have more disastrous impacts than in developed countries. Freeman (1999) estimates that because of the enormous disparity in the GDP, the per capita cost of natural disasters in relation to GDP in the developing world is 20 times higher than in developed countries. The Centre for Research on the Epidemiology of Disasters (CRED) in Brussels has this figure at a more conservative six times higher than developed countries (Guha-Sapir et al., 2004). Either way, the disparity is significant (see Figure 5.4 below). Figure 5.4 indicates the significance or value of tourism receipts to the overall GDP of countries in the APEC region, which is in some cases, the main industry contributor to GDP. 


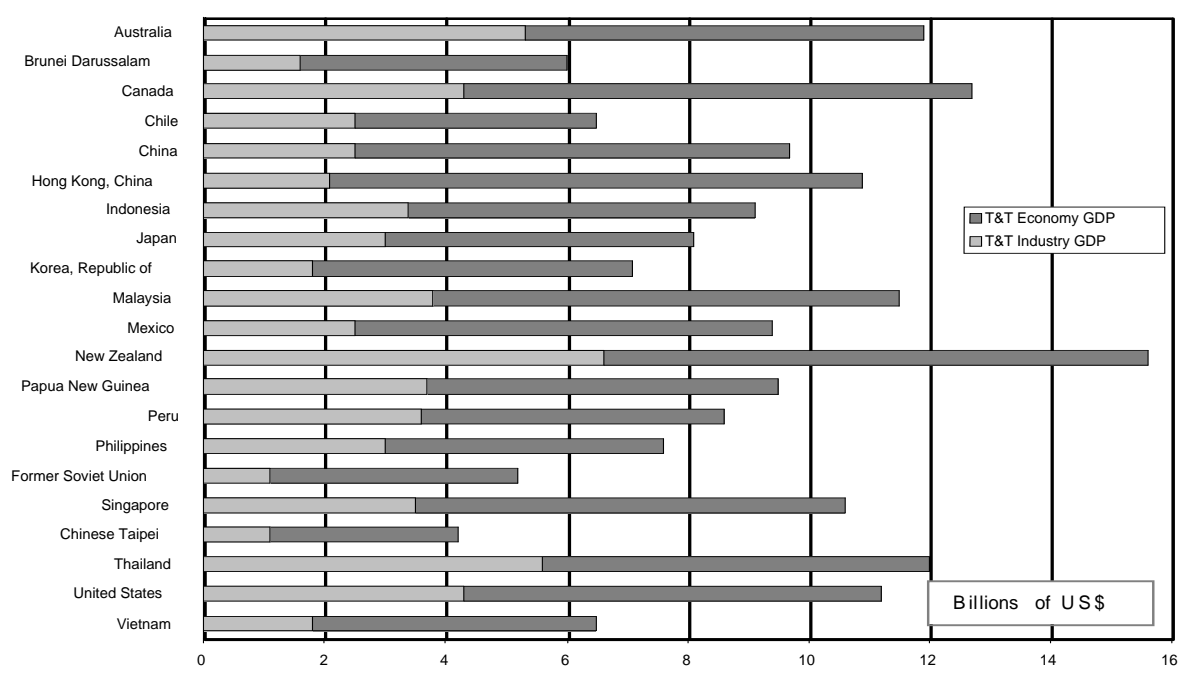

Figure 5.4 The contribution of the Travel and Tourism (T\&T) sector to GDP in APEC countries Source: WTO, 2002

In GTZ's Technical Cooperation projects, disaster risk management comprises: action (programs, projects and/or measures); and instruments, whose intended impacts are expressly aimed at reducing disaster risk in endangered regions and mitigating the extent of disasters. Disaster risk management is the generic term for the operational areas of risk assessment, disaster prevention and mitigation and disaster preparedness (GTZ, 2003).

Despite the awareness raised by the United Nations' International Decade of Natural Disaster Reduction (IDNDR), disaster risks have continued to accumulate in most developing countries. The vast majority of national and international efforts by bilateral and multi-lateral development agencies remain fundamentally focused on preparedness and response, seen as the most urgent needs. Isolated successful experiences at 'piloting' risk management approaches have however begun to build a substantial body of knowledge, particularly in the Asian region (Kishore, 2003). On a more positive note, Evans (1996) suggests that "the use of mitigation as a primary strategy in facing the consequences of natural disasters is slowly, but increasingly, gaining acceptance in public and private sectors around the world" (p. 5). 
Not all views of the decade of work of the IDNDR were as positive, evidenced in a critical editorial in the New Scientist (1989):

All the aims of the IDNDR will cost money, and, in particular, money for things that appear to have no immediate benefit ... for 10 or 20 years, let alone a century. Add to this the fact that many of the measures that would cut (sic) death toll from disasters will disrupt people's lives, and you have a very good excuse for doing nothing (Anonymous, 1989, p. 2).

This says nothing of the short-term political horizons of most governments in developing countries and their subsequent capacity and willingness to create and pay for long-term strategies to deal with natural catastrophes.

In the Caribbean with its intense coastal tourism developments, the development agencies' responses to assist the region to manage natural hazard risks fall into the following basic categories:

- Hazard mitigation and vulnerability reduction measures adopted prior to a hazard event to optimise protection from damage; and

- Economic mechanisms aimed at pre-financing the repair of the damage caused by disasters (the mechanism of insurance is in this category).

The former can be considered ultimately more efficient than the latter, which does not prevent or minimise the impact of the damage. This distinction is at the heart of cost-effective natural hazard risk management in developing countries.

An important finding of the UN-IDNDR, was that global data sets are missing substantial numbers of disasters at the national level due to deficiencies in international reporting. 


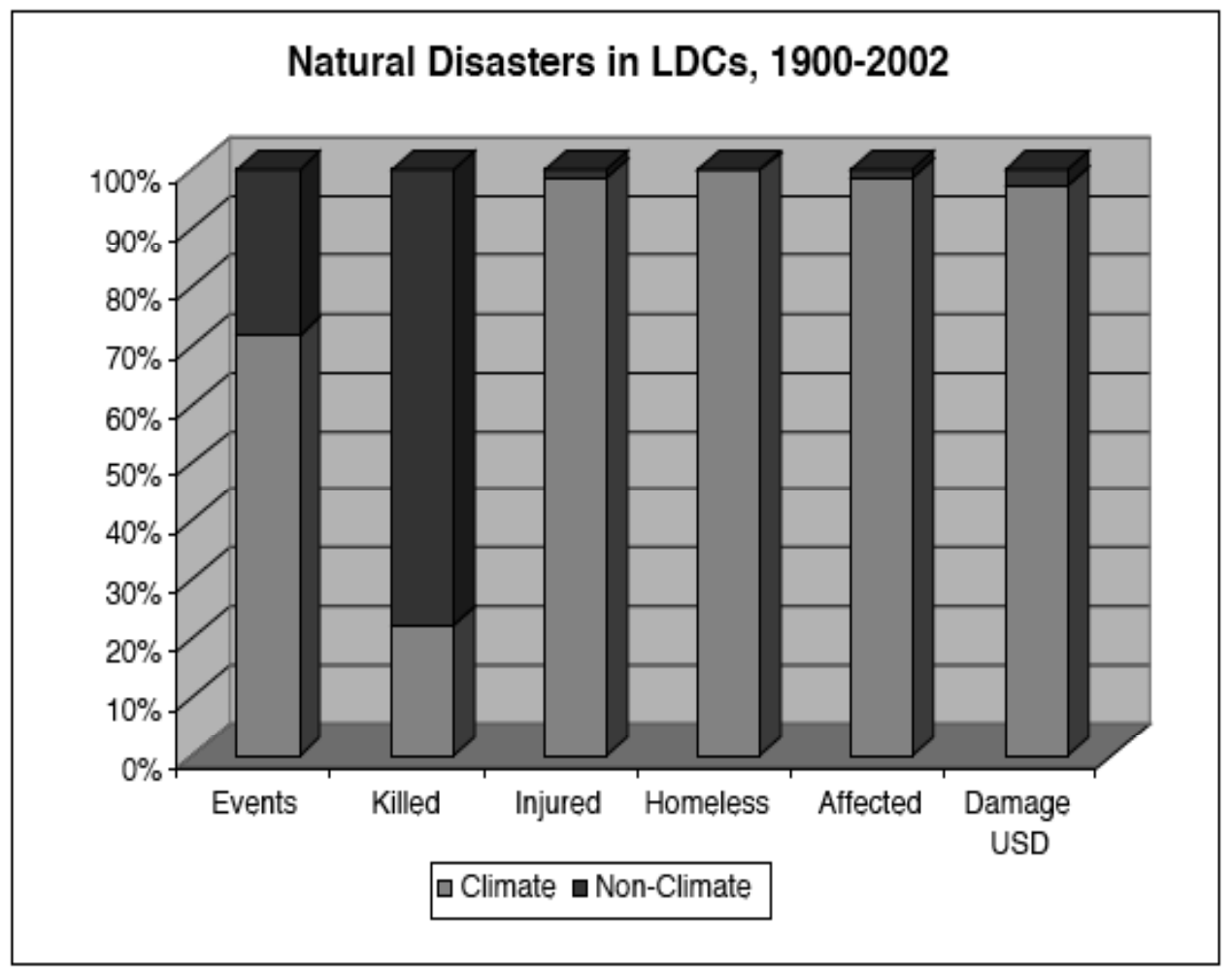

Figure 5.5 Disaster losses in Asian LDCs Source: CRED/ OFDA database, 2004

National datasets capture a greater proportion of the total losses but most developing countries do not maintain consistent and comparable records. There are immeasurable variations in methods and standards making comparison difficult, if not impossible. Economic losses are inadequately captured and recorded. For instance in J amaica, of disaster events with more than 10 persons killed and/ or 100 persons affected, around 11\% of these are not captured at all by international reporting, and for disaster events with less than 10 persons killed and/ or less than 100 persons affected, around $84 \%$ of these events are not captured at all by international reporting (UNEP, 2003). The figures are similar for Chile, Columbia and many other developing countries.

In the developed world, the insurance companies and national emergency management agencies fill that gap more thoroughly. The insured loss potentials ensure that insurers have a good grasp of the necessary data for modelling and underwriting. Developing countries are well behind in the sharing of risk through insurance.

In 1998, catastrophes claimed the loss of around 50,000 lives, and estimates of economic damage are in the range of US\$90 billion, the second highest 
financial loss in history (Munich Re, 1998). The rising worldwide costs of catastrophes and disasters can be explained mainly by increasing concentrations of populations and capital, and fragile infrastructure in hazard-prone areas (Linnerooth-Bayer, 1999), particularly in developing countries. Obviously, the hazard-prone coastal tropical areas with concentrations of both tourists and infrastructure development are increasingly vulnerable for the same reasons.

The impacts of natural disasters in coastal tropical areas of developing countries are often devastating, given the reliance on tourism in the overall GDP of many less developed countries (LDCs), particularly the small island states of the Asia-Pacific region. As Figure 5.5 indicates, disaster losses as a percentage of GDP are significantly higher in developing countries, but not as high as Freeman (1999) suggests.

Disaster losses include not only the spectacle of direct impacts reported in the news, such as the loss of life, housing, livelihood, and infrastructure, but also indirect impacts such as the foregone production in utility services, transport, labour supplies, suppliers, or markets. Secondary losses include impacts on such macroeconomic variables as economic growth, balance of payments, public spending, and inflation. The process of recovery from disaster in developing countries is more difficult because of by poverty at the community level, and the lack of emergency resources and strategies at government level. Climate related disasters in the Asian region over the last 100 years account for around 68\% of all disaster events, many of which occurred in coastal areas having significant impact on tourism business and disruption. Total economic losses, and those individuals and families affected by natural disasters were climate-related in the vast majority of cases as Figure 5.5 above indicates.

Asia remains the region with the most catastrophes. For example, in 1996, Asia suffered about half the catastrophes registered around the world, with about $70 \%$ of the fatalities. The low insurance density in Asia meant the region had only a $6.3 \%$ share of the global sum insured (Swiss Re, 1998). The situation is however improving as disaster response and preparedness improves (stockpiling of relief goods, warehouses, contingency planning), and with the increased applications of engineering solutions (dams, embankments, early warning systems etc.). Vulnerability however remains as a central theme to address necessary improvements to integrated, comprehensive risk management. 


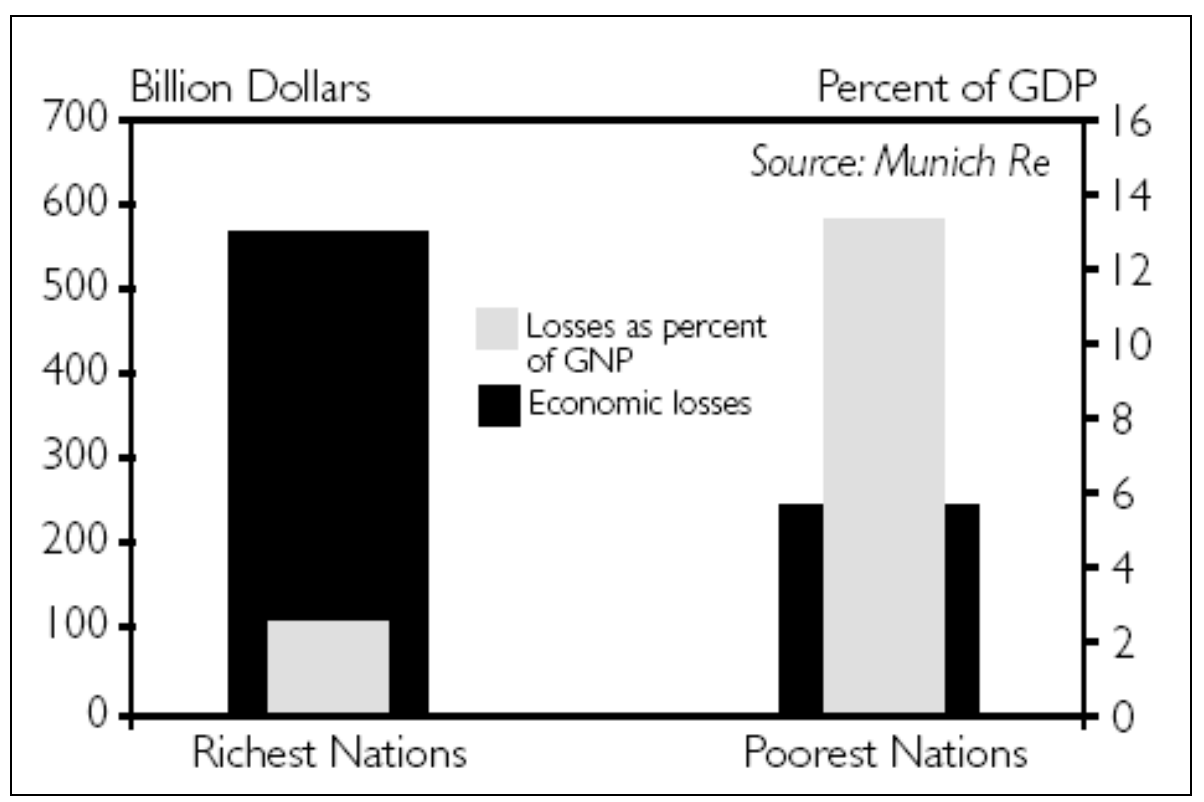

Figure 5.6 Disaster losses, total and as share of GDP, 1985-1999

Source: Munich Re, 1999; Abramovitz, 2001

The strongest demand for insurance worldwide comes from medium-sized businesses and homeowners. Since most developing countries do not have either a substantial middle class (with large numbers of homeowners) or many medium-sized businesses, there is a small natural clientele for insurance, and thus a lack of demand for catastrophe insurance. Although the situation of underinsurance, particularly in Asia, is likely to change considerably in the coming decade, effective risk reduction cannot be carried by insurance alone, and should involve mitigation measures in hazard prone developing countries.

Such measures include land use planning, structural design and construction practices, and disaster warning systems. In addition to employing scientific and technical knowledge, risk reduction may also involve overcoming the socio-economic, institutional and political barriers to the adoption of effective risk reduction strategies and measures in developing countries. Tools have to be developed to assist the very poor to be able to more effectively manage risk of disaster. This includes micro finance mechanisms that can respond to a variety risks and disaster hazards, and that builds social capital and encourages risk mitigation for the very poor. In addition to that, measures may include safety nets and calamity funds, and other informal risk sharing mechanisms. The World Bank and the Asian Development Bank in particular, have in the last five years developed a 
strong focus on poverty alleviation in all aspects of their technical assistance and lending programs to developing countries.

\section{Conclusion}

Risk management for the tourism industry is an on-going process that is critical to every aspect of business including the viability and sustainability of the support community, the reputation of the destination and its local and national tourism leadership, and to the safety and security of the tourists themselves. Risk is a part of virtually every aspect of the tourism industry from accounting practices, to client satisfaction, and from health and safety needs to terrorism and fraud. It cannot be avoided, and to fail to recognise the value and significance of tourism risk management is perhaps the greatest risk of all. 


\section{6 \\ Tourism crisis: Management and recovery in tourist-reliant destinations}

\section{Yetta Gurtner}

Tourism and travel for leisure are by no means new pursuits. With technological innovations and increased discretionary income over the past sixty years, such activities have rapidly generated a global industry. Renowned for stimulating social and economic growth tourism has also become a motivational force for development in many diverse locations. As a destination or specific host-community becomes more reliant on the opportunities and revenues generated from the tourism sector, it exponentially increases its vulnerability to a potential tourism crisis. Given that the successful tourism enterprise is based on both physical and intangible qualities, the associated hazards are innumerable. Recent events such as the violent terrorist attacks in Bali highlight the relevance of crisis management strategies in facilitating the process of both community and destination recovery.

\section{Tourism and Development}

With growing access, services, opportunity and demand, tourism has rapidly become a prosperous and dynamic global industry. The World Tourism Organisation (WTO, 2002) defines tourism in the following manner:

...comprises the activities of persons travelling to and staying in places outside their usual environment for not more than one consecutive year for leisure, business and other purposes not related to the exercise of an activity remunerated from within the place visited (p. 1).

Although such a definition establishes the capacity of a tourist, it fails to elaborate on the business or occupation of tourism, including, the economics, the infrastructure and even the role of associated stakeholders. As an industry, tourism encompasses much more than the activities of the visitor. 
McIntosh and Goeldner (1986) describe tourism as an interactive process, it is "the sum of the phenomena and relationships arising from the interaction of tourists, business suppliers, host governments, and host communities in the process of attracting and hosting these tourists and other visitors" (p. 4). Tangible elements include transport, accommodation, food, environment and entertainment facilities, while the more intangible elements may involve culture, hospitality, ambience and relaxation. With increasing foreign exchange earnings and revenues over the past few decades, tourism has become the world's largest growth industry, comprising over $10.6 \%$ of global GDP and generating the equivalent of one in every twelve jobs (World Travel and Tourism Council, WTTC, 2005).

Given such lucrative fiscal and employment potential, tourism has been widely promoted as a catalyst for economic and social development. As a labour intensive industry, a successful tourism endeavour can create significant income and job opportunities in both the formal and informal sectors. Associated investments often stimulate new and improved infrastructure, including transport networks, utilities, sanitation and medical facilities. While many facilities are intended to advance tourism prospects, such services may also improve the general standard of living for proximate residents. Governments can also profit because of related trade opportunities, foreign receipts and tax revenues generated through travel and tourism. As a source of such opportunities, the promotion and development of tourism has proved attractive to many destinations whether at the country, state, region, city or town level (Bierman, 2003).

\section{Tourism-reliant destinations}

While the nature of tourism in any locality depends on both dynamics and scale, much of the industry appears to have been developed with limited consideration to long-term sustainability (UNEP, 2002). In many destinations, particularly within developing nations, rapid and uncontrolled growth of the tourism sector has already resulted in significant social, cultural and environmental consequences. Although tourism enterprise may generate tangible financial prosperity for many stakeholders, growing dependence on such trade can actually increase the risks of experiencing future adversity.

Lured by the apparent economic prospects and incentives, individuals, businesses, service providers and even the governments within host communities often realign activities to conduct and openly support tourism. More traditional pursuits such as agriculture and manufacturing may be abandoned in favour of tourism-related employment, and consequently the economy becomes increasingly less diversified. Pertinent resources, both 
natural and cultural, are often appropriated as a consequence of tourist demands, with limited public consultation or future recourse. The more a destination becomes contingent on the demands and fortunes of the tourism industry without consideration to sustainable development, the greater the level of socio-economic vulnerability (Glaesser, 2003).

\section{The vulnerability of tourism}

Historically, tourism development has proved to be a sensitive, erratic and precarious undertaking. It is in its capacity to offer so many options and easily accommodate changes in consumer desires, that the fragility of the tourist market and the vulnerability of dependant destinations are revealed. As a voluntary activity, travellers have the discretion to simply cancel plans, postpone trips or opt for alternative destinations. The motivations behind variations in market demand can be diverse as economics, trends or even a shift in demographics. However, the research conducted by numerous academics and industry professionals (Cavlek, 2002; Pizam \& Mansfield, 1996) have clearly established that sudden and radical adjustments to travel plans are regularly instigated by a change in destination image and public perceptions of safety and risk.

In their book Tourism, Crime and International Security, editors Pizam and Mansfield (1996, p. 1) reassert the popular premise that "safety, tranquillity and peace are a necessary prerequisite for prosperous tourism". While there are many elements that may influence destination choice, consumer decisions are strongly based on an assessment of the level of personal risk (Bar-On, 1996). The perceived risks may entail the chance of disruption of planned activities, crime, property loss and/or damage, exposure to danger, injury or even death. A variety of external factors including media coverage, travel advisories, business, economics, peer pressure and insurance policies; may also help persuade or prejudice the subjective process of risk assessment and evaluation. The more a destination is publicly associated with an adverse threat or hazard, whether real or perceived, the greater the likelihood of consumers making alternative arrangements.

\section{Tourism and hazards}

There have been numerous typologies regarding the sources of risks for tourism businesses and destinations (WTO, 2003; PATA, 2003; Shaluf, Ahmadun \& Said, 2003; Faulkner, 2001), however, much of the popular literature employs the generic classifications of natural, human induced and technological hazards. A natural hazard may be climatological (e.g. flood, drought, extreme cold, hurricane, cyclone, wildfire) or geophysical (e.g. earthquake, volcanic eruption, landslide, avalanche, tsunami). Human- 
induced events are as varied and diverse as transport accidents, crime, political instability, terrorism, war, industrial action and epidemic diseases. Although not as widely covered in tourism studies, technological hazards may entail mechanical/systems failure, industrial and even nuclear accidents. If it had been substantiated the Y2K (millennium bug) had the potential to disrupt computer travel and booking procedures, transport and navigational equipment and even the supply of amenities on an almost global scale.

While the threat of any such hazard agent may generate public apprehension, a hazard does not necessarily result in a definitive "event" or incident. With adequate warnings, preparation and contingency plans it may be possible to avert or eliminate a prospective hazard, or to effectively minimise the level of actual damage sustained. Irrespective of the level of awareness or planning however, experience consistently demonstrates that not all hazards may be accurately forecast or avoided (Faulkner, 2001).

Given the complex social, economic and environmental context in which a host community fosters tourism development, the impacts and consequence to a hazard-afflicted tourist destination can be highly unpredictable and highly differential. An environment of physical exposure, poverty, high urbanisation, poor social dynamics and unsafe conditions (vulnerability) typically enhance both the degree and severity of adverse impacts (WHO/EHA, 2002).

Tourists themselves are often more susceptible to direct danger due to reduced alertness, limited local hazard knowledge and less familiarity with the resources that can be relied upon to ensure their personal safety (Faulkner, 2001). In an emergency situation, immediate response and relief efforts are generally determined by the extent of local coping capacity and resources.

Direct hazard impacts may include injuries, fatalities, evacuation, extensive damage (physical, environmental and social) and substantial economic costs (Shaluf, Ahmadun \& Said, 2003). The scope may be localised to a single business, destination, or affect an entire geographic region. Beyond the more apparent physical effects, many hazard agents also generate indirect and 'ripple effect' consequences which can lead to longer-term issues. Associated reconstruction costs and travel market instability has the potential to generate significant social and economic repercussions for any tourist-reliant operatives. Depending on the variables measured, evaluative criteria, and conceptual definitions applied, such hazard events have been variably referred to as accidents, emergencies, disasters and/or crises (Shaluf, Ahmadun \& Said, 2003). 


\section{Tourism crisis}

Rather than employing a definitive scale or quantitative approach, the WTO (2003) defines crisis (as it pertains to tourism) as "any unexpected event that affects traveller confidence in a destination and interferes with the ability to continue operating normally" (p. 1). Sonmez, Apostolopoulos and Tarlow (1999) utilise the more comprehensive term of 'tourism crisis' to describe circumstances:

which can threaten the normal operation and conduct of tourismrelated businesses; damage a tourist destination's overall reputation for safety, attractiveness, and comfort by negatively affecting visitor's perceptions of that destination; and, in turn, cause a downturn in the local travel and tourism economy and interrupt the continuity of business operations for the local travel and tourism industry, by the reduction in tourist arrivals and expenditures...

(pp. 13-14).

Given such definitions, it becomes evident that unlike an accident, emergency or disaster, a tourism crisis is not necessarily precipitated by the threat of a real and imminent danger, or the direct physical impact of a hazard agent. While natural and human-induced incidents seem to be the most abundant instances, tourism crisis may be triggered by external and less tangible factors that adversely affect destination image, such as proximate regional instability, rumour and bad publicity. As it remains feasibly and logistically impossible to insulate against every such contingency, no tourism destination can ever be completely immune from crisis (Bierman, 2003).

While the repercussions of the tragic terrorist attacks of September 2001 and outbreak of SARS (Sudden Acute Respiratory Syndrome) confirm that the entire tourism industry is sensitive to the turbulence and instability of crisis, some destinations and host communities remain more disposed to experience adversity. Although it is impossible to eliminate every risk, it is apparent that to minimise susceptibility to such crises, such destination stakeholders need to implement greater initiatives towards vulnerability reduction, consistent with effective crisis management.

\section{Developing tourism crisis management strategies}

The relative frequency and high profile of such recent international events has resulted in increasing industry and academic attention towards the promotion of tangible tourism-based crisis management strategies. Based 
on an amalgam of disaster and business management principles such initiatives are intended to minimise any negative destination impacts and help retain the confidence of both travellers and the travel industry (WTO, 2003; Bierman, 2003; PATA, 2003). As with an integrated disaster management approach, a tourism crisis management framework is generally premised on the continuum of risk reduction and response (refer to Figure 6.1). While the terminology often varies, the proactive phases before the 'crisis trigger' include assessment, prevention/reduction, mitigation and readiness/preparedness. Post-event stages include response/relief, rehabilitation, and recovery/ reconstruction.

Ideally, the experiences and lessons learnt from any preceding crisis would be used in mitigating future contingencies.

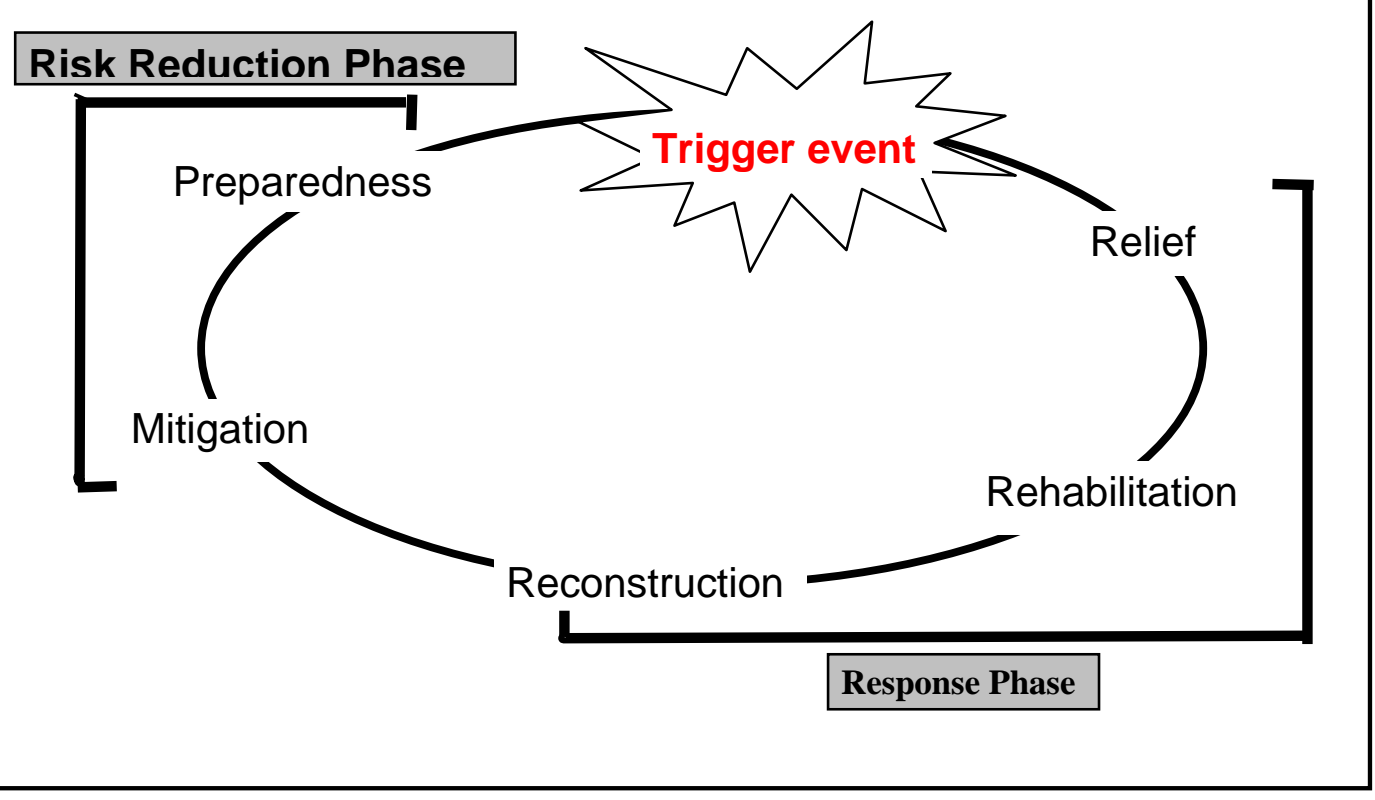

Figure 6.1 The crisis management continuum

Source: Adapted from WHO/EHA, 2002

Founded on extensive industry experience PATA's (2003) generic planning guide Crisis: It won't happen to us! reveals that in the case of tourism, the nature of the event/issue, visibility, the number, age and prominence of people involved, and the level of associated media attention commonly influences the extent and duration of subsequent crises. Given the importance of maintaining a low risk perception and positive image, similar popular destination crisis management plans also highlight facets of communications, safety and security, market research and promotion (WTO, 2003). While formal crisis management initiatives are often resourced and 
planned at the business, government or organisational level, a holistic approach suggests that the development of a comprehensive strategy for the tourism sector be co-ordinated between all relevant stakeholders (Sonmez, et al., 1999; Cavlek, 2002).

Cavlek (2002) and Sonmez et al. (1999) counsel that at a minimum, a destination management task force should include government officials, relevant travel, tourism and hospitality professionals (domestic and foreign), and community leaders. They further elaborate that an effective and operational plan requires dedication to destination improvement/recovery, the ability to exercise appropriate authority, and access to adequate resources and financial assistance. While disaster researcher Quarantelli (1998) proposes that this process of active cooperation and preparation is inherently more valuable than the production of a written plan, some tourism proponents recommend the creation of a tourism specific crisis management guidebook detailing relevant contacts, responsibilities, agreed terminology, useful sample/templates and communications strategies (Sonmez, et al. 1999). Irrespective of the preferred methodology, most researchers agree that crisis management endeavours are best instigated before the advent of a significant hazard.

\section{Crisis risk reduction and mitigation}

Based on the experience of countless complacent and ill-prepared destinations that have faced a substantial tourism crisis, the majority of tourism scholars and industry authorities now promote a proactive approach to crisis management, beginning with risk assessment (WTO, 2003; WTTC, 2003; Gee \& Gain, 1986; Sonmez et al., 1999; Glaesser, 2003). Employing various methodologies and means of data analysis, mapping and monitoring, such an assessment generally involves an evaluation of risk relative to hazard probability and destination vulnerability. With the existing context as a foundation, such calculations should also deliberate on any potential physical (environment), social and economic impacts, including anticipated losses.

In distinguishing and prioritising all conceivable hazards that may have a negative effect on a destination, the risk management process is intended to generate strategies and initiatives to minimise potential impacts. Proposed structural measures (WHO/EHA, 2002) may involve enforced compliance with minimum building standards, effective zoning and infrastructure redevelopment, such as transportation networks, airports and medical facilities. Other policies may include partnering with law enforcement officials (Sonmez et al., 1999) (e.g. tourist police and foreign intelligence 
sharing), coordination with media outlets and improved community awareness and education.

Sonmez et al. (1999) again propose that the development and dissemination of a clear, comprehensive, crisis management plan/guidebook is one of the best visible indications of a destination's preparedness. The essence of proactive risk reduction, mitigation and preparation is that all feasible contingencies, including appropriate training, warnings and evacuation plans need be regularly addressed and practised. Less formalised procedures may include public education and enhancing local response capabilities, flexibility and confidence. Where written documents may exist it is advised that details are consistently monitored and reviewed for both relevance and accuracy. Even though such crisis management planning may be developed within the context of the tourism sector, it is important that any measures and actions undertaken are consistent with broader scale emergency/ disaster management operations.

\section{Crisis response}

Contrary to the recommendations made as early as the mid-1980s (Gee \& Gain, 1986), the majority of popular tourist destinations still don't appear to have adequate or effective crisis management planning (Faulkner, 2001; Beirman, 2003). Many places, particularly in the developing world, continue to lack the skills, resources and capacity to efficiently deal with the onset and impacts of any major hazard. In such cases, the reality of a crisis often becomes the catalyst for developing inexperienced, reactive strategies.

While emergency relief and response prioritises the protection of life and property in dangerous situations, activities undertaken by the tourism sector in the first 24 hours of a crisis are considered crucial (WTO, 2003; WTTC, 2003). Irrespective of the level of perceived damage or destruction, responsible management requires the maintenance of credibility. Most destination case studies support the assertion that honesty, transparency, professionalism and good communications with both public and media can facilitate faster recovery (WTO, 2003; PATA, 2003; Ritchie, 2004). To minimise uncertainty, it is recommended that authorities establish a respected spokesperson to immediately address any concerns regarding safety and security, and effectively relay both the facts and pertinent issues. Beyond any negative imagery and sensationalism by the popular media, competent public relations can help provide balance and direction.

When triggered by a tangible hazard agent, the duration of the subsequent emergency period is determined by the context, type, scope, speed of onset, and direct impacts of the event (WHO/EHA, 2002). If the situation is 
beyond a community's capacity to cope, the destination may require the urgent assistance of external agencies and organisations. Standard response strategies include the establishment of an emergency operations centre with an adjunct media/public relations facility. Less critical rehabilitation strategies, which may include clearance of debris, utilities restoration, facilitating job returns and resumption of commerce, can take weeks or even months. Disputed issues of insurance, liability, ownership and jurisdiction also often cause delays.

Beyond the immediate concerns regarding physical infrastructure, direct losses or operational capabilities, to retain visitor numbers and expenditure a significantly damaged tourism sector is likely to require rapid and extensive recovery strategies (Cavlek, 2002). Without tourism, many destination stakeholders will struggle to resume pre-crisis operational capacity and productivity. If an afflicted destination's tourism sector is to remain viable it must restore consumer confidence.

\section{Recovery from crisis}

The length of any particular crisis and associated recovery period can vary substantially. Impacts are multidimensional and can be difficult to quantify or assess including, medical and emotional recovery of victims, economic and social losses and physical/ environmental damage (Cuny, 1983). When a hazard has compromised public risk perceptions, effective recovery for the tourism sector and associated stakeholders requires extensive image rebuilding.

The WTO (2003) suggests that at the most fundamental level, the management of information and related media should continue to address consumer concerns about safety and security. Subsequent investigations, improvements to operational practices and systems, law enforcement and preventative measures should similarly be reported on in a timely and objective manner. Experience reveals that the diversion of major transport carriers, insurance restrictions, and the introduction of international travel advisories can be particularly damaging to a destination.

Reliant on good public relations, an adversely affected tourism destination typically needs to embark on new, improved and often aggressive destination marketing and promotional campaigns (Bierman, 2003; Glaesser, 2003).

Negative publicity such as media coverage conveying loss of life, human suffering, broad scale disruption and/or extensive damage should be amended to provide positive images and impressions. Confidence building measures such as celebrity visits, journalist familiarisations and staging 
international events are often employed to influence the subjective opinions and attitudes of potential consumers. Supplementary actions include the diversification of product base, targeting new market segments and improving the levels of both quality and competitiveness. (UNEP, 2002)

While restoring faith in the destination is considered essential for the recovery of the tourism sector, it traditionally requires substantive cooperation, direction and fiscal collaboration. Without adequate support from government, private enterprise and relevant stakeholders, there is no guarantee that a damaged tourism sector will be fully rehabilitated. Given the diversity and choices afforded by the industry, it is unrealistic to rely on customer loyalty or the natural assets of a destination to re-establish conditions following a significant crisis. While discounting and incentives may afford short-term gains, commitment and substantial investment are considered necessary to ensure that such strategies also produce medium to long-term benefits. Effective recovery strategies need to be focused on more comprehensive and sustainable outcomes. Consistent with the ISDR (2004) definition of disaster recovery the process implies "decisions and actions taken after a disaster with a view to restoring or improving the pre-living conditions of the stricken community, while encouraging and facilitating necessary adjustments to reduce disaster risk" (p. 7).

In holistic crisis management terms, the recovery process can also provide opportunity. The experiences and lessons learnt should be evaluated and utilised to develop improved strategies to mitigate future crisis. For destinations that are heavily reliant on tourism, such reforms imply significant economic, social and structural investment. Susceptibility may also be reduced through improvements to existing facilities, institutions and an increase in self sufficiency.

\section{Sustainable development and tourism}

While a crisis may highlight the underlying vulnerability of any destination strongly focused around the tourism industry, the restructuring necessitated by crisis recovery can provide the opportunity to adopt a more holistic and sustainable approach to tourism and development. Sustainability implies an integrated, participatory process which fairly balances social, economic and environmental interests (WTO, 2004; UNEP, 2002).

Traditionally, tourism development has been driven by governments, businesses, corporations and large scale organisations, with limited public input or consultation. While communities may benefit from associated infrastructure, employment and income, such enterprises and investments are often focused on realising a financial agenda. Sustainable tourism 
development ideally accommodates and empowers all interested parties in both formal and informal tourism structures. Through an inclusive, consultative and coordinated approach to development, it proposes that it is possible to secure a more equitable distribution of benefits for all segments of the population.

Such development and restructuring within the tourism sector may be guided by representative decision making forums including participants from the national tourism structures, the police, the public, the business community, vendors, tourist information agencies and any other pertinent stakeholders. In achieving effective horizontal and vertical integration, resolutions regarding delegation, responsibilities and subsequent implementation need to be consensus-based and compatible with community goals. Control, transparency and accountability are considered integral to an open process. In addition, construction and/ or maintenance of an integrated tourism crisis management strategy would be essential.

Many of the social and economic impacts following a crisis are indicative of the extent to which a destination has become reliant on tourism. When committing significant recovery resources into destination marketing, promotion and restructuring it is necessary to consider the inherent vulnerability of the industry. Adversity resulting from any tourism crisis may actually be reduced by less direct dependence on tourism generated income and revenues. Assistance and funding provided to help a destination recover may alternatively be used to accomplish other community aspirations and priorities, such as improved education and social conditions. Recommended strategies include enhanced self-sufficiency, resilience and diversification of the economy (Bloom, 1996).

Achieving the ideal of social, economic and environmental sustainability needs a committed and democratic approach to both development and governance. Extensive understanding, awareness, training and education are required at all levels. The successful operation of sustainable strategies and practices in both community development and the tourism sector should ultimately reduce a destination's vulnerability to crisis.

\section{From theory to practice}

While neither tourism crises or destination vulnerability are new phenomena, Robert and Lajtha (2002) assert that crisis management, as a science, is still in its infancy largely due to the difficulties in measuring, standardising, and comparing one crisis situation with another. Each hazard situation and destination is unique, and as such circumstances may never be effectively simulated or replicated. In developing improved strategies to 
facilitate destination crisis management, recovery and sustainability it is necessary to understand both the relevance and application within a real context. Case studies of afflicted destinations may similarly provide many tangible lessons of utility to other vulnerable host communities.

\section{Bali - a case study of a tourism crisis in a tourist-reliant destination}

Bali, often referred to as 'Paradise on Earth', is a small island located in the tropical Indonesian archipelago. Renowned for its vibrant indigenous culture, diverse natural attractions and capacity to cater for almost any class and budget of traveller, it rapidly grew into a popular and well patronised international tourist destination. The impact and subsequent events triggered by the terrorist bombings of 12 October 2002, rapidly and effectively undermined this burgeoning tourism industry. As the vulnerability and socio-economic significance of this sector became more apparent, the community of Bali has been faced with a long and difficult road to recover from tourism crisis.

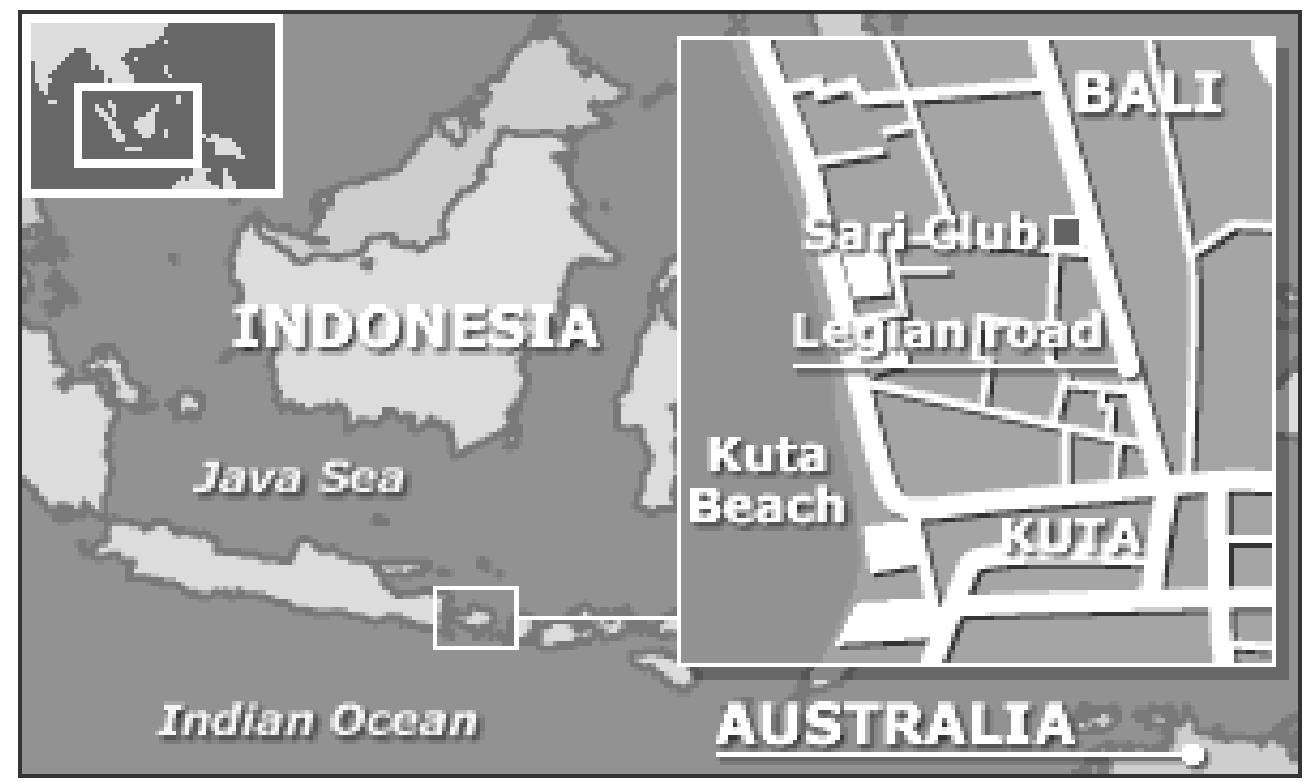

Figure 6.2 Location of the terrorist attacks in Kuta, Bali, 12 October 2002 Source: Bali SOS, 2002

\section{The context - tourism reliance and vulnerability}

While travellers' interest in Bali is not a new phenomenon, the island only gained popularity as an international destination during the late 1960s 
(Kalla, 2003; UNDP, 2003). To further encourage visitor growth, the Indonesian government actively pursued tourism-specific development plans that included the construction of an international airport. However, through a subsequent lack of public consultation or regulatory control most urbanised areas in southern Bali rapidly expanded beyond government influence. Locations such as the former fishing village of Kuta/Legian, grew to be overcrowded and over-commercialised. Many rural Balinese and other Indonesians enticed by the social and economic prospects of anticipated tourism earnings chose to abandon traditional pursuits and activities to migrate to such areas. Through the supply of food, natural and cultural attractions, arts, and other commodities and services, most of Bali came to benefit from development of this industry. An increasing reliance on these social and economic gains however, also established a significant level of dependence on commercial tourism.

Whether as a legacy of its geographical location or predominant belief in karma and harmonious balance; Bali had always been perceived as safe, tranquil and immune from the problems and instability that have affected other regions (World Bank, 2003). Residents (with the exception of some persistent touters and hawkers) are renowned for their calm friendly attitude and easy smiles. Travel features display images of religious and cultural festivities, rice fields, sunsets and extensive accommodation and tourist facilities.

While tropical climate conditions and a diverse terrain mean the island is susceptible to natural hazards (including landslides, drought and volcanic eruption) it had never been perceived as a high-risk destination. The possibility of travel accidents, disease and transportation delays were generally accepted as common hazards of overseas travel. Similarly as the island's residents, businesses and government authorities conducted their various daily activities little thought or investment had ever been given to the idea of significant crisis.

\section{Bali in crisis - the trigger and response}

At approximately 11:20pm the night of 12 October 2002 the peace and ambience of Bali were shattered by two explosions at crowded nightclubs on the popular tourist entertainment strip of J alan Legian (Legian Street), Kuta. In the chaos and destruction that followed it became apparent that the emergency services of Bali were ill-prepared and ill-equipped to deal with such a disaster (Bali Recovery Group, 2003). There was no operational emergency/crisis management plan - either generic or tourism related. Immediate response actions were focused on the basic instinct to protect life and property. Even with the dedication and efforts of available emergency 
response crews, hospital staff and volunteers, there were numerous fatalities (a final death toll of 202), mass casualties of varying severity, and extensive physical damage. With victims from 22 countries and rampant speculation of terrorism, this incident quickly gained a high profile and global media status. Images and stories of the carnage, the extensive devastation, inadequate medical facilities and raw emotion were rapidly and prominently presented on television, radio, in print and via the Internet.

Overwhelmed Indonesian government authorities were quick to express sympathies and reassure visitors of personal safety, but were unable to successfully control or direct the ensuing media reports. Lacking a singular spokesperson or media centre any credibility was effectively undermined by instances of confusion and contradiction. Local community groups instituted street patrols while official safety measures and crime investigations were implemented by both the police and military. As financial aid, medical expertise and technical assistance was made available from around the world, the Bali Recovery Group (a coordination committee of existing local non-government organisations), was created with the aim to deliver the best services, collect data and minimise duplication of effort. With most of the immediate medical needs soon assuaged, official strategies began to focus on the clean up and restoration of vital functions of the community.

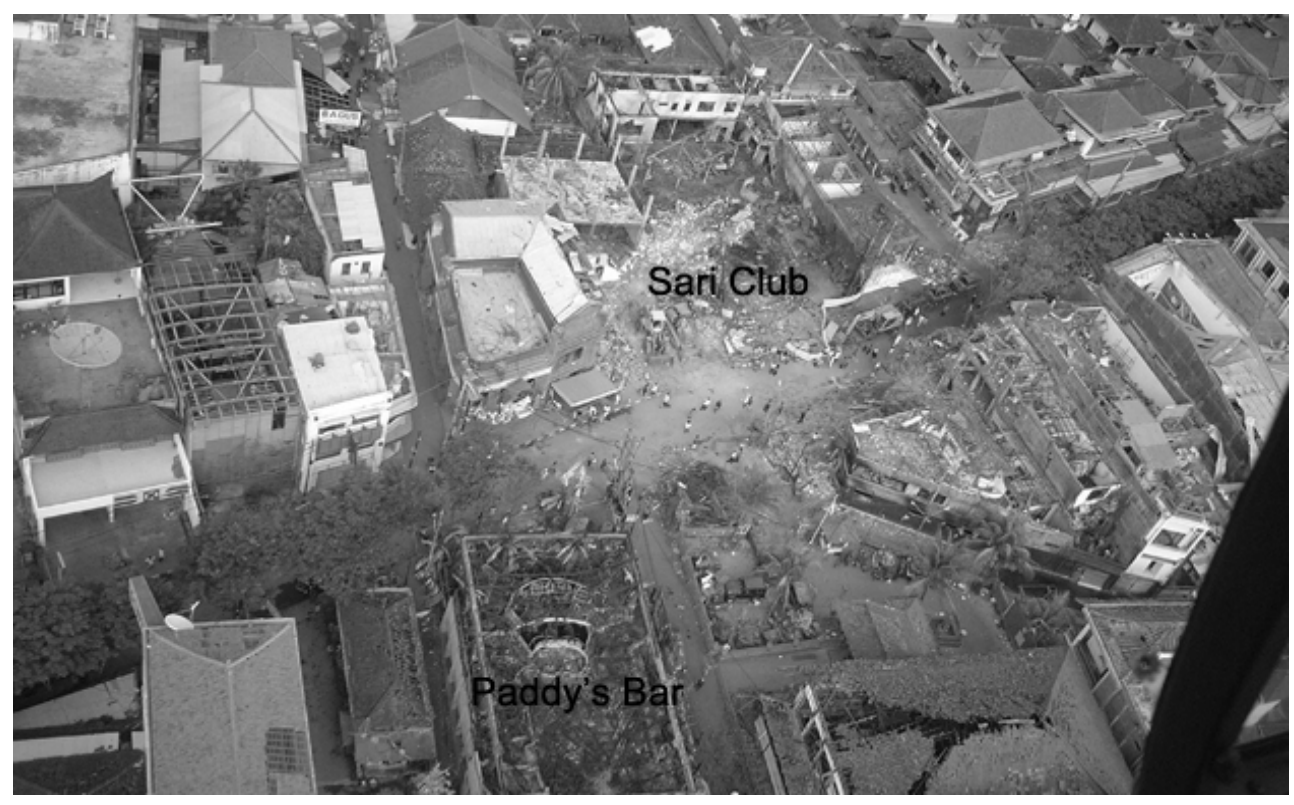

Figure 6.3 Aerial view of the damage caused by the explosions at Paddy's Bar and the Sari Club

Source: courtesy of Steve Palmer, November 2002 


\section{Rehabilitation: short-term initiatives}

While formal efforts were made to remove and analyse the structural debris it became quickly apparent that the explosions were planned by terrorists, intentionally and specifically targeting tourism in the area. International travel warnings/bans were immediately upgraded as most of the remaining tourists abandoned the island and surrounding region. Already affected by the economic slowdown caused by the 1998 election riots and the 11 September 2001 attack on the World Trade Center, Bali was effectively plunged into a tourism crisis (Kalla, 2003; Karyadi, 2003; World Bank, 2003). In a period that traditionally coincided with peak season, direct tourist arrivals dropped, occupancy rates decreased to single figures and associated earnings plummeted. Residents struggling with the emotional, psychological and even physical effects of the bombing were now faced with the disruption of their livelihoods.

In the days and weeks that followed all stakeholders were genuine and concerted in their efforts to minimise the socio-economic impacts. Government measures focused on a commitment to security and law enforcement, tourism promotion and the provision of a social safety net (World Bank, 2003). The Bali Recovery Group (2003) worked predominantly towards direct victim and family support - medical, financial and educational. Most hotels and businesses laboured toward the resumption of services and the restoration of Bali's tourist image, although efforts were rarely coordinated. Meanwhile, individuals and families within the community were forced to implement short-term coping mechanisms such as return migration to the villages, selling assets, reducing household expenditure and accessing savings. While there were growing concerns about reprisals against Muslims and related ethnic tension, few incidents were reported. Special non-denominational religious 'cleansing' rituals were held to help restore balance to both the physical and spiritual world.

As foreign visitor arrivals remained low in early 2003, successful marketing strategies led to an increase in domestic visitors and an expansion of the Asian market segment (UNDP, 2003). Air Paradise, a locally owned airline, commenced flights to Australia in an effort to help revive visitor numbers. Locally and regionally, security became the top priority as a new policing policy focused on greater visibility and upgrades to existing measures at all ports of entry. Several international events and tourist operator/journalist familiarisations were also presented to increase the profile of Bali and assurances of safety and security. Despite such strategies, businesses and the community continued to suffer. As operational costs surpassed income, hotels, restaurants, shop fronts and transport providers faced closure and/ or bankruptcies. 
Residents experienced job cut-backs, unemployment/underemployment, income reduction and diminishing social standards. As reduced business and tourism revenues resulted in less expendable income for the communities of popular resort areas, residents were forced to change their usage and consumption habits. The effects and influence of such reduced spending gradually spread throughout the island's economy and conditions in the poorer areas of Bali deteriorated; this is sometimes referred to as the 'ripple effect'.

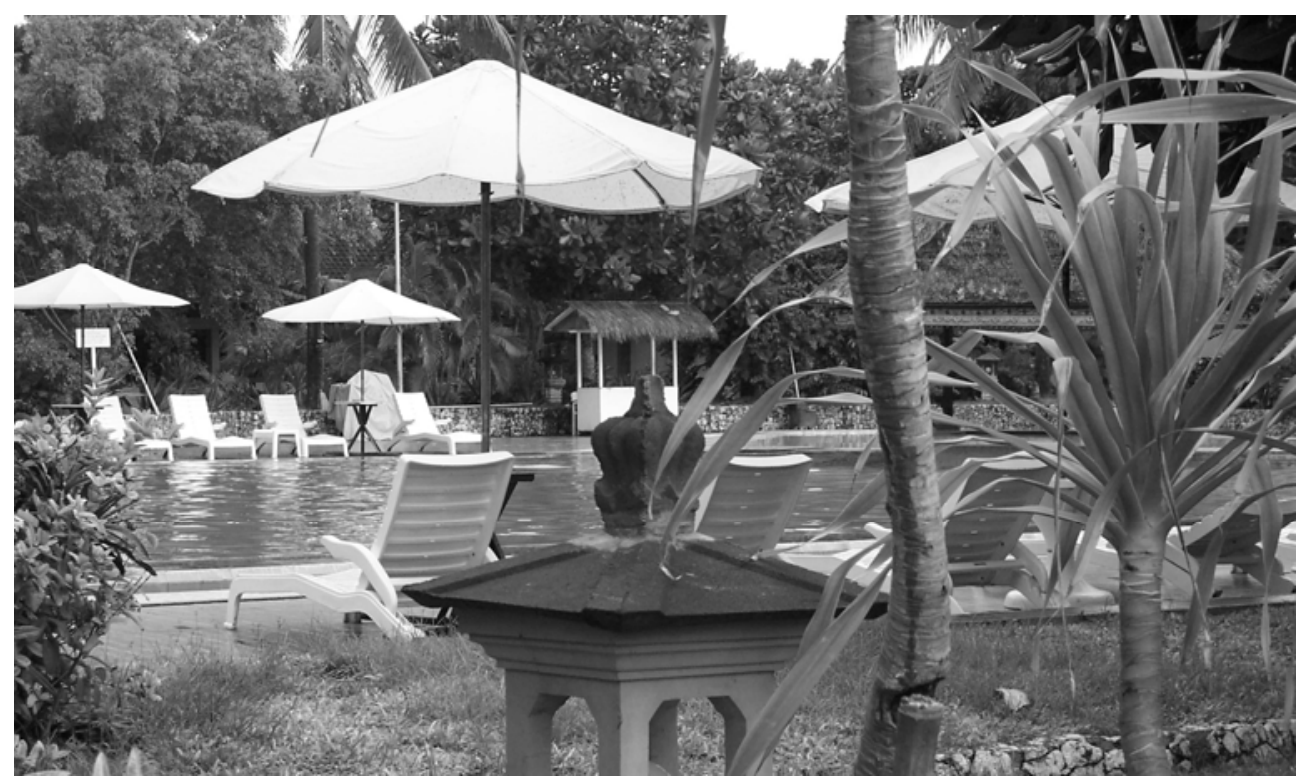

Figure 6.4 Tourism crisis - a deserted hotel pool-side in Kuta, January 2003

\section{Reconstruction to recovery}

As mandatory work permits and hotel accreditation standards were introduced to improve accountability, international travel concerns regarding the risk of contracting SARS and the war in Iraq seem to have minimised any initial improvements in direct visitor arrivals. While the national government introduced new anti-terrorism initiatives and secured the convictions of the Bali bombers, the August 2003 terrorist bombing of the Marriott Hotel in Jakarta quickly undermined any progress regarding perceptions of improved safety. Despite such events and the continued travel advisories, by the end of the year visitor numbers were increasing and gradual improvements occurred in tourism business prospects. The oneyear anniversary of the attacks and associated memorial services successfully attracted much international media attention and publicity, yet for many it 
only revived the issue of terrorism rather than promoted the merits of the island.

January 2004 was a record month for foreign visitor arrivals to Bali, but closer investigation of the associated socio-economic statistics revealed a different story. Benefiting from the discounts, sales and bonus incentives offered by tourism providers, visitors were actually staying for shorter periods of time and spending less money, minimising business profit margins. The Indonesian Government's controversial introduction of a new visa fee in February 2004 was met with further disdain by both consumers and operators. As few of the post-bombing donor agencies remained operational in Bali, many community members were forced to sell more personal possessions and property as a means of coping. A large number of the programs introduced to increase economic diversification and social support eventually collapsed due to lack of adequate investment, commitment and finances. Numerous reports have suggested that through this experience of shared adversity many traditional and familial support networks were strengthened (Hitchcock \& Darma Putra, 2005). While tourist numbers suggested a return to pre-crisis levels, a further bombing outside the Australian Embassy in J akarta in September 2004, again added uncertainty to a delicate market.

While the devastating Indian Ocean tsunami on 26 December 2004 did not directly impact on the island of Bali, many tourist operators reported that subsequent cancellations were caused by a geographical association with the Indonesian province of Aceh. As former recipients of aid, the empathetic community and non-government organisations of Bali reactivated many support networks to provide resources and assistance for the tsunami victims. With a return of economic stability for many residents, programs were also established to support more local community health centres and improved access to public education. Whether as a consequence of successful marketing and promotion, the inherent attributes of the island or a diminishing risk perception, in 2005 there were unprecedented numbers of direct visitor arrivals to Bali. Even the controversy surrounding several high profile 'foreigner' drug cases failed to dissuade most tourists. While this new market segment consisted of less long-haul European and North American tourists, Australians had again returned to this popular 'playground' supplemented with travellers from throughout regional Asia. For many Balinese this restoration of business and profits heralded the end of a difficult period. 


\section{Crisis revisited}

During September 2005 the highest ever number of direct arrivals was recorded (Table 6.1), but on 1 October 2005 the island was again subjected to the tragedy of tourist-focused terrorism. Although the explosions in restaurants of Kuta Square and J imberan Bay were significantly smaller (25 fatalities) than the previous incident, subsequent international media attention was quick to surmise a pattern for premeditated violence against tourists. Having learnt from past experience, medical personnel and authorities were quick to respond, establishing an emergency centre at the Sanglah Hospital with an effective media capacity. The Chief of Indonesian Police General Made Pastika, who had been seen as responsible for capturing the perpetrators of previous bombings, was quickly presented as the official spokesman to address questions and make any formal statements. Familiar with the potential needs of the victims and their families, community-based volunteer and support networks were assisting within the hour.

While travel advisories were reinstated and large numbers of tourist chose to avoid Bali, cancellations were not as dramatic as following the 2002 attacks. Maintaining occupancy rates of between $40-50 \%$ many analysts have drawn the cautious conclusion that perhaps the travelling public are becoming more accepting of terrorism as a risk of modern day travel. As visible safety and security again became a high priority, the Bali Hotel Association together with several other private enterprise stakeholders made substantial financial commitments to supplement security upgrades. Despite the level of destination loyalty, lower visitor numbers again precipitated socio-economic hardship for the host community, exacerbated by the subsequent collapse of the locally owned airline, Air Paradise. With international uncertainty regarding the probability of further attacks, many have also been critical of Indonesian government's slow commitment to Bali's tourism recovery efforts. With profits and revenues again lagging the Governor of Bali formally announced the establishment of a Bali Security Council in October 2005 with membership including the police, military, academics, nongovernmental agencies, government bureaucrats, and community leaders. Part of this group's responsibility is intended to support a wide range of tourism promotion, recovery and security issues. 
Table 6.1 Direct foreign tourist arrivals in Bali 2001-2005

\begin{tabular}{|l|c|c|c|c|c|}
\hline & $\mathbf{2 0 0 1}$ & $\mathbf{2 0 0 2}$ & $\mathbf{2 0 0 3}$ & $\mathbf{2 0 0 4}$ & $\mathbf{2 0 0 5}$ \\
\hline January & 92,604 & 87,027 & 60,836 & 104,062 & 101,931 \\
February & 104,083 & 96,267 & 67,469 & 84,374 & 100,638 \\
March & 110,582 & 113,553 & 72,263 & 99,644 & 117,149 \\
April & 109,634 & 104,960 & 53,726 & 111,021 & 116,272 \\
May & 103,939 & 119,284 & 47,858 & 117,191 & 116,615 \\
June & 122,352 & 130,563 & 81,256 & 131,685 & 136,369 \\
July & 142,946 & 147,033 & 111,828 & 148,086 & 158,453 \\
August & 144,324 & 160,420 & 115,546 & 155,000 & 157,229 \\
September & 104,008 & 150,747 & 106,763 & 141,900 & 162,102 \\
October & 129,932 & 81,100 & 97,435 & 128,297 & 81,109 \\
November & 110,145 & 31,517 & 83,853 & 110,471 & 62,705 \\
December & 102,290 & 63,393 & 94,196 & 125,376 & 75,877 \\
\hline \hline Total & $1,376,839$ & $1,285,864$ & 993,029 & $1,457,107$ & $1,386,449$ \\
\hline \multicolumn{7}{|r|}{ Source: BPS Statistics Indonesia, 2006 }
\end{tabular}

Table 6.1 indicates the fluctuations in visitor numbers which reflect the market sensitivity to external events such as the 11 September 2001 attacks, the 12 October 2002 bombings, SARS, the Jakarta bombings and further attacks on 1 October 2005.

\section{Lessons in crisis management and recovery}

While Bali has a unique context, it presents many lessons of value to any popular tourist destination. As Australian tourists comprised a significant proportion of victims in both terrorist attacks, the Australian Government and national tourism authorities have also been forced to face the reality that terrorism can happen to anybody, anywhere and anytime. The most apparent message from this experience is that no destination should consider itself immune to crisis and that preparation and proactive capacity building are more effective than complacency. Irrespective of the type of hazard agent or crisis trigger, there are some universal tenets to effective crisis management. Consistent with the recommendations of peak industry bodies such as the WTO, WTTC and PATA - safety and security, communication, promotion and marketing are integral to positive image and consumer confidence. It may not always be possible to prevent a crisis yet the duration and adverse impacts may be minimised.

In responding to the first terrorist attacks Bali had limited skills, experience or even adequate medical facilities. Although the physical impact area was 
small and security was rapidly improved, the media, officials and even tourism operators failed to convince potential consumers of their personal safety. Subsequent promotion and marketing based on discounts and incentives, while numerically successful, also reduced profit margins. Securing an increase in the domestic and regional market segment to sustain the industry through times of hardship was perhaps one of the most productive tourism strategies. While tourism arrivals gradually increased towards 2005, the influence of numerous external events served to reinforce the erratic and often fickle nature of tourism. Lacking the requisite infrastructure and resources for greater economic diversification the hostcommunity of Bali has been forced to become more adaptable, resilient and self-sufficient. Although the level of tourism reliance remains high, obvious improvements in the response to the second series of attacks reveal a vast improvement in both management and coping capacity. Consistent with the concept of enhanced sustainability further time will reveal the success of current endeavour towards greater stakeholder integration, participation and collaboration.

\section{Conclusion}

Like many destinations throughout the world, the tourism industry in Bali was developed in a generally unsustainable manner. While prosperity generated significant opportunities, limited consideration was given to the risks of market instability and growing levels of socio-economic reliance. Faced with the reality of tourism crisis and adversity, this unsuspecting host community was forced to adopt purely reactive response strategies. Lacking the relevant experience, knowledge and skills, the popular tourist island Bali has experienced a difficult path to re-establish its market stability. As unrelenting external events have reaffirmed the inherent vulnerability of any popular destination and its stakeholders, an improved resilience and coping capacity demonstrates the value of employing effective formal and informal crisis management strategies. 


\section{Oral histories about weather hazards in northern Australia}

\section{Douglas Goudie}

This chapter draws on a collection of stories by Australian Aborigines about extreme weather impacts, mainly floods, and contrasts the embedded lessons with detailed descriptions from more recent Australian events. In the Dreamtime Australian Aboriginal stories, the recurrent theme is that everyone drowns. The ways Indigenous Australians 'read' the weather from many natural indicators may pre-empt 'technological' signs of disruptive weather.

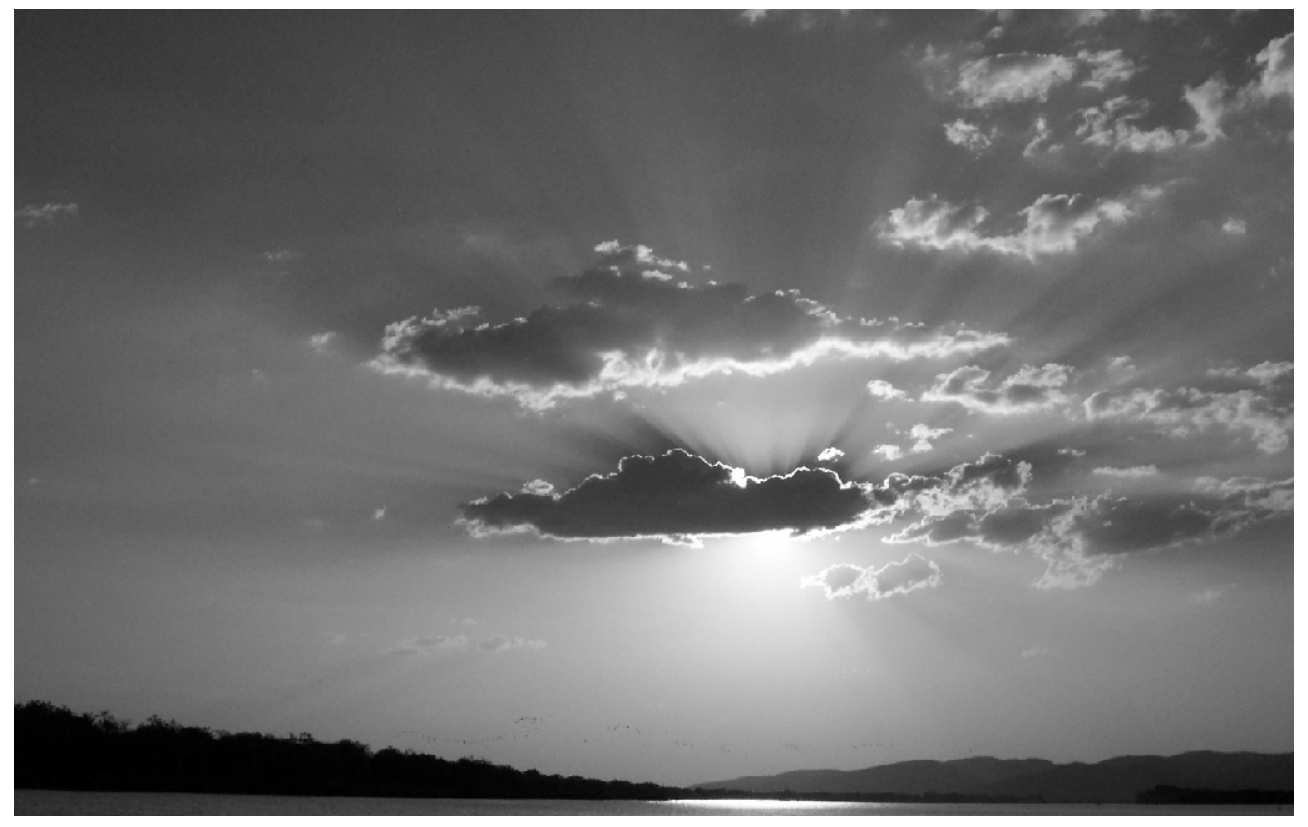

Figure 7.1 Cloud in the Kimberley - weather generally rules our lives, extremes can kill

'Safety' weather warning messages are developed to encourage aware and prepared communities to respond in a precautionary and active way to any likely threat. In more vulnerable communities, make sure residents are informed, and preferably practised in either staying safely where they are, or 
evacuating to safety early. Community safety is the umbrella under which all threatened individuals are encouraged to shelter. In Australia, infrequent extreme weather events are dealt with, and community value systems are important; safety weather warnings need to be credible. How people manage their own lives, their relationship with their local environment and their own community become central to good risk reduction. This is clear and current thinking to maximise community response and safety. People need to make and encourage choices which are robust and produce maximum safety.

\section{Old stories from across Australia}

The first two stories detail landscape and extreme events and are included to show the strong oral traditions of stories about weather in Australian Aboriginal culture. Some of the following stories long predate the rise of Egyptian culture; before Rome existed; and before other civilisations developed in other regions.

Some of the flood stories are allegories illustrating how it is perceived appropriate to respect and care for old people; others are chilling tales of what can happen if children disobey their parents, or harm animals.

\section{First story group: stories about the distant past}

\section{The Origin of Lake Eacham}

Robert Dixon (1991) recorded this story from the tablelands west of Cairns, in north Queensland.

I first recorded an account of the origin of the three crater lakes on the Atherton Tableland (Lake Eacham, Lake Barrine and The Crater) from George Watson, in the Mamu dialect of Dyirbal. The story he told was very similar to the Yidiny one given here - how two newly-initiated men broke important taboos and so angered the rainbow-serpent. This spirit then caused the earth to erupt, bringing about the formation of several deep lakes. Both texts (Dyirbal and Yidiny) provide a plausible account of volcanic eruption.

After telling the story, in 1964, George Watson remarked that when this happened the country around the lakes was 'not jungle - just open scrub.' The volcanic eruptions that formed the lakes are said by scientists to have been at least 13,000 years in the past. George was saying that at this time there was no rainforest on the Atherton Tableland. In 1968 a dated pollen diagram from the organic sediments of Lake Euramo by Peter Kershaw showed that the rainforest in that 
area is only about 7,600 years old. This suggests that the story of the volcanic eruptions may have been handed down from generation to generation for something like 13,000 years (which is not implausible, since Aborigines are known to have been in Australia for at least 40,000 years) (Dixon, 1991, pp. 41-42).

\section{How the Sea Level Rose}

Robert Dixon (1991) recorded this story from the Cairns area in north Queensland.

... a legend which must have been taken down by E.R.B Gribble between 1892 and 1909, while he was at Yarrabah, published on pages 56-7 of his The Problem of the Australian Aboriginal (Angus and Robertson, 1932) under the title 'The Great Barrier Reef':

'According to the natives on Cape Grafton, northern Queensland, the Barrier Reef was the original coastline of the country. Goonyah was the first man in that country. One day with his two wives, he went to the coast to catch fish. In some way he offended the Great Spirit Balore. It is said, that he caught and ate a certain kind of fish that was forbidden. Balore in anger caused the sea to rise in order to drown Goonyah and his women, but they fled to the mountains. The waters rose rapidly as the fugitives climbed to the heights of the Murray Prior range. This range is called by the aborigines "Wambilari" [Moses said that this must be a reference to Wumbilgay, a baldy-headed mountain]. The two women became very tired, and stopped running. Goonyah, well ahead of them, stopped on a huge boulder of granite, and called upon them to hurry. The natives took the author to this spot, and showed him the footprint of Goonyah. It is a patch of very dark stone in the granite about fifteen inches long and very wide. It is said that the mark was left by Goonyah's muddy foot. He must have been something of a giant. They succeeded in reaching the top of the highest peak in the range, and there they made a fire, and heating large stones rolled them down the mountain side, and succeeded in checking the flood. The sea, however, never returned to its original limits. (Goonganjie tribe)'.

Although Moses had never previously heard a story about Gunya the theme was familiar to him - many Yidinyji stories are concerned with rising seas and what olden times people did to try to stop them (Dixon, 1991, p. 90). 


\section{Stories from northern Australia telling of weather extremes and impacts - often most people died}

Quite a few of the stories of major events seem to have a moral of either people not sharing food (a 'sin' for nomadic, subsistence people), or of children being disobedient and tormenting animals. The latter is the case in Dumbi the owl (Utemorrah, 2000b). Here, as is often the case, every-one drowns. In Eye-of-the-sea (Utemorrah, 2000a), the vengeance of an old woman for her lost son seems to trigger a tsunami. Nearly every one was drowned and she was speared to death.

The introductory notes to Songs from Yarrabah (Moyle, n.d.) shows that the very skin or kin groups are categorised to wet and dry season groups of objects or animals. People on north east coastal Queensland were steeped in weather as part of their spiritual existence.

The accounts in The floodmakers of Langu Narnji (Trezise, 1993) record the living culture of the Mornington Island area, where legends indicate some individuals or groups were able to control storms. This was a source of intergroup power, but also retribution when a great flood, unsummoned, wreaked havoc on other groups, who then sought vengeance.

\section{Weathermen - Rain-making, Thunder, and Lightning-making}

Walter Roth (1897), an anthropologist, recorded stories about rain-making in Queensland at Boulia, Roxburgh, Lake Nash and amongst the Kalkadoon people near Mount Isa and thunder and lightning-making by the Kalkadoon people.

The Miorli men at Springvale or the Diamantina Gates execute a dance and song to bring rain. The rain-stick (koo-roo-mun-do) is made of a thin piece of white wood about $400 \mathrm{~mm}$ long. Three pieces of white quartz are glued on the end. Beard hair is added and further embellished. More than one stick may be used. Around midday the men go to a secluded water hole where preparations lead to the dance. When the rain falls the koo-roo-mun-do is removed. In the heavy floods of early 1895, Roth was later assured that all the rain and water was produced by the Miorli men. Roth notes variations of this ceremony at Roxburgh, Headingly, Lake Nash and in the LeichardtSelwyn district (Roth, 1897). 


\section{Superstition, magic, and medicine - Thunder, Lightning and Storms.}

Roth (1903) also recorded stories from far north Queensland when he was stationed in Cooktown as the first Northern Protector of Aborigines.

Thunder can make lightning, men, and women - Thunder is the most potent agency known: lightning is considered to be the fire lighted by him, ...

At Cape Bedford thunder can produce lightning by the rapid exposure of his generative organ, ... (Roth, 1903, p. 8).

These stories from north Queensland show that the Aborigines in the early 1900s often believe that men can make thunder and lightning. On the Bloomfield River storms are made by killing a particular kind of lizard. There are other ways of interfering with nature which can cause lightning and thunder. Storms can be started and stopped by men.

\section{People from the Cairns area}

Anthropologist Ursula McConnel, worked in northern Queensland in the 1930s and Alice Moyle, an enthnomusicologist, worked in the Cairns area in the 1960s.

People of the Kurakulu or Kuraminya moiety occupied the shores of Mission Bay (mira wungala), Palm Beach (giriga) and Turtle Bay. To the Wet Season division belonged water, cloud, rain, thunder, shark, "alligator" (crocodile), water snake, eel, wild duck, white timber, and other light-coloured things; to the Dry Season division belonged subjects such as rocks, clay, fire, grass, kangaroo, emu, pelican, sun, star and wind (McConnel, 1935 cited in Moyle, n.d., p. 2)

\section{The power of the Mornington Island Weathermen - The floodmakers of Langu Narnji}

This story is about the Lardil people of Mornington Island (Langu Narnji). The stories were gathered by Percy Trezise in 1964.

The tidal influences in the Gulf of Carpentaria are similar to those in the Gulf of Mexico, there being usually only one high and one low tide in each twenty-four hours. During certain phases of the moon the tide may 'double', and may also remain high or low for longer than the average period. Strong winds also have a marked effect on the tides; a 
strong persistent south-easterly may create an abnormally low tide in southern reaches, whereas a strong northerly wind, usually associated with a cyclonic disturbance, may cause the tide to back up in southern reaches and cause extensive flooding in low-lying areas.

The Lardil have many legends of great floods that occurred in the past. One story relates that during one great flood only the trees on low ridges of Forsythe Island remained above water, and the Jungarl people survived by tying their rafts to the trees. On Langu Narnji only the top of a twenty-metre-high sand ridge could be seen.

In 1948 a tidal surge which rose three metres above king tide level was said to have been caused by Shilling, a Lurrumbanda man, who, after a quarrel with the missionary, had gone to Langu Narnji to make a flood in revenge.

The Lurrumbanda say they were blamed by surrounding people for every flood which occurred, whether they had made the flood ceremony or not, and united war parties often came to attack the Lurrumbanda after disastrous floods. The Lurrumbanda exacted tribute from adjacent island and mainland clans by promising not to cause any more floods.

The floodmakers do not speak as they rejoin their families to prepare for the coming flood.

The flood may come in different ways, it may come as a giant tidal wave in clear weather, or as a series of tides, each mounting higher and higher; but it usually comes with a cyclone. The first sign from Dewallewul may be a large ring around the sun by day, and the moon at night.

Then the air becomes hot and still. The clouds become denser and darker, and the wind begins, soft and sighing at first then becoming stronger and more gusty by the hour. The rain commences and increases to a steady downpour. Gusting winds get stronger, then cease abruptly and the moaning roar of the next gust can be heard coming far off. Finally a distant roaring is heard, getting louder and louder until a powerful wind engulfs the whole island with horizontal rain and a thunderstorm roaring as it smashes all the trees. It may last for many hours and all the people can do is roll up in paperbark and huddle together on the ground until it is over. 
Due to a much lower barometric pressure, the main flood surge is contained within the central eye of the cyclone, and if its arrival coincides with a king tide it produces a flood from which nightmares and legends stem.

When the people consider they have caused enough trouble they have a meeting and ask the flood men to stop the storm. They gather up stones on the beach, make a big fire and heat them. When the stones are very hot the flood men rake them out, and using bark to protect their hands, pick up the stones one at a time and run down the beach to cast it into the tunnel of a wave as it curls over to crash on the beach. They continue until all the stones are gone and the waves know they must go back (Trezise, 1993, pp. 71-75).

There are or were many Aboriginal groups which could exercise control over the weather (e.g. Mornington Island), but the following story gives one of many spiritual or Dreamtime explanations of the weather, particularly heavy rain. With much time for contemplation, and the human desire to explain everything (the modern approach it through 'science), there are Aboriginal stories explaining just about everything.

\section{Making humans, getting children and causing flooding rains}

The Mowanjum Mission has collected many stories from the Kimberley region of Western Australia including The Spirit Water by Elkin Umbagai (1980).

Wandjina, or Ngarjaia (spirit beings) made the world and everything in it including man and woman whom he made from two of his own ribs, one large and one small, which he threw into two separate pools in which they were created. Man went back to the pools in his dreams to get children, to give to woman, to bring into the world. Wandjina protects the child spirits of the pools.

When the child is stolen from the pool, both the Snake and Wandjina are angry, and the water is stirred up to form clouds. Then there are always big rains and floods during which Wandjina and Wundgudja, the Snake, think they might find the spirit child and bring it back to the pool (Umbagai, 1980, p. 77). 


\section{Second story group: extreme impacts and older people}

\section{The Flood - Ngawarra-kurlu}

In this story by Napurrurlarlu and J akamarrarlu (1988) an old Aboriginal man has a dream of a big flood. He tells all his people of the dream and that they should not sleep in the creek, but they don't listen to him. He leaves to escape the flood. When he comes back after the flood there is no one around. During the night it rained heavily a long way up river. When the flood waters reached the camp all the people in the creek bed had to run to higher ground in the middle of the night leaving all their belongings behind. If they had listened to the old man they would not have lost all their possessions.

So the old man went back to his camp feeling so upset. He then picked up all his things and went far away where his brother was. Other people saw him coming and asked him, What's the matter? Why are you looking so sad?"

Then the old man said, "There is a big rain coming. I've seen it my dream. I told my family about the flood but they wouldn't listen at all."

Then the next day the old man went back to the creek bed to have a look and he didn't see anyone there. Then he looked around. He could see the smoke on the hill. The people told him what had happened to their food and all their things they lost in the flood. People were crying for their things they lost during the flood (Napurrurlarlu \& Jakamarrarlu 1988, p. 19).

\section{Tsunami or Cyclone? - Maambulbarda: Eye-of-the-sea}

In this story by Utemorrah (2000a), a long time ago a woman lived in the Montgomery Islands with only one son. She was persuaded to let her only son go fishing with others. The son was washed overboard in a storm and drowned. She was very distressed and sought vengeance.

"Karraai! Karraai!" she cried. "My only son, why did they let him die?" Then she thought, "So what can I do to them?"

She thought to herself for a while. "I'll stab the Eye-of-the-Sea," she said. "Wait until they're all asleep."

She stabbed the eldest of the eyes first, then she stabbed the middle eye. Only then did she stab the big one, the Eye-of-the-Sea. Away she went, paddling hard away from there. Then the sea rose boiling up after her, and it followed hard behind her (Utemorrah, 2000, pp. 99100). 
She climbed a mountain while nearly all the others were drowned by the rising sea. Some escaped and climbed the mountain too. When it was all over they stabbed her with many spears. Then they left and she is still there, on top of Mount Wundamarro.

\section{The Woman Who Destroyed the Old World}

In another story collected by the Mowanjum Mission, Jean Wungunyet (1980) provides a further example about Lake Gregory (Paruku) which is a version of the previous story, to show how the telling may be different, but the message is the same for oral history.

Near Montgomery Island, north of Broome in Western Australia, now with a large Aboriginal Reserve on the mainland to both east and west, people could live all year round as there was plenty of food. An old woman and her people lived there hunting and fishing.

Her husband would share his turtles or fish with the group but not with his wife so she vowed to:

destroy these people, because they don't give me any of their meat.

So she set out in her canoe to live alone on the coast. Out on the reef were two blow-holes, one big and one small. She picked up her wooden spear and stirred and poked the waters with it. Immediately the waters started to bubble and rise. She walked across the reef and climbed the highest hill she could see. The water rose and rose and flooded over the land.

Some of the men saw the woman on the hill and decided that she was causing all this trouble. They chased her with their spears and killed her. But they were too late - everyone was drowned.

And that is the story of the great flood. Even today our people are afraid to go near that place where the waters boil over (Wungunyet, 1980, pp. 90-91).

\section{Flood - The Flood and the Bird-men}

This story from the Northern Territory was related by Kianoo Tjeemairee (1968) of the Murinbata tribe. The story was translated by Roland Robinson and it tells how heavy and continuous rain fell day and night until the land was flooded by the rain waters and the rising levels of the sea. 
In the time called Kardoorair which means At first all things were blackfellows, a big rain began to fall. It fell all night, all day, all night, all day. The water began to cover all the Murinbata country called Darimun. The rain did not stop. The water filled up the creek and the sea came up and covered all the country, the hills, the trees, everything. There was only water (Tjeemairee, 1968, p. 87).

\section{The flood and its result}

This story by David Unaipon (2001) is a flood story of the Berrwerina people of the Darling River area.

A long time ago there were so many families of animals they found it difficult to live together and so they had a great conference to try and address the situation. One particular tribe related to the reptiles had rainmaking abilities and their totems were:

the elements Lightning, Thunder, Rain, Hail, and Wind. They were becoming important. They resolved that they would not consult anyone, but act as they pleased. This selfish family was the Frilled Lizard. They sent representatives to various parts of the country with the instruction: 'On days and evenings of the week preceding the new moon, let every Thunk cum bulli (Lizard) begin the singing of the Storm Song.'

And when the time arrived, they took their flint knives and cut the body, causing the blood, and then they smeared the body with fat and red ochre and daubed the face with pipe clay, and then began chanting their prayer song, pleading that the Great Spirit of the Lightning, Thunder, Rain, Hail, and Wind should grant this their humble request: 'Come oh Thildarrin (Lightning), come oh Rroararund (Thunder), Pa noondi and Miyundi, come with all thy force and destroy the Platypus family, they have become too numerous and they are more easily overtaken in the flood than any other tribe.'

And they sang and sang their song of the Storm until the last few days and evenings before the appearing of the new moon. Then great dark clouds began to mantle the clear sky, and out of the black cloud the lightning flashed and rent the darkened sky and earth, and struck terror into the hearts of the Animals, Birds, and Reptiles. And the thunder roared its reply to the angry lightning flash, and the winds came hurrying, all in response to the thunder's voice, tearing the limbs from the huge towering gum trees, uprooting smaller trees and shrubs, 
strewing them along its path, driving the rain and hail into every hiding place of Animal, Bird, and Reptile.

When the Bird tribe saw what was coming, they took to their wings, and mounted upon the wind, up and up, until they were far beyond cloud and storm, into lands beyond the sea. The Animals struggled into the blinding storm, seeking shelter up and up, dodging behind the trees and rock boulders of the mountain-side, until they reached the summit, seeking a place of safety. Thus ended the conference with no satisfaction but desolation and death.

It rained and rained. The valleys and low-lying countries were deluged, all life living therein was nearly all destroyed in the great flood (Unaipon, 2001, pp. 28-29).

\section{Kalpartu the Dreamtime Snake}

This flood story from Gracie Greene, J oe Tramacchi and Lucille Gill (1992) is from Billiluna country south of Halls Creek.

The Willy Wagtail man came for a visit but the people tried to keep him out of the dances. They teased him and made him feel unwelcome.

So Willy Wagtail man went for help to his cousin brothers, who were Dreamtime snakes.

The snakes surrounded the dancers. They made a big flood, which killed all of the people except for one, who changed into a white corella. Now you can see these white corellas. They stay near the rockhole. They are the people who lived there in the Dreamtime (Greene, et al., 1992, pp. 27-28).

\section{Flooding of Sturt Creek and Lake Gregory}

Readers are invited to compare this following story from George Nunkiarry (1996), a flood story from the time before the arrival of non-Aboriginal people, with a version by Rex J ohns as related to the author in 2003 which is presented following the Nunkiarry story.

In the Dreamtime there came a huge flood from the east. It brought my ancestors from the east to Lake Gregory. It came downstream 
straight for where Inverway Station now stands. The flood came from Gulbulundu and headed down towards Birrindudu. It filled Sturt Creek to overflowing. J ust the tips of the river gums along the bank stuck out of the water. White people, if they had seen it, would have said it was just like a tide coming in. From bank to bank it swept down to where Gordon Downs is today, to the south of the river. As it ran it met up with other floodwater from the north and west. That was where the crocodile and the goanna fought over their teeth. The crocodile stole the goanna's sharp teeth.

The flood kept sweeping downstream and met smaller floods at Bindi Bindi or Sturt Creek Station. It filled up all the big waterholes along the river as it passed by Sturt Creek Station. As it went, the flood swept up birds of all kinds, ducks, guluyu - bush fowl, white people call them. It swept them all downstream towards Lake Gregory in the south, where two pelicans saw the flood and all these birds approaching. One of the pelicans said, 'I'll go north and meet all these birds and bring them into the lake.' We say dabarunga but white people say pelican.

The two pelicans came up from the south and met the duck, and the bush fowl, and the brolga, and all the other birds caught in the flood. And that is how tribal laws from the south and the north met at Lake Gregory. In the Dreamtime the two pelicans brought all the birds together at Lake Gregory.

Billiluna used to be beside the lake; Billiluna old station, which we call Warngu. They moved Billiluna north to the higher ridges, and they built new houses. It used to be much closer to the lake. From Warngu, in the Dreamtime, two white dogs started to chase an emu. They chased it for along way to the west. White people might say they chased it for twenty or a hundred miles. We just say that they chased it for a long way west.

After some time, the emu started to swing around and run back the way it had come. Back towards the lake which is called Barugu. Finally, at the lakeside, the dogs caught the emu and cooked it and ate it. You have to remember in all these stories that the animals in those times were like people. After that the lake began to fill up from the south bank to the north. Barugu is huge. It might stretch as far as from Old Town to Palm Springs. To go around it is like going from Halls Creek to Fitzroy or perhaps to Wyndham. 
Well, the whole lake started to fill up. White people would say it is like an ocean. We went round it once and it took us two nights camping to get around. My grandfather, grandmother and my father lived there and that is where they are buried (Nunkiarry, 1996, pp. 10-11).

\section{Mulan Dreamtime story - The two dingoes}

This story is from Rex J ohns, Mulan elder and founder, as related to the author in 2003.

There were two emu up north from around Inverway Station, from Nungaroo Creek who were chased by two dingo. A big distance away at Nungaroo.

People were walking south. The emus were in front. The people were singing and dancing, and they were in between the dingoes and the emus. There were floodwaters behind the dingoes.

When people were camping the flood would stop. There was one old man, he had a string line and he would cut the water while they camped. He would hold the waters back while they camped. While they would sing and dance. Where they camped the water was held up. That is where the billabongs in Sturt Creek are now. Like at Bindalaorro. The black and white water bird, the one with the long legs, the little bird was with the people. Birds and other animals joined the people as they moved south, singing and dancing.

They were coming down, straight down to the lake on the Sturt River side. But the dingo chased the emu round the other side. Around to number 51 well (water bore) around to Gillang-gillam.

The dingo chased the emu back and forth on the main lake. One dingo was chasing one emu and the other dingo was chasing the second emu. Back and forth. Each dingo grabbed an emu when they passed but they each grabbed the wrong emu. They grabbed 'em and killed 'em and ate 'em.

The people on the other edge of the lake, in the main channel, camped again. In that main camp they sung and danced, that was where we call Lera Yard. 


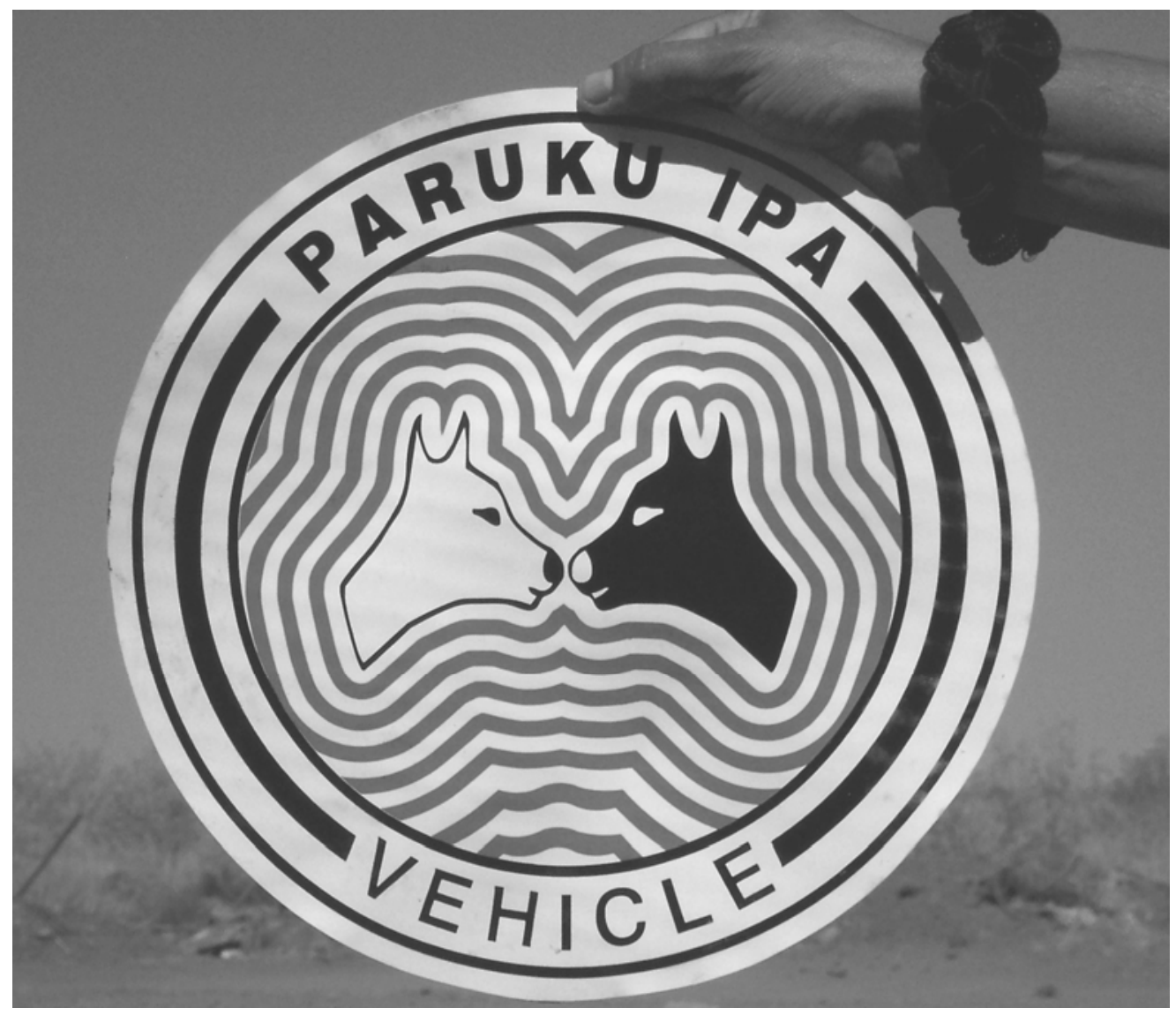

\section{Figure 7.2 Two dingoes - the story of the great flood of the Sturt Creek}

When the two dingoes were full they walked up the other channel to Mulan. There was a soak there and they dug in. They're still there.

Then the water came in from both sides and all the people got drowned.

One old man walked off and sang them (he put a deadly curse on them all). They all drowned because they hadn't shared some food with him. But when he walked off, another old man spat on him, cursed him, so that first old man who walked off died too (personal communication, Rex J ohns, October 2003).

The Sturt Creek and Paruku (Lake Gregory) are central links for the desert communities in the East Kimberley. It is now common knowledge around Mulan that if the early floodwaters are a milky colour passing through the Balgo Hills area, it means a major flooding rain north, about five days 
earlier, and the creek levels would probably stay high for months. If the water was red, it means local rains from the smaller, near catchment, so the creek level would probably go down in a few days.

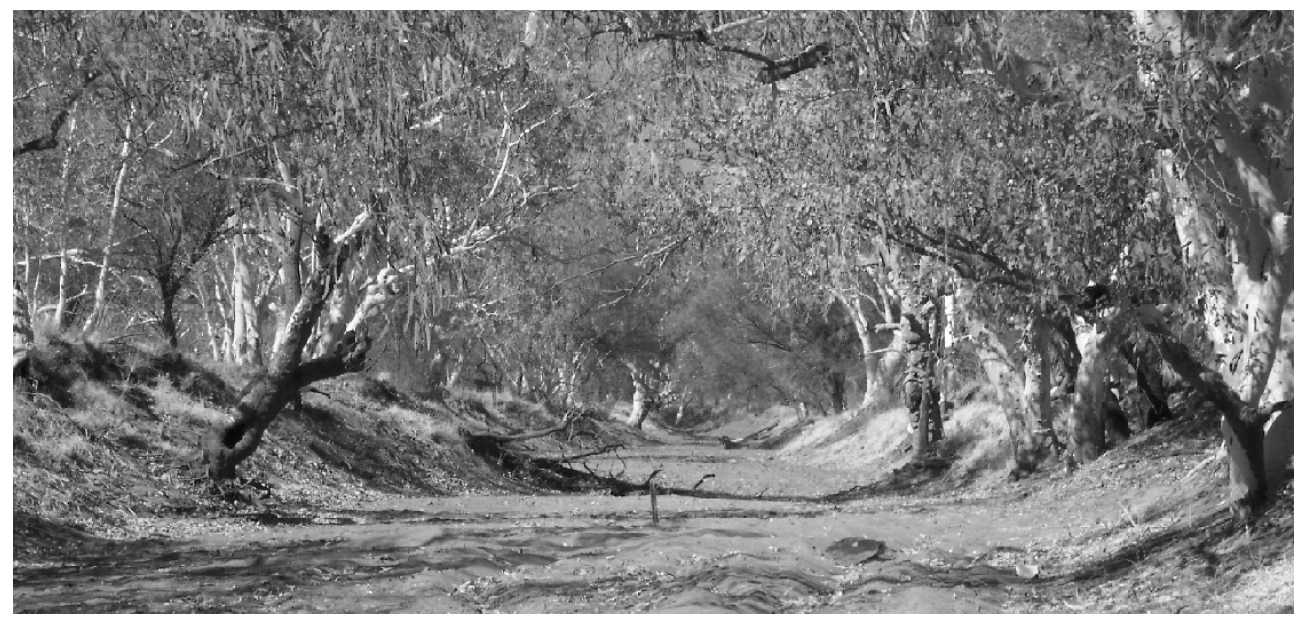

Figure 7.3 Sturt Creek, subject of a Dreamtime story of flood and loss, which includes moral teaching.

\section{Floods and discipline lessons for children}

\section{How the people were all drowned}

In another story collected by the Mowanjum Mission, Daisy Utemorrah (1980) provides a flood story How the People Were All Drowned. In Aboriginal Dreaming a tribe called Dillangari from north west Australia had huge dogs as big as calves. Wandjina didn't want the dogs to talk and if they did he would drown everyone.

So parents were very careful to tell their children never to tease a dog.

The tribe went to hunt at a place with plenty of food, the men telling the women to make sure the children didn't tease the dogs, "and the women gathered the children together and warned them, 'First of all, you must not hit any special bird which belongs to Wandjina, such as Tumbi, the Owl. If you do, the Wandjina will send rain and storms and we all will be drowned. And the second thing is that you must not tease the dogs. Don't try to make them talk like us because Wandjina has told the dogs that they are only allowed to bark.'

The children asked why they couldn't play with the dogs, and the women answered, 'If you do, and a dog answers you, we will all be 
swallowed up by water. No one will survive. The Wandjina will cause the water to rise and drown us all.' So the children agreed to leave the dogs alone.

Some of the women went off to look for berries and wild honey and yams. The remaining women were told to keep an eye on the children, but instead of doing this, they went down to the river to gather waterlily roots.

A group of children started to play with the dogs, calling and yelling to them. The women were so busy with the waterlily roots that they didn't hear the children, who continued to tease the dogs. Suddenly one of the dogs answered back, speaking like a human.

As soon as that happened, Wandjina caused the whole tribe to disappear under the ground and under the water. Only the Wandjina themselves were left (Utemorrah, 1980, pp. 46-47).

\section{Dumbi: The owl}

In another story by Utemorrah (2000b) young children were told not to torment the owl. One of the boys decided to kill the owl. Others tried to stop him but he climbed into the tree, grabbed the owl, pulled out all his feathers and threw him down. They stabbed the owl and tormented him in many ways. The Wandjina (spirit being) wanted to know from the owl what happened. When the Wandjina found out he decided to punish the children by getting rain. He got the dragon lizard to go out into the plain and wave his arms around to bring all the clouds. The dragon lizard did that. The rain and lightning came. That scared the children. Their parents came back and asked why was all this rain falling and discovered what had happened. The children said they were only playing with the owl.

“Well, we told you and told you, when you see the owl you mustn't hurt it. But you just wouldn't believe us.

The rain kept falling. The rain fell and lightning flashed all around them. They swam about in the flood waters, trying desperately to climb up into the highest hills. But the flood rose up higher and they all perished.

But there were two children standing up on a hill, a boy and a girl. And a kangaroo came hopping towards them. "Let's climb onto this kangaroo," they said to each other. 
...the Wanddjina destroyed all the other people. They all drowned and the land was left empty (Utemorrah, 2000b, pp. 9-11).

\section{A moral story with dire weather consequences}

In Daisy Utemorrah's story above the torment of an owl resulted in a great flood in the Kimberley. The Wandjina got the dragon lizard to go out into the plain and wave his arms around to bring all the clouds. The dragon lizard did that and the rain and lightning came and the children were frightened.

During a disaster risk management study conducted in Eidsvold, inland from Gympie, southern Queensland, the author learned from Neville, of the local Wakka Wakka group, that he spent time with traditional men in the 1950s. He was shown a local lizard (moos moos in the Wakka Wakka language) slowly waving one 'arm', then the other in front of its face, while standing on a high piece of a fallen branch. These lizards are smooth skinned, not very common, and about $200 \mathrm{~mm}$ long. The old men said that event meant there would be rains soon after. The younger blokes laughed and thought that was not going to happen. According to Neville, "storms came from all over the place that night. It rained a lot" (personal communication, Neville, 2003).

From an ancient story of a prior major flood in the Kimberley to living oral traditional knowledge of reptile behaviour preceding flooding rains in southern Queensland, there would appear to be an early, observable warning or forecast of rain.

\section{Lightning}

J ean Ellis (1991) collected this story The Lightning Man about the legend of Wala-Unayua who lived deep in a waterhole in the Liverpool River in Arnhem Land. Local people knew he was easily angered and would strike people down with lightning.

He was at his most dangerous, however, during the wet heat of the monsoon season. As soon as the monsoon rain began to fall, WalaUnayua would fly into an uncontrollable rage. In that rage he would travel across the sky, hiding in thick clouds, and his angry voice would thunder, crashing and echoing across the land.

Flashing the lightning of his long arms and legs he would savagely attack the earth, throwing down the trees and leaving a stricken landscape in his path. As soon as the monsoon season came to an end he would gradually become calmer, eventually returning quietly to his own waterhole. There he would stay, always on the watch, ready to 
strike out again if anyone or anything dared disturb him (Ellis, 1991, p. 106).

This section shows that old stories, Dreamtime stories for Australian Indigenous people, can help make real the rare and unusual threats of flood, fire or destructive winds which may impact upon people's lives in the future. It should be possible for these old ways of reading the weather to be communicated into the technological and hard data' systems employed by the Australian Bureau of Meteorology to help predict flooding rains.

\section{Readable weather warnings, direct from nature}

The following compilation of traditional weather predictors results from a team of researchers from James Cook University's Centre for Disaster Studies visiting many northern Australian remote Indigenous communities in late 2003. With the core business of finding out from communities about how to maximise the safety of communities ahead of disruptive weather, researchers also asked community members: 'What natural indicators tell people that there is going to be, or likely to be, a bad or dangerous weather event (including bushfire, flood, severe storm, cyclone, surge, cold snap, drought etc.)?' They were also asked: 'What are the natural indicators for the onset of the wet, and the dry season?' and 'What kind of traditional ways do people have of recognising or predicting a change in the weather and an increase in a hazard?' Some 'weather reading' techniques are explained below.

\section{Yarrabah}

From Yarrabah, near Cairns, in coastal far north Queensland, people can tell if storms are coming because ants are more common indoors, and cockroach behaviour is erratic before a big wet. Certain plants and flowers are used to indicate seasonal changes. The behaviour of the storm bird, a type of tern, is erratic. This bird flies low or circles in the sky and flies off in the direction of the coming cyclone just days/hours prior to the event. Also, increased numbers of crocodile tracks and drag marks heading up the mudflats/ beach indicates that it is going to be rough weather at sea for about the next week, possibly due to storm or cyclone. A dark, shadowy ring around the moon means that bad weather is coming. Unusually high tides means a storm is coming - conversely 'blue' sea water close to shore is said to indicate good weather for the next couple of days.

When the bush creatures are quiet, it means the birds have left for the mainland, and there will probably be a big storm or cyclone. This may 
happen before the formation of a storm has become clear by way of electronic means.

\section{Palm Island}

From Palm Island, near Townsville, major storm indicators include large amounts of cloud and fine mist. A red sunset probably means major rain and crabs moving inland may indicate cyclones. Similar to Yarrabah, major storms are signalled when birds gather in flocks and fly around quickly before leaving the area. It is known that when you are in the path of a big storm it all goes quiet - all the birds have left. That kind of quiet will tell you where the worst of a cyclone is going to hit.

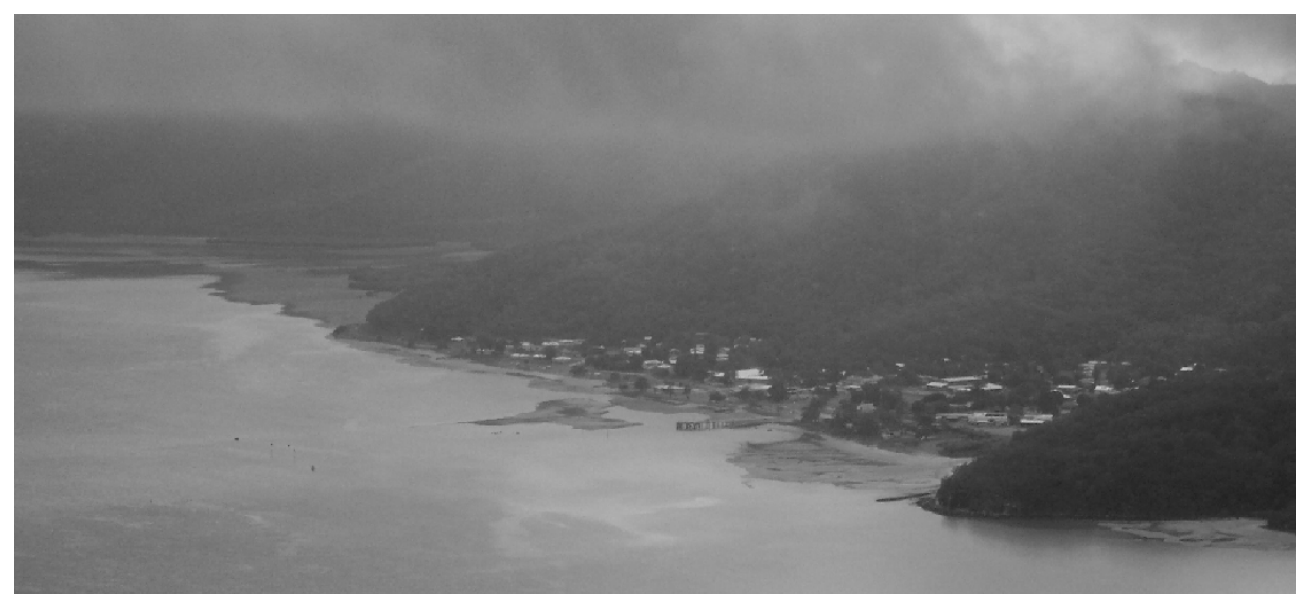

Figure 7.4 Main settlement, Palm Island

People of different cultures know that cockroaches and ants become very active before bad weather. Sudden changes in wind patterns may indicate a storm is on the way and cloud types may indicate approaching storms.

All the bush animals breed up ahead of a good wet season, but they would not breed much if there was not going to be much of a wet. With the traditional fruits - when all the trees were in fruit, one tree may start to fruit again. People would know that something unusual was going to happen, that different weather was approaching.

\section{Old Mapoon}

In Old Mapoon, on the Cape York Peninsula in northern Queensland, traditional ways of reading the weather are much the same as all communities in northern Australia. A period of continuous very hot and still 
conditions precedes monsoonal rains or a cyclone. Indigenous elders state there are certain natural indicators for different types of weather events, the most important predicting cyclones.

Many local people indicate the manahawk (Aboriginal name for a large black ocean going frigate bird) when seen in large numbers in the coastal areas indicates that strong winds, possibly cyclonic, are expected within two to three days. Bad weather can mean severe storms or a cyclone. In normal weather conditions, these birds can be seen circling in a group, high in the air along coastal areas. When conditions are extremely rough, in the case of an approaching storm or cyclone, they move inland to seek shelter, flying low to avoid wind gusts.

Crocodiles building their nests higher than usual above the high tide mark and long stalks on the mango fruit indicate that a big wet with greater than average seasonal rainfall is expected. The wet season is heralded by a gradual build-up of clouds over weeks, high tides, and very hot conditions. When the dry winds start to blow from the south east, causing the grass to lose all moisture, turn brown and die off, winter is beginning.

\section{Kimberley region}

At the Kimberley settlement of Ringer Soak, ants are observed about 6 weeks before the wet to start building tubes up from the ground about 2 inches (50 $\mathrm{mm}$ ) high. The ants close off the top of the tubes just before the rain starts a day or two before. J ust before the wet the bees gather pollen then seal off the combs with wax, just leaving a tiny breathing hole. Budgerigars and goannas come out with the lightning and thunder near the start of the wet, while the budgerigars breed at the end of the wet. First there are rains, then there are the flying ants. If there are more flying ants there will be more rain. It is known that most of the weather comes from the north east. Bush trees start to flower after a cold snap, and the Sturt Desert Pea stops flowering at the end of the wet. 


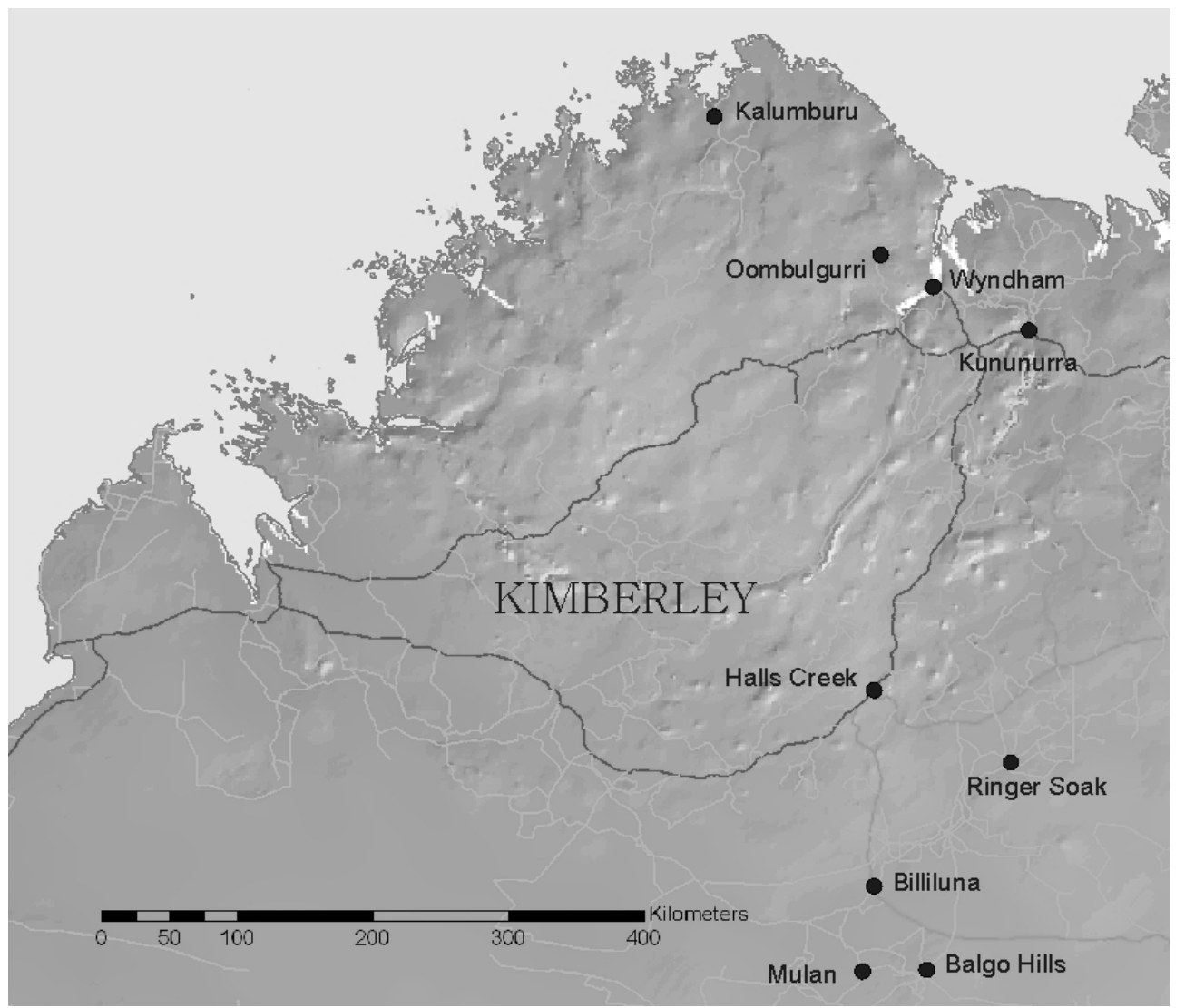

Figure 7.5 The Kimberley region of north west Australia [map by Adella Edwards]

In Mulan in the Kimberley, the days are hotter before the rain, in October or November. The cicadas are heard and then there are big rain clouds and goannas become active. There is some rain, a dust storm, rain, then lightning strikes then the wet. In Balgo Hills, the ants store food night and day indicating there will be heavy rain in about three days. J aum is the local name for the rains that come after Christmas. The weather seems to follow a four or five year cycle. Clouds go round in circles just before the rains come. In Billiluna, the start of the wet is indicated by ant activity, big cloud banks and the general humidity and temperature build-up. 


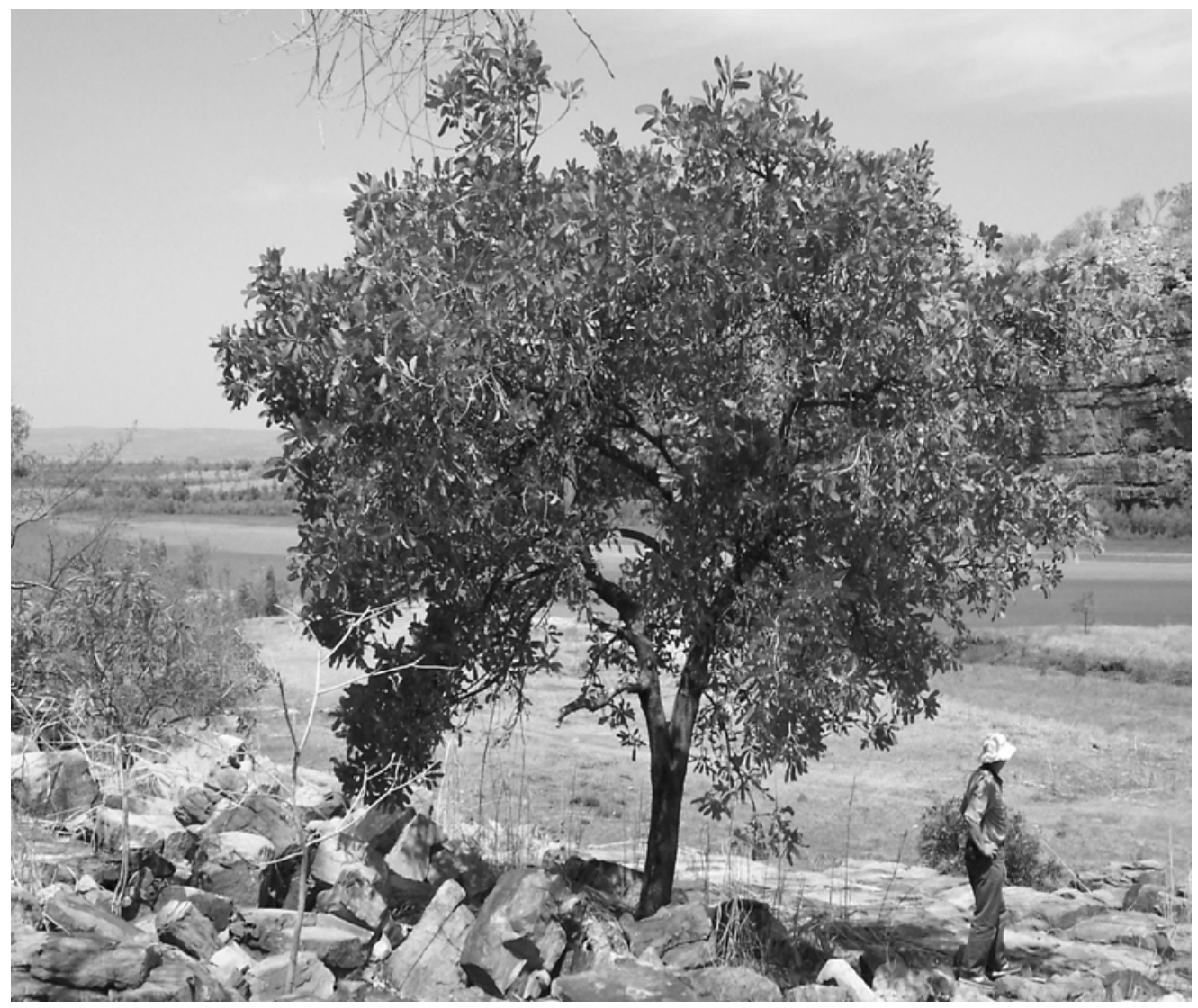

Figure 7.6 Forrest River landscape at Oombulgurri in the Kimberley

In Halls Creek in the Kimberley the onset of the wet season is heralded when the leaves have fallen off the trees and they've begun to grow back. The clouds building up, days getting hotter, and hot, dry wind blows. The boab trees will flower and when these flowers fall it means the rain will be coming soon. Echidna will walk, looking for ants. Green frogs start making noise, before it starts raining. Sugar bag or wild bee hives are full of honey, and rain can be predicted by the tilt of the quarter moon: if the quarter is on its back, not much rain; if the quarter is standing tall, it should be a good wet. When there are rings around the moon at night, the more rings the bigger the wet.

The onset of the dry season is signalled when cockatoos and blue mountains parrots lay eggs. Nights get colder and flies are a major pest until the weather starts to get cold. The sugar bag flies come out and start laying eggs, and sugar leaf grows on the leaves of trees. If there has just been a big wet, there is more chance of having a colder winter. 
Traditional ways of recognising or predicting weather change can include: looking at the sky for clouds or lightning in the distance; following the direction of the wind, especially if rain or lightning are near; and watching insects, birds and animals, the known indicators of imminent rain and wind. The abundance of bush fruits and animals which should be in season is also a way of recognising the change in weather.

In Oombulgurri (the former Forrest River Mission) in the Kimberley people say they can smell the onset of the wet. There are flowers before the wet, like the kapok and the gelay. Boab trees start shooting leaves. You get the knock-down' rain at the end of the wet, the rain that knocks down all the dead grass stems right before the dry starts. The wet is known to have finished when the fast moving cloud is observed.

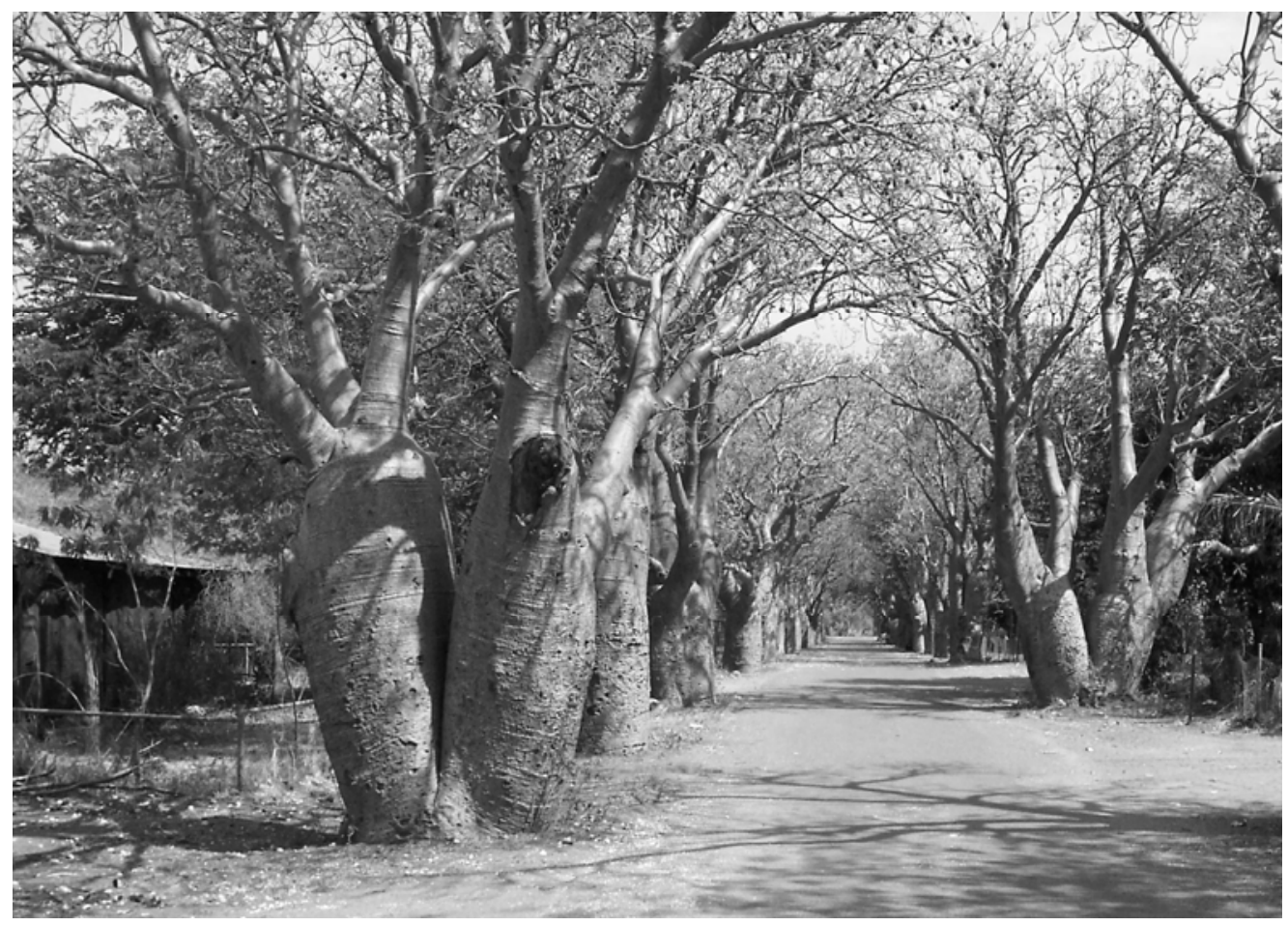

Figure 7.7 Boab trees in Oombulgurri in the Kimberley

\section{Conclusions}

This chapter has shown that there are knowable threats from extreme weather, recorded in the oral traditions of Indigenous peoples, and in more recent western accounts. It is also clear that some of the learned indicators from widely separated areas are good predictors of disruptive weather, from 
lizards waving their front legs about, to sea birds wheeling in unusual groups. Simple observations such as: 'the bush goes quiet because all the birds have left' could save lives ahead of a cyclone impact, if the traditional knowledge had remained widespread, respected and used. It is still possible for much Indigenous weather knowledge in Australia to be used in this manner.

Making the threat real to endangered listeners is the core to effective 'safety' weather warnings. The old stories provided in this chapter, call them Dreamtime' or 'folklore', tell of extreme weather events, while the living cultural knowledge gained and passed on over thousands of years tells, how to 'read the weather' locally. A long-term outcome of technological weather predictors testing could be to respect and learn from Indigenous weatherreading methods. Indigenous weather stories and readings could be incorporated into education about weather patterns. To maximise safety, credible warnings and action statements from reliable sources need to be received and responded to appropriately. This is central to the purpose of safety weather warnings: use of material in this chapter may help savelives. 


\section{Lardil weather stories and experiences from Mornington Island}

\section{Eddie McLachlan}

Mornington Island is an isolated community, located in the Gulf of Carpentaria, off the south western coast of Cape York Peninsula, approximately $125 \mathrm{~km}$ northwest of Burketown, $200 \mathrm{~km}$ west of Karumba and $440 \mathrm{~km}$ north of Mount Isa. It comprises an area of about 700 square kilometres, and is the largest of the twenty-two islands, which form the Wellesley Islands group in the Gulf.

After the end of the Ice Age, approximately 6,500 years ago, rising sea levels reached their current height. Before this change, the Wellesley Islands formed a peninsula that was part of the Carpentaria mainland. The Mornington Island landform comprises a prominent sloping plateau, and low, rounded and flat-topped ridges, separated by broad, shallow valleys. The highest parts, which feature the Mornington Plateau, are between twenty and forty metres above sea level.

Streams which often flood during the wet season, flow down to the coast forming wide inlets. In the dry season, the mouths of large streams and creeks of the island dry out to form clay-pans or salt-pans. Larger streams have permanent waterholes. The vegetation is mainly grassland, open medium to dense scrub, and low open forests and woodlands (Memmott \& Horsman, 1991).

The original Indigenous inhabitants of Mornington were the Lardil Aboriginal people. They formed the largest tribal group that formerly occupied the North Wellesley Islands, which included Mornington, Sydney and Wallaby islands. The Lardil believed that long ago, in the Dreamtime, their ancestors came over from the Australian mainland. The link with the mainland constitutes an important legend for the people. It involved three characters, Maarnbil, his wife Jirnjirn, and Diwaliwal, who was Jirnjirn's mother's brother. It is believed the trio travelled across from the west when the Wellesley Island group was still part of a peninsula, which extended from the mainland. As they passed through the land, which is now the islands, the 
three beings created rivers, hills, animals, trees, fresh water wells and stone fish traps. The legend tells that while Maarnbil was away, Diwaliwal and his niece, J irnjirn had wrongful sexual relations, triggering catastrophic events, which would later have cultural significance for the Lardil people. The revelations of this particular section of the legend contains a range of connotations relating to the basic elements of traditional Lardil law, including incest taboos, moral obligations, and kinship relationships. Many of these concepts have since been ingrained into the Lardil world view, and traces can be seen in the society today. As an example, in the Gununa community, the uncles are responsible for teaching their nephews Lardil traditions essential to their developing into men. A very important aspect in this procedure is that from an early age the children are taught the importance, and meaning of their family totems (Ahern, 2002).

The association between the Lardil and their natural environment has always been a close one; the people-environment relationship is a cohesive one. Although the people have adopted most of the elements of western culture, they still maintain strong links with the bushland and surrounding seas of Mornington Island, and as part of their continuous relationship with nature, most have a strong understanding of the local weather system.

Before colonisation, each Lardil group was separated into four tribal areas (see Figure 8.1). These boundaries were set by the four winds in accordance with traditional Lardil beliefs. The Balumbanda were the West people, Leelūmbanda were East people, Larūmbanda were South, and Djigürrumbanda were people from the North. Natural features such as creeks, ridges, a line of trees, or a cluster of rocks, formed boundaries for each group. Clan groups were also generally known by reference to their location, associated with the influence of the island's primary winds, the east, and south-easterlies. The Leelümbanda and Larūmbanda, who were directly exposed to the winds, were known as the Windward people, and on the sheltered side, the Djigürrumbanda and Balūmbanda were named the Leeward people, (Binnion, 1987).

These days, residents from Gununa visit their homeland sites for short periods on weekend camping trips, and hunting and fishing expeditions. At some of those places where there are reliable sources of fresh water, outstations have been established, and are occupied by members of traditional owner's families. The island has a population of about 1,200, most of whom are Indigenous, and reside in the township of Gununa. 


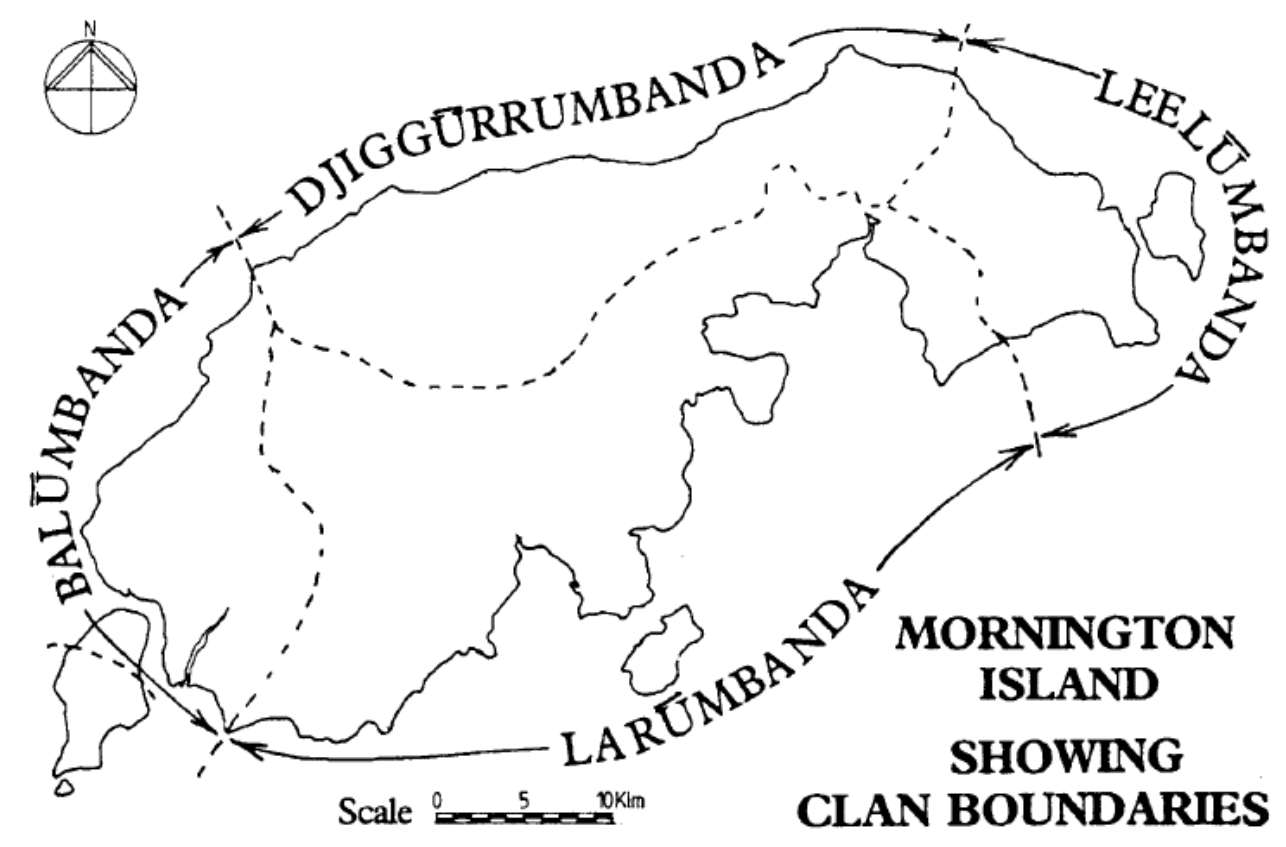

Figure 8.1 Lardil clan boundaries (Source: Binnion, 1987, p. 2)

Since the early part of this century, Mornington Island had been managed under the provisions of various Aborigines Acts, by the Uniting Church. Since 1978 the island has been managed by the Mornington Shire Council. A few of the original missionary buildings are still standing, a prominent one being the guesthouse (see Figure 8.2 below), which was in fact the old missionary's residence.

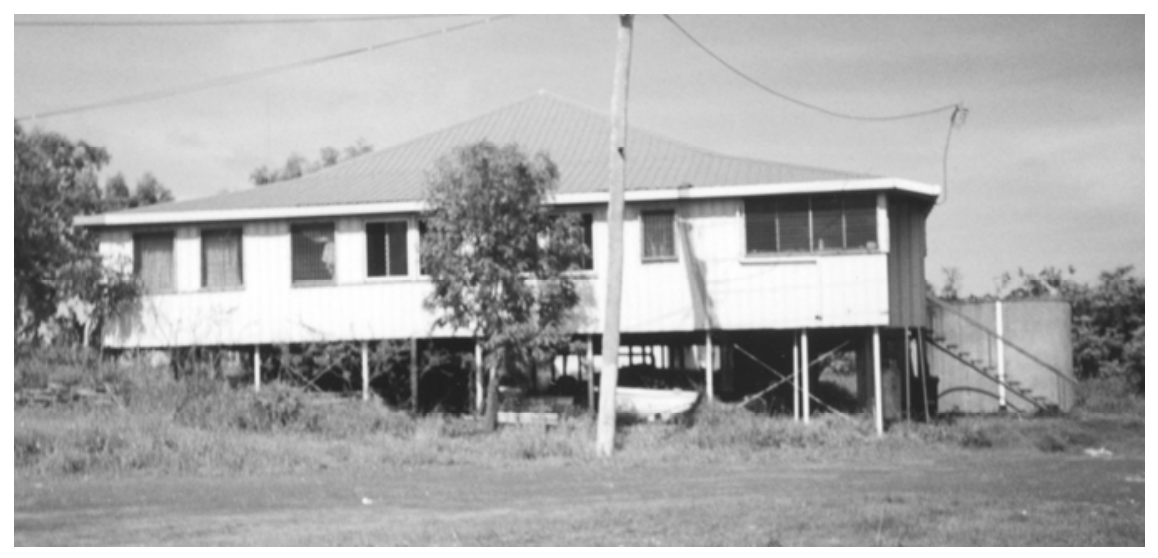

Figure 8.2 The old mission house, now guest house, Mornington Island 
The community library is housed in what was originally the old church building. The library contains many people-related tales about being part of the missionary system, or living on the island at the time of the mission, while other stories are of their parents who were 'mission children'. Many stories of Mornington Island relate to the weather.

\section{Lardil people and cyclones: some personal stories}

I grew up here...and I been through a lot of these things. I know how this cyclone season, this crisis of cyclone... if a severe one come, and if it isn't a severe one, you gotta be prepared-act ready and be prepared, at all times. It's life or death, you gotta be prepared (Melville Escott, personal communication, 2001).

These words spoken by an elder member of the Lardil people of Mornington Island, signified the knowledge held by the Indigenous inhabitants, about natural hazards in the region. He indicated his experience of cyclones by stating people have to be prepared for the cyclone season, and they know nature is unpredictable, so they have to be ready regardless if it is a small storm or a severe tempest. An unprepared community risks leaving itself vulnerable to the fury of a cyclone. This essential survival knowledge for Lardil Aborigines has been accumulated from a long history of experiences, and related stories, passed on from generation to generation. It is an important part of the traditional knowledge that exists in Indigenous communities in remote Australian areas. Though now the Mornington Island township of Gununa, consists of infrastructure that boasts modern buildings and contemporary facilities, Lardil residents maintain their connection with, and hold intimate knowledge of, the surrounding land and sea. That knowledge is essential in keeping their identity, and maintaining their culture.

\section{Personal cyclone experiences}

The following are personal accounts of several Lardil residents of Gununa, detailing their experiences of encounters with cyclones, and also provides insights into the Indigenous perspective of related events, and personal views. The narratives are in their own words, because it is important that people's emotions and actions, are portrayed truthfully. Their stories contain Indigenous attitudes about cultural and environmental links, which symbolise the significance of local knowledge discourse in Australian remote communities (Sinatra \& Murphy, 1999).

Like many Indigenous residents of Gununa, Melville Escott's parents were not from Mornington Island, but Melville, like others of his age group, was 
born there. Melville is in his early sixties, and is a member of the Escott family, one of the oldest and well-known families on Mornington Island. He is an adept traditional and contemporary artist, and has spent time off the island when a young man, working as a stockman on various cattle stations in the Gulf of Carpentaria region.

My parents originally come from the mainland, but I was born here. My father, he originally from Burketown, Gungullita tribe, and my grandfather been the king of that tribe.

Melville said in his lifetime, he had experienced a few cyclones while on Mornington Island, but Ted is the cyclone that he remembers most clearly, chiefly because of the destruction it wreaked on the island and in the township, Gununa. His recollection of the event in December 1976, painted a picture of dramatic physical effects caused by the storm:

I been here, yeah, I was here. I was young fulla, I was young man Cyclone Ted - when we had Cyclone Ted.

Like most Indigenous people of his age group, Melville recalled events that had a lasting effect on his life, and linked them to the stage of his life at the time. Hence he said he was, "a young fulla...a young man", meaning he was probably more than twenty-one years old, because at the time, that was the legal age of consent, when young people were regarded as adults. So, although most of the Indigenous people interviewed, may not have known their exact age, or the year of their birth, if an event was dramatic enough, nearly all can remember some details. It is the event, and consequent effects, which are more important, not the age of the witness, or the exact point in time.

In December 1976, Cyclone Ted hovered for some time off the northern coast of Mornington Island, a short distance from the Birri Fishing Lodge, before it impacted upon the island.

He came direct, straight in, he was stationary out there for a while. Yeah, come straight from out the open sea, from out of the Arafura Sea" (Melville Escott, personal communication, 2002).

According to Melville, the damage in Gununa inflicted on buildings and possessions left out in the open, was quite spectacular:

We had old houses, old timber houses, never had steel frame houses...Yeah, that Cyclone Ted, he came straight in, directly, yeah, he came straight in, it just flattened all them old houses. He flattened all 
them top houses, that video there, them old photos showing how, what disaster it made. How it wrecked this place-luckily no one was killed! Lost dinghy, lost boats and things what, you know-never been brought up, or flung from the land, out in (the) sea - what was wrecked (Melville Escott, personal communication, 2002).

The 'top houses' mentioned by Melville, were the twenty prefabricated houses erected in the early 1970s, on the town ridge. The 'old houses' were undoubtedly the residences situated down on the old village beachside area. Reports by newspapers confirmed the extent of the damage to the township buildings, an indication that they were not constructed to withstand a storm of Ted's ferocity. From accounts by those few who experienced Cyclone Ted, the consensus was that most Indigenous residents sheltered in the old mission house. They knew it would offer protection, because they either experienced occasions when they used it themselves, or they had been told by elders, of the building's reputation as a safe haven from severe weather. These actions are testament of local Indigenous knowledge that was utilised by residents, in a crisis situation, as a method of survival. This was a Lardil lifestyle strategy, which was acknowledged by Melville:

No one was injured, but then, you know they had to manage, to protect their own life (Melville Escott, personal communication, 2002).

Alma Moon, an Aboriginal woman in her forties, has lived and worked on Mornington Island for most of her adult life. Alma recounted her experience of the cyclone, saying her family had to move from their house to safer buildings. The former mission house, now the island's guesthouse, was considered one of the sturdiest and safest structures, so it has been extensively utilised on occasions when shelter was needed in times of a natural hazard crisis. Alma remembered:

We used to live down the old village, down near the waterside there. So we had to move up to my husband's mother's home. Then cyclone got really worse, they had cars moving people down to that old mission house, and the old canteen. And all under that old mission house, mission house was full of people, on top, underneath, we all stayed there (Alma Moon, personal communication, 2002).

A couple of days later, after the danger had passed, those who had sought refuge in more secure buildings, moved back to their homes and proceeded to clean up their wrecked houses. 
We run away, but when that cyclone settled down, we go down, look for all our things now. I had a lot of things, photos...everything was taken out to sea, even our boat's motor was taken off. That's Cyclone Ted (Alma Moon, personal communication, 2002).

Alma also had an exciting experience on Bentinck Island during a cyclone. From her recollections, and a study of relevant records indicated the storm was probably J ason, a cyclone which struck Bentinck in 1987.

Alright that night now, we sleep-rain been pouring in, we sleep (in) wet blanket. I had my daughter with me, my eldest. Morning time now, I said to old Luke "You go make cup of tea for us." But when he went to make breakfast, he said "Oh the stove's wet, where power, gonna cook?" So we went round to the kitchen, we were sitting downhe said "What cyclone look like?" Soon as he said that, iron been rip past the side, and I just grabbed Beatrice, my daughter, (and said), "Come darling me-two go die together". And that house, been lift offthe whole frame-right up. We was just sitting there (in the house), and (then) we all ran behind the (water) tank. We had to lead each other, hold hands, so if one drift away, we all go. Some one said "Oh, let's stay in that freezer there, that big freezer," And I said, "No! We can't stay in that freezer, that wind go (will) come back, and that freezer go (will) fall down, and then we'll be dead!" So that freezer went, (did blow over) that big freezer, all our food, the gas stove, everything went (was lost) there la (on) Bentinck. So we had to start building again, build it up again (Alma Moon, personal communication, 2002).

Alma's account contained details of an Indigenous person's personal view of a cyclone, and the actions taken to preserve their lives, in the face of a natural hazard. Strong family ties are extremely important to Indigenous culture, a fact stressed by Alma, as she expressed that at the height of the storm, she hugged her daughter and was content to perish, as long as she was with kin.

From the same incident, Alma described the Kiaidilt people's methods of survival on Bentinck Island in a cyclone situation. Similar to the Lardil, Kiaidilt Aborigines had their traditional strategy of constructing shelters, as protection against severe weather conditions.

Old Bentinck Island people, they had this special grass, for little humpies. Luckily we had them old people that been grow up there. My cousin, and my brother-in-law now, we sitting down, watching now - soon as he been stop now, (cyclone passed), them boys had to 
go and break them big grass, but we never hide, we been make, like, little breaks, like a wungura (Lardil small shelter). And we all sit down in that. All these boys, been go look for freezer (that had blown away), because we lost all our tucker. We had tinned stuff, but we needed flour, tea and sugar, and something fresh to eat (that was) nutritious (Alma Moon, personal communication, 2002).

This once more, emphasised their ingenuity in converting a natural asset into a cultural element, conducive to the group's survival. The scenario on Bentinck, also accentuated the fact that as a matter of survival, when modern building technology failed them, Aboriginal people had to employ a traditional survival strategy.

Cecelia Reid, an Aboriginal woman about fifty years old, whose family has a long association with Mornington Island. She acknowledged that the old mission house has been used on numerous occasions, as a refuge, for people who had to evacuate unsafe dwellings.

We all had to move out of our homes. They had to put us all in safe homes. I went from my parent's place, to my aunty's place, and then ended up in the guesthouse. It was really bad (Cecelia Reid, personal communication, 2002).

Cyclone Ted? Struck in 1976, but there was many more in the 1960s. The worst one that struck here was when all these buildings were down, was 'round about "76, December '76. That's the worst one we had here (Edna Hills, personal communication, 2002).

Edna Hills, a Lardil woman in her forties, has lived on Mornington Island most of her adult life. Like most residents her age, she had left the island to work on the mainland when she was younger. Her mother was Margaret Hills, an elder of Mornington, and was one of the few remaining people who, as a child, was a member of the earlier mission dormitory system. She talked about a cyclone that struck Mornington Island when she was a young girl during mission times.

Two dormitories - senior and the junior dormitory. And during that time we were in the dormitory we couldn't get out, you know, playing in the rain because that was the law that we might get wet and we, you know, we was under the missionaries and then we was playing and playing, never think of anything you know, going to happen. And as we were playing there this big cyclone wind came up and he lifted the building off the, off the, what you call it, foundation boy - it was on a block, not on a bricks. And it lifted up and when we saw it, we 
ran up - we ran out - and instead of we running under the house, where them big house is, the mission house, we ran down to the beach at the point boy, at the point. But a older woman said "let us go back around else you might, the wind might throw you into the deep - into the sea with the waves and ah, so we all came back boy, and we ran under that building there, up there - see that old mission house? Yeah. We went there - missionaries was there with us - Reverend Wilson and his family, and we stayed there, and then stayed there overnight, because our dormitory was lifted off the block, and I think we stayed there for the night, and might be a week, and that was all. I wasn't like I am now - I had no breasts, I was a young girl. That was all, boy. But a very serious cyclone it was. Brought down lot of housing on this mission. And that's all I can tell you what had happened while I was in the dormitory and of course I can't remember, they must have replaced, made the young dormitory get back to normal again. Yeah, they built it - and that was all (Margaret Hills, personal communication, 2002).

Literature indicates the event was probably a cyclone that occurred in February 1936 which was recorded by Reverend R.H. Wilson. Wilson reported, "Most of the buildings were demolished and there was a storm surge estimated at 5 foot or so" (Callaghan, 2003, p. 4). Other Aboriginal elders also referred to the dormitory buildings that stood beside the missionary house, which still exists and functions as the island guesthouse. As several dialogues have shown, it is a sturdy structure that has withstood numerous cyclones, so it is understandable that it was used for shelter as Margaret had indicated.

An interesting issue in Margaret's interview, drew out the contrast in Lardil and western law, prevalent in the dormitory system of the era. Margaret remembered that as children, when the storm moved in on the mission, they were not allowed to venture out into the rain, as they would have done before colonisation. The cultural differences were further extended, as she related that when their dormitory succumbed to the cyclone's destructive winds, the panicked children fled to the beach, instead of the missionary's residence, which was still intact. However, after they realised the peril of their action, and at the insistence of an older girl, they did move back to the shelter of the standing mission building. Arguably, the children's action indicated their natural Indigenous instinct, to get away from a dangerous situation to a context more familiar to them, namely the natural environment.

Yeah. Tide came right in boy. People down there - all water came up into them little creeks, and up to this creek boy. And knocked down all of the vegetable trees, our garden, and made our well there - they 
used to pump the water from the well there up to the tank and then and we got salt water in it... (Margaret Hills, personal communication, 2002).

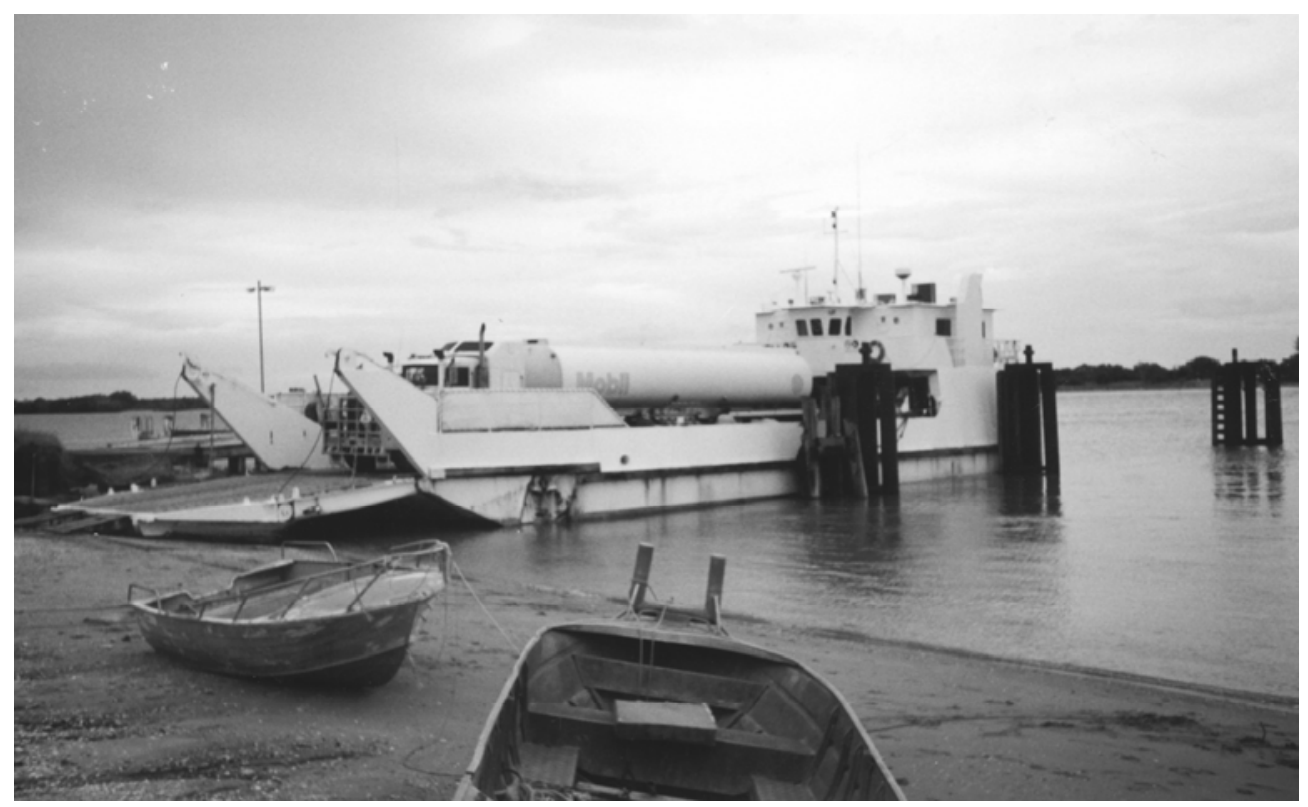

Figure 8.3 The wharf and channel at Gununa, Mornington Island

The creek Margaret referred to was the narrow waterway which ran from the Appel Channel to the east of Gununa, and snaked along the bottom of the town ridge, to the west, where it flowed into a small swamp. The mission garden was situated in the small valley that was alongside the creek, which meant that when there was an unusually high tide, salt water from the channel was forced along the creek, up to the swamp. When this was combined with the heavy rains of a cyclone, the swamp would eventually fill and overflow, and consequently, the creek burst its banks, flooding the garden. The well that provided fresh water for the mission's use was also dug in the valley, so was subjected to inundation by the rain and sea water.

\section{The effects of cyclones}

The devastation caused by Cyclone Ted triggered a number of major changes in the Gununa township. It resulted in the shifting of the old village from the vulnerable beach site on the Appel Channel, to the ridge, where one hundred and twenty new prefabricated homes were erected. The natural landscape was also drastically altered, the most talked about among those who were there, was the spectacular effect on the trees. 
... come direct, straight in, straight in the pocket, full blast! When it hit, he burnt all them trees! - top, with the wind pressure. I don't know what it was, but it just burnt, all that oak tree ay. Threw most of them seeds (oak tree) right up on dry land. Today, you go look there, you see oak trees growing up there right up the coast-inland, right up, up here, where this main highway going! (indicating the road to Birri Lodge, which is to the north of his house). Oak tree seed(s), trees growing, they were flung, taken by that wind (Melville Escott, personal communication, 2002).

...Cyclone Ted was the one that made everything baldy, it took all the leaves, stripped all the leaves off the trees, and you could see for miles, because of the damage (Cecelia Reid, personal communication, 2002).

This appears to be a natural phenomenon remembered by all Lardil people who were there in 1976, when Ted tore across the island landscape. The force of the wind was so fierce, trees were stripped of leaves, and branches were snapped, and in the case of some trees, the bark was ripped completely off the trunks. Similar effects from cyclones have been observed in other parts of northern Australia, such as the Northern Territory (Skertchly \& Skertchly, 2002). From all accounts, the effect was similar in appearance to that of a bushfire, as described by Ossie Escott, when he awoke the morning after the cyclone.

I get up now, and look, next day, it looked like big bushfire been go through, the trees had been burned. Burnt. Had no leaves on them trees eh, you could see right through them (Ossie Escott, personal communication, 2002).

Ossie Escott is the younger brother of Melville, and a long-term resident of Mornington Island. He is in his late forties, and is partner to Alma Moon.

Ossie has worked at various jobs, including time as a crewman on boats, and stock work on the island, and on the mainland. He also had an interesting cyclone experience which is related in detail in the following narrative.

\section{'Good' effects of cyclones}

On occasions after the storm had passed, the men would go down to the beach, and collect seafood that had been washed ashore by rough seas.

They'll find fish, fish in millions! Up along the tide (mark on the beach), where he chuck 'em up.. and where he sort of ease down, and 
go back low (tide). And he look again, they might look-dugong! Still live one. .kicking on the shore-side. Out here, you know, we used to do the same cycle how them old people used to do before - get up and go! After you feel that winds die down, no matter we got fresh beef in the fridge ay, people just want that fresh feed - that dugong or turtle, fish, crab, oyster, and them big prawn too. Big, ah, tiger prawn. They couldn't survive that underwater current. Must've got caught, got drowned and washed up on shore (Melville Escott, personal communication, 2002).

This is one activity that is still carried out, after a cyclone passes, by Mornington Island Lardil people, in much the same manner as their ancestors in times past. They take advantage of a natural event, which on occasions, also creates disastrous consequences. As well as providing necessary rainfall, the rough conditions result in washing seafood up on the shores. It is a positive method integral to their survival, within the context of a potentially dangerous natural phenomenon.

I tell you, when we have real bad cyclones here, fish just get washed up and people go along the beach and they find fish kicking about on the beach. They just go and pick them all up and put them in buckets. They take buckets or they take bags and fill them up with fish (Clara Reid, personal communication, 2002).

Clara Reid explained a food collection method using modern tools to continue a traditional gathering strategy, whereby they collect seafood washed ashore by rough seas, in plastic buckets and bags. Clara is in her late sixties and has a large family on Mornington Island, which includes sons, daughters, and numerous grandchildren. Some of her children work off the island but return for frequent visits. As an elder of the community, Clara had many experiences to relate regarding culture, community, and personal issues.

\section{Laws: old and new}

One point discussed by Clara, and which was prominent in interviews with other elders, was the issue surrounding the many elements of traditional Lardil law, and the Western legal system. Melville also spoke about how strict punishment by traditional Lardil law was, compared to the view of some people of today's leniency of the Western judicial system, when people committed crime in the community.

They knew laws, strict laws - they knew how to abide with it. You break the law, and that's it! You don't get punishment what white 
men give you - punishment today, me and you - that punishment is (was) severe! You know what that severe is? - (long pause) - You get speared! Death penalty! Penalty is death! Me and you get jailed today for that, that penalty is twenty-five years imprisonment (Clara Reid, personal communication, 2002).

The implication was that traditionally, punishment for breaking of laws was so severe, that people, especially the younger generation, were effectively deterred from any wrongdoing. The traditional laws as referred to by the people interviewed, included ordinary, every-day behaviour, as well as the more serious components. According to those who participated in the project, one prominent factor in the breakdown of present Lardil culture, appeared to be the attitude of the younger generation towards their elders.

Clara further reiterated this issue stating that:

In the old days, no children ever over-ruled an old person. If a child was ever caught doing anything naughty, it could be spanked by the aunty, or uncle, or the grandfather. That was the law of the land, of our days. No children were naughty in those old days (Clara Reid, personal communication, 2002).

Traditionally, Lardil Aborigines were taught from a young age, to listen and learn from their elders. As Clara asserted, youngsters who transgressed the law, were punished by their aunt, uncle or grandfather, who in accordance with Lardil tradition, were responsible for overseeing the behaviour of nieces, nephews and grandchildren.

Traditional law also encompassed the relationship between Lardil people and the Mornington Island natural environment (Binnion, 1987; McKnight, 1999). Limited references of traditional Lardil law, indicated that there were rules that involved an association between people and nature that were to be followed, as a matter of survival. According to Lardil legend, the Dreamtime creator responsible for the weather is Dewallewul, who can punish the people by sending a cyclone if laws are broken (Trezise, 1993). In that context, Melville suggested that in the past, because survival knowledge was passed on as Lardil traditional law, it would be accepted, and adhered to unquestioned, by the next generation:

Might be soft, he act strong too, and he gotta be strong - he naked, and he gotta survive to look after his family. He gotta look after his line - family tree. He don't care about his own self, his life is nearly through. But them, them mob, their life is only starting. So he protect(s) them (Melville Escott, personal communication, 2002). 
Melville's statement meant, that the will, and the instinct to survive, were put into practice by his ancestor, to ensure the survival of his younger family, with the premise that they in turn, would carry on the family bloodline. This is in fact, the Lardil practising, "traditional Aboriginal Law and culture, and associated appropriate behaviours for coping with severe weather in tropical monsoon environments" (Skertchly \& Skertchly, 2000, p. 43).

Colonisation has meant that over time that traditional knowledge has been interfered with, resulting in changes, with which the Lardil had to cope. To outsiders, the knowledge and practice of adaptability and resilience, may not be visibly displayed by the Aboriginal residents of Gununa, but it is a key element of their survival.

\section{The effects of Cyclone Tracy, and other cyclones in the region}

There were also tales of the effects of other cyclones felt in the community, especially Tracy, which destroyed much of Darwin in the Northern Territory, on Christmas Eve 1974.

Had that cyclone in '74, we got half of that wind, and half of that tidal wave, sea. Imagine how far it is (from Darwin to Mornington Island)..it's over the west coast-north western coast. I nearly got killed. I nearly got drowned! Well I was working on a boat up at Gove (on the north east of the Northern Territory coast). We (were) supplying petrol to Taiwanese vessels. And when I wanted to come back, the skipper asked me then, he said, if I'd love to spend Christmas with him-in Darwin. I said "No, I'd rather go home to my family", you know? 'Cause something telling me, "Go home, go home and see your family." But I never really thought of dying, or getting sick, or them sort of things. He said, "Alright then, okay son". So he brought me home - brought me out here (pointing towards the western coast of Mornington Island) - low tide, he was gonna throw me up, leave me at that new cemetery - but then, I seen a boat coming out - he my brother-in-law. Yeah, anyway he brought me back here, dropped me..then, coupla weeks after, it was New Year's Eve - or Christmas Eve, it's going into, going into Darwin, they couldn't make it, they couldn't make it. He tried to shelter, he couldn't run, run to no shelter, because there's no shelter there! He was caught! He was caught out in the open, that boat couldn't go any (faster) - only ten knots. That's all he done. I suppose he can go faster that, but, it was only a wooden ship - three masts, sailing - engine and sail. That's fast enough though. Yeah, he got caught out - out in the open - and I been thinking about this a long time. You imagine how all his boat was 
flung from the water - right up, on dry land! About twenty metres. Yeah, I lied down on the bed, and I turned the radio on...Yeah when that ah, I switched that radio on ay, right on time when that news came on, I heard, I heard that Cyclone Tracy struck Darwin. Right on the eve - Christmas eve of "74. And I thought about my mates, I thought of my mates, "I wonder how they got on?" But they rang up to me, they knew that I was on the ship, and they had to contact me. So ah, one of them Tiwi Islands, ay? Melville, I think it was...That ship broke up there, smashed like a match box-impact of that cyclone, it was so severe, that instantly, the skipper and his crew just died (makes a whistling noise), in the blink of an eye! No warning, no warning whatsoever (Melville Escott, personal communication, 2002).

Following Melville's description of the boat, and its duties, a search of literature indicated he was probably talking about the Booya. The Booya was a Dutch-built 35.8 metre, three-masted schooner, which was owned by the Denham Island Transport Company, and sailed frequently between Darwin, Asian ports and other remote Australian ports. The ship was built in 1917, and was probably one of the last of its type still sailing the seas at that time. Records say it had been sailing to Dili when it sank without a trace, during Cyclone Tracy, 24 December 1974, and four men and one woman perished. An article in the Herald Sun, dated November 1, 2003, stated that the wreck of the Booya had been discovered in shallow water in the Darwin Harbour, about five nautical miles off shore. It was believed that the vessel was due to sail from Darwin to Dili on Christmas day, and was carrying cargo, that included fuel and stores.

These facts seem to agree with Melville's description of the boat, "...wooden ship - three masts, sailing - engine and sail", except of course, the Booya had a steel hull. The boat was familiar to people in ports in the Gulf, and western coast of the Cape York Peninsula, up to Thursday Island, and many older residents of Gununa recall hearing about its presence. Melville's brother Ossie, related a story about when he was in Weipa at one time. He mentioned the boat by name, and also referred to its prominent feature, the three masts.

Well, bulla, I was in Weipa - coast in Weipa, me and 'nother island bloke, and this old sailing boat - he had three masts, we call it Booya. Big prawn factory used to be over here (pointing to Denham Island, that was visible across the Appel Channel) used to be doing the prawn season, and things.. I was working in Weipa, that time - the three of us there, and the skipper said, "You boys ready to sail back, but - we have to sail up to Groote Island (sic)", somewhere, you know, before 
we came back to Mornington Island. And that time, the weather wasn't too good, you know? That's when Cyclone Tracy started, you know? Oh, that place been dark (because of cloud cover), three of us, we said, "Oh we'll just go up the pub first, have a few beers". And we thought that you know, it might calm down a bit - but, we didn't really wanna go, you know? But we had something in us, you know? Like something wrong - something telling us. He went (the skipper) So off that old boat went. Skipper said "Oh well, you boys can stay, next time we can pick you up again". (He) went to Groote Island, then he went up to Darwin. That the time Cyclone Tracy...and all them mates mine, that's on the boat, everything was...all gone! Skipper, and the boat.. And we said to ourself, "We could'a been with that other mob!" You know...We felt Cyclone Tracy, you know? Yeah, it was inside...That's my story now - Ossie, Escott. (Ossie Escott, personal communication, 2002).

The premise of Ossie's narrative was that he, and his two crew mates, could have been aboard the Booya on its fateful journey to Darwin. Luck or fate played a major role in why they did not take that voyage. In all likelihood though, it was probably their acquired abilities to read weather conditions, which caused them to forgo the trip. As Ossie expressed, at the time, they knew Cyclone Tracy had formed near Darwin, and the weather conditions over Weipa were unsettled, with heavy cloud cover producing a dark atmosphere. These facts, plus the knowledge that the skipper wanted to travel across the rough, open Gulf waters to Groote Island, was a deciding factor in their staying in port.

It appeared that Ossie and his crew mates adjourned to the local hotel, where they discussed the weather conditions, after which a decision was reached to not board the Booya. According to Ossie's narration, it was their experiences and knowledge of weather conditions with which they were familiar, that ultimately influenced their final decision. On reflection, years later, he surmised it was their weather knowledge, plus a certain spiritual feeling.

Melville also went on to speculate about the effects of Cyclone Tracy. Whether this was based on his personal experience, or information he had picked up from media outlets - television and radio, or perhaps a combination of all three - it is an interesting narrative, nonetheless.

It was about five category - five category cyclone, and I think he wiped, he even wiped aeroplane off the main runaway! Even at the hangar, big jets, tip 'em over! Well that five category, ay, it be around about six or seven - about five - five hundred miles an hour! That's fast! Two hundred is fast enough - two to three and a half - would 
have been three - would have been three hundred and fifty kilometres an hour. How that cyclone lifted everything! Smashed poles - right on the old station, out there bout ten, twenty miles away, iron flew from that main capital of Darwin. Yeah, right out in that ah, mustering camp and all that stations where they used to muster, ten twenty miles away - and that cyclone was severe (Melville Escott, personal communication, 2002).

Melville's estimation of the wind gusts was overstated, but from his perspective, it would have taken winds with that velocity, to cause the type of damage he described. The account of smashed telephone and light poles, and sheets of corrugated iron being found twenty miles away from Darwin, could well have been based on events he witnessed during Cyclone Ted, mentioned earlier. The effects of the winds on Mornington were similar, as he stated that high winds were responsible for seeds from trees on the island coast, being found some distance inland.

\section{Lardil weather signs}

Long before the technology available today, Lardil people relied on nature to tell them about weather patterns. The natural cycles were vital to their existence, because the availability of natural food coincided with the seasons. For the Lardil, the wet season was divided into two periods. Firstly, Mulung was for the period December, January, February (i.e. summer), and secondly, Lee-a-lin for the period March, April, May (i.e. autumn). This period traditionally, due to the rains, meant hard times for people, because food was hard to obtain, and living conditions were uncomfortable. Constant heavy and windy downpours confined families to shelters on the coast, and the inland areas were too wet to hunt for food. The Lardil diet through Mulung, was restricted to parrot-fish and mullet, captured from the reefs and creeks, and wallabies. Lee-a-lin was better, as salmon were in abundance, and other bush foods were in ample supply. Fresh water supplies were plentiful due to storms and the occasional cyclone (Binnion, 1987).

My grandmother used to talk about cyclones. Always talk about big tides associated with cyclones. Big tide, strong winds - how they destroy, bring destruction with them. My mum always seems to know when there's going to be a cyclone. I think it's because of her experience in cyclones and from what she heard from my grandparents. My grandparents said if a cyclone was coming you couldn't run - if you were to run, you would have to run in a zigzag line. She reckon because the winds were so strong, you would get blown away. But I couldn't understand. Maybe she was in that situation where she had to do that. But the tide was always unusually 
high just before a cyclone. No matter how many miles away from Mornington - kilometres away - it could be way up in Nhulunbuy. It could be over in Weipa - we always experience very high tides. We call them king tides. And they more or less - we get the idea there's a low somewhere, you know (Cecelia Reid, personal communication, 2002).

The intimate details of the Mornington Island landscape and the sea, as indicated in Cecelia's statement, were derived from centuries of knowledge about the natural environment, accumulated by the Lardil, which is traditionally passed on to the next generation. The local Indigenous knowledge is learned from individual observations and interpretations, plus the incorporation of traditional beliefs. Thus, Cecelia remembered the advice her grandparents imparted, about how to run if caught in a cyclone, but the observation regarding high tides, and the implications, were derived from her own experiences.

And we noticed too with the weather going hot and cold - going to have a cyclone. And the formations of the clouds. But it's when the clouds start moving and they pretty low and we get the real big king tides and it just gets so unbearably hot. But even before cyclone too, I think - fish - well, sea life - they sensitive to cyclones. Because before J ustin (1997), a day before J ustin, we went fishing in the channel and we just caught salmon, salmon, salmon. They were all hiding out in a jew hole. And we didn't know. But after the cyclone we knew why they were there. Well, another thing too that tells us we may have a cyclone - the sea, the temperature of the sea. It's very hot, really hot. You're pulling fish in and you feel them warm - even bait. And you can tell when a cyclone is approaching too - when going to have a cyclone - the sea turns green (Cecelia Reid, personal communication, 2002).

The natural indicators mentioned by Cecelia were obtained by a process of observing changes in patterns of natural weather cycles. Cecelia knew from experience that when unusually high tides were seen on beaches at Gununa, there was probably a low system somewhere, in the Gulf of Carpentaria region. This is a reliable indicator, because the waters of the Gulf are shallow, and confined between the landmasses of the Cape York Peninsula, and the Northern Territory. When there are major disturbances in the height of tide phases, it is transferred through the sea, to other areas in a rippling effect. Therefore, as Cecelia explained, if a low developed in the waters even at great distances from Mornington Island, it affected the tidal levels at Gununa. 
However, knowing if a cyclone was imminent entailed correlating a number of other natural weather indicators as well as tide levels. This is evident as Cecelia and others pointed out, that it was a combination of elements that forecast the presence of a cyclone. The common factors observed, were uncommon high tides, extremely hot weather, and low heavy clouds. To ascertain when the cyclone approached Mornington Island, Lardil people looked for further natural signs, namely frigate and booby birds flying over Gununa from Rocky and Manowar Islands to the north, and also seagulls from the other coasts, seeking shelter on the town airstrip.

Local elder, Howard 'Bluey', Wilson, said he knew that a:

...cyclone was getting closer when I saw the seagulls all flying in and landing on the airstrip (Howard Wilson, personal communication, 2001).

Howard explained it meant that conditions at sea, and along the coast of the island, were so rough due to the approaching storm, the birds sought shelter inland. From experience, he knew the storm was about one, to two hours away before it reached the Gununa township. Also, when birds referred to locally by the Lardil as manowar, or manohawk, are observed flying over Mornington Island, people know there is either a severe storm or a cyclone approaching. The birds nest on the small, outlying Manowar and Rocky Islands, which are located a short distance to the north of the Mornington Island coast line.

Clara Reid confirmed this with further information regarding Rocky Island:

...you can see it (Rocky Island) sometimes from Birri (Lodge) then, but you go further on, you see straight across. It got no trees - it's just a big, high sand bank It got rocks there, and a big, high sand beach. Very rich country, oysters all around it, and turtle. But seagulls and pelicans and manowar and boobies live on that island. When we have cyclone, those birds come across to Mornington Island side, they stay along our side of the country (Clara Reid, personal communication, 2002).

Every respondent emphatically asserted ocean tides are strong indicators of imminent severe weather conditions. However, it was not any single natural indicator from which they drew conclusions of impending weather.

When this high tide - I know about this high tide - when it's high tide, then you know the cyclone's coming. And we see the booby and manahawk birds flying high. Them birds with bony wings, bent 
wings, they start to come around, and the water get higher (Digger Adams, personal communication, 2002).

Digger Adams, a resident of the Aged Persons Home in Gununa, at the time of interview was very old, stating he was born in 1936, and he provided the information with a degree of pride at being able to remember such things.

Several people told of how past and present Indigenous Mornington Islanders read warnings from nature of impending 'bad weather', a local term applied to severe storms as well as cyclone conditions. According to locals, another reliable natural indicator of impending rain is the flying ant, which is attracted to light sources at night, and comes out in swarms a few days before the event.

\section{Traditional shelters}

Melville Escott described how his Lardil ancestors built shelters for protection from cyclones:

They get that cane grass and they make a big, humpy too - shelter, like a, just like a anthill. But they, yeah create it, and make a big one - well, four or five family(ies) each, they help to create that thing. Might be a big one, you know, a large one to - (accommodate) like four families where it's close to (their) relatives. They get together, they help one another - it's just like them ants you know, how they get prepared waiting for rain? They gotta help one another, yeah, well like that. They get prepared! Preparation ready! Same like that. But them old people used to keep well away from - keep out in the open, or down where - where there's wind-break. Not big tall trees, little scrub - they build that - it on a slantish area, on a hill. So that water don't rise - it runs. Very clever ay?

Smart. How they used to manage, you know? They used to get dry wood, get prepared - break 'em up, stack 'em up inside, and it was a big enough shelter. They have a stack load of wood there - lot of fish, meat, raw food waiting to be cooked, and they cook 'em in there too. They take that stick by that water, where that water not far, so they can keep that clear distance between that rising tide-how far that tide comes, well they know how far the tide come in, they know where to build that thing. They just keep watching that rising tide-current. Yeah, we still do it today, we still, you know...

Another way again how they used to survive, they used to get up on the top of the hill, where there's no trees. If that cyclone coming on the 
north side, they got to go on the south side - where they dig that make a hole. They make a hole and put - make a little frame - and they make a little breathing hole too - to breathe air. But they wait for the right time - like you know? So, he just wait and watch, if it's coming, he know that thing's coming closer he (says) "Alright, time now, get in there", and he put that bark over that hole. They lie down, belly-up, and he cover them with sand. Behind the hill, behind the wind break, that's how they survived. The little air-hole too - but they used to put a rock, put a rock on that air-hole, (they'd sit up?) but they'd breath about that far off that hole (indicating with his hands about thirty centimetres), they can't breathe that far (indicating closer to hole) because they might be breathing grit and stuff, you know, coming in - they keep it about that far away - big enough hole. They get that bark, paper-bark, sticks too, just put the sticks up there on top, put the paper-bark on top, put the hole on that side - they lie down this side they just cover it then, with heavy sand. The weight, feel that sand heavy, on that bark there. When that cyclone, he over, they come out dry one (Melville Escott, personal communication, 2002).

The Kaiadilt people from Bentinck Island also had unique traditional shelters. Bentinck Island is south of Mornington Island, and is the second largest island in the Wellesley Island group. In missionary times, the small population of Kaiadilt was encouraged to move to Mornington Island, where they tried to keep their separate identity, as well as inter-marrying with the Lardil. In recent years, Kaiadilt descendents have moved back to Bentinck Island and established a small modern village.

Old Bentinck Island people, they had this special grass, for little humpies. Luckily we had them old people that been grow up there. My cousin, and my brother-in-law now, we sitting down, watching now - soon as he been stop now (cyclone passed). Them boys had to go and break them big grass, but we never hide, we been make, like, little breaks. And we all sit down in that (Alma Moon, personal communication, 2002)

Like a wungura (small shelter). Little grass-little thing! Cyclone lifted the whole building! And that grass (shelter), it hold all them... (Ossie Escott, personal communication, 2002).

Melville Escott described the construction of the Kaiadilt shelters in more detail. 
In them days they had no houses then.. no houses. Well, I was told by an old person, old Indigenous person from Bentinck (Island) - well I'm married to a Bentinck girl - she come from here, she born here, but her mother from Bentinck. And ah, I was told by these old Indigenous people, how they survived, and I, you know, I think... I used to think - how they used to survive? You know? No cave there! Well they got here and there a bit of cave, you know, but - you gotta go down (to) the water. The, ah, tidal area - where there's that, where (there is) rock. Where that wave he create the cave, to make a bit of a shelter...wave created that shelter. And every time it's cyclone season, that tide he come up very high - and he cover that shelter."

But how, one old fella told me, how they used to survive too, they used to get this ah, cane grass - they used to get this cane grass, before, when, this sort of time now - they feel it, they feel it in them that there (is) gonna be a cyclone somewhere or (a) low. They get prepared, they get that, they get a double - they double that cane grass, and over Bentinck Island, that cane grass over there, (it's) ohh, thick, thick, thick! especially along the creek. Yeah they got this grass, now, this cane grass, they get it woven - I don't know how they do it - but they get it and double it, they double that grass. When they finish that, they make a sort of little window, to cover that too. They make it a double, so when that wind blow, they put that paperbark in between - like that, you know, that have it very closed - like two inches apart, or three - three inches apart. So that thin piece of bark just fit - thick piece of bark just fit in the middle, so when that wind blow, straight through that point, it won't move, itll just lock on. Yeah with the pressure of the inside of the...yeah, you know how an aeroplane fly ay? You'l be blown out if that ...if there's an opening on the side - suction, yeah. Well they make a little fire, to cook, and to keep warm too. And inside of that shelter, there they just sleep... sleep in peace, good, dry. But mainly old people you know, who really want to get out there and hunt, 'specially after that cyclone (is) finished-when he passed through (Melville Escott, personal communication, 2002).

Melville Escott expressed his thoughts regarding different survival methods of Aboriginal groups of the region, and elsewhere in Australia.

Yeah, you go to another place, he the same, but he different again too. All tribes, they got different way of surviving cyclones. Alright the desert people, I don't know how they... oh there...they already got it's created...caves and that. Not like we mob, we gotta build to survive, stay alive, build stronger things to stay alive. And then they 
get that grass, that cane - grass, good thing that was - very handy one ay? Yeah... (Melville Escott, personal communication, 2002).

These thoughts were given as a result of Melville having long, and numerous connections with Aboriginal groups from the Northern Territory, and the Queensland coast. Dance groups from Aboriginal communities from these areas frequently gather on Mornington Island for traditional dance festivals. During these events people renew acquaintances with relatives, as well as learn different dance methods, and participate in a general exchange of knowledge.

\section{Houses in Gununa today}

Lance Gavenor had a different experience of cyclones, saying he had not been in Gununa when severe Cyclone Ted had struck the township, in 1976:

Cyclones? Oh, only two cyclones I been hit, in this (place) or three... about three I think, three cyclones. There's one cyclone I wasn't here, ah, 1976, I was in Sydney then. Cyclone Ted, yeah, I wasn't here. About three, I was here. Ah, no nothing, nothing, no one lost their lives, but ah, few buildings got a bit bumped around, shaked up, (laughs softly) ... yeah."

During those storms, Lance sheltered in relative's homes, which were modern cement block dwellings:

Oh, one of them, old type...them brick house, now. Yeah pretty safe, in a brick house, oh yeah, gotta be safe in a brick house. Corrugated roof-fly everywhere.

Like most present Gununa residents, Lance intimated the 'safe' feeling that a solid building constructed of brick walls, provided to the people. When he was younger, there were different types of buildings in which he could remember Aboriginal families residing.

Yeah, yeah, they used to have them old corrugated iron diners, water front, there, they had a big village there, they used to have ground huts, you know, to live in, sleep, houses with corrugated iron around them, that's all they had.

These homes were constructed down in the old village area along the Appel Channel shore. According to Lance, they were similar to the type of buildings they had when Cyclone Ted impacted in 1976. 
Yeah, that's when Ted knocked the whole village down, took 'em all (the houses). Some of these new homes, they still stood up there, some of them fell down,... like old Clara Reid's, them type of buildings...

See, like what Anthony Jingles got, old mum and dad had one like that, but this only the front iron part went, and the two bedrooms left and the shower. That's all lost - that's when I came back from Sydney, then, that was 1976 (Lance Gavenor, personal communication, 2003).

The new homes he referred to were the pre-fabricated houses built in early 1970. They were the first residences that were erected on stilts, and contained several rooms. Electricity was also connected, and the new houses also featured kitchens and electric stoves (Binnion, 1987).

Lance described where he lived now, and commented it was not a safe place to be in if a cyclone struck the island:

Well I live in a house, yeah, in a house, family, relative's home. It's a little, low, upstairs one, it's on the ridge up there...Yeah, one behind the power station there, fibro, fibro house.

The house Lance indicated was one of the many that were probably built in the late 1970s, after Cyclone Ted, and were constructed of fibro walls and sat on metre-high stumps. Most of these dwellings were showing wear from years of exposure to general weather conditions, with the outside walls, roofs and wooden materials, in an advanced stage of dilapidation.

I think he bit too old, now, I don't think it'd be safe enough. Yeah, I think it might.. see most the time, most people move out of there, some go to neighbours, or police station. I don't think that house that I'm staying with a relative, I don't think it'd be safe, not now. (It was) ...built some time ago, now. Yeah, I'd rather go to a brick home. Another family's home-relatives (Lance Gavenor, personal communication, 2003).

\section{Communications}

While the communications system for the island is sufficient, when there are severe storms in the area, television and radio signals are blacked out, as observed by Cecelia Reid:

Yeah - go off, yeah...the antenna. We just get cut off. So we just cut it off, turn the TV off. The TV breaks up - picture breaks up. I don't know why, but that happens to every TV on the island when there's a cyclone. Yeah, it would be nice to know where the cyclone is. But you 
can virtually watch it for the first - but once it's almost here on us you can't watch it. On TV they just show you a map of the Gulf, that's all. But you can't see the cyclone. I suppose you could watch it from elsewhere you know, outside of Mornington Island. It was - we were getting it from the satellite, our reports, because we weren't getting much from the TV channels. We were trying and trying. Only ABC (Australian Broadcasting Commission) was pretty good - the next day we heard about Mornington being hit by a cyclone (Cecelia Reid, personal communication, 2002).

This flaw in the communication system of Mornington Island has the potential for serious consequences. While early television and radio reception indicates to residents where a cyclone is located, and when it will probably impact, as it nears Gununa, these communication lifelines are severed. During this blackout, the cyclone can change course, or more seriously, intensify.

The Lardil people possess knowledge about their natural environment, and the weather of their region, which is a result of thousands of years, residing in their particular surroundings. The stories recited by the people, indicate that knowledge of survival has been maintained, though both traditional strategies, and Lardil lifestyle which have been adjusted in relation to time, and Western colonisation. That is, the residents have had to adapt to an alien social culture imposed on their society, as well as keeping traditional methods of survival relevant, within the structure of their ever-changing culture. The information from the story-tellers, regarding these subjects, demonstrated that this knowledge was still passed on through generations.

Clearly, Gununa long-term residents like Cecelia, have had many experiences with cyclones, and the associated effects. From their accumulated experience, these residents know that every wet season, there is a high probability of at least one cyclone hitting the island, or forming in the Gulf of Carpentaria region. Cecelia pointed out, that it is seldom the island that comes under siege from more than one cyclone in a year, although, that can also happen. She also stated that Gununa residents do not sit around during the monsoon period, worrying if a cyclone is going to come; it is simply not a priority. However, when there was a low system, or cyclone detected in the Gulf region, home-owners began pre-cyclone preparations. The cyclones that have passed over Mornington Island, in the last few years, have not posed any major problems for island residents, which prompted Cecelia's vow that she would remain on the island, no matter how strong a cyclone may be. Because of its natural land barriers, any major disturbances to the seawaters in the Gulf region, brought about by a cyclone, affects areas within it, including Mornington Island. To most of the Lardil inhabitants on 
Mornington Island, the place is their home in every sense of the word. Nearly all of the Aboriginal people over forty, who have been born and raised on the island, as they matured, have been taught essential traditional Lardil knowledge. Weather knowledge is a vital factor in their lifestyle, so elders tutored youngsters in reading various natural signs, which indicated changes in the weather pattern.

Yeah, he got TV there at the house...used to have radio, but they bust that radio up, yeah, young children, teenagers. Yeah, still got the TV. That's a good thing, that, look the news, and what's happening round the world. Yeah, watch the weather, or you can do that too when there's cyclone around, you know? (Cecelia Reid, personal communication, 2002).

When conducting interviews and talking with Indigenous town residents in general conversation, there was a consensus that the weather maps shown on television weather broadcasts, were hard to understand, particularly synoptic charts. Although, like most of the Australian population, Gununa residents find stylised pictures of clouds, rain and cyclones depicted on television reports easy to grasp, they do not have a functional understanding of the lines, arrows and other characters featured in synoptic charts.

Oh, yeah, they hard (to understand)..see most people don't know about that...(Lance Gavenor, personal communication,2002).

Cecelia Reid spoke about cyclone preparations:

Yeah. The CDEP boys go around or men in the Air Sea Rescue, they get around and they pick up all the things that are possible missiles and put them away and people batten down their boats. Everything sort of gets looked into just prior to the cyclone. So everyone's rather busy and people - the shop is - the shop caters too because it stays open and it even allows the people to get credit. Some people may not have food so they allow for them to get food and things like torches and candles. Get them because most of the time cyclones usually hit at night and everything else necessary, you know - like water. I always put a lot of water aside - 2 or 3 buckets of water. Ready for the cyclone because we know when the power goes off you have to - the water goes off. But this time, this last cyclone just this year, we didn't need to because it was only a small cyclone - Category 1 . I think it was a Category 1 - it could have been a Category 2, but it wasn't that extensive. Yeah it just went past - and we still had the lights. We still had power on. 
Cecelia stated some people would stay on the island, even if asked to evacuate in times of crisis, preferring to remain and look after their homes, and possessions:

No. They won't. You won't move them. They'd stay. They wanted to send people off the island after Cyclone Ted because there was no water. Something like that. Or the damage that was done to the homes - homes were flattened - but they would not move. No, they love Mornington too much."

On refuge places in times of cyclones:

Yeah there's safe places. People go to the hospital, it's good to go to the hospital because, well they're prepared too, you've got doctors and nurses on hand. You got - even if there was a blackout they have their own generator to keep the hospital going, you know. So that's one good place to go. Police station - you can go and wait in the cells. But I don't think I'd want to do that. And they build houses today too, to, for cyclones. Yeah, ever since Ted, they've been building homes that suit cyclonic weather."

Referring to the guesthouse, Cecelia said:

Even this one (the mission house) was built stronger. She had a really - you go underneath this place and you look at how they've screwed on things underneath and the timbers are hard - you know, very thick timbers. Yeah. And the roof. Cyclone Ted took a bit of roof off, but they put that back on and it hasn't been moved since. Since Cyclone Ted. So the sheets are stable. I'd rather be here than anywhere else. I think this is the strongest building on the island, this house. I think this is the place I'd want to be. Guest house. Yeah, we get frightened. Mainly because of the wind that comes with it. The gale force winds - and you don't want to be caught in a house where suddenly the roof goes off - iron lifts off - and you're standing there, or sitting there, and you don't know what to do next. Because if that's happening you couldn't possibly go out in the cyclone then. Be far too dangerous for flying objects, you know. Because that's what happened I think in Darwin when Tracey hit. People weren't prepared for it and that's what - that's our greatest fear because we learnt from what happened to Tracey - so we learnt to go out and find a safe place before it happened. And everything was in order for Cyclone Ted. People moved around, like, really helping everybody to get out of their hands if they didn't feel their homes were safe enough and they were taken to safe places. All prepared and bedded down 
before the cyclone hit. We were all ready for it - because we knew if we weren't ready, we might get caught up like those ones did in Darwin. Yeah all this area down here was flooded - salt and fresh water mixed. Well, as soon as the cyclone is over everything's sweet. The water just drops. The water inside just goes straight out into the ocean. But we've had weather in the past - growing up as a child, I've seen weather where we've had king tides and no cyclones, but we used to live down in the old area, the old village. And we used to come across, and just - see the ridge running along that way, high ride, and this flat area - that used to be full of water. Yeah. And we used to cross knee deep, as adults, knee deep. And us kids, it used to be up to our waist. Just to get across to this side. Not so much for schooling, but to do shopping. Yeah there were bad tides in those days. I don't see that tide anymore, only when there's a cyclone looming (Cecelia Reid, personal communication, 2002).

Cecelia talked about the general attitude of the Indigenous people on Mornington, regarding cyclones:

Yeah, I stay for cyclone any day. Once a year, yeah. You're lucky to get a second cyclone. It may just come by, or you hear reports of a cyclone approach. But we rarely get two in one year. A couple of years - I think a couple of times we come close to having two in a year. People sort of just go about their own business until it happens and then they get ready, you know, but they don't look in anticipation - "I wonder if we're going to get a cyclone?" you know. They don't look forward to it, they just accept it when it comes. And it always starts with a low pressure.

This last Cyclone Bernie - Wednesday night, we were getting horrific winds coming from that direction and it was supposed to be up this way. We couldn't understand. That's why I moved from the back rooms to this side where Rachel is because the wind was just coming through to the toilet and bathroom and we were in and out and everything was just wet in my room, so we moved around here. And it was Thursday night when it was supposed to have hit and we didn't get much out of it. You could hear the wind shaking the trees behind us here. Horrific. We didn't have to move out of my back room. We went back into it and it was quite comfortable. And the wind was coming from this direction then, the actual direction that the cyclone was supposed to be in. Yeah, it was strange you know. Mum said "Well the cyclone's on us now", because the wind was very strong. Very gusty winds. Made those poor old trees - gave them something to shake for. But the next night when we were expecting the cyclone- 
I think we may have gotten a bit during the day, but that night it settled down - was good. Cyclone was over - the next stage. The water still hasn't quite cleared up... (Cecelia Reid, personal communication, 2002).

The cyclone Cecelia referred to, Bernie, was a category 2 cyclone, which passed to the north of Mornington Island. Consequently, the island was battered with strong winds and heavy rainfall from the storm, for several days. The unpredictability of nature was emphasised, even to experienced individuals such as Cecelia and her family. During the event, in relation to the position of the storm, they were expecting strong wind gusts from one direction, but were surprised when the building was pummelled from the other side. At the time of the interview, Cecelia noted that water in the Appel Channel was still murky, as a result of the rough sea currents churning up the sand of the waterway.

\section{Lardil resilience}

The Lardil of Mornington Island have not only survived the invasion of their land and world by Western culture, they have managed to maintain and rebuild elements of traditional culture, which was destroyed during the upheaval of change. Although the Lardil culture now present in the Gununa township on Mornington Island is not the same as their forefathers knew, it is nonetheless distinctly Lardil. Many traces of the traditional features can be observed in the dances, craft making, and the Lardil language that has been preserved by elders, teaching the young and others who want to learn. Resilience has been a major factor in the evolution of Lardil culture, and linked to that is their environmental and weather knowledge.

The Lardil's traditional ability to adjust to changes was developed as a survival strategy, which they implemented to cope with seasonal environmental and weather conditions. Over generations, they learned and modified methods on how to live with normal weather seasons as well as the extremes, which on occasions affected the island with sweltering summers and bitterly cold winters. Particularly strong cyclones wreaked devastation on the Mornington Island natural landscape, and put the lives of the Lardil inhabitants at high risk to injury and death.

When the missionaries arrived, the Lardil utilised their traditionally acquired skills of adjusting to different situations, to understand and devise a method to cope with the alien Western culture imposed upon them. This was an important phase in Lardil history, because it was at this point that development of a new form of Lardil resilience emerged. They constructed a system to contend with changes to their lifestyle. The prime instigation of major change to their way of life was the forced placing of their children into 
dormitories, and the consequent moving of Lardil families to the mission area, to be near them. Ultimately, this action brought together four separate groups that usually did not associate with each other, unless it was necessary. Prior to the mission period, encounters between clans were brief, and were for trading resources, marriages, or seeking permission to enter another's homeland. The act of having their young taken way had dramatic ramifications on a personal level for families, and for the clans, because it took away the next generation, which was the essential resource for their continual existence. Elements of resilience and adaptability were forged as parents dealt with their personal losses. The imposed situation made the Lardil face problems they had not experienced before, so they had to develop ways to manage. It was a unique strategy constructed by the Mornington Island Aboriginal inhabitants, as they received no guidance or assistance from elsewhere about how to cope with the foreign changes. Settling in a cluster of camps near the mission ground forced the groups to soon learn how to associate and cooperate with people from other groups outside their own. This process entailed adjustments to individual and group behavioural patterns, which the makeshift settlement needed to operate efficiently as a community.

The Lardil developed their form of resilience by drawing upon internal resources and competencies, from within family and tribal groups to manage the demands, challenges, and changes, which they encountered. This highlighted the capacity of the traditional Lardil system to maintain its integrity, and the relationships and balance between elements in the presence of significant disturbances.

In communities like those on Mornington Island, that are vulnerable to disruptive and destructive natural hazard activity, which temporarily incapacitate institutional resources, a focus on individual resilience and adjustment, is important. When such a disruption occurs, primarily it is individuals and families who will be responsible for their own safety and well-being until institutional resources recover. 
9

\section{Fire risk in Aboriginal peri-urban landscapes in northern Australia: Case studies from western Cape York Peninsula}

\section{Jim Monaghan}

This chapter focuses on characterisation of the peri-urban areas of remote Aboriginal communities in northern Australia; fire behaviour and the fire risks associated with Aboriginal peri-urban landscapes; and the sociopolitical and infrastructural aspects of remote Aboriginal communities that are relevant to fire hazard management.

In particular, it focuses on Pormpuraaw and Kowanyama as these towns have been a subject of research by the author for more than 12 years; more than five years of this time having been spent living and working in both communities (Figure 9.1).

The three main forms of Aboriginal settlement in rural northern Australia are Aboriginal towns, town camps, and Aboriginal communities.

Aboriginal towns include places such as Fitzroy Crossing in Western Australia; Borroloola in the Northern Territory; and Coen, Normanton and Chillagoe in northern Queensland. They are small towns with populations of no more than 2,000 of whom the majority are Aborigines, and their economies are based largely on welfare payments.

Town camps are features of the larger Northern Territory towns of Darwin and Alice Springs; their residents are people from outlying Aboriginal communities, and they come and go on an intermittent basis. Some residents are people who have been left stranded in town after hospital treatment or after having completed custodial sentences, others have been ostracised from their communities, and others are drug and alcohol dependant people. Some camps are permanent and have their own services. Temporary 'drinking' camps arise in parks and other public urban spaces in Cairns and Townsville in North Queensland. 
Aboriginal communities are settlements that commenced as church missions in the latter nineteenth and early twentieth century. The main reason for their establishment was concern about the effects of the pastoral, mining and fishing industries on the survival and well being of Aboriginal people in the north (Kidd, 1997; Loos, 1982). The population of these settlements is largely of traditional owners of the country in which the community is located, and also of 'historical' or 'diaspora' people who have been relocated, mostly under duress, to these settlements by the implementation of Queensland Government policy throughout the twentieth century.

Historically people may assert interests in 'community' country, even though they have no traditional affiliation to it, which are based on the precedent of their use of the country in recent generations and on the contingencies of State government legislation in the 1970s and 1980s which emphasised community land as a kind of generic 'Aboriginal' land rather than a domain which is subject to the traditional protocols of land allocation practice that are based on clan and kin affiliation. The influence of 'historical' people in community political life and community land management issues is greater on the east coast of Queensland in Aboriginal communities such as Hope Vale, Yarrabah, Palm Island and Woorabindah; their influence in the more remote areas of south-western Cape York Peninsula in communities such as Kowanyama, Pormpuraaw or Aurukun is negligible.

The larger missions in Queensland received Deed of Grant in Trust' (DOGIT) tenure from the State government in 1968 and most of these areas came under State administration at about that time. There are 15 DOGIT communities in mainland Queensland whose occupants, other than some Council or Shire staff and service providers such as nurses; teachers or police, are entirely Aboriginal communities. The Queensland Government transferred trusteeship of the DOGIT tenure to locally elected Community Councils in 1987. The Aboriginal Communities (J ustice and Land Matters) Act 1984 (Queensland Government, 1984; previously the Community Services (Aboriginal) Act 1984) defines the roles and responsibilities of the Community Council and its powers to create byelaws. 


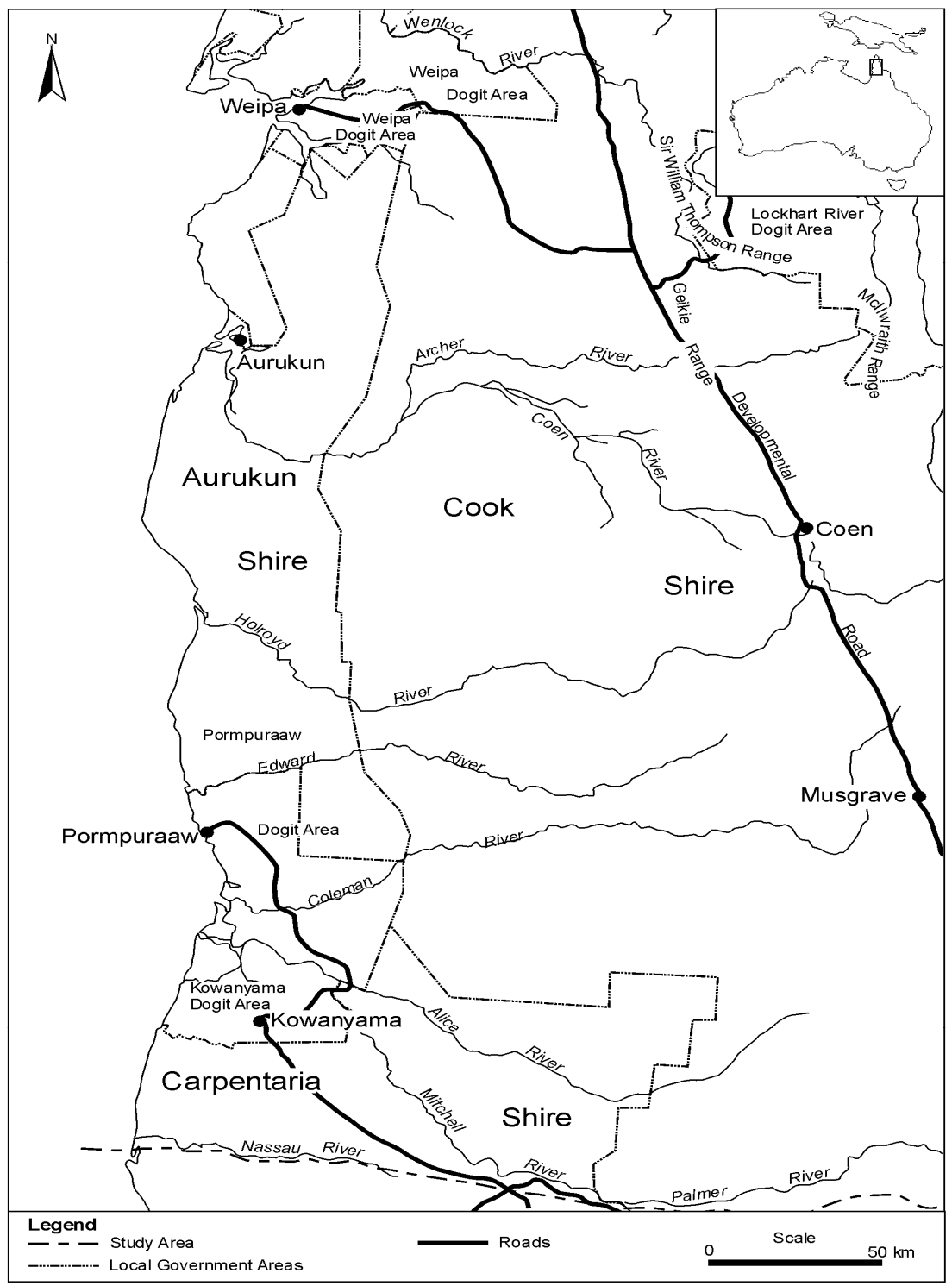

Figure 9.1

Western Cape York Peninsula

Source: Connell Wagner, 1989

The Queensland Department of Communities (previously the Department of Family and Community Services) audits council finances each year. Each council is also a member of the Queensland Aboriginal Coordinating Council (ACC). The ACC comprises representatives of all of the Aboriginal DOGIT communities in the State and is a forum within which the Queensland government develops policy for these communities. There are also 18 Torres Strait Islander DOGIT communities which are served by another 
Coordinating Council. The Community Council comprises seven members who are elected every three years. They are served by a clerk who is also chief executive officer with a staff of about 30 people who provide financial administration, parks and environmental health, and building and engineering services that are typical of a local government authority. Unlike local government authorities elsewhere in Queensland, DOGIT councils do not have any legal obligation to the requirements of the Integrated Planning Act 1997 (Queensland Government, 1997) and hence do not have any formal planning function to deal with infrastructure, environment, or land use planning issues (Monaghan \& Taylor, 1993).

\section{The geography of Aboriginal peri-urban landscapes}

Many DOGIT communities are experiencing considerable development of their hinterland since the Aboriginal Land Act 1991 (Queensland Government, 1991), the Native Title Act 1993 and the Native Title Amendment Act 1998 (Commonwealth of Australia; 1993, 1998) have provided mechanisms for traditional owners to make either land or native title claims to their traditional country, and are developing peri-urban characteristics. Some townships are developing as centres around which a constellation of residential, smallholding and rural enterprise settlements are growing with the township providing retail store, fuel, and police, health and education services. The geography of Aboriginal peri-urban areas is determined by a number of factors including historical land use trends and the location of the township in relation to the traditional country of origin of its inhabitants and the jural and proximal entitlements (Sutton, 1998) that are asserted by local people to urban hinterland country (Monaghan, 2005).

\section{Historical land use trends in Aboriginal northern Australia}

Most of northern Australia has a highly seasonal environment with marked wet and dry seasons. Prior to European colonisation, Aboriginal people lived a nomadic existence based on movement that followed socially and environmentally prescribed routes around the wet and dry season landscapes. The social organisation of these routes was based on primary and secondary rights of ownership or land use under the 'clan estate' and 'range' systems of socio-spatial organisation respectively (Stanner, 1965). Each person had a distinct suite of rights of ownership or access to the natural and spiritual resources of particular tracts of landscape depending on their status within the local kinship and clan totemic systems that determine the distribution of primary and secondary rights. Primary or clan affiliation rights are based on patrilineal descent systems and embody notions of land ownership. Secondary rights are kinship based and relate to rights of natural resource use (Stanner, 1965). 
With the arrival of European pastoralists and missionaries into Aboriginal country in the latter nineteenth century and early years of the twentieth century, a process of 'centralisation' took place with the movement of Aboriginal people into the missions or cattle stations that were established in their country. This led to the development of a set of socio-spatial relations amongst Aboriginal people which was based on whether their traditional country was 'inside' or 'outside' the newly established settlements (Anderson, 1988; Freier, 1999; Gribble, 1933; Monaghan, 2003a; Smith, 2000; Strang, 1994). Terms such as 'myalls', 'station blacks' and 'mission blacks' were used to refer to Aboriginal people on the basis of their origins and locations (Monaghan, 2005). These features are further reflected in the spatial and social organisation of households and neighbourhoods in Kowanyama and Pormpuraaw (Taylor, 1979; Monaghan, 2003a, 2005).

Access to traditional country from the mission settlement was at least allowed and in many cases was encouraged by church missions which were often not in the position to be able to supply their residents with food rations because of their poor financial circumstances: hunting and gathering activities continued to be an important form of subsistence for mission residents (Kidd, 1997; Taylor, 1984).

The years of Queensland State administration, from the mid-1960s to the latter 1980s, were characterised by a policy of 'assimilation' and a more enforced centralisation of what were now called communities, following the Aborigines and Torres Strait Islanders (Land Holding) Act 1985 (Queensland Government, 1985); and land use and access to traditional country was actively discouraged by State administration officers (Kidd, 1997). This prohibition was less so in the more remote communities such as Pormpuraaw and Kowanyama in western Cape York Peninsula where the distance from Brisbane led to the development of a more tolerant relationship between local people and the government officers who superintended their affairs (Monaghan, 2005). For instance, 'holidays' in the dry season landscape were still common in Pormpuraaw throughout the 1970s and 1980s with families living in temporary camps out in the bush for weeks on end (Taylor, 1984). Nonetheless, the Uniting Church was removed by the Queensland Government from their management of the Aurukun and Mornington Island communities in 1978 because of their active support for local groups who were setting up outstations in their traditional country (Kidd, 1997).

DOGIT communities became autonomous with the transfer of DOGIT title from the trusteeship of the State to that of locally elected community councils in 1987. The Aboriginal Land Act 1991 (Queensland Government, 
1991), the Native Title Act 1993 and the Native Title Amendment Act 1998 (Commonwealth of Australia; 1993, 1998) have accelerated the 'return to country' movement which had gathered momentum through the latter 1980s and early 1990s. There are 13 outstations that have been established in Pormpuraaw since 1989; and 22 that have been set up in Kowanyama since 1997. Outstations are the main features of the peri-urban landscape, which are now emerging around Aboriginal communities; they are small settlements that are located in the traditional country of their residents and are mainly occupied in the dry season, which is also the time of the greatest fire risk in the landscape.

\section{Structural features of Aboriginal peri-urban landscapes}

The main structural features of Aboriginal peri-urban landscapes are the immediate town hinterland area, dinner camps, camp sites and outstations.

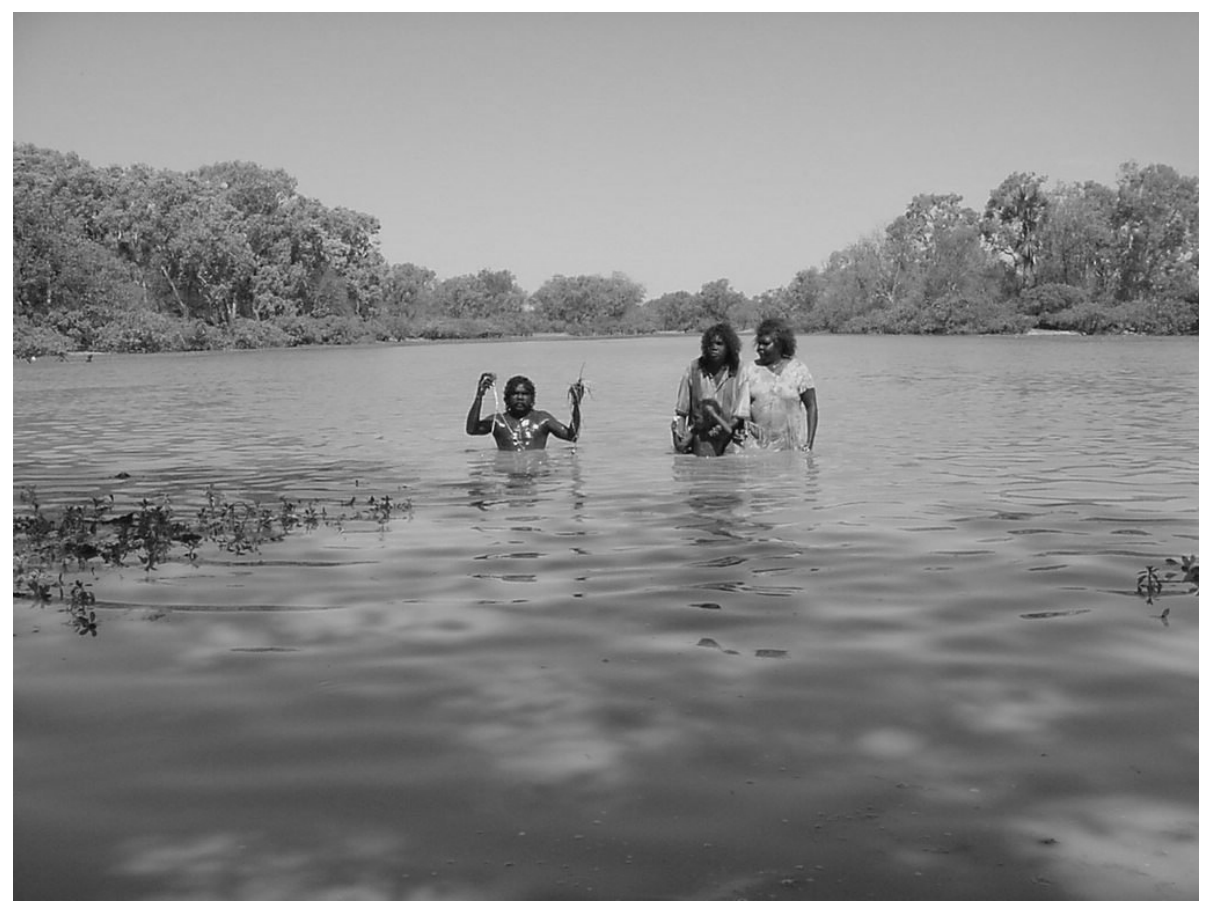

Figure 9.2 Magkara Lagoon is a popular dry season fishing place in the Kowanyama hinterland Source: Kowanyama Collection 


\section{Town and hinterland}

The hinterland is that tract of landscape around the township that people can access year round without the need for a motor vehicle. It is the area where people will go to hunt or to forage for fruits and bird eggs; in many respects it is the community larder' and an important source of protein which is often expensive to purchase at the community store or which might be in short supply in the wet season. It is also a recreational area where families will camp out for a night or for a weekend. With an extensive wet season the hinterland is inevitably smaller than in the dry season and extends over the area where water is shallow enough for people to walk or wade out to at that time of the year.

\section{Dinner camps}

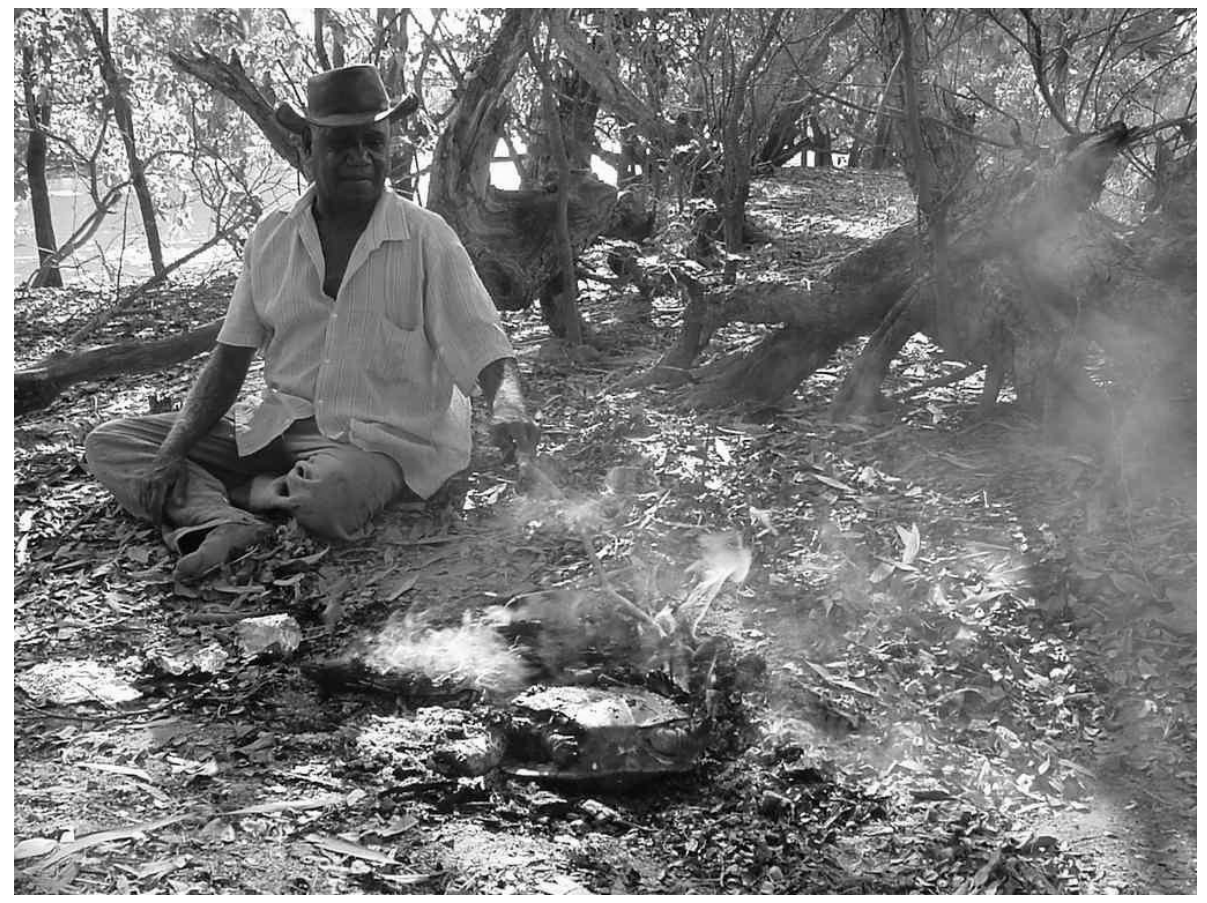

Figure 9.3 Open fire cooking Source: Kowanyama Collection

Dinner camps are places where people will stop and cook their catch when they have been out on fishing or hunting trips (Figures 9.3 and 9.4). They are most frequently found near shady areas or rivers but are found throughout the landscape. They usually comprise a kup murri' cooking pit which is up to $1.5 \mathrm{~m}$ long along the main axis and about $0.50-0.75 \mathrm{~m}$ deep. A fire is lit to make coals and these are placed in the bottom of the pit and the food placed 
on top. In turn, the food is covered with either pandanus leaf or melaleuca bark, or sheets of corrugated iron; and earth placed on top of this covering. Food cooks very quickly in these ground ovens and a dinner camp stop where food is cooked, consumed, digested and the camp remains then cleared away is usually of no more than three or four hours duration. Despite their transitory nature, dinner camps may be longstanding features in some places because of the local availability of cooking materials, or the proximity of good fishing opportunities.

Figure 9.3 shows Edmund Eric, a Kokoberra Elder, cooking a turtle at an open fire and Figure 9.4 shows Yvonne Jimmy and Ezra Michael, who are Kokomunjen [Yir Yoront] elders, ensuring that a kup murri pit has been completely extinguished.

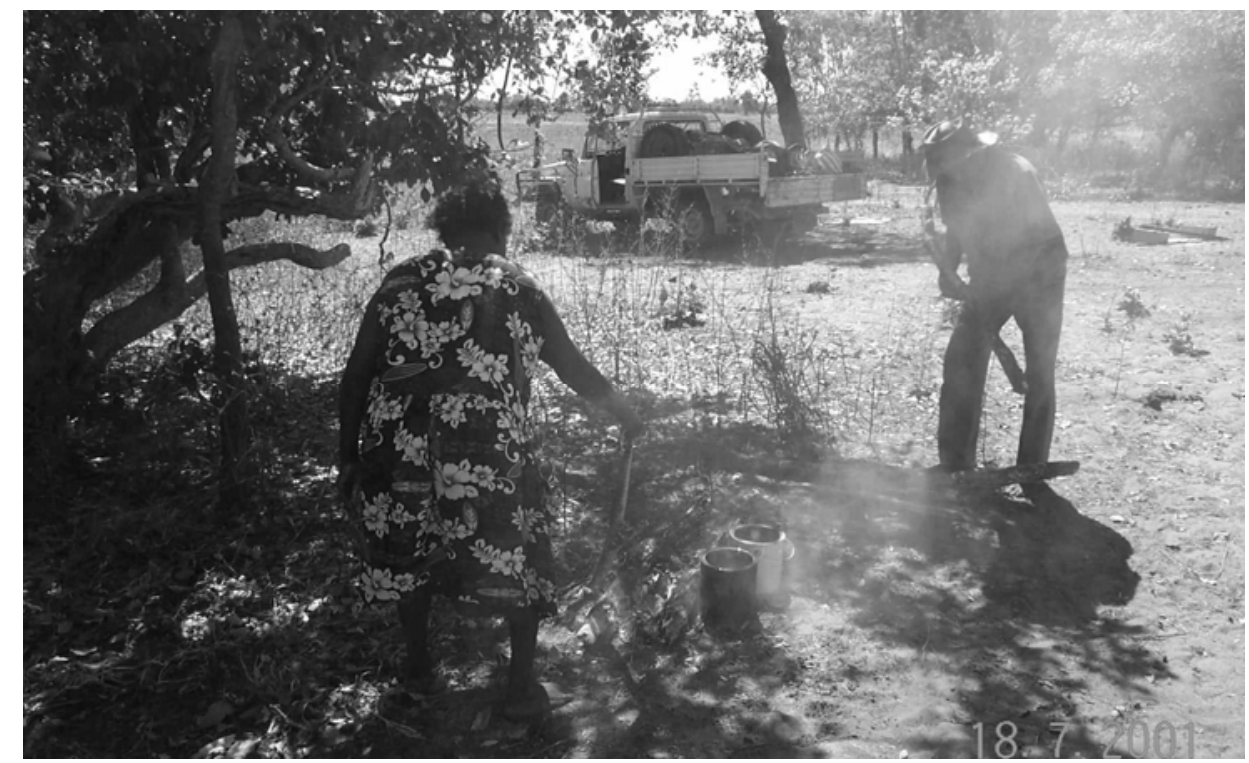

Figure 9.4 Tending to a kup murri pit Source: Kowanyama Collection

\section{Campsites}

Campsites are found throughout the dry season landscape usually at locations where cattle infrastructure affords shelter and at traditional places which form the core of traditional homeland country (Figures 9.5 and 9.6). Many are in abandoned cattle yards where fencing still exists or timber is available from derelict yard buildings, or they are adjacent to lagoons. They usually comprise shelters constructed from 'star pickets' or fencing posts and blue tarpaulin, with bed frames or breeze-block bases and old sink units supported by timber frames providing the furniture (Monaghan, 2005). 


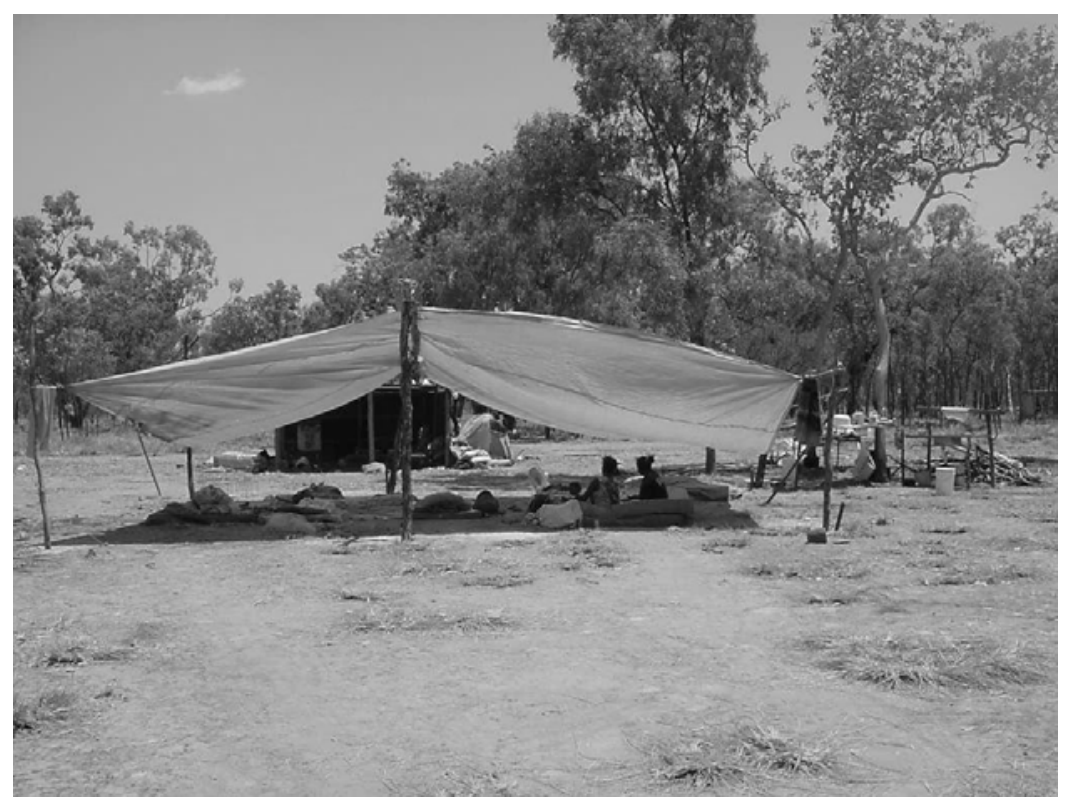

Figure 9.5 A dry season camp site Source: Kowanyama Collection

Families will holiday at campsites for many weeks on end. Children and old people are the main occupants during the week as many working-age adults are at work in the township and they join their families at the weekend. Truancy levels at community schools are very high in the dry season. Some campsites are considered community places because of their longstanding and school camps are held at them during National Aboriginal and Islanders Day Observance Committee (NAIDOC) week. There are, for instance at Kowanyama, four or five nodal campsites each of which, because of their location, has a distinct tribal or language group association and school camps are held at each of these sites for children from that respective background. Other campsites, which are usually close to town, are occupied by families who have camped there for many years, even though they have little traditional association with the campsite, they may be given permission to have their own camp site because their own traditional country is a long distance away. 


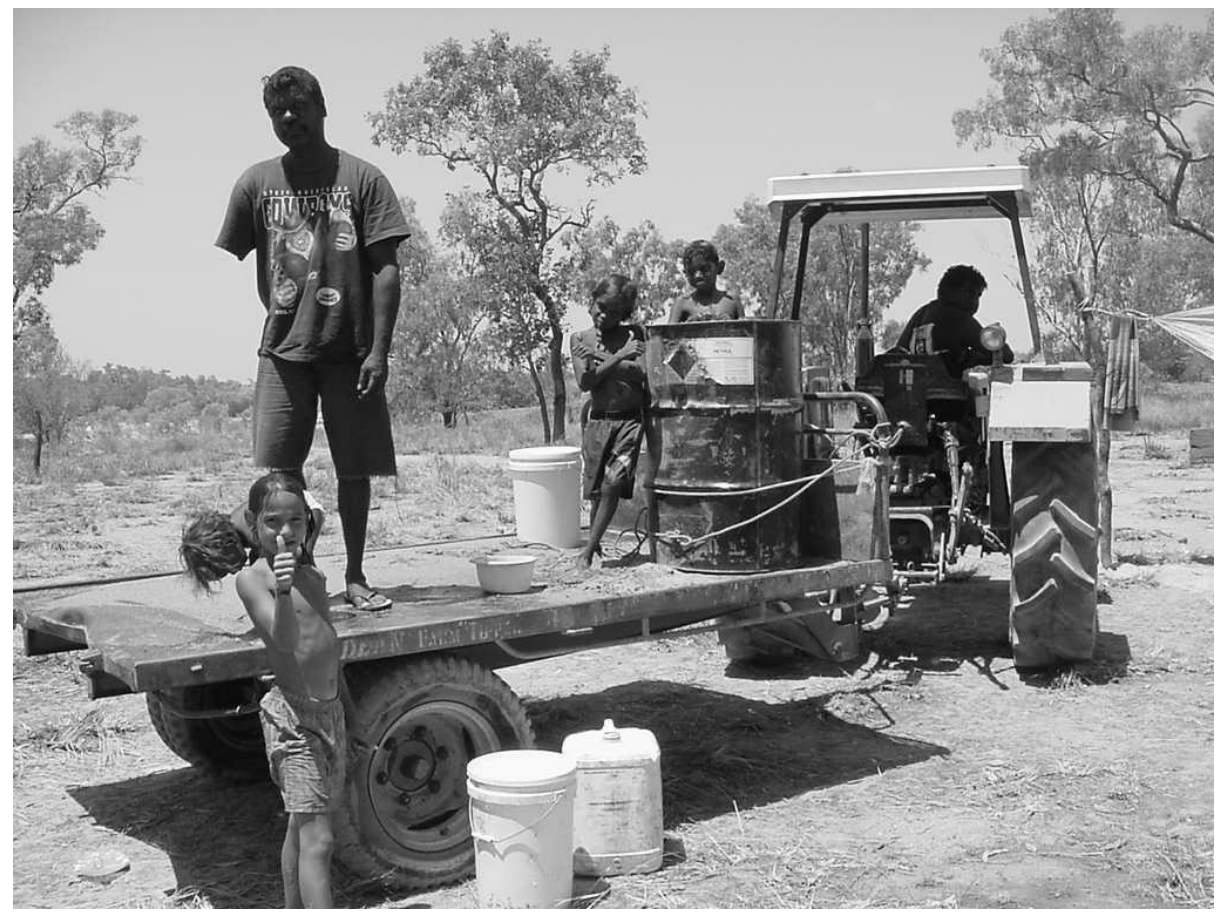

Figure 9.6 Carrying water and supplies to a dry season camp site Source: Kowanyama Collection

Figures 9.5 and 9.6 show aspects of a dry season camp site at I'ygow on the Mitchell River. This site, which is in Kunjen country, has had an outstation established on it since late 2002.

\section{Outstations}

Outstations are usually at locations where families have maintained their traditional links to their country in the occupation of temporary seasonal shelters or campsites over the years. Many of these sites now have more permanent 'shed' like structures on them which are set in concrete foundations and which have diesel generators to supply electrical power, a fresh water supply from rainwater tanks, toilet and shower facilities, and a communal cooking area. Each outstation usually has space for between 15 and 20 residents.

The majority of outstations consist of a cyclone-proof shed with a ground area of about $15 \mathrm{~m}^{2}$ and $30 \mathrm{~m}^{2}$, a generator, cooking area and water tank (Monaghan \& Taylor, 2003). Outstations usually commence at a dry season camp. Once a site is established, infrastructure support in the form of fencing and water supplies, and concrete foundations for more permanent 
residential structures are supplied as funds become available. The minimum infrastructure requirements for each site are stock-proof fencing, a shed for residence, water and solar energy supplies, and toilet and shower facilities. A sum of around $\$ 20,000$ has been allocated in the past for 'start up' costs for each site and Community Development Employment Project (CDEP) labour is used in their construction. The Federal Government has recently announced changes to CDEP parameters but as yet the effects of these changes are unknown. Longer-term aspirations are for the construction of permanent homes at some sites with the provision of between four and six houses depending on the number of families who live there (Monaghan, 2003a, 2003b). People at almost all outstations have aspirations to set up their own enterprises and exercise control over land use in their outstation areas. Prospective enterprises include small-scale cattle or aquaculture operations, or camps for tourists and recreational fishing. People spend as much time as possible on their outstation in their homeland country so as to escape the occasional rigors of township life and to enjoy the tranquillity of the bush (Monaghan, 2003a).

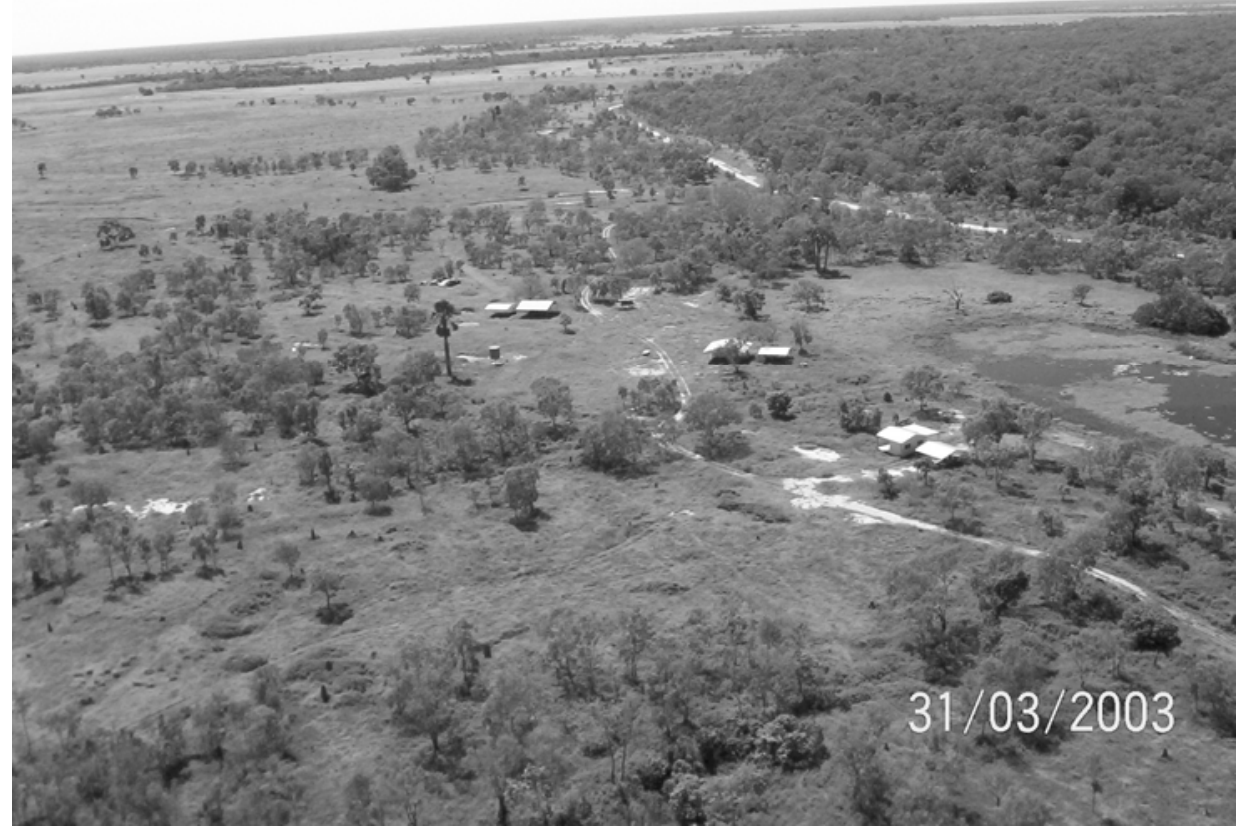

Figure 9.7 An outstation in Kokoberra country

Source: Kowanyama Collection 


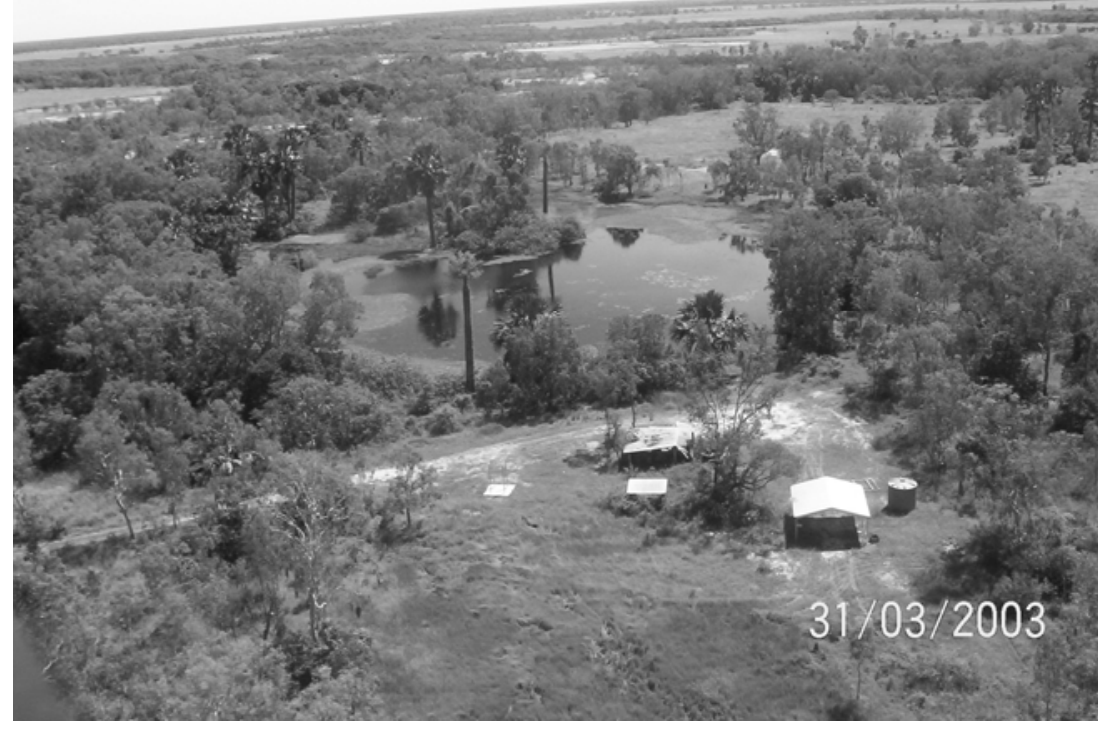

Figure 9.8 An outstation in Kokoberra/Yir Thangedl country Source: Kowanyama Collection

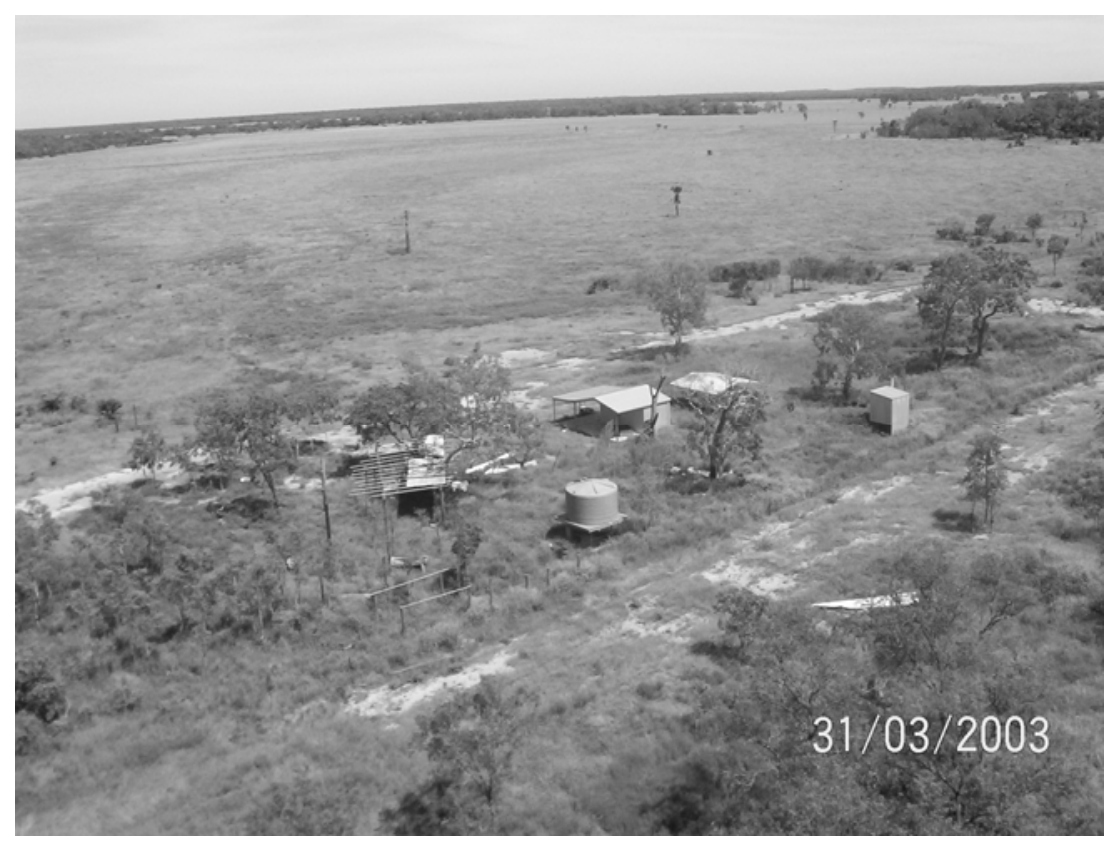

Figure 9.9 An outstation in Yir Thangedl country Source: Kowanyama Collection 


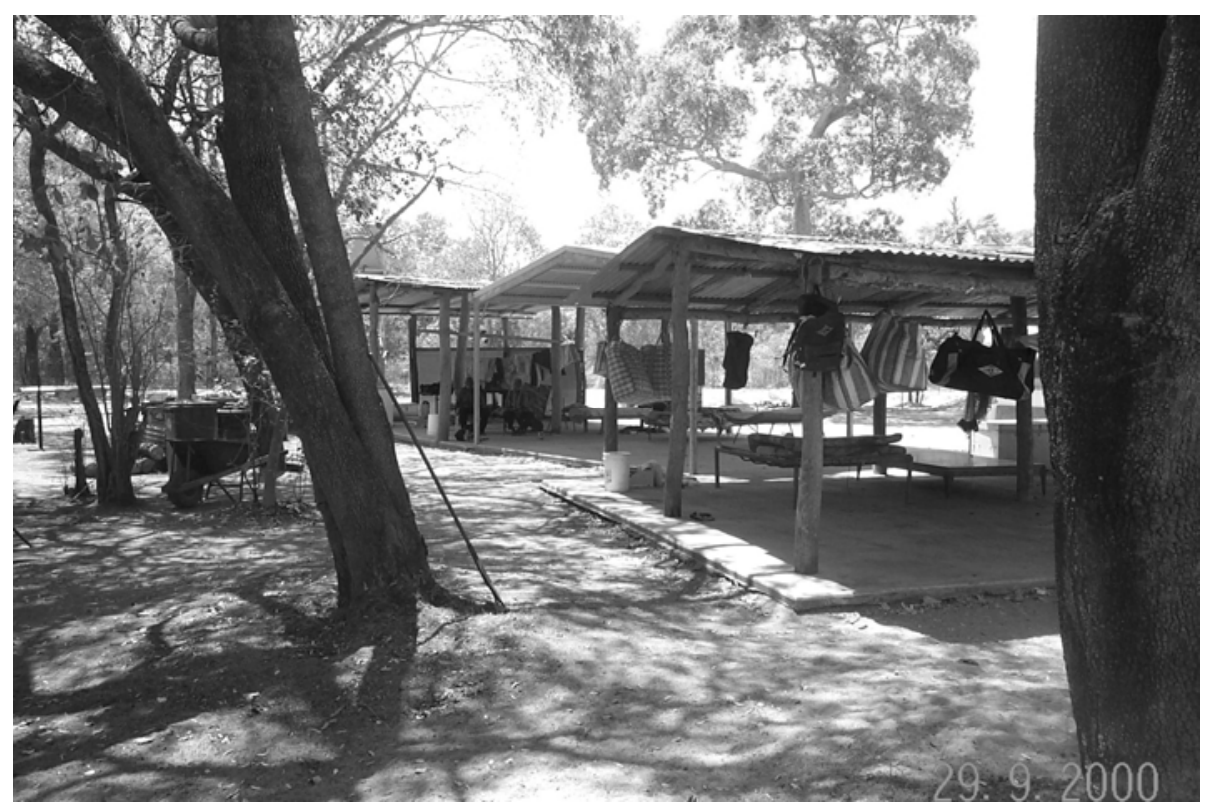

Figure 9.10 An outstation in Yir Thangedl/ Yir Yoront country Source: Kowanyama Collection

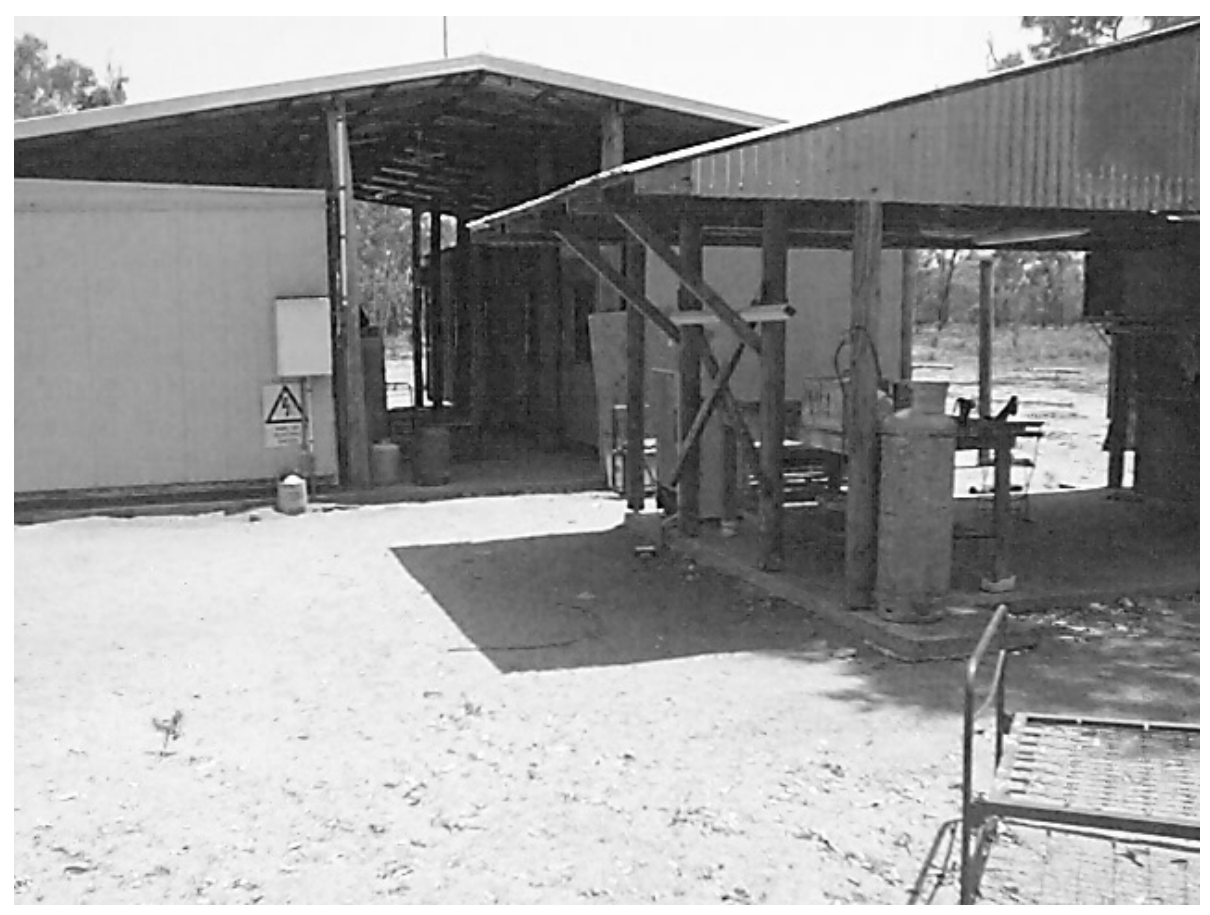

Figure 9.11 An outstation in Kuuk Thaayore country Source: Pormpuraaw Collection 


\section{Public and private space in peri-urban landscapes}

Decisions about where to locate outstations, and who should have access to them, are based on local criteria and negotiation between traditional owners and never involve any government agencies. Outstation groups are invariably identified either by the name of their leader, the surname of the dominant affiliate family, or by the name of the place or country where their homeland site is located. Affiliation, based on mother's country or father's country, underwrites the setting up of a homeland and the endorsement of all of the people with these affiliations is always sought before an outstation group proposes to establish a site. The group leader's immediate kin and those of any of their brothers and sisters, and the partners and offspring of any of their children are usually the people who will live at a homeland site. Otherwise, membership of an outstation group is by invitation. People do not put themselves forward and ask to join an outstation. If there is a sufficient number of uninvited people, who are proximally related in both a geographical sense to country, and in a social sense to family, then they may form their own homeland group and look for a site elsewhere within that region that is available to them (Monaghan, 2003a).

All outstations are private places and people are not allowed to visit them unless they are invited. In particular, they are exclusively Aboriginal spaces where people go to escape the rigors of township life, to assert their identity and connection to country, and to escape dependence on community health, education and police services. Each outstation is the centre of a tract of country that either reflects the traditional clan estate interests of its members or an area that has been negotiated with neighbouring outstation groups and other community members. Many people may have rights of access to country even though they are not members of any of the outstation groups within the country. These rights of access are usually based on secondary rights of association to country and natural resource use, which are transferred through kinship protocols (Sharp, 1937; Taylor, 1984).

The above processes mean that there are considerable variations in the accessibility of peri-urban landscapes, and their relative social permeability, which are also due to historical contingencies such as the nature of local mission and State Government administrations and geographical contingencies of distance from township, and wet and dry season access to traditional country (Monaghan, 2003a). For instance access to the Pormpuraaw landscape is heavily prescribed by traditional clan affiliations and outstations are discrete social and spatial entities that are maintained by various forms of social boundary defence (Cowlishaw, 1987) in public and private behaviour in community life (Monaghan \& Taylor, 2003; Monaghan, 2005). Even use of the Pormpuraaw hinterland is prescribed by clan and 
kinship affiliation. This is evident, for instance, in distinct household residency patterns in the township and in the wet season in the distribution of dinner camps and fishing parties along the seashore. A walk along the beach from the Chapman River to the Mungkan Creek when there is a wet season 'run' of salmon or black-tip shark in the near-shore waters of the Gulf of Carpentaria is an introduction to the cultural geography of western Cape York Peninsula. On the other hand, Kowanyama is a more permeable landscape in terms of patterns of social organisation, and patterns of outstation occupancy and natural resource use. This is particularly so in the Kowanyama hinterland where hunting and fishing are largely regarded as communal rights for Aboriginal people and for white 'staff' residents alike. Further away from the hinterland permission is always sought of an outstation group if any hunting or fishing trip is planned in their country, and this is invariably granted (Monaghan, 2003b).

The movements of any visitor to either Pormpuraaw or Kowanyama are always negotiated and planned before their arrival. People who arrive unannounced are accommodated if vacancies exist at designated camp sites; otherwise, they are directed away from the community. Kowanyama has a number of camps for recreational fishermen. Fishing permits are limited and demand for them is always high and never satisfied. The traditional owners of each camp site are consulted before the start of the fishing season on how many people may be allowed to fish there that year and a proportion of the fees that are received is paid into their outstation account and another proportion is allocated to the funding of aerial and boat surveillance of commercial fisheries in the Gulf of Carpentaria by community rangers (Monaghan 2003c). Tourist fishing camps have also been set up in the last three or four years at Pormpuraaw and some outstation groups there, as at Kowanyama, are looking at ways in which tourist-based enterprises may be included in future outstation planning. On the whole though, most people do not like to see strangers in their traditional country.

Both communities also have a herd of between 4,000 and 5,000 cattle which are run as part of open range operations and the low nutrient status of pastures and distance to market preclude any financial investment in infrastructure in the form of fencing, paddock control and artificial watering points or bores. Nonetheless, people at almost every outstation aspire to run their own herd of 'killers' or 'breeders' and negotiations between groups and the 'cattle company' in each community to exclude 'company' cattle from outstation country or to receive agistment fees for their use of country have increased in recent years. These negotiations can be quite terse with the cattle people regarding themselves as 'modernisers' and as managers of a community resource, and the outstation groups asserting their traditional authority over community lands. 
The community cattle operations are managed in the same way as any other pastoral enterprise in northern Australia and an important set of negotiations with outstation groups at the start of each dry season concerns the fire regime for the following year and in particular, when and by whom fires are going to be lit. These negotiations invariably require the reconciliation of two different systems of fire management, which are practiced by the cattle company and outstation groups respectively.

\section{Fire behaviour and fire risk in Aboriginal peri-urban landscapes}

Whilst some fires have their origin in lightning strikes, most fires on Cape York Peninsula are started deliberately as part of a land management regime of one kind or another. Controlled burning of the landscape has almost certainly been a feature of Aboriginal land use for many thousands of years and many of the traditional patterns of burning in terms of the location, timing and intensity of fires are repeated in present day control of pasture for cattle grazing.

The burning season starts almost immediately at the end of the 'wet' so that wet season growth and the more rank and unpalatable grasses can be cleared and cattle mustered or game such as wallaby driven out into the open for hunting. Early dry season fires tend to be low temperature and relatively small in extent. Burning continues through the dry season in order to promote the grouth of palatable pastures for cattle, and increases in intensity and extent in the late dry season as the surface and interstitial water reserves required to promote grass growth become depleted. In October/ November it can seem as if the whole landscape is either on fire or in some form of recovery from a fire. Indeed, a perusal of monthly fire-scar mapping between 2000 and 2003 by the Cape York Peninsula Development Association (CYPDA, 2003) shows that there are hardly any areas of the Peninsula that are not burnt at some time.

Fire is also a phenomenon which is part of Aboriginal cosmology and is a motif of clan identity for some people in western Cape York Peninsula whereby they are required to perform duties that involve the creation and maintenance of fire in the landscape so that its contributory role to Aboriginal belief systems and the existence of the physical and social world is ensured. Traditionally, the failure to perform such duties would threaten the entire physical and social world and the cosmology or 'stories' that describe and underpin the creation and continuity of the universe (Sharp, 1937). Fire is linked through creation stories to other elements of the physical world and the narrative must be continuously maintained in story-telling and in actions in the landscape; for instance, members of the Grass Clan have important duties to perform in ritual aspects of the use of fire in land management as 
grass is both destroyed and created by fire. The performance of these duties is an affirmation of personal identity and of responsibility to the rest of the community. 'Smoking the country' is a ritual act of purification of the landscape which is widely practiced throughout the western Peninsula, usually following the ending of a mortuary ban which is a period when areas of the landscape are closed following the death of a person affiliated to that country. This ceremony is very localised and performed at the place of strongest totem affiliation or sentimental attachment for the deceased. Mortuary bans often disrupt the operations of the community cattle company and also the holiday plans of visitors to the community.

Traditional owners monitor the physical appearance of their country and if, because of the growth of understorey vegetation ('rubbish'), they feel that it has not been adequately burned then they will perform that duty. Some traditional owners who have been away from their country for a long time will light a fire anyway, probably to demonstrate their ownership and their duties for the custodianship of that land. Such fires tend to be small in extent as, particularly later on in the dry season, ground cover can be very sparse and there is often little combustible material around. The large hot fires of this time of the year have to be started by incendiary devices that contain diesel or petrol. In summary, fire setting can be an expression of identity, of control of the physical, mythical and social world, as well as a land management technique.

In a Natural Disaster Risk Mitigation study for the Pormpuraaw community (Monaghan \& Taylor, 2003), local people regarded uncontrolled fire as the main natural hazard in the dry season landscape. In fact, uncontrolled bushfire was unequivocally identified as a greater natural hazard than cyclones or extreme wet season floods. Fires can break out suddenly and extend over large areas very quickly. In this sense, they are the least predictable of all natural hazards. The reason for their unpredictability, which was identified unanimously by all of the outstation and cattle people who were interviewed in the study, is that the main cause of uncontrolled fire is negligence by people who drop matches or poorly extinguished cigarettes. Most outstation residents expect a bushfire to come in close proximity to their property at least once a year. Strathgordon, an Aboriginal-owned pastoral property about 60 kilometres from Pormpuraaw, experienced a bushfire in August 1999 that came close to the homestead and which could only be extinguished with the help of neighbouring pastoralists. The dry season is also the time of year when most tourists visit the community. At present, the activities and camping locations of tourists are largely unregulated though the community has established a Ranger service recently. The supervision of tourist activities is one of their roles. Camping locations at Kowanyama are more closely supervised and Pormpuraaw is 
obtaining advice from community rangers there on procedures for the surveillance of tourists.

One of the most unappreciated properties of western Peninsula landscapes is the number of Aboriginal people who are camped in them at any time during the dry season and in particular at weekends. The bush, both within periurban areas and beyond in more remote areas, is literally alive with people, who move around either on foot or in four-wheel drive vehicles. It is hard to avoid people or indications of the presence of people such as a recently vacated dinner camp. Current scientific opinion is that most of the western Peninsula is a 'wilderness' (Abrahams, et al., 1996) with exceptional nature and remoteness qualities. This is quite literally an anti-social perception of landscapes in the region as they are populated by highly mobile, and in the context of bush hazards, highly vulnerable people. A few years ago, a search was conducted by the Australian Army for an area where live ammunition' exercises might be undertaken in the western and central Peninsula. The search was abandoned as it became clear that it was not even possible to fire a handgun at any place or in any direction without the risk of endangering lives.

When people set up camp, vegetation is cleared on a large area of ground to create a firebreak and then they collect fuel and light a fire. Fires are continuously tended and when the camp moves on, fires are extinguished with earth and water and the remnants buried. Fire risk reduction is an abiding principle of bush life for people on the Peninsula.

Despite the unpredictability of bushfires, Pormpuraaw people feel that they can manage and remove the risk of uncontrolled bushfires (Monaghan \& Taylor, 2003). The fire regimes practiced by pastoralists, whether European or Aboriginal; rely on any area of the landscape only being burnt once, and twice in exceptional circumstances, in any dry season. Good fire management regimes not only promote fodder for cattle but they also remove fuel loads for future fires. Outstation organisers and cattle workers in Pormpuraaw and Kowanyama continually remind the rest of the community that only they should light fires in the bush. Planning meetings have been held at the start of the dry season in Kowanyama to formally plan each year's fire regime and monthly satellite images and fire-scar mapping are inspected by traditional owners and cattle company workers to monitor the extent of burning in the landscape.

The greatest risks of a catastrophic bushfire are around outstation sites as they often have generators and stores of diesel fuel on site. In terms of risk reduction it is clear that fencing around sites; well-defined firebreaks and little vegetation or vegetation debris within the living area at each site are the 
best ways of safeguarding a site. During visits to outstation sites in November 2001 it was clear that those sites which had been identified as the most fire-prone were unfenced and had a lot of undergrowth and dry vegetation debris within their vicinity and were clearly at greater risk from late dry season wild fires (Monaghan \& Taylor, 2003).

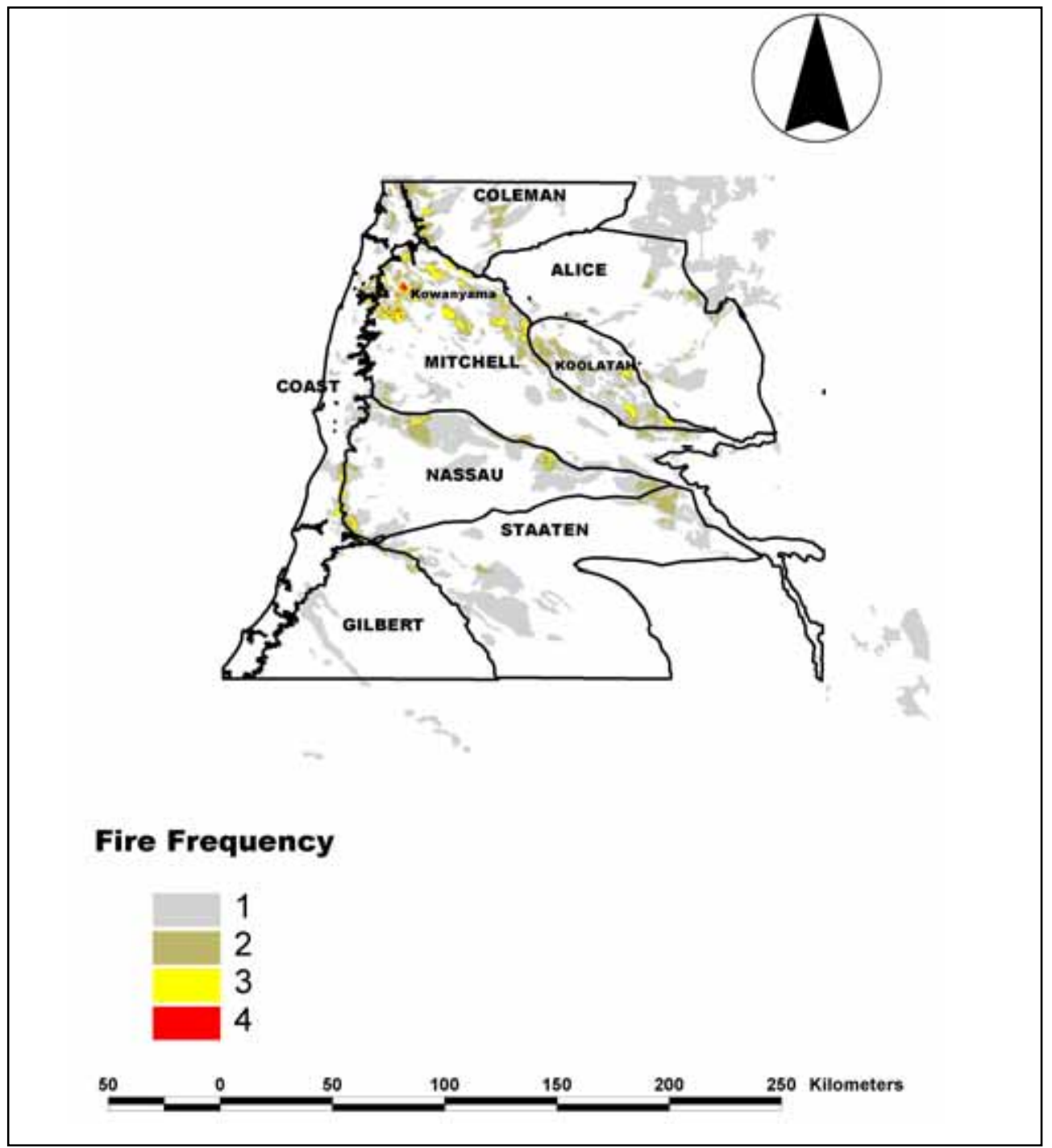

Figure 9.12 Early dry season fire frequency 1999- 2002

Source: Monaghan, 2005 


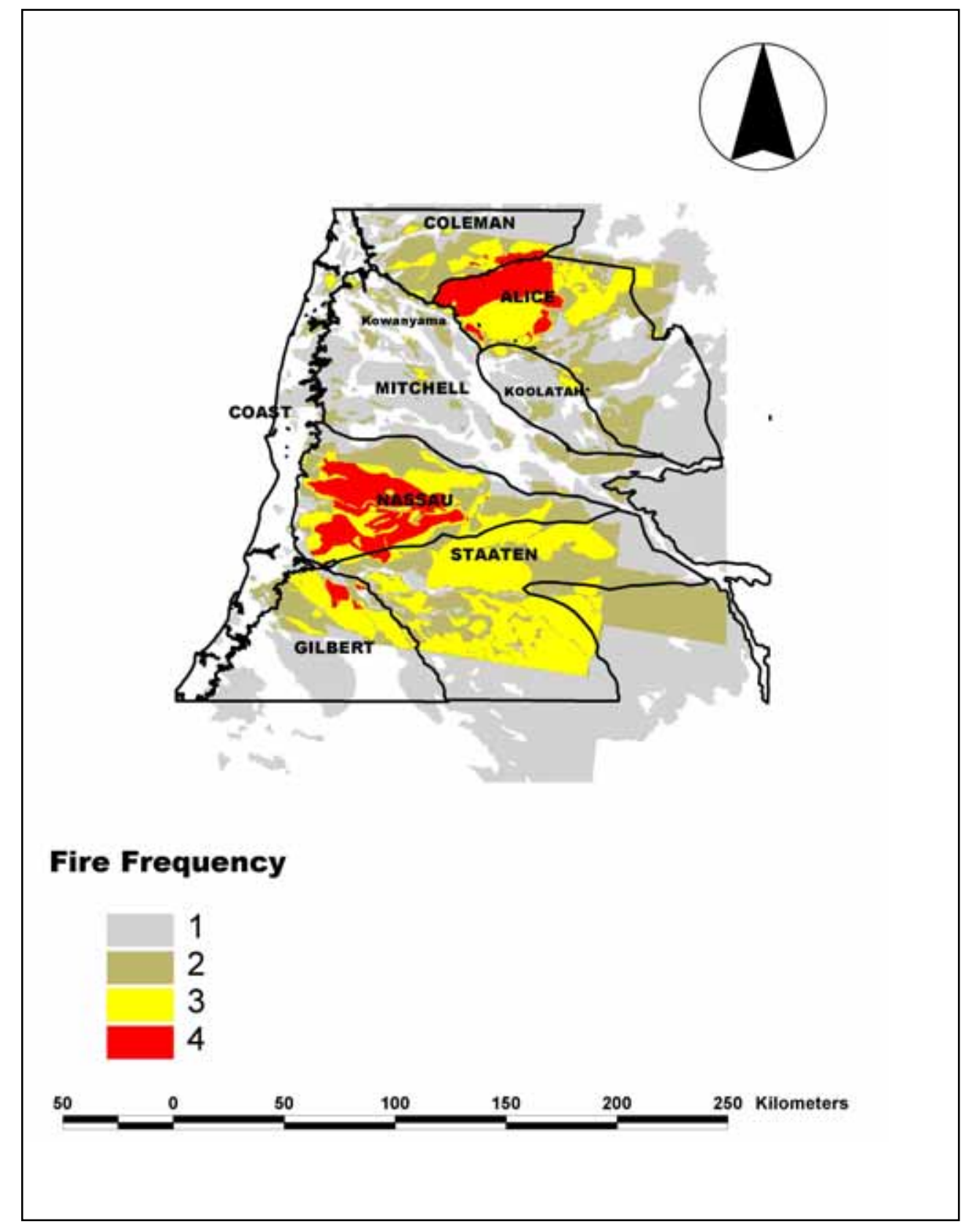

Figure 9.13 Late dry season fire frequency 1999- 2002

Source: Monaghan, 2005 


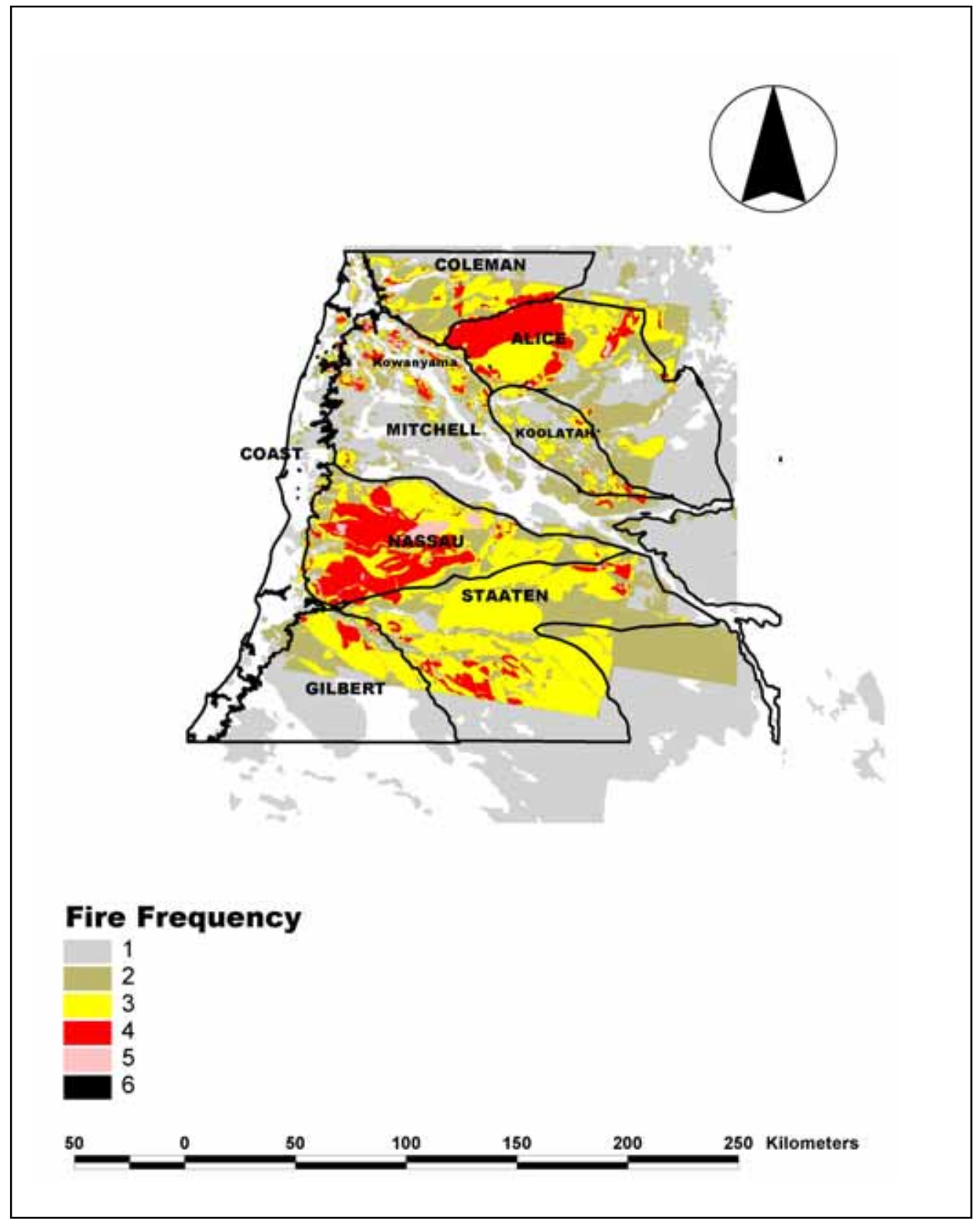

Figure 9.14 Entire dry season fire frequency 1999- 2002

Source: Monaghan 2005 


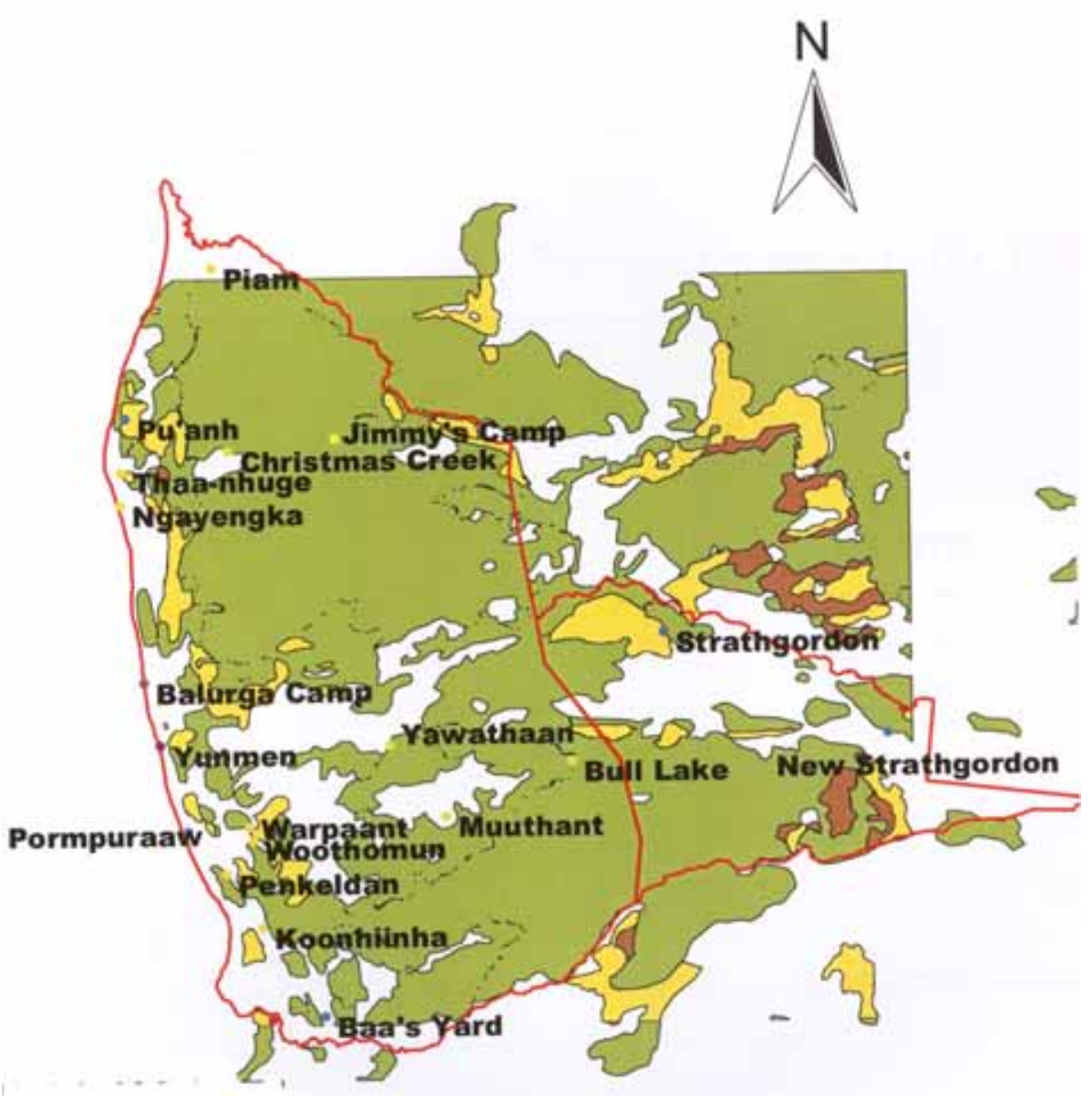

Fire Frequency

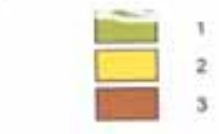

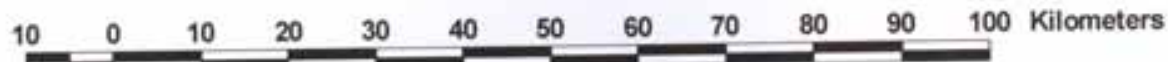

Figure 9.15 Outstation sites and fire frequency in 2001 in the Pormpuraaw DOGIT and Strathgordon pastoral property

Source: composite of CYPDA J une, J uly, September and October 2001 fire-scar 


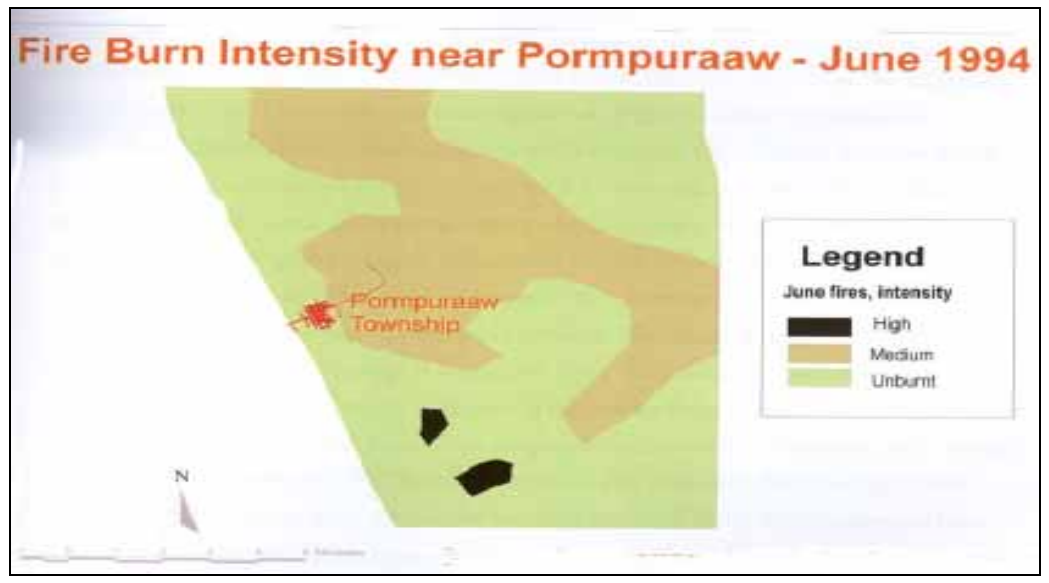

Figure 9.16 Fire scars in the vicinity of the Pormpuraaw township J une 1994 Source: Anyango, 1997

Table 9.1 Bushfire risk treatment options in Pormpuraaw Natural Disaster Risk Mitigation Plan (Monaghan \& Taylor, 2003)

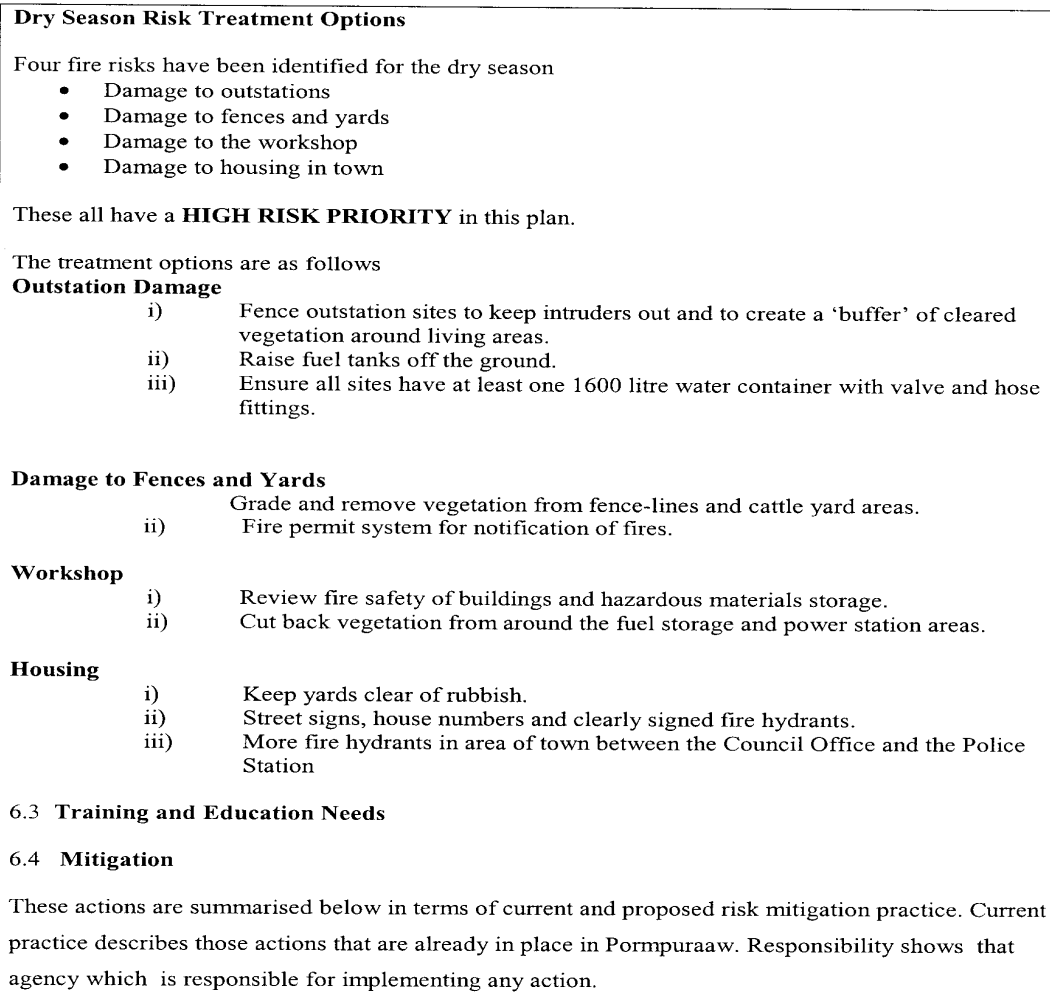

iii) More fire hydrants in area of town between the Council Office and the Police Station

6.3 Training and Education Needs

6.4 Mitigation

These actions are summarised below in terms of current and proposed risk mitigation practice. Current practice describes those actions that are already in place in Pormpuraaw. Responsibility shows that agency which is responsible for implementing any action. 
Table 9.2 Fire management in Kowanyama Natural Resource Management Plan (Norris, 2003)

\section{CURRENT SITUATION}

- Many areas are burnt every year.

- Burning is a widespread practice to improve pasture in either the early or late wet dry season

\section{STATUTORY REQUIREMENTS}

- Permits are required from the Fire Warden (Bob Crapp) for fires in the vicinity of town.

- Local fire bans were enforced during Government administration time at Kowanyama (1960's to 1980’s).

\section{COMMUNITY VIEWS ON FIRE MANAGEMENT}

- Protect people and property from fire damage--create fire breaks systematically (e.g. around the community and around homelands).

- Minimise spread of fires across Kowanyama's boundaries, either from Kowanyama onto our neighbours, or from our neighbours onto Kowanyama - create boundary fire breaks.

- Plan burning of Kowanyama country systematically each year.

- Learn more about the long-term effects that our current burning is having on our country.

- Meet our current legal requirements for prevention and control of fire at Kowanyama.

\section{CURRENT POLICIES AND PRACTICES}

- Burning is important for looking after country.

- There are times during the year when some places shouldn't be burnt, even if they could be. Some people light fires when they should not.

\section{Reasons to burn}

\section{Burning by Cattle Company}

- prepare the ground for new grass, ready for the wet season; rejuvenate the country

- clear scrub for fence lines

- burn out cattle ticks

Burning by Traditional Owners

- clean up/rejuvenate country, get rid of old wet-season grass, make way for new grass for wallabies, cattle etc.

- improve access to country, fire is an important tool for hunting and gathering (some areas you can't get into or through without burning) e.g. collecting turtles in swamps is easier after a fire.

- make places safe e.g. burn out snakes

- communicate using fire and smoke - white smoke $=$ all is well; black smoke $=$ come and help.

- burning around homeland areas to create fire breaks

- burning for traditional reasons:

- some people have fire or grass as their story, and it is important for them to burn their country 
- ceremonial burning, when people 'meet the place' after funerals and closures of country

\section{Other burning}

- burning for weed control (this is currently a side-benefit of burning, it is not yet done systematically or deliberately for weed control)

\section{Reasons not to burn-risks of burning}

- can ruin cattle pasture at the wrong time of year (early fires that deplete cattle feed for later in the dry season create a problem for the cattle company)

- badly timed fires can disrupt cattle company work during mustering operations

- can damage property and injure people

- can damage wildlife and wildlife habitat (e.g. geese egg/nesting areas)

\section{Sources of fires-who lights them?}

- Most fires are lit by Traditional Owners or the Cattle Company.

- Fires for improving cattle feed are generally lit by the Cattle Company (although Traditional Owners also burn to improve grass).

- Fires for improving access to country are generally lit by Traditional owners (although Cattle Company also burns for access).

- Tourists and neighbours sometimes start fires.

- Some fires are accidental (lightning strikes, camp fires getting away, cigarettes out the window).

\section{INTERIM STRATEGIES FOR FIRE MANAGEMENT}

\section{Activity area}

\section{Interim Strategies}

\section{Planning}

Mapping could be invited to be involved.
- Have annual (or other regular) meetings so that Traditional Owners, Cattle Company and Land Office can discuss the timing and location of fires for the coming season. This should happen late in the wet season or early in the dry season when the roads open (e.g. after easter). Our immediate neighbours

- Homeland groups to plan their firebreak burning each year.

- Land Office to keep receiving and monitoring satellite pictures, to watch what fire is actually doing to Kowanyama country, so that we can understand fire better

- Land Office to contact the DNR fire project team in Mareeba to thank them for the satellite data and assure them that we want to keep receiving the data.

- Land Office to confirm current legal requirements for fire permits at Kowanyama (local SES coordinator has details) and communicate these widely to the community. 


\section{Fire risk reduction}

Table 9.1 provides a summary of the risk treatments that were developed, on the basis of current community infrastructure and human capacity, for coping with bushfires in the Pormpuraaw study (Monaghan \& Taylor, 2003).

The main recommended on-site treatments for outstations include the following:

- fencing of outstations and the creation of a 'buffer' area of bare ground around living areas;

- $\quad$ raise fuel tanks off the ground onto supporting stands; and

- $\quad$ ensure an on-site water supply.

It is clear from interviews, historical fire incidents and from fieldwork that those outstations that are most at risk from fire are either unfenced or have dense vegetation around them. At the level of regional infrastructure, anecdotal reports on the western Peninsula and fire scar maps created from satellite imagery (for instance Figure 9.15) show that there is a clear concordance between roads and fence-lines and the outbreak of bushfires, either from careless disposal of matches or cigarette butts or from arson. As in the rest of Australia, arson is a potential problem and clearly as new outstations are introduced then the potential for new access roads arise and hence the overall fire risk of the landscape that is traversed by them increases. Fire came within 200 metres of every outstation at Pormpuraaw on at least one occasion in the 2001 dry season, and to within 100 metres of four of these sites.

Figures 9.12 to 9.14 show fire frequency in the Kowanyama region against a background of the major physical and cultural landscape units that have been identified in the region by Kowanyama people as part of a community natural resource mapping program (Monaghan, 2005). These maps show fire frequency between 1999 and 2002 and illustrate, at a regional scale, a stable pattern of seasonal burning with each landscape unit encompassing a fairly distinct 'signature' in terms of fire frequency and fire scar size. This pattern suggests that fire regimes are as much a product of their physical environment as any prevailing land management regimes. There are some exceptions to this pattern in that late dry season burning to the north-east of Kowanyama (see Figure 9.13) is characteristic of a particular pastoral property These outbreaks have led the Kowanyama community to take precautionary measures in clearing firebreaks on the community boundary. Late dry season fires are invariably more extensive in area and in intensity than early dry season fires. Figure 9.16 shows the distribution of fire scars around the Pormpuraaw township in J une 1994 (Anyango, 1997). 
The occurrence of fires close to town is quite frequent and is mitigated by a fire break that is cleared around the town each year. Fires also come in quite close to Kowanyama and the Magnificent and Gooseberry Creeks, which always contain water, provide natural buffers to the spread of wildfire, also the country that is closest to the township is burnt and grazed early in the dry season so that later dry season fuel loads are never too high.

Table 9.2 is an extract from the Kowanyama natural resource management plan (Norris, 2003) and provides a summary of the main points about community fire management in Kowanyama. The creation of firebreaks around outstations ('homelands' in Kowanyama) are part of annual fire planning with the community cattle company.

The Pormpuraaw study also identified the following issues as germane to effective natural hazard risk management:

- The difference in perceptions of risk from natural hazards between local people and the 'staff' population - local people are more accepting of these risks and of their ability, and the capacity of the Council, the police and the SES to deal with them;

- The maintenance of risk standards in the future planning of community housing, infrastructure and land use;

- The absence of a rate revenue base and the reliance on external funding for Council operations;

- $\quad$ Training and equipping of SES volunteers and community rangers (Monaghan \& Taylor, 2003).

The main issues in bushfire risk management planning in remote Aboriginal communities revolve around the socio-political context of each community in terms of staff-community relations and local Indigenous systems of governance.

\section{Socio-political considerations in fire risk management}

Remote Aboriginal communities are characterised demographically by a large, permanently resident Indigenous population with a more transient population of service deliverers who are mainly European Australians. There are also two separate systems of governance in DOGIT communities in Queensland in a locally elected community council which fulfils the role of a local authority as is found in communities elsewhere in rural Queensland. The other form of government is in local polities which consist of tribe and clan affiliations that are based on traditional governance protocols and more recently in the 1990s and early 2000s in homeland or outstation groups who are the land-holders of traditional country. 
With reference to Pormpuraaw and Kowanyama, this section of the chapter highlights the socio-political differences that exist between Aboriginal communities and the implications for regional-scale risk management strategies in northern Australia.

\section{Community demography and service delivery}

Pormpuraaw currently has a population of about 633 people (ABS, 2002), 559 of whom are Aboriginal people who are long term residents, the majority of the remainder are white 'staff' residents who tend to remain in the community for between two and five years. Kowanyama has a population of about 1200 people and a staff population of comparable size. As was highlighted in the previous section of this chapter, the attitude of these two populations to the management of bushfire and other natural hazard risks can differ quite markedly.

Staff are individuals and their families who have positions in Council administration or its agencies, or in the State Government service sector. Most staff are temporary residents, mainly non-Indigenous, and employed on a term contract. They are generally highly skilled people who work as police, teachers, nurses, clerks, accountants, and managers or tradesmen. Those employed in the State Government positions rarely stay for longer than two years and many are in the community under financial inducement or with the promise of a 'fast track' posting to a more a desirable location or a more senior position. Those people who work for the Council tend to stay longer. In time, all staff members move on and on the whole the staff population is a transient and changing one. About $20 \%$ of the staff population at any time are single persons. Married couples with no children or with grown-up families make up more than $50 \%$ of the staff population. Those staff families who do have children of school age send them away to boarding school. It is common for both married partners to find employment in the community (Monaghan \& Taylor, 2003). A similarly constituted staff population is also present in Kowanyama.

Turnover in the staff population can lead to swings in 'corporate' morale in the various service centres in a community and individual people can have great influence, if they choose to exercise it, in community life. More so than Pormpuraaw, Kowanyama is characterised by a relatively stable staff population who tend to remain in the community for a longer time. On the whole, western Peninsula communities have a welfare economy and local people have a low material standard of living by mainstream Australian standards. They are poorly equipped to deal with the kind of investment in supplies and household preparations that are normally undertaken by a family to prepare for a natural disaster and have great reliance on the 
Community Council and Federal and State government agencies for sustaining daily life. Most of the employed population work on schemes funded by the Commonwealth government's CDEP scheme that supports projects that provide or aim to improve infrastructure and social services in the community. Many of these projects in fact provide essential community services. The wages that people receive are the equivalent of social security or unemployment benefit payments (Monaghan \& Taylor, 2003).

Good relations exist between staff and permanently resident populations in both Pormpuraaw and Kowanyama. New staff members are often introduced into local families and many are assigned fictive relationships within local kinship networks which enable them to gain an insight into local systems of social organisation and modes of community governance. It is impossible for many staff to work effectively without this understanding of how local society works and those who acquire this knowledge and familiarity with community life are often those who are less susceptible to 'burn out'. Council and other service staff are invariably busy people who are also faced with the pressures of being expected by government to deliver mainstream standards of service in contexts where under-funding, lack of peer support and remoteness and isolation often make such expectations unrealistic. Local people are often supportive of staff who would otherwise find it difficult to cope and help them to 'cut corners' so that their work may be done, mainstream goals achieved (though not necessarily in the way that government policy demands) and their morale sustained.

The Pormpuraaw study identified a tendency for local people to rely on service deliverers, such as emergency services personnel; this is part of a wider pattern of dependencies that arise out of local economies that are overwhelmingly welfare-based. In another sense this dependency can be viewed as an active rather than a passive phenomenon, which is symptomatic of the way that local-mainstream relations are conducted by Aboriginal people so that their distinctive cultural and social identities are maintained. Australian government attempts to assimilate Aboriginal people into mainstream lifestyles have been described in terms of 'social' and 'material' technologies (Chase, 1980; Smith, 2000). For the purposes of this chapter, social technologies may be regarded as paradigmatic changes by government in their management of Aboriginal affairs such as church administrations, DOGIT tenure and the introduction of regional scale Aboriginal government in the Aboriginal and Torres Strait Islander Commission (ATSIC) and Land Councils in the early 1990s; and now in the early 2000s the transformation of DOGIT administrations into shire councils, just like those that exist elsewhere in rural Queensland. Material technologies are those instruments such as housing and infrastructure, 
health and education services, or telecommunications which are the expected agents of social change within any prevailing paradigm (Monaghan, 2005).

To briefly summarise the influence of social and material technologies on mainstream-Aboriginal relations, the Aboriginal response to institutional change through social technology is to 'underground' the main cultural elements of their society and to accommodate social change within their own systems of social organisation. An example of the latter is in the fictive relationships that are assigned to staff people so as to place them within the local Aboriginal social universe. 'Undergrounding' refers to the oblique view of the Aboriginal domain and of core decision-making by people about their affairs outside of the community council that is often only partially visible on initial visits to a community. Political activity is conducted within the network of locally evolved traditional and historically based protocols that determine social relations within any particular community and is exclusively Aboriginal.

\begin{abstract}
Aboriginal decision-making and relative autonomy or domains of relative autonomy tend to be concentrated in areas conceived of by outside interests largely as private affairs not as part of the public domain, and these are areas such as entertainment, gambling, sport and religion or ceremonies or whatever. In reality, though, these areas may be the very ones that contain focal and basic stages on which Aboriginal public, political and economic life is lived out and in which they exercise what to them may be quite critical areas of relatively autonomous decision-making. In other words, they are not a side show, they might be core activities for people, and core activities for whole communities (Sutton, 1990; cited in Rowse, 1992, p. 20).
\end{abstract}

In terms of material technology, services such as welfare and pension payments and household and neighbourhood organisation, which have arisen from town planning, are received into local modes of social reproduction such as kinship and reciprocity relationships (Monaghan, 2005).

"Material practice is embedded in and is the articulator or mediator of social meaning" (Smith, 2000, p. 429). For instance, natural resource management practice by community rangers in Kowanyama and Pormpuraaw includes the use of remote sensing and computer satellite images and global positioning systems as well as control of the environmental and mythical properties of the landscape from those special places, poison places or increase sites, where the ritual knowledge and belief systems that are associated with natural resource management are located. There is no sense of any traditional or modern dichotomies in management 
practice by rangers; instead, all of the technologies and techniques that are used by them are regarded as one integral suite of management tools (Monaghan; 2001, 2005). Community rangers are also at a nexus between the delivery of mainstream services or the enforcement of mainstream regulations and local customary practice, and on the whole they try not to confront the authority of traditional owners who may accuse them of acting like a white fella', or who may invoke clan and kinship affiliations to question the authority under which a ranger is working in any situation. The latter criticisms are strongest in any issue to do with land management, more so in homeland country. Also, such criticisms are strongest in issues, such as bushfire risk management, where the feeling is that intervention or support from outside is not required because most people feel that they deal with the issue adequately; and when such opinions are expressed then this is often true.

The successful introduction of mainstream management practices into local communities, whether they are Aboriginal or otherwise, requires a period of time in which they are allowed to embed themselves into local practice. Moreover, the uptake of mainstream management practices is even more successful if people are made aware of their availability and then left to make their own decisions on their utility; and, providing a grant or unsolicited financial aid is absolutely no guarantee of success.

Homelands are becoming more autonomous political and land-holding entities in the early 2000s in Cape York Peninsula and native title rights and forthcoming legal changes in the way that Aboriginal community councils are constituted are probably going to make them the authority and operational unit in the management of Aboriginal peri-urban landscapes within the foreseeable future.

\section{Political considerations in the management of Aboriginal peri- urban landscapes}

As stated earlier in this chapter, there are two forms of government in remote Aboriginal communities in the locally elected council and in the 'Aboriginal domain' of tribe, clan or kinship affiliations. These polities tend to look after the affairs of the township and the landscape respectively.

Councils comprise seven members and are elected every three years. Each council has a chair elected from their membership and a Council Clerk or Chief Executive Officer is responsible to Council for the administration of the community. Membership of the council in Pormpuraaw is usually representative of the 'tribe' or language groups who live there. The township is divided into two neighbourhoods based on linguistic affiliations. There are 
speakers of Wik dialects in the northern neighbourhood - 'Mungkan side' and speakers of Kuuk Thaayore on the southern - 'Thaayore side'. There are also Yir Yoront speakers on Thaayore side and speakers of non-Wik dialects such as Bakanh on Mungkan side. The distinctions between the two neighbourhoods are based on language and clan estate affiliations and there is little overlap between people in these groups in daily life. The composition of the council at Kowanyama is more eclectic and reflects a larger and more heterogeneous population whose traditional country may be found over a wide area of the southern and western Peninsula and the northern Gulf country.

Pormpuraaw (formerly the Edward River Mission) was the last Aboriginal mission to be established in Queensland in 1939 whereas Kowanyama (formerly the Mitchell River Mission) was established in 1903. There are clear differences between the two communities in their colonial histories and in their respective geographies in the way that State-assigned reserve boundaries coincided with the underlying political geography of pre-contact Aboriginal tribes and language groups at the time of their establishment. For instance, Pormpuraaw traditional owners have lineages based on descent to the mythical figures who are emblems of clan identity (Taylor, 1984) and those in Kowanyama mainly have a cognatic system based on connection to apical ancestors who are identified by the name of those male ancestors who were alive at around the time of the establishment of the Mitchell River Mission (Taylor, 1999). Despite the post-colonial changes that have occurred in social organisation, almost all patterns of social behaviour and land management practice in both communities find parallels in those recorded by ethnographers in the early years of the twentieth century (McConnel, 1931; Sharp, 1937; Roth, 1907).

The most visible form of Aboriginal polity in community life and the one that has the greatest authority in land management is the homeland or outstation group.

The role of the leader and their capacity as a broker in reconciling secular and traditional interests in their homeland country and in negotiating for homeland services with the Community Council or with government agencies is crucial to the success of a homeland group. Three or four homeland groups may combine to form a 'mutual society' of support for their members. These societies prioritise homeland development plans between themselves and make plans for enterprises, such as cattle grazing, aquaculture or fish ranching, or tourist fishing camps to sustain their homelands in the future. They occupy geographically contiguous areas and share strong clan associations and also have the strongest corporate identities in 
community life. Their 'focal' leaders, of which there are four or five in Kowanyama and in Pormpuraaw, exercise considerable influence and their groups are the basic operational units in community natural resource planning and management in sea and inland country on the southern Gulf Lowlands (Monaghan, 2005).

Focal leaders often exercise a quiet authority and can have a low and understated profile in community life so that, for instance in Kowanyama, they may appear to have little or no involvement in mainstream affairs or in the community council. Homeland groups are identifiable in township life as large co-resident groups with members often living in houses that are in close proximity to each other (Monaghan, 2005).

Other distinguishing criteria which can set homeland groups apart from the rest of the township include the following:

- $\quad$ stability of co-residence;

- a common surname;

- cognatic descent or clan affiliation to geographically contiguous areas of the landscape; and

- $\quad$ an age and gender balance in their membership that maintains a high reproductive potential for the group (Monaghan, 2005).

These criteria are not exclusive of each other and all criteria have to be satisfied before a homeland group can be confidently identified. For instance, a high density of a common surname in one part of the township is not necessarily indicative of the presence of a homeland group. Stability of residence is a particularly important indicator which can only be established by repeated censuses of household residents over many years. Three household surveys over a period of more than 15 years at Pormpuraaw have demonstrated that household mobility, a feature of Aboriginal community life, whereby people move between households over periods of weeks or months, is virtually absent in those households occupied by homeland groups (Monaghan, 2005). The national census cannot be used to profile homeland groups as they can only be identified at the household level (Monaghan, 2005). Their identification relies more on sociological than economic criteria as almost all community residents are participants in a welfare economy. Household or group 'wealth' is more evident demographically in terms of the number of women of reproductive age and in the number of young people who can act as future leaders for a homeland group and who can lobby for their interests in community life. Also from an economic perspective, a good distribution of children, working adults and pensioners may not necessarily endow advantages in terms of gross income but it can ensure access to a spectrum of welfare, wage and pension incomes 
at different intervals over the fortnightly household income cycle (Monaghan, 2005).

Homeland group membership, like traditional clan affiliation, forms a sociocentric or corporate identity for those people who have access to that place where their homeland is situated. There are also other people who have their own egocentric or personal rights to homeland country through traditional law but who are not members of a homeland group resident in that country. These latter rights may include important ritual links to country and even though they are not members of the homeland group, these people have to be acknowledged or consulted in land management issues. Their absence from group membership does not mean that they have a minor role in the affairs of homeland country. 'Ideological' or personal identities are heavily grounded in traditional law and in personal sensibilities of 'being'; the protocols of kinship and clan or homeland affiliation also enhance the unique sense of identity that each person has in Aboriginal society, and because of this individualism, a wide variety of opinions can be expressed in community political life. The contingencies that relate homeland group or sociocentric identity to personal or ideological identity are quite complex (Monaghan, 2005); at the very least it has to be understood that even though a person may not be a member of a homeland group that this does not necessarily exclude them from 'talking for country'. Conversely, a person may be a member of a homeland group and be actively involved in land management issues but have no authority to 'talk for country'.

\section{Implications of socio-political organisation for bushfire risk assessment}

There is a general resistance, in Cape York Peninsula at least, to any attempts at regional level organisation of issues that concern homeland country. Also, despite the widespread structural similarities in homeland group characteristics in Aboriginal Australia there are considerable differences in their modus operandi, even between two adjacent communities such as Pormpuraaw and Kowanyama, which preclude generalisations that might be made about fire management or regional scale peri-urban trends in remote Aboriginal communities. Fire behaviour and fire management practices can only be understood at the community scale.

The significance of social and group, and ideological and personal identities had to be continually borne in mind in the Pormpuraaw Natural Disaster Risk Management study (Monaghan \& Taylor, 2003) and thus community consultation was time-consuming as it had to include consideration of mainstream organisation in the community council and its agencies, and the 
various traditional and contemporary polities that make up the Aboriginal domain there. Many people in remote communities, and not just Aboriginal communities, will assume that the investigator has an understanding of local political life and local modes of social organisation because the community is their entire social universe and they know no other. Some may only visit a regional urban centre such as Cairns or Townsville for their birth and their death. Consequently, research prior to a visit or some time devoted to getting to know people is crucial before the start of any study as ignorance of the ways of local society on the part of 'outsiders' is often not tolerated in remote communities. Certainly, attempts to sample people in surveys or reference groups, as opposed to getting a complete census of opinion, that the author has observed in natural and cultural resource management projects over the years have rarely succeeded in eliciting adequate information or participation to make subsequent management plans work. Everybody has to be personally invited, and many people will be gratified by the invitation and will then defer to the authority of community leaders, otherwise any recommendations resulting from a study will be ignored.

'Mainstreaming' approaches adopted by regional planning strategies such as the Cape York Land Use Study (CYPLUS) to community consultation in the mid-1990s failed to recognise the diverse range of natural resource interests and the local polities that exist within communities in the Peninsula (Monaghan, 2005). Similar encounters between Aboriginal communities and State agencies involved in land and natural resource use planning and management have been reported elsewhere (Lane \& Chase, 1996).

Lane and Chase describe land use projects in the Lockhart River area of the east coast of the Peninsula, and report that despite the existence of formal planning processes for their inclusion, that there was often only a limited recognition of Aboriginal perspectives in the projects.

Too often the 'community' is seen simply as a homogenous unit, with a simple representative structure (the council) which somehow stands for or represents the varied local traditional interests in an unproblematic way (Lane \& Chase, 1996, p. 182).

The creation of formal planning structures should be the outcome of careful and detailed local ethnographic inputs, an appreciation of local historical factors and, more importantly, detailed knowledge about the politics of relevant Aboriginal communities and domains (Lane \& Chase, 1996, p. 173). 
Similar criticisms can be applied to academic studies of Aboriginal natural resource management where 'culture' is treated as an indeterminate constant or invariant background to management practice, and where the interactions between social practice and management practice are reviewed in terms of 'traditional' and 'modern' dichotomies, which are largely unrecognisable to the Aboriginal people with whom the author has worked.

At the same time consultation has to consider the multi-valence that attaches to statements about the landscape and the wide range of economic, mythological, kinship, or resource and ownership values that can be expressed for any place within it. Statements about country, either its physical or social properties, can rarely be taken at face value; sometimes, the social context of the informant has to be known before their statements can be interpreted. This distinction has to be borne in mind in natural hazard risk assessment as in other resource assessment studies when people talk about bushfire, are their comments grounded in the general knowledge of the physical environment and its seasonality that most people share, or does it have a phenomenological base in the totem affiliations, and stories or experiences that underpin personal identity? More importantly with questions related to management - does this person have the authority to make recommendations about risk management strategies in any particular area of the landscape? Such assessments are critical if management recommendations are part of the outcomes of a study.

Above all, the aims of a community consultation have to be presented clearly and unambiguously as there are barriers of language and vocabulary that sometimes have to be overcome so that participants may be able to contribute their own risk values or mitigation strategies to community planning confidently. The use of a geographical information system to store and display graphical media that represent landscapes and infrastructure and environmental hazards and that also presented risk models and local perspectives of the landscape based on recognisable landmarks has been particularly effective in natural hazard risk assessment in Pormpuraaw (Monaghan \& Taylor, 2003) and in natural resource assessment projects there and in Kowanyama (Monaghan, 2005).

The changes to Aboriginal community governance that are now taking place as a result of the introduction of shire councils and of ongoing native title determinations, mean that in the future the affairs of the township and the landscape will be dealt with by different bodies. The administration of the township will be by a council that operates under the various local government acts that apply to local authorities elsewhere in the State, and that of the landscape will be by homeland groups. The latter may function cooperatively as a lands trust with each group acting as a prescribed body 
corporate' under Queensland corporate law and federal native title legislation. Such arrangements already exist at Injinoo and Hope Vale, where land claim determinations under the Aboriginal Land Act 1991 (Queensland Government, 1991), the Native Title Act 1993 and the Native Title Amendment Act 1998 (Commonwealth of Australia; 1993, 1998) have already been made. This will lead to a higher profile and greater visibility for homeland leaders in public life and also one might anticipate a more densely occupied peri-urban landscape where the present day townships provide a service centre for the appropriate hinterland.

A modified version of this chapter was first published as Fire risk in Aboriginal peri-urban landscapes in North Australia: Case studies from western Cape York Peninsula, on a Centre for Disaster Studies web site in April 2004. 


\section{0 \\ Bushfires at the urban-rural interface}

\section{Luke J. Balcombe}

Bushfire-prone areas of most concern to the Australian public, Governments and fire authorities are those where the economic costs and social/ environmental impacts are greatest. Such impacts of bushfire appear to have been experienced more intensely in the south-eastern states/ territory of Australia and to a lesser extent in Western Australia and Queensland. The most significant bushfire risks in Australia generally occur where populated areas meet with areas of bushfire risk - the areas referred to as the ruralurban interface.

\section{The rural-urban interface}

Rural-urban interface areas exist wherever homes and other developments are intermixed among trees and other combustible vegetation. The ruralurban interface or peri-urban developments in Australia are also known as the wildland-urban interface when referring to the equivalent in North America.

The conception of the physical layout of peri-urban locations needs some clarification according to Cottrell (2005):

Peri-urban zones can be totally new suburbs with small lot housing, shopping centres, service facilities, but essentially a suburb next to bushland. Peri-urban zones can also be large lot suburban developments. In many areas, they may be a mix of suburban and industrial zones as housing has spread into peripheral industrial estates. In other areas they may be conurbations gradually infilling unsettled areas on the periphery, and in yet other areas they may be encroaching on rural production (Cottrell, 2005, p. 110).

Communities in the rural-urban interface (areas on the fringes of cities) tend to feature relatively large populations living in close proximity to highlyflammable bushland areas. High fuel loads are often complicated by rugged topography with poor access and exit points. A high proportion of the inhabitants in these areas are commuters with little experience of living in 
the bush or fending for themselves in a major fire (Miller, Carter \& Stephens 1984). Nicholson (1995) suggests that "fringe communities are the most vulnerable part of the Australian and world wide environment" (p. 3).

In the context of bushfires there are four general types of urban-rural interface conditions that may occur:

1. Interface condition: Structures adjoin bushland fuels. There is a clear line of separation between structures and bushland fuels along roads or back fences.

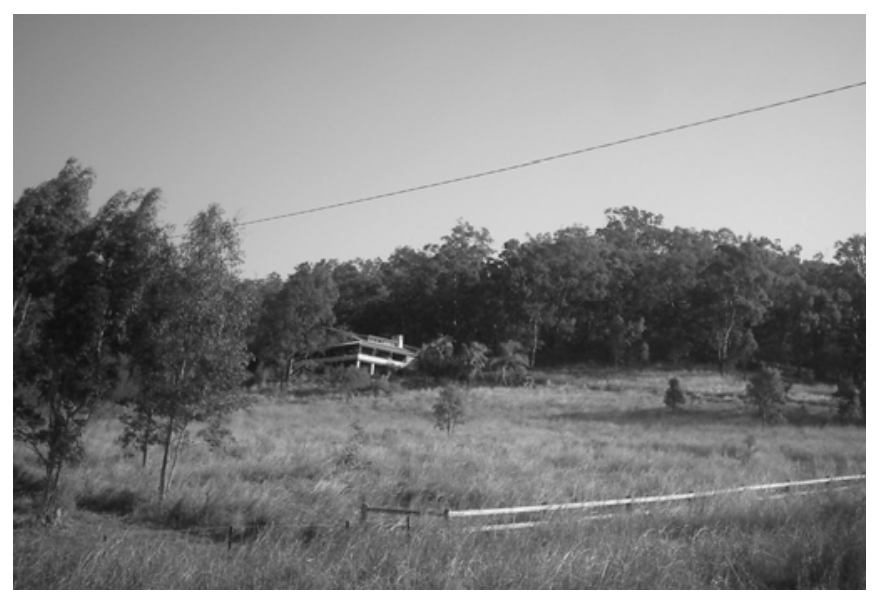

Figure 10.1 Interface condition - Tamborine Mountain, Queensland 
2. Intermix condition: Structures are scattered throughout the bushland area. There is no clear line of separation; bushland fuels are continuous outside of and within the developed area.

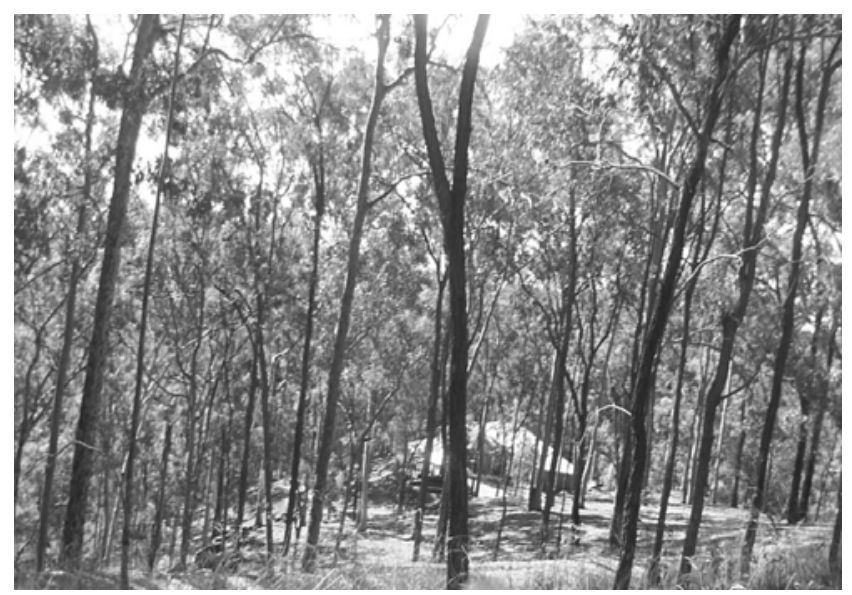

Figure 10.2 Intermix condition - Tamborine Mountain, Queensland

3. Occluded condition: Structures abut an island of bushland fuels, normally within a city, such as a park or other open space. There is a clear line of separation between structures and bushland fuels along roads or fences.

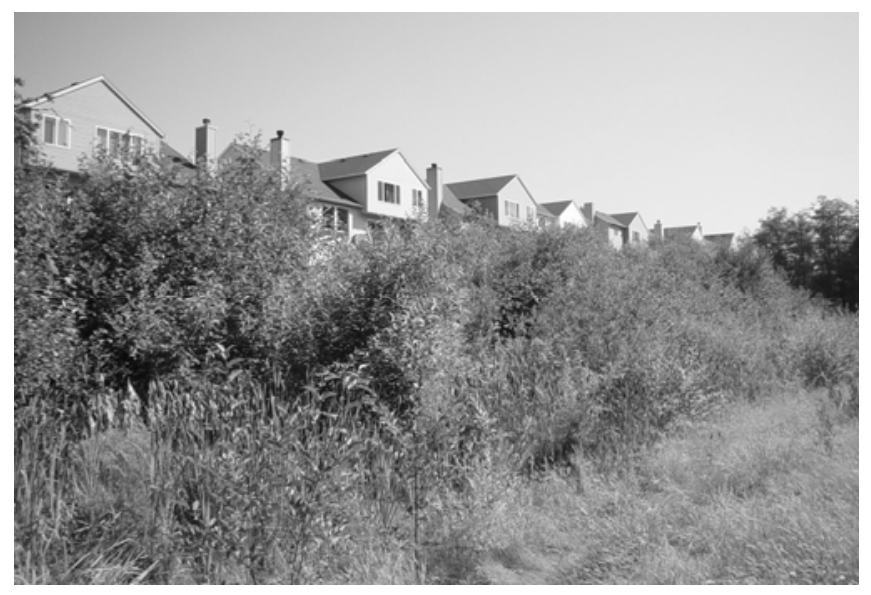

Figure 10.3 Occluded condition 
4. Rural condition: Scattered small clusters of structures (such as ranches, farms, resorts) are exposed to bushland fuels and there is much space between developments.

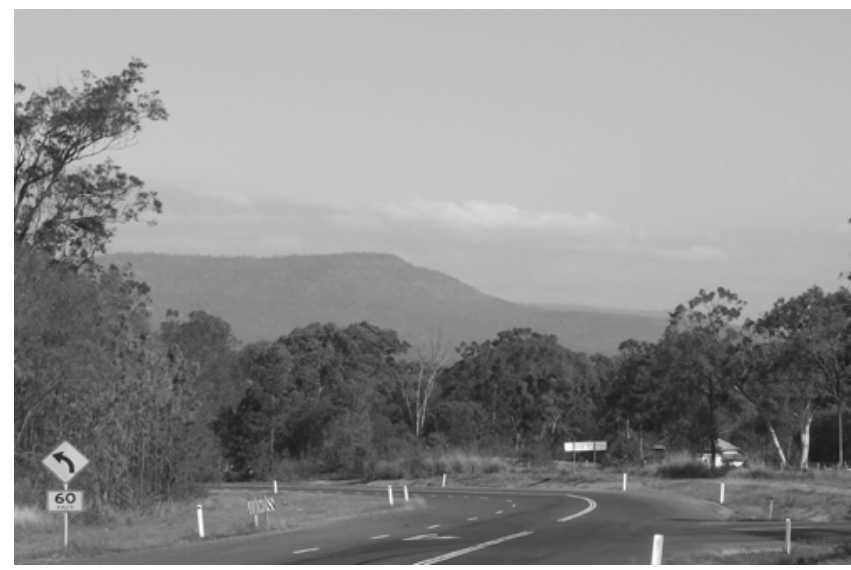

Figure 10.4 Rural condition - Tamborine Mountain, Queensland

In response to the devastating effects of the Canberra fires in J anuary 2003, there has been an increased interest within the Queensland Fire and Rescue Service (QFRS) in the identification and management of the urban-rural interface. The interface zone (i-Zone in Queensland) is where human population and flammable vegetation meet and is also known as the urbanrural interface zone. The classic example of this is where high-density housing is in close proximity to flammable vegetation, as was the case in Canberra (Type $1 \mathrm{i}$-Zone). Another type of dangerous interface zone is present in Australia, where rural residential properties are set amongst flammable vegetation and this has been identified as Type $2 \mathrm{i}$-Zone.

The GIS/ Risk Management division of QFRS undertook a project to identify these two types of i-Zone. They used two criteria for the model, firstly population density which was derived from a combination of land parcel size and proximity to the next property and secondly vegetation flammability (as identified in previous studies of bushfire risk). 


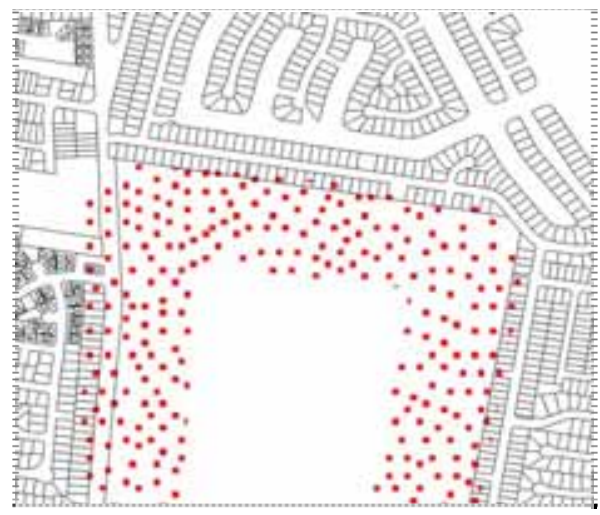

Figure 10.5 Type 1i-Zone

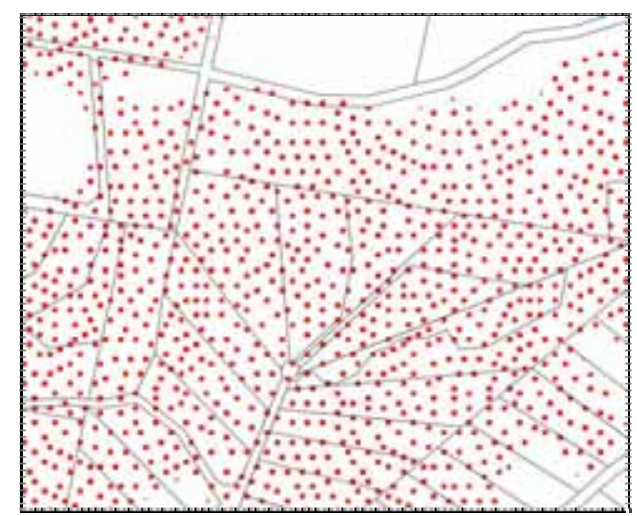

Figure 10.6 Type 2 i-Zone

The resulting categorisation identifies potential areas of concern for both urban and rural brigades. Specialised training for those personnel working within these areas of concern was identified by the QFRS as being required so as to reduce the potential risk of serious loss of structures and life. The two types of i-Zone are illustrated in Figures 10.5 and 10.6. Figures 10.7 and 10.8 (below) indicate where the two types of i-Zone can be found in the Mount Tamborine and the northern Gold Coast area.

The National Inquiry on Bushfire Mitigation and Management says that the i-Zone project is about holistic service delivery for communities in the ruralurban interface zone: "It is focused on Fire and Rescue Service personnel and how they can make a difference through a shift in culture, from separateness to inclusiveness" (Ellis, et al., 2005, p. 195). There is mention that the service providers can make gains by resolving i-Zone challenges in every aspect of service delivery, from the planning of new developments through to community education and awareness, service delivery planning, and response activities. 


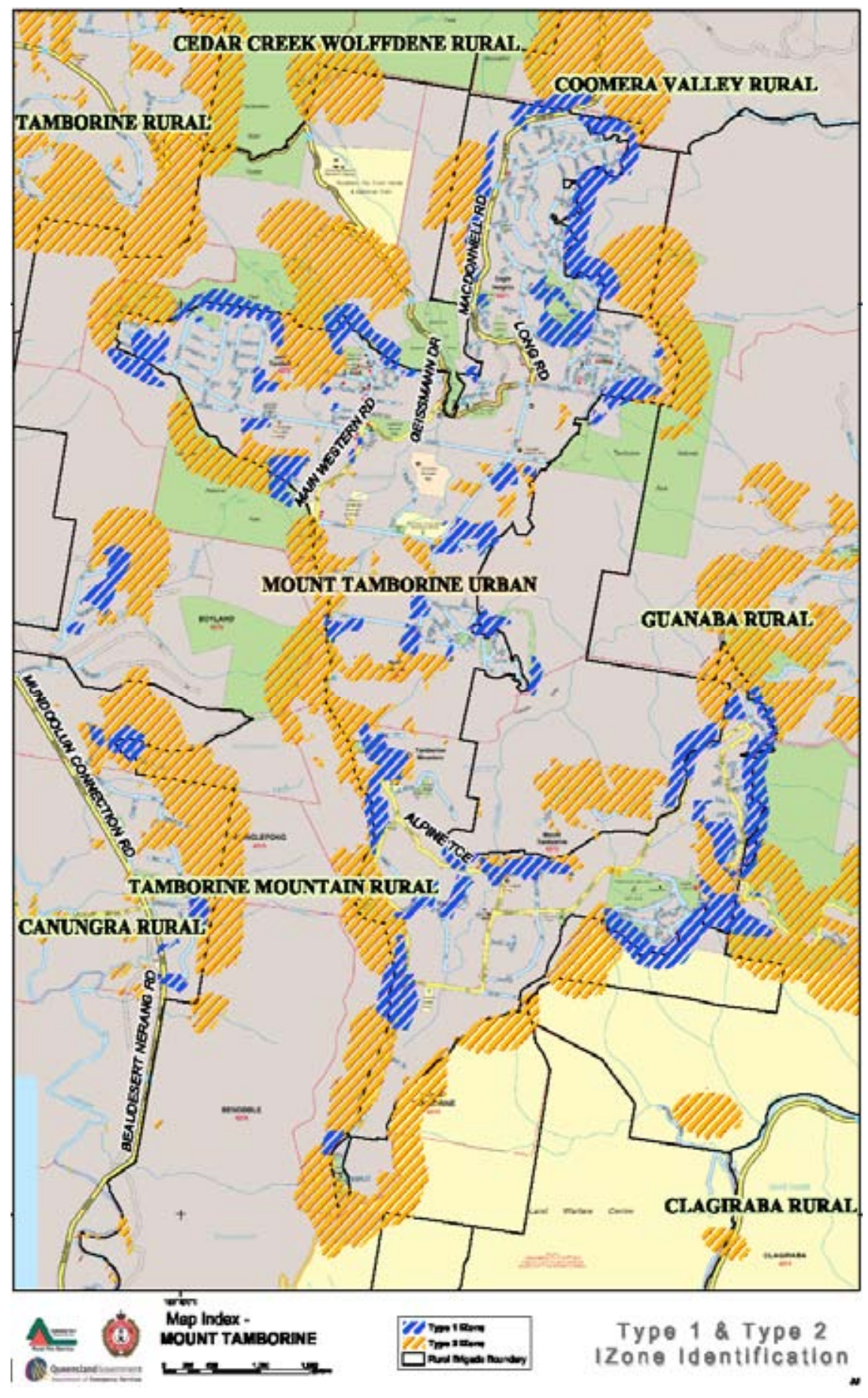

Figure 10.7

Mount Tamborine 


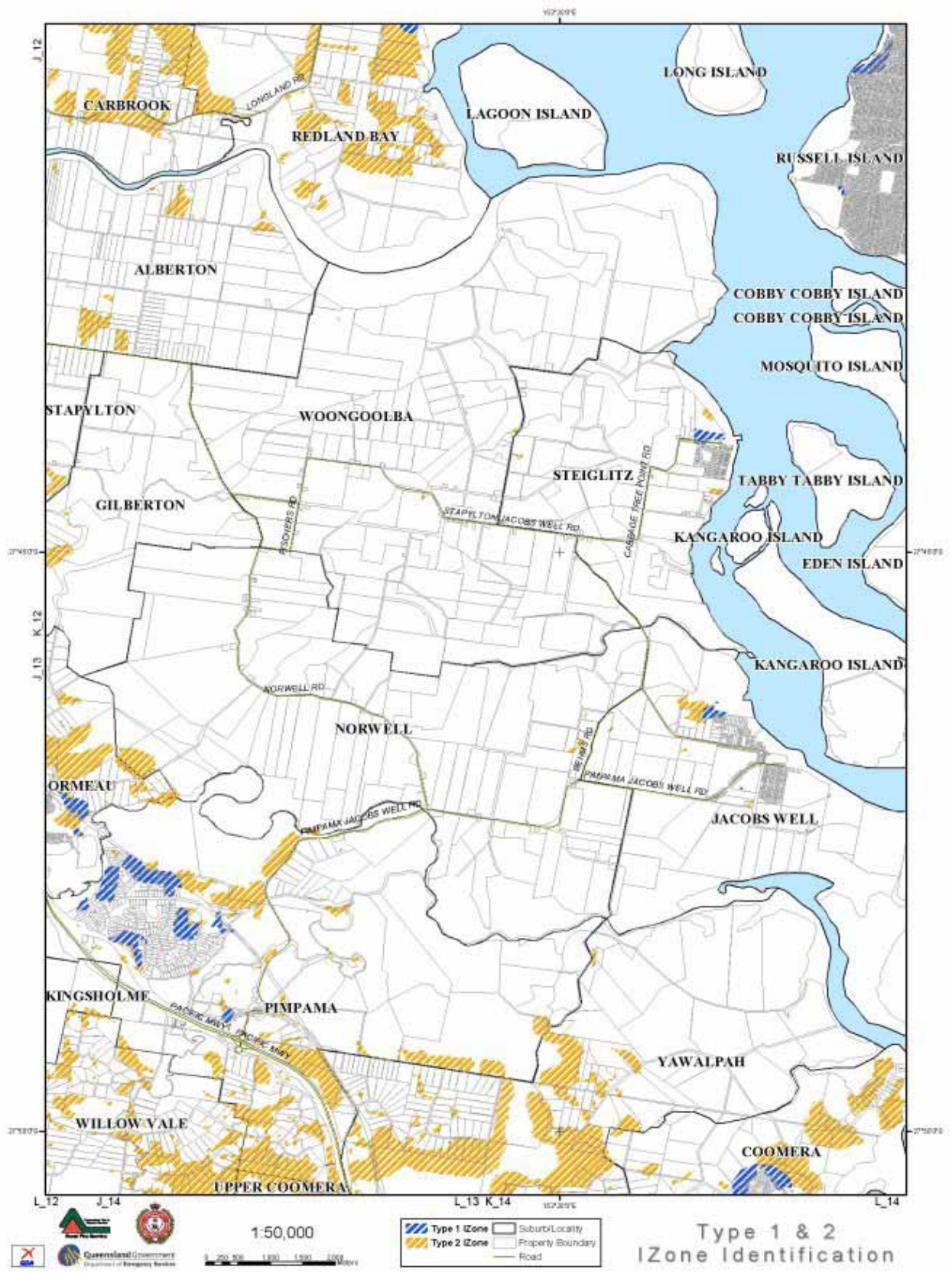

Figure 10.8 Northern Gold Coast 


\section{Current Situation}

Consequently, there is strong recognition that the interactions between the fire services and the communities they serve are crucial if there is to be successful avoidance of substantial losses to infrastructure and property, especially to interface zone housing. The legacy of some very poor planning decisions that were implemented three to four decades ago, exposing many interface zone housing areas to impact by high intensity fire is now apparent. As history has shown all too graphically, that threat can easily be realized whenever the necessary elements combine. A particular reason why interface zones are difficult to manage is that "appropriate planning protocols were not mandated until the mid 1980's, albeit in an ad hoc manner, with few of the necessary development controls keeping apace with new developments" (Koperberg, 2003, p. 2).

The impacts of fire upon the rural-urban interface are increasing for three primary reasons: fire suppression and less hazard reduction has led to increased fuel loads; fire risk has worsened due to drought conditions; and the population and density in areas of high fire risk is growing and ruralurban interface areas are growing rapidly, as more people seek to live in nonmetropolitan areas and near amenity-rich areas (Frentz, Farmer, Guldin \& Smith, 2004).

\section{Reconsidering the Future of the Interface}

The incidence of bushfire at the interface is dependent more on a set of environmental and human conditions than on a geographical location. Although the geographic location does dictate a set of general climatic conditions that encourage fires, the conditions in which interface zone fires occur (or have occurred) exist in nearly every community in the world. It is these conditional elements of weather, humidity, vegetation, building construction, road construction, lot size, housing density, topography, and other factors that simply make some communities more vulnerable to wildfire losses than others.

Smalley (2003) estimates that the most likely future is that "the grouth of communities into previously forested areas is one of the three major factors that will propagate the pressures of the interface on communities. The other two are unusually severe weather events (from prolonged drought to severe heating periods and floods that erode soils and vegetation) and inadequate infrastructure due to the rapidity of growth or aging" (p. 5). The issue of adequate infrastructure is the one that community-focused programs can most effectively change when implemented locally (Firewise Communities, 2003). It is more difficult to change the communities that already exist in 
hazardous conditions, however, there is a good opportunity to make wise fire-safety decisions at the outset of planning for new housing developments.

\section{Breaking the Cycle of Loss}

Planning for fire events and establishing creative incentives for encouraging homeowners to take appropriate responsibility are two things that community leaders should be doing immediately. Smalley (2003) warned that "insurance companies are not going to give significant premium adjustments for positive action, nor are they willing to increase premiums or cancel insurance for perpetuating hazardous conditions" (p. 7). Floods, earthquakes, cyclones and hailstorms are disasters that can be taken into account for adjusting insurance premiums, however, bushfires are an exception to this category. Reliable formulae to predict losses or project the mathematical expectations of wildfire occurrence are not available. Therefore, the data (loss and predictive) are not available to justify the financial decisions for adjusting rates and the bushfire risks that affect their bottom line.

What is needed are local solutions to encourage "doing the right thing". For example, if homeowners want to make improvements to their property (e.g. putting on a non-combustible roof) local government should provide real incentives. Perhaps waiving building permit fees for preventative improvements, waiving higher taxes on the preventative improvements, or providing community guidelines for preventative improvements would provide mitigating incentives. Homeowners, especially, must share the responsibility through active participation.

Smalley (2003) argues that "when the responsibilities are clearly defined and direction is provided, the paradigm of protector/victim is redefined" (p. 8). Firefighters and homeowners (along with other organizations) become partners. Community-wide and community-based fire protection can exist through mutually agreed-upon and mutually-respected responsibilities.

\section{Community Response during Bushfires}

The Australasian Fire Authorities Council (AFAC) has an agreed position in relation to community safety and evacuation during bushfires. Essentially this position advocates that where people have adequately prepared themselves and their houses and properties, they should remain with their homes during bushfires, rather than evacuate. Conclusive research conducted by agencies such as the CSIRO following major bushfires in Australia underpins this position. Most buildings lost in bushfires are the result of initially small fires started by sparks and embers. Buildings will 
generally survive the initial passage of a fire front providing adequate preparations have been made and providing people remain to extinguish small fires started in and around them. Exposure to dangerous levels of radiant heat created by bushfires is the greatest risk to people's safety. Consequently people who are prepared and take shelter in their homes are well protected from radiant heat. Last minute evacuations from bushfires are inherently dangerous and can create much greater risks than remaining in the fire area.

Most Australian fire authorities no longer support large-scale evacuation of people from areas threatened by bushfires. The approach advocated is to empower people and communities to take increased responsibility for their own safety. Gledhill (2003) advises that "this is a departure from the conventional paternalistic approach of emergency services in dealing with large-scale emergencies. It in many ways is a move back to the preemergency service era when communities were left to take care of their own safety" (p. 1). Such empowerment creates many advantages but also brings with it many challenges. Bushfires are a natural hazard which can be foreseen, prevented and combated to a greater degree than hazards such as severe storms, floods, earthquakes, tsunamis and volcano eruptions. Australian fire authorities have the challenge of reducing the negative impacts of bushfires on a community who increasingly wants to live close to the bush complete with all its natural attributes including fire hazards.

\section{Stay and Defend or Leave Early}

People who have not undertaken adequate preparation are advised not to stay and defend their property against bushfire. Where a house does not have sufficient defendable space and access to water supplies, the chances of saving it are greatly reduced and the danger for remaining occupants is increased. The advice therefore, for those people is to leave, but to do so early. Quite commonly in the Australian environment, because of the steep terrain and the rapid fire spread through spotting (fires started ahead of the fire by burning embers), there can be little warning time. Escape routes become blocked by smoke, fire, falling trees or power lines. In such cases when the dangers posed by escaping exceed those of remaining, clearly the best option is to stay.

The road systems in the interface and rural areas are typically not designed to handle high traffic flows and speeds, particularly when people are going in the opposite direction to responding fire appliances. The logistics of moving a lot of people quickly and safely make large scale evacuations very difficult. Television images of people with belongings packed, caught on blocked highways fleeing from danger are not uncommon. Even organized 
evacuations are not always orderly. Inexperienced and frightened people faced with evacuation from a terrifying fire may behave irrationally. Being told to go by authority figures - police or fire officers, is the final signal that all is far from okay. Seeing and hearing people in authority anxiously urging people to leave sends a very strong message that disaster is imminent.

The responsibility or duty of care of those who order evacuations is such that they are answerable to ensure that the evacuees are safe during the transit process as well as being safe in the chosen refuge. While fleeing from danger is a normal human instinct and not being there is the safest option, as discussed above there are many reasons why this is not a practical or safe option. Fire events are very dynamic and place specific. The orientation of the interface and the road network with respect to a fire front or series of fire fronts, as well as smoke effects make it very difficult to realistically simulate or predict bushfires. The inclusion of community factors such as demographics, community expectations and identification with the bush, and previous bushfire experience increase the difficulty of pre-incident planning.

AFAC implicitly accepts that there will be occasions, hopefully very rare, where a person will be killed by staying with their home. In such cases where a person's life is immediately at risk by them being in a particular location (in the opinion of the on-scene fire or police officer) they may be advised to evacuate. Should the advice be not heeded, then in most States, legislation enables evacuation to be ordered (with force if necessary).

Evacuation as a safety strategy has in the past been supported and employed in the belief that people are prone to panic and irrational behaviour when faced with an unfamiliar and threatening emergency situation. Evacuation from a bushfire can itself result in some people being exposed to greater safety risks at times, as well as often resulting in much greater property losses. In the absence of residents, property has to be defended by often limited fire-fighting resources. If people are well informed, prepared and empowered, they are capable of taking appropriate actions to protect themselves and their property without the need for evacuation or close supervision and direction by emergency services. Such active community involvement will free up fire fighting and emergency resources, allowing their more effective deployment.

\section{Lessons from a major bushfire at the urban-rural interface January 2003}

The Canberra fires of J anuary 2003 provided a special opportunity to draw conclusions from a fire that impacted on the critical area of interface zones 
and was readily observed by fire-fighters, scientists and members of the community. Four people died and many more suffered injuries. The fire had a significant impact on urban dwellings and burnt large areas of natural and commercial forest. Over 500 dwelling were destroyed. The Canberra fires reflected the characteristics of many other bushfires because they occurred in natural Australian bushland as a result of lightning strikes and they were of little media interest initially as they were in the hills. The issue of greatest concern was the destruction which occurred at the interface during one afternoon. Ellis (2003) described the following features of the fires that were unusual and make them of special interest:

“- $\quad$ they were well observed throughout the event

- a series of fires joined to create a super conflagration with unique characteristics

- the impact into the suburban fringe extended far beyond the initial street of houses" (Ellis, 2003, p. 1).

In the end, protection from bushfire is reliant on individual householders. During the Canberra fires in January 2003, individual residents or their neighbours saved the vast majority of homes. While fire-fighters may be in a position to assist, in all probability during a major bushfire, it will be individual planning, actions and preparations that will most likely determine whether they and their home survive. It is inevitable in Australia that bushfires will occur again. The outcome from those bushfires is dependent on the partnership between fire authorities managing the overall event and attacking and defending against the bushfire and individuals protecting their own lives and property.
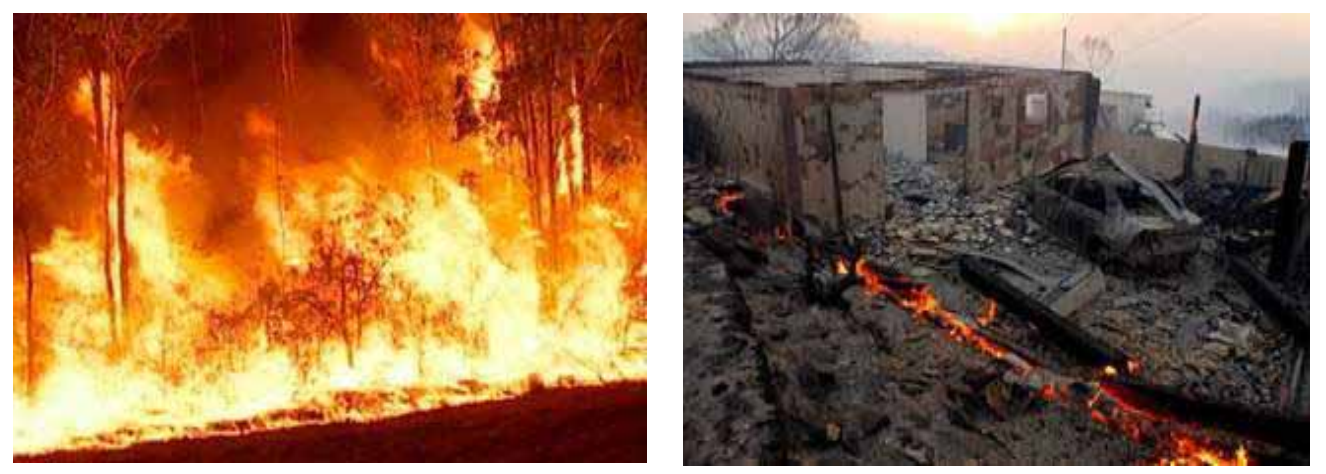

Figures 10.9 and 10.10 Canberra bushfires, J anuary 2003

Finally, the Canberra fires indicated to the Government that money spent on fire prevention and response is an investment in the future safety and 
sustainability of the community and although it comes at a cost, this cost is far less than the cost of community recovery after such a devastating event. Ellis (2003) noted that "fire prevention and preparation for response is insurance, and needs to be viewed as a valuable risk management approach" (p. 5). The Canberra fire event of 2003 developed into a firestorm that few had seen before and Canberra has not experienced on its urban fringe for many years. Unfortunately many of the lessons identified in Canberra are lessons re-learnt across the industry. However, this tragedy provides a powerful opportunity for the industry to reinforce these lessons and ensure communities are better prepared in the future.

\section{Social Considerations of the Interface}

The social issues sparked by bushfire are as diverse as the needs and uses of fire. Careful consideration of social norms and culture, economic needs and history of communities must be given to issues of suppression, fuel reduction, prevention, education, and other activities. What may be an acceptable practice in one location may have negative or even disastrous consequences elsewhere. What may seem a logical and practical step in one place may out of the question in another, solely due to social values. Indeed, social considerations may be as vital to the success of a prevention activity as a well-prepared shift plan or having the proper equipment available is to a suppression effort. Hamilton (2003) said "that community support is a direct result of a sense of community initiative and ownership, and not from a top-down, mandated approach" (p. 1).

The best of intentions and the best in technology are not guarantees that fuel loads will be reduced in the critical areas where homes and bushfire meet at the interface. As Hamilton (2003) notes, "Wildland-urban interface neighborhoods are social systems. Failure to work with the social system will probably doom efforts to promote fire hazard mitigation" (p. 1). The challenge to fire management leaders in Australia is to address these issues, exchange ideas and techniques, involve and listen to communities, and work toward solutions in individual neighbourhoods. It is only through the initiative and commitment of neighbourhoods and communities that prevention and education programs will make more permanent the changes that are needed to reduce fire danger to people and their possessions. Understanding what stakeholders think about bushfire, and linking these cognitive patterns (e.g. value orientations, social norms) to management actions, is an important first step in developing a scientific means to inform bushfire educational and communications programs. 


\section{Future Challenges}

Educating people in at-risk-from-bushfire communities about bushfire preparation is a significant challenge. Empowerment must extend beyond people knowing what to expect and how to react when threatened by bushfire. The stay and defend strategy is only effective if it is preceded by adequate preparation. Preparation isn't necessarily just creating a defendable space, but also mental preparation - knowing what to expect. Gledhill (2003) warned that "fire services need to be realistic in what they communicate to people in fire situations. The success of the strategy relies heavily on the people in affected communities making appropriate decisions. For that they need to have access to timely and accurate information about the fire situation" (p. 5). The emergency managers in those communities also need to conform to the policy. Gledhill (2003) also claims that "police and others need to accept that people will want to stay with their homes and need to be supported in place. They too need timely and accurate information". Whilst that seems reasonable, gathering timely and accurate information and communicating it to the people needing it, presents a considerable challenge. Gledhill (2003) identified that "whilst most firefighters appreciate the importance of accurate and up-to-date information, few have seen a need to provide it to the people at risk" (p. 6). The empowerment and consequent effectiveness of residents is dependent on them also having good information.

\section{Public Agencies Assisting Community-Based Solutions}

Increasingly, fire agencies recognize that they cannot protect all citizens from all bushfires. The limitations of both rural and municipal fire agencies become most evident during major fires at the interface (Boura, 1999; Cohen, 1999; Rohrmann, 1999; Tasmania Fire Service, 1994; Smith et al, 1991). Citizens too, are beginning to recognize that neither land management agencies nor local fire authorities can maintain fire suppression capabilities sufficient to conserve private property under extreme fire conditions. With this recognition, comes a growing understanding that the private property owner bears a margin of responsibility for protecting his or her own safety and property (Boura, 1999; Cohen, 1999; Ingalsbee, 2003, Waldron, 2001).

Progressive fire authorities are adapting to this changing operational environment by empowering people to take responsibility for their own safety and developing their own fire mitigation strategies. In fact, experience suggests that people will rigorously implement fire prevention and mitigation strategies only if they have helped develop them (Beckingsale, 1994; Boura, 1999; J urie, 2000). 
Progressive public fire agencies will adapt to this changing operational environment by recognizing the importance of empowering people to take responsibility for their own safety and developing their own fire mitigation strategies. DeGrosky (2003) stated that many of our best solutions are "community-based solutions which allow groups of people to rally around a commonly perceived problem that threatens their community; agree on the nature of the problem; and tackle it" (p. 1). Highly successful community efforts produce durable results, and derive from processes that are participatory, inclusive and highly collaborative. Successful communitybased solutions also require "community capacity," or an ability to act. A combination of commitment, resources and skills that a community can deploy represents that community's capacity to address a problem. Public agencies across Australia are exploring ways in which they can initiate and facilitate community efforts, build community capacity, develop commitment and produce lasting results.

Increasingly, "community-based solutions" provide effective, and perhaps the best, solutions to public policy issues. DeGrosky (2003) stated that "successful community-based solutions typically share three essential characteristics. First, they are collaborative. Second, they are inclusive. Finally, they get people involved, resulting in commitment that allows durable or lasting results" (p. 2). The desired outcomes of self-reliant communities adequately preparing themselves and their homes for bushfire are much more likely to occur in the future if there are steps towards a realistic resolve in tackling the "what-ifs".

\section{Collaboration}

In regard to community initiatives, collaboration occurs when people with different viewpoints work together to foster mutual understanding, build agreement and resolve disputes regarding community issues (Helling, 1998; Margerum, 2002; McKinney, 1998). According to Helling (1998), "collaboration creates a temporary forum within which consensus about the problem can be sought, mutually agreeable solutions can be invented, and collective actions to implement the solutions can be taken" (p. 336) The value of a collaborative process lies in the ability to produce inclusive, sustainable results that people implement with commitment. However, community organizers may also encounter members of community groups and task forces who view the act of collaborating as a sufficient accomplishment in itself. Given the growing desire for processes that produce results, public fire authorities hoping to foster community-based solutions to fire problems with lasting results would be wise to measure their success by the results produced, rather than simply by the tools they use. 


\section{Inclusion}

Successful community initiatives involve those people affected by the issue, those needed to implement any agreement, and anyone who may undermine the process if not included (McKinney, 1998). This description provides an effective definition of a class of people commonly known as "stakeholders." Helling (1998) provides an alternative definition, characterizing stakeholders as "all individuals, groups or organizations that are directly influenced by actions others take to solve the problem" (p. 336). In practical terms stakeholders are parties with an interest in an issue and may include individuals, groups of people, organizations or institutions.

Successful community-based solutions typically evolve from efforts that include all relevant stakeholders, regardless of perspective. Efforts primarily driven by agencies, without sufficient involvement by stakeholders, run the risk of rejection by the community as "just another government program". The success of community initiatives facilitated by government agencies (whether the local volunteer fire department or the Federal government) largely depends on conscious decisions that the facilitators make about inclusion and cooperation. No formula exists for determining the appropriate degree of inclusiveness and collaboration for a given project or circumstance. However, most often, as involvement and participation go up, commitment and potential for success follow.

There exists a tension and a system of competing forces. DeGrosky (2003) explained this is because "collaborative approaches nearly never accomplish work expediently. The value of collaboration lies in the potential for higher quality and more lasting outcomes that a group effort brings". While public agencies naturally, and rightly, seek a compact and efficient public process, with each decision the organizers make to exclude people or groups, they lessen the likelihood that those people or groups will feel like they are an adequate part of the plan or decision. DeGrosky (2003) warned that "stakeholders, unsatisfied with their role or influence in a process, rarely support the resulting decision or plan. Similarly, with each decision that the organizers make to reduce collaboration, in other words to reduce the influence the group has over the process, the problem definition, the solutions and implementation, the greater the possibility that people will grow unsure, apathetic, resistant or hostile to the decision, plan or solution" (pp. 3-4).

\section{Involvement, Participation and Commitment}

To succeed, community-based initiatives require commitment both by the involved communities and by the involved public agencies. A community 
achieves commitment when it obtains sustained support throughout implementation of the solution, agreement or decision. Commitment to community-based solutions requires the active participation of community members. Doyle (2001) asserts that implementation will be incomplete and will be likely to fail without participation.

With perspectives on the responsibility of the private property owner shifting, public fire authorities have shown increasing interest in empowering people to take responsibility.

Ideally, a group of people rallies around a commonly perceived problem, agrees on its nature, and finds and implements the solutions to the problem with a high degree of commitment. Unfortunately, as DeGrosky (2003) advises, "this kind of effort remains relatively uncommon, particularly because they require public agencies and their staffs to relinquish a degree of control that they have traditionally maintained, and often require agencies and their personnel to significantly alter their relationship and approach to the community" (p. 5). Typical efforts organized by public agencies allow for public involvement, and they increasingly include most, if not all, stakeholders. However, DeGrosky (2003) explained that "too often, agency led efforts fail to meet the expectations of either the agency or the community. One reason is that, even when inclusive, communities perceive agency-based efforts as token, insincere or somewhat coercive" (p. 5). Too often, public agencies simply go through the motions of involving the public, bringing groups of people together merely for the purpose of fulfilling legal requirements or to create the impression of "public involvement." In today's operational environment, they do so at their peril; as half- hearted or lessthan-sincere efforts tend to breed distrust and can produce the unintended consequence of inspiring the active resistance of citizens.

Herein lies a relatively new and evolving role for the public fire agency. This new role builds upon and enhances, rather than diminishing or replacing, the traditional function of the fire service. Progressive fire authorities increasingly recognize their role as community capacity builders and their responsibility to create awareness, motivate community members to take responsibility, and to facilitate community-based solutions (Frank \& Smith, 2000; Lipnack \& Stamps, 2000). Most communities will need the assistance of a fire agency as they develop their community-driven fire mitigation responses. For example, in an evaluation of Community Fireguard programs in Victoria, Rohrmann (1999) found that a considerable degree of guidance and direction is necessary in order to get resident groups activated and eventually taking responsibility for improving fire preparedness. 


\section{Fostering Community-based Solutions}

The Australian Community Fireguard programs provide an example of an effective collaborative approach through which public fire authorities enable community-based solutions and help communities to build capacity. Community Fireguard initiatives provide a unique case study because the program has existed for ten years. Both anecdotal evidence and scholarly research offer evidence that this community-based approach benefits residents in fire-prone areas and improves fire risk mitigation by both individuals and the community. Preliminary findings by Rohrmann (1999) found considerable potential for the Community Fireguard concept, and offer encouragement that inclusive, participatory and highly collaborative fire mitigation efforts can achieve durable results that originate from the community (Beckingsale, 1994; Boura, 1999; Rohrmann, 1999; Tasmania Fire Service 1994).

Originally conceived by the Country Fire Authority (CFA) in Victoria, Community Fireguard programs have spread to other Australian states including New South Wales, South Australia and Tasmania. This community-based initiative allows groups of people to come together, agree on the nature of a fire problem threatening their community, craft solutions that make sense for the community, and develop "community capacity," or an ability to act. According to Boura (1999), Community Fireguard programs "involve small groups of people living in high fire risk areas, taking responsibility for their own fire safety and working together to devise survival strategies which suit their own situation" (p. 6). Most Community Fireguard groups are self-initiated by members of the community.

The proportion of a community who effectively prepare for a bushfire varies greatly. Recent large-scale studies of community response to bushfire include the survey of 1200 residents affected by the NSW 2001 fires undertaken by Rhodes (2003) on behalf of AFAC, and a major quantitative study of preparedness in Victoria completed in 2002 by CFA. Rhodes (2003) found that "in some of the surveyed communities approximately half the population might be considered moderately to well prepared. However, in many communities the level of preparedness was lower, with a large proportion of the population poorly informed and prepared" (p. 9). There are many factors that are likely to determine the extent to which people become prepared. One of these factors is the extent to which the community is exposed to information and programs to increase preparedness. Evaluation of CFA community education programs (Rohrmann, 1999) indicate that such programs do lead to increased preparedness, but also that change is not uniform for all participants and that it is incremental and occurs over the long term. 
When it comes to fostering community-based solutions, the appropriate role for public fire agencies depends on the circumstances and on the agency's needs and motivations. The agency may choose to remain in the traditional role of community educator, stakeholder or other vested participant; convene the collaborative process; or facilitate the group effort. Depending on the circumstances, all the roles described here may prove appropriate for public fire agencies, and all can fit into a community-based, collaborative process. DeGrosky (2003) advises that "to effectively influence communitybased initiatives, public fire agencies must consciously decide and make clear the agency's role and its motivations for participating" (p. 6). Given the growing desire for processes that produce results, public fire authorities hoping to foster community-based solutions producing lasting results are advised by DeGrosky (2003) to "assure that the collaborating parties establish objectives for the outcome of the process and articulate criteria for evaluating results" (p. 9).

\section{Successful community programs}

Successful community programs share the following five common traits:

1. Identify the particular interface bushfire problems of the community

Interface zone bushfire problems are different throughout the country and have the potential to develop in all states and affect communities of any size. Therefore, cause and effect of bushfires are a significant factor to consider in planning for local, regional and national contexts.

\section{Define roles for the affected agencies and individuals}

Changing attitudes and behaviour is a complex task even when the goal seems simple in attempting to reduce the threat from bushfire faced by people, homes and natural resources. The value of involving all of the affected agencies has long been understood. The roles of the members of the working team must be defined to improve efficiency and to prevent wasted or duplicated effort. The best organizational effort will be able to harness the strengths of each team member. Roles are best defined when the process is done formally, in writing.

\section{Secure inter-agency cooperation}

The value of inter-agency cooperation is clear in that a team/ group can accomplish more than an individual when the goal affects a large number of people. The tough part is getting separate agencies with different priorities and perspectives to work together. To help this cooperative process, the U.S. 
National Interagency Fire Center published six steps to help improve fire protection effectiveness.

The six steps from the National Interagency Fire Center (NIFC, 2001) include the following:

- $\quad$ Obtain the commitment of the separate agencies to work together;

- $\quad$ Examine your problems together;

- $\quad$ Set joint goals and objectives;

- $\quad$ Develop programs and policies;

- $\quad$ Approve and implement the plan;

- $\quad$ Evaluate and revise the program as needed.

4. Develop public support

If lack of public awareness of interface zone bushfire safety contributed to the dangerous conditions seen in many areas, better public education will be a key element in improving those conditions. The first task, and the hardest, is to get the public's attention. To reach varied audiences with such a wide demographic range requires an extensive and intensive media campaign involving a maximum sharing of information about every aspect of the problem.

5. Implement, coordinate and evaluate programs.

Ultimately, it takes action to change public attitudes and behaviour regarding bushfire safety. The successful programs show that there is no single answer or approach that will produce perfect fire safety in every community under all conditions. Good planning is essential, but eventually those plans must be translated into programs that are implemented and coordinated to keep them on target. After the programs get under way, an objective evaluation helps measure the success and serves to refocus efforts as needed to improve success. 


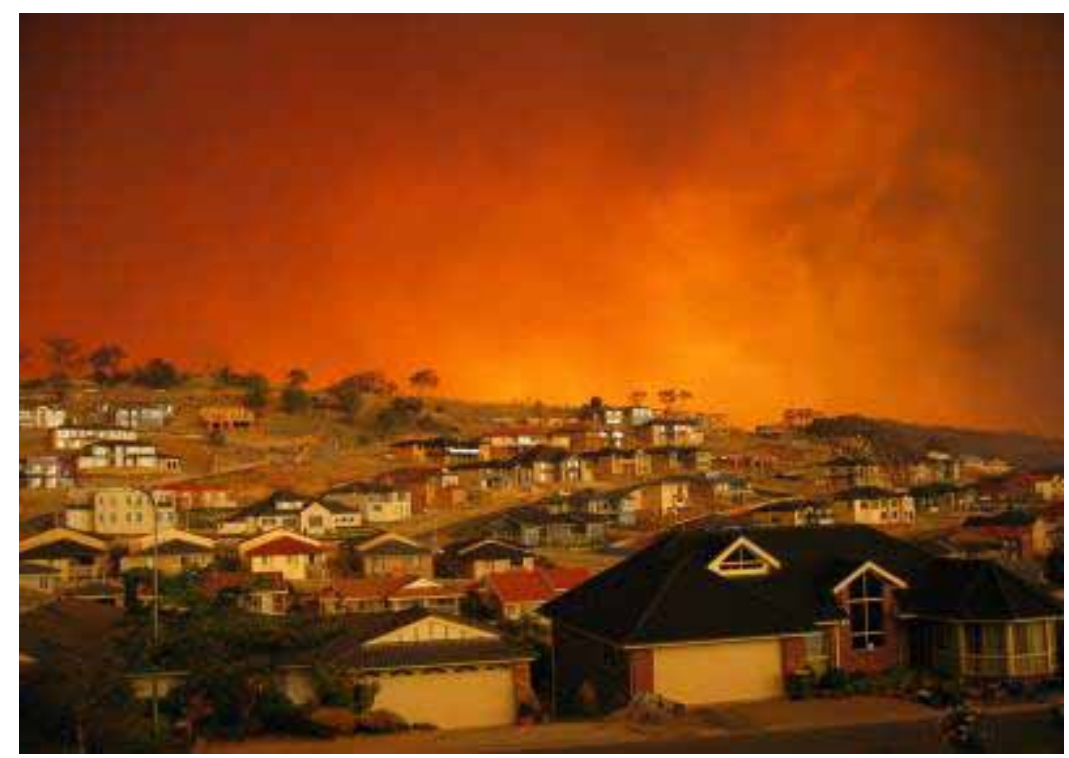

Figure 10.11Canberra bushfires, J anuary 2003

Interface bushfire management requires collaborative partnerships for planning, implementation and evaluation of global concepts on the local landscape level. Over time, it is hoped that fire services help communities to become more self-reliant.

\section{Conclusions}

As more people move out of cities to the interface, tragic and disastrous bushfires will inevitably occur. Whilst people, directly and indirectly, are by far the greatest cause of bushfires in Australia, controlling people and their use or abuse of fire is not a realistic or practical solution. Empowering the communities at risk from bushfire to play an active part in their own safety and in the protection of their assets in partnership with the fire services is a viable long-term strategy to enable safe co-existence with fire as a natural element of the environment. The combined efforts of fire protection services, legislators, planners, developers, land owners and homeowners will be required to prevent tragic loss of lives and homes at the interface. For fire services to provide these communities with effective protection from bushfire requires a holistic approach based on the needs and aspirations of all community members. In many instances the local community that is potentially at risk needs to be educated on those risks and the consequences of action, as well as inaction, if they choose to ignore the risks.

Australia has realised that long-term planning and commitment from all levels of government can sustain investment in research and development 
for safer communities, economic development and fuels management and forest health. Collaboration is required among the many stakeholders to assess and prioritise which interface zones and landscapes to concentrate on and to reconcile conflicting management objectives. 


\section{Living with bushfire: What do people expect?}

\section{Sally Bushnell and Alison Cottrell}

The physical and economic impact of bushfires has been well documented, particularly in the United States of America. A National Interagency Fire Centre (NIFC, 2003) report revealed that in 2002, more than 88,450 recorded fires burned 6.9 million acres and 2,381 structures, and the total suppression cost for the federal agencies reached \$US1.6 billion. Figures for preceding years are similar, but suggest that these impacts from bushfire are growing in magnitude. Similar bushfire impacts have been recorded in Australia. The Ash Wednesday bushfires of $16 \mathrm{~J}$ anuary 1983 are perhaps the most renowned in Australian history, and the following statistics suggest why: in Victoria and South Australia 76 people died; 2,463 houses were destroyed; and 360,000 hectares of land was burned (Ramsay \& Rudolph, 2003), total property loss were estimated to be over $\$ A 400$ million (Willis, 2004). The J anuary 2003 bushfires, in New South Wales, Victoria and South Australia, rivalled Ash Wednesday in terms of widespread destruction and property loss (Gilbert, 2004), where four lives were lost, over 500 homes destroyed and total damage cost more than $\$ A 300$ million (Willis, 2004). The 2003 fires were also a harsh reminder of how susceptible Australia is to bushfire. In a global context, Australia is widely regarded as the most fireprone country (Rohrmann, 1999; Gilbert, 2004). Furthermore, the situation may be worsening due to long-term droughts and higher average temperatures (Whittaker \& Mercer, 2004).

Loss of life and property, and the economic costs associated with suppressing fires and recovering from fire, are significant and obvious outcomes of bushfire, however there are many other impacts and costs of bushfire which are often not anticipated because they are more indirect and therefore not as obvious to the general public. These include social and economic costs to the individual, family and community such as the loss of livelihoods, interruption of life patterns and relationships, and in some cases the entire social fabric that defines a population as a community can be severely weakened (David, Baish \& Hearn Morrow, 1999).

Because fire is, in general terms, a natural ecosystem process (Beringer, 2000), it is a hazard or a disaster only when human life and property become 
threatened or destroyed; "The disaster itself occurs within society and not within nature" (Weichselgartner, 2001: 86). Indeed, in many areas of Australia and the world that have evolved with fire, bushfire plays a positive and sometimes crucial role for native vegetation and animals, which depend on fire for regeneration, refuge, protection and reproduction (Beringer, 2000; Haswell \& Brown, 2002). Accordingly, the climate, vegetation type and existence of ignition sources characteristic of these areas are compatible with fire and thus indicate that fire is inevitable (McGee \& Russell, 2003).

In many countries, including Australia, there is a growing pattern of population movement into peri-urban areas (Hugo, 2002). These areas tend to be bushfire prone and because of the resultant, ever-increasing mix of people, property and bushfire (leading to the potential consequences of physical, economic and social impacts described above) bushfire is now a significant hazard (McCaffrey, 2004).

\section{The peri-urban area and bushfire risk}

Cottrell (2005) summarised a number of terms used to describe the periurban area, these include the wildland-urban interface, rural-urban fringe and exurban, for example. The peri-urban area includes the extension of urban areas into rural areas and regional urban areas. There are many types (see Cottrell, 2005), however all peri-urban areas are typically areas where structures (whether residential, industrial, recreational, or agricultural) are located adjacent to or among combustible wildland fuel (CFS, 2004). There are many reasons why people are moving into peri-urban areas, a commonly cited reason is the attraction to rural areas because of the associated aesthetics of the landscape; other reasons include cheaper house prices and reduced crime, pollution and crowding (Monroe, Bowers \& Hermansen, 2003a). In essence these are quality of life issues.

However, with the potential benefits of living in the peri-urban area come potential costs. The peri-urban area is the most fire vulnerable due to mixture of bushland, houses, people, paddocks and stock (Haswell \& Brown, 2002). The fire risk exposure has indeed grown significantly over the last several decades (McKee, Berrens, Jones, Helton \& Talberth, 2004) and is expected to increase as peri-urban populations grow (Gardner, Cortner \& Widaman, 1987). Furthermore, it has become quite clear that many bushfires cannot be fully controlled resulting in serious economic, social and ecological damage, as demonstrated by the previously mentioned statistics. Therefore, people living in peri-urban areas are exposed to a significant level of risk from bushfire and its consequences. 


\section{Reducing the risk}

Traditionally risk reduction strategies have been the responsibility of the government and its agencies, and have included fire suppression, fire prevention through reducing fuel loads and building firebreaks, building codes and zoning (the latter two however have not been implemented to such an extent, and not necessarily with other strategies, to significantly reduce the bushfire risk). More recently there has been a redistribution of rights and obligations and/or changes in the allocation of costs and benefits from the government to the public (Winter \& Fried, 2000). For example, educational messages are commonly disseminated to the public to encourage individual fire prevention efforts (e.g., create a defensible space around the home by clearing vegetation), ordinances have been imposed requiring individuals to fireproof their homes (e.g., retrofitting roofs) or to pay tax on additional fire protection, and homeowners are often motivated themselves to take preventative measures voluntarily and/ or engage in community programs to reduce the fire risk to themselves and their neighbourhood (Winter \& Fried, 2000; McKee, Berrens, J ones \& Talberth, 2004).

Given that bushfires are often uncontrollable and fire-fighting and other emergency services and resources become so overwhelmed that it is impossible to provide people and property with adequate protection, people need to take some responsibility to protect themselves and their property. However, there is considerable empirical evidence that households in areas prone to natural hazards risk under-invest in protective measures (McKee et al., 2004). Government intervention has often been unsuccessful due to lack of enforcement of ordinances, lack of support from the public or opposition to fire prevention strategies, and the public have often been unmotivated to take action themselves due to a lack of incentives or a lack of understanding of the risk (Winter \& Fried, 2000; McKee et al., 2004).

There are no guides to 'best practise' for community safety, not one strategy or combination of strategies are necessarily successful, nor have been adequately successful as discussed above. Therefore bushfire in the periurban areas has become a major, often contentious, issue, and mitigating the risk and reducing the impact of bushfire is a problematic and complex challenge, but one that requires urgent attention. In addressing the challenge, input from the community at risk is important, if not crucial. Policies and management strategies should reflect what people expect or at least will accept. But what do people expect? Intuitively, people do not want to lose their lives or house to bushfire or suffer any other consequences of bushfire, but do they perceive the risk? Do they actually expect a significant impact? And in terms of protection and resilience, what do they expect of themselves? What do they expect of the fire service? What do they expect of 
the government? To answer these such questions, this paper will review the literature to gain a better understanding of people's knowledge, perceptions, attitudes and expectations in relation to bushfire.

\section{The peri-urban community}

The term community can have a wide range of meanings. A community is a group that has a number of things in common, which may be defined by location, interests, or function for example. A person can belong to a number of different communities, and there can be a number of different communities within a single location. Furthermore communities are not static with changing membership, ideologies or beliefs, for example (Boughton, 1998; Marsh, 2001; Cottrell, 2005). Defining and typifying communities in a location, and their members, is therefore a complex, if not impossible, task, and this may be especially so in peri-urban areas where there is substantial mixing of rural and urban community characteristics.

There are a number of possible factors influencing the diversity of peri-urban communities. Perhaps the most obvious is the composition of communities. Along with long-term residents, there is an influx of people from urban areas which indicates a high proportion of newcomers with urban rather than rural backgrounds, and due to the attraction of the beauty of the rural landscape, there is also a number of weekend and seasonal residents, and holidaymakers. Therefore, substantial differences both within and between peri-urban areas may be observed in terms of demographics and socioeconomic status, life experiences, knowledge, attitudes, opinions, perceptions and expectations, for example. Furthermore, J akes et al. (2002) also highlighted differences in social capital, human capital and cultural capital between locations within peri-urban areas. Such differences can have a significant bearing on bushfire management, and community preparedness and resilience, and further highlights the issues for fire policies and services. For example, Brunson and Shindler (2004) argue against the "one-size-fitsall" policies and strategies (about fuels management). They found differences between respondent knowledge and acceptability judgements of wildland fuels management, which was associated with location-specific social and environmental factors as well as individual beliefs

\section{Bushfire awareness and risk perception}

Until recently, bushfire has not been perceived as a significant hazard (McCaffrey, 2004). Perhaps because throughout history (unlike other hazards) fire was depended on for warmth, cooking, and to heat water (De Cicco, 1990), and complete fire suppression was successful until only the last few decades. Today it is clear that bushfire is in fact a significant hazard, and 
growing numbers of people are at risk. Risk however is a complex concept, but Meacham (2004) has provided a broad definition:

[Risk is] the possibility of an unwanted outcome in an uncertain situation, where the possibility of the unwanted outcome is a function of three factors: loss or harm to something that is valued (consequence), the event or hazard that may occasion the loss or harm (scenario), and a judgement about the likelihood that the loss or harm will occur (probability) (p. 204).

Assessing risk involves both judging the likely occurrence of an event and the likely damage that will be incurred, thus risk perception can be extremely subjective, especially in regards to bushfire risk (McCaffrey, 2004). There is evidence that risk is perceived differently by experts and non-experts; "experts" tend to base their perception of risk on statistics, however risk perception for lay people is much more complex. Therefore, in addressing risk issues, it is important to understand the risk perception of those at risk to move beyond a purely statistical approach (Meacham, 2004).

Lupton and Tulloch (2002) conduced interviews with a group of Australians to gain a better understanding of the ways in which a range of risks are understood and dealt with by lay people, and how their risk knowledges are constructed and maintained or transformed. They found that risk was defined differently by different interviewees, but the major discourses centred around "the notion of risk as negative, frightening, involving taking a step into the unknown but also a degree of rational judgement and choice on the part of the individual concerning whether or not to take this step" (Lupton \& Tulloch, 2002, p. 331). The interviewees own position in the life course, their gender, age, sexual identity, class and so on phrased the risks to which people felt they were exposed. Risk was seen as a part of life and also strongly tied to an individual's life situation, which both exposed them to certain risk and influenced the ways in which they viewed phenomena as risks or not. Many described a life course trajectory of risk-taking and riskavoidance involving risk-taking when young, avoiding voluntary risk-taking when responsibilities such as family were important, and some reported increased risk-taking again in later years when responsibilities lessened. Few people avoided risk-taking altogether, in fact many argued for the importance of deliberately taking risks.

In Lupton and Tulloch's (2002) study, bushfire was not perceived as a risk to the interviewees themselves nor as a risk to fellow Australians, which is not surprising given that the study was not limited to any particular type of risk, and interviewees were not necessarily at risk of bushfire. However, it was noted that environmental problems in general were not identified as major 
risks by the majority of interviewees. Although "environmental problems" encompasses a wide range of potential risks, it does include natural hazards such as cyclones and floods, as well as bushfire, the risk to which many Australians are exposed. One possible explanation is that perceived risks (to Australians) were closely tied to current issues receiving extensive media attention and public debate at the time of study. Perhaps if the study were undertaken after the 2003 bushfires, which received plenty of media attention and public debate, bushfires may have been identified by interviewees as a risk facing fellow Australians. However, there is evidence that people, even those directly exposed to the risk, simply underestimate the risk of natural hazards (Cunningham \& Kelly, n.d.).

Gaps between individual and community perception of risk and the objective data on the magnitude, frequency and consequences of the hazard can be influenced by a number of issues. Natural hazards, including bushfire, are relatively infrequent and not part of everyday life for a given individual or community, and are thus easily forgotten. Information on the nature of the hazard may be incomplete or ambiguous. In the absence of information, risk estimates are based on little data. Acknowledging the risk may bring about an uncomfortable psychological state, and coupled with the inherent uncertainty of hazards, individuals may resort to various mental strategies including denying the risk (e.g., "it won't happen to me"), or giving in-place adjustments (e.g., fire suppression) the power of complete rather than partial protection, or reasoning that if an event happened recently it won't occur again in the near future (Cunningham \& Kelly, n.d.; Kumagai, Carroll \& Cohn, 2004a; McCaffrey, 2004). Furthermore, "dread risk", "unknown risk" and number of people exposed have been found to influence the gap in risk perception and actual risk. Bushfire fails to score high in this instance also: in some cases bushfire evokes little dread due to a feeling of control by agencies undertaking suppression of fires. McCaffrey (2004) argues that in Canada the extent of bushfire is reasonably limited and there are few fatalities, particularly in more recent times; bushfire and its effects are wellknown; and few people are exposed due to adequate warning for evacuation. Individual risk perception can also be shaped by the community in which the individual lives. Risk perceptions are filtered by community influences such as shared experience and existing power relationships, and a cohesive community will continually shape and mould their collective perceptions of problems (Flint \& Luloff, 2005). Gough (2000) inferred from her study that community structure and cohesiveness is linked to a better understanding and acceptance of natural hazard risk. 


\section{Vulnerability and Risk}

Vulnerability is inextricably linked with risk. Vulnerability describes the degree of susceptibility to harm of those at risk (Young, 1998). Vulnerability, in terms of natural hazards, is obviously influenced by geography; a person living in a fire-prone area is thus vulnerable to the effects of bushfire. However, how vulnerable a person is can be influenced by socioeconomic characteristics and other characteristics of the individual, knowledge and experience of the hazard, and also the community in which a person lives in terms of social structures, community cohesiveness and support, and the structural environment in terms of infrastructure (Young, 1998; AndersonBerry, 2003). Vulnerability can also be determined by a person's perception of risk; a person who underestimates the level of risk will likely expose themselves to the risk to a greater extent than a person with more realistic perceptions thereby becoming more vulnerable (Anderson-Berry, 2003). Vulnerability however, similarly to risk, is not always perceived realistically. People with adequate threat knowledge and risk perception do not always perceive their own susceptibility to the threat, and furthermore often perceive that, in the event of a hazard, that they would be resilient and recover quickly (Odgers, 2002). For example, when a person has experienced a minor hazard, or even survived a disaster, they may infer from their ability to cope in that instance the ability to cope with any future occurrence of the hazard, or assume that a future occurrence will not exercise an adverse influence on them (normalisation bias). In addition, people often simply rate themselves less vulnerable, and more skilful than average (optimistic bias) (J ohnston, Bebbington, Lai, Houghton \& Paton, 1999; Kumagai, Carroll \& Cohn, 2004a). Also, a person who has taken a step to reduce the risk of their house burning (e.g., created defensible space around their home) may be overconfident thus underestimating their vulnerability (a whole suite of strategies may need to be employed to significantly reduce the risk) (Montz, 1993).

In view of the above discussion, the perceived risk of a natural hazard and vulnerability of those at risk to the hazard is distorted primarily by ignorance and non-comprehension of the hazard. However, people are not entirely unaware of the risks and often do have a good understanding of the risk as well as their own vulnerability but chose to accept or tolerate it. According to Handmer and Penning-Roswell (1990) (in Gilbert, 2004), the perceived probability of a natural hazard is not only distorted by ignorance and noncomprehension, but by recognisable and tangible benefits of the non-hazard experience, and by the existence of family and friends nearby (i.e., awareness of a sense of community). Ultimately, people balance the perceived risk and the benefit of living in a particular area: the higher the perceived benefit, the greater the risk tolerance (McCaffrey, 2004). 
Understanding the risk perceptions and vulnerability of communities in hazardous areas is important for a number of reasons. Perception of risk and vulnerability can be extremely subjective, and peri-urban communities in particular may have diverse levels of risk perception, in contrast with other areas, because of a diversity of people living in peri-urban areas. Risk perception has been linked to preparedness; at least in theory, a person who perceives a high risk is more likely to act to reduce exposure than a person who perceives low risk (Beringer, 2000; Odgers \& Rhodes, 2002; AndersonBerry, 2003; McCaffrey, 2004). Furthermore, level of risk perception has been found to be influenced (to a variable extent) by awareness-raising programs (Rohrmann, 2000ab; Anderson-Berry, 2003). Therefore, in understanding the risk perceptions of people in a community and how they may be influenced, and identifying those who are particularly vulnerable, a community-based approach can be incorporated, which increases the adaptability of community safety policies, strategies and programs addressing risk issues to the uniqueness of the situation as required. Additionally, because people will accept or tolerate risk to a certain degree, an understanding of risk perceptions of the community at hand and the factors which distort perceptions can determine an acceptable level of risk on which policies, strategies and programs may be based.

As would be expected from the discussion of communities and risk perception thus far, a variation in levels of inter- and intra-community risk perception would not be surprising. Research into peri-urban resident's perception of bushfire risk has indeed revealed that there are considerable variations. For example, Monroe and Nelson (2004) found that a large majority (84\%) of sampled homeowners in Minnesota and Florida were very aware of their risk of wildfire, McGee and Russell (2003) reported that almost all respondents (90\%) in a Victorian community adequately perceived the risk of bushfire, and Beringer (2000) compared two communities in Victoria and found that about half (52\%) of the residents in one community and less than half (36\%) in the other were aware of the high bushfire risk in their area.

\section{Perception of Risk Levels}

In McGee and Russell's (2003) study, the high level of risk perception of many of the respondents, and a good knowledge of bushfire, can be attributed to past bushfire experience and a close association with the local fire brigade. Furthermore, the cohesiveness of the community appears to have lead to similar realistic perceptions of risk of other community members who do not have the same direct experience with fire and have not been as involved with the fire brigade. Unfortunately this community is more of a 'model' community rather than a community representative of peri- 
urban communities. Not all peri-urban communities are as cohesive, which will be explored further in following sections, or as involved with the local fire brigade. This community has more rural than urban characteristics and is very cohesive. The authors did mention that there was some degree of separation between established farm-families and people living on smaller blocks, particularly newcomers, but high levels of risk perception were being maintained through contact between newcomers and the fire brigade, initiated by the fire brigade. Perhaps this community is more representative of a process where community cohesion and the existing social, human and cultural capital is sufficiently strong to maintain the bushfire risk perception.

Although this was not addressed by McGee and Russell (2003), a number of authors have linked risk perception with level of community cohesion in growing peri-urban areas (Anderson-Berry, 2003). For example, Gilbert (2004) observed "the diminishing importance of community [in a Victorian peri-urban area] with increasing numbers of new arrivals to the area" (p. 40 ), and found spatial differences in risk perception that were tied to community cohesion: people living in the more established and community oriented streets were far more aware of the bushfire risk than people in newer areas.

Beringer (2000) also observed significant differences in bushfire risk perception between newcomers and long-term residents in his study. He explained that new residents cannot identify their level of exposure to risk until they assess the hazards to which they are exposed. He attributed a delayed assessment of the hazard to the reluctance of some people to believe in the reality of a threat, and the interval between moving to the area and receiving bushfire literature from the fire brigade. Information programs have indeed been linked with increased awareness of bushfire risk (Rohrmann, 2000ab; Anderson-Berry, 2003). However results from assessments into the effectiveness of such programs are inconsistent. Providing information on bushfire risk is not a straightforward process and there is not one type of material or method that is consistently successful in raising awareness of risk, and information sources are further subject to a person's biases and preconceptions (McCaffrey, 2004). In any case, newcomers to peri-urban areas appear to become more aware of the bushfire risk over time, and the higher the initial awareness the more aware a person will be with time, leading to a high perception of risk (Gardner, Cortner \& Widaman, 1987). Therefore the initial period of residency of newcomers to peri-urban areas is an important time for developing perceptions of bushfire risk, and low awareness can correspond with the time of the year that the home is purchased (Cortner, Gardner \& Taylor, 1990). In the non-bushfire season, the bushfire risk is not always obvious because of the deceptive appearance of the landscape, and bushfire would not be a current issue 
leading to a possible lack of education and social information indicating the bushfire risk. Additionally, the acceptance of risk depends on the degree of confidence placed in the organisation charged with its management (Smith, 2001 in Gilbert, 2004). For example, distrust in a government may mean that any information received through that government is disregarded thus having no impact on risk perception. There appears to be a greater trust in community-based organisations, such as the local fire brigade and their community schemes, than governmental organisations (Gilbert, 2004).

Gardner et al. (1987) investigated newcomers' perception of risk over time and found that $6 \%$ of respondents surveyed in two Californian communities perceived the fire situation to be very serious at the time they bought their house. At the time of the survey the proportion of homeowners perceiving a serious risk had increased to $27 \%$. These results may reflect newcomers growing connection with the existing community and an increased share in the communities' social, human and cultural capital over time or the exposure of respondents to fire information and brigade personal, for example. Gardner et al. (1987) mentioned that increased awareness of bushfires in their particular study was due to respondents witnessing recent bushfires in the area or obtaining information on these bushfires from media coverage. Many studies have reported that respondents with past personal experience of bushfire have a significantly higher awareness of the risk of bushfire than those with no experience (Blanchard \& Ryan, 2004; McGee \& Russell, 2003; Gilbert, 2004). Winter \& Fried (2000) stated that direct and indirect (e.g., via accounts from neighbours, friends and mass media) experiences with wildfire are more influential in perception formation and reinforcement than the hazard information received by homeowners in their study.

Gardner et al. (1987) also compared risk awareness and perception of risk of people in a fire-affected community and in a non-affected community. They interestingly found that risk awareness in the community that was affected by the bushfire tended to remain low, the non-affected community felt more aware of the danger of bushfire in their neighbourhood. Furthermore, respondents from the affected community assigned a much lower probability of future fire than the non-affected community. The authors suggested that there was a dampening effect on awareness levels and risk perception in the fire-affected community. The respondents may have based their assessment on the adage that lighting does not strike twice in the same place, or on the assumption that the recent fire has reduced the vulnerability of the landscape to another fire. J acobson, Monroe and Marynowski (2001) also suggested that experience with bushfire reduces the perception of risk, but the type of experience had different effects. The authors found that experience with bushfire smoke was correlated with increased awareness and 
interest in learning more about fire management, perhaps because it reminded individuals about fire without generating great fear. McCaffrey (2004) also agreed that indirect experiences with wildfire are more influential than direct experiences on risk awareness and perceptions. However, she commented that perceptions based on a single experience are limited and biased, but on the other hand repeated experiences can lead to a "disaster subculture" where people become used to the hazard and do not perceive it to be a great risk. Experience with a natural hazard and its effect on risk perceptions therefore appears to be rather inconsistent.

Without reinforcement of risk perceptions such as the reoccurrence of fire or reception of bushfire information, risk perception may change over time. Cunningham and Kelly (n.d.) investigated bushfire perception levels and changes in knowledge over time. They surveyed households in 1993 and 2001 in a New South Wales peri-urban community that was affected by fire in 1985. In 1993, all (100\%) households that had experienced fire understood the high fire risk in their area, in 2001 only 58\% understood the fire risk suggesting a clear attrition in individual perception of risk. Similarly, knowledge about bushfire history decreased between surveys. As time progresses from the fire incident and people recover from the impact and return to their normal lives, the memory tends to fade and other issues begin to take priority. In the same study, the community (including those who had and had not experienced the fire) in $1993 \mathrm{had}$ a good understanding (70\%) of the high fire risk in their street with $33 \%$ of households having experienced the fire. In 2001 only $27 \%$ understood the fire risk despite $26 \%$ of households having experienced the fire. With a similar reduction in community knowledge of bushfire history, this study also highlights a clear attrition in community perception of risk and knowledge. This appears to be subject to individuals changing perceptions over time and possibly a decrease in the instances in which people discuss bushfire issues, it may also be due to changing community structure and processes typical of growing peri-urban areas (i.e., changing community cohesion and social, human and cultural capital), all leading to a lack of collective memory. However, Cunningham and Kelly (n.d.) did not investigate reasons behind the observed changing perceptions of risk of their respondents.

\section{Regulations and Risk}

A few authors have also considered the influence of building codes and regulations on risk perceptions. Institutional arrangements influence how people think about and respond to risk (Winter \& Fried, 2000). Gilbert (2004) found varying effects: those who had built their homes and had to adhere to building codes specifically addressing bushfire safety were more aware of the risk because their attention was thus drawn to the issue; 
however there was no such effect in the new housing estates, because people moving to these areas were largely urban people with little prior knowledge and awareness of bushfire risk, a lack of concern and even interest. However, Montz (1993) suggested that such building requirements may provide a false sense of security to residents, who may see their home as hazard-proof when it is not, thus distorting their perception of risk. Blanchard and Ryan's (2004) study indicated that people who are less aware of the bushfire risk are particularly susceptible to low levels of risk perception after undertaking some degree of fire-proofing. Fire insurance, which is commonly perceived as highly effective in protecting investment from bushfire, as suggested by Nelson, Monroe, Fingerman Johnson and Bowers' (2004) study, may also provide a false sense of security: if it is believed that belongings will be replaced if lost or damaged, perception of risk will be lower (AndersonBerry, 2003).

Anderson-Berry (2003) suggested that "an accurate understanding of insurance status and extent of coverage is essential for an accurate and realistic perception of risk" (p. 226). Although, many people simply consider themselves less vulnerable to hazards than others in the same area who are exposed to the same level of risk. The literature indicates that people in high fire risk areas more accurately perceive the risk of fire in and around the area they live than the risk of fire to their own property. For example, Holden, Jones and Gabler (2000) found that while $64 \%$ of respondents, from a number of Gold Coast suburbs at medium to high levels of bushfire risk, perceived a medium to high fire risk for their area, only 35\% perceived a medium to high risk of damage to their home from a bushfire. This may be driven by an unrealistic perception of preparedness. For example, Holden, Jones and Gabler (2000) also identified a large gap between stated preparedness and actual preparedness. Such gaps between perceptions and actual susceptibility moderates the perceived level of risk, which consequently leads a person to be more at risk.

Many people move to and live in peri-urban areas for non-hazards benefits. The literature clearly indicates that people highly value the aesthetic appeal of the rural surroundings, and that this is the primary reason for living in the area (Gilbert, 2004; Monroe, Bowers \& Hermansen, 2003a). Living in the area because of the importance of community such as to be close to family and friends, as proposed by Handmer and Penning-Roswell (1990) (in Gilbert, 2004), appeared to be a minor motivation throughout the literature. For example, Gilbert (2004) found that just $11 \%$ of respondents cited community benefits, which was suggested to be the result of a decreasing sense of community in his study areas. Nevertheless, such non-hazard benefits do distort perceptions of risk, many people are aware of the bushfire risk but choose to live with it in order to gain the perceived benefits. Most of 
Gilbert's respondents agreed that the benefits of living in their peri-urban area outweighed the risks. Holden et al. (2000) found that people in their focus groups were particularly well aware and knowledgeable about bushfire in their area, but were still willing to take that risk.

Bushfire risk perception has also been related to various demographic and socioeconomic factors. For example Beringer (2000) found that the perceived fire hazard rating decreased with increasing age, he explained that older residents may consider themselves less vulnerable because of increased experience and knowledge of the fire hazards. Gilbert (2004) also observed a pattern similar to Beringer (2000) in one community, however he found the reverse in the other community and suggested that increased experience and knowledge may have alternatively lead to increasing risk perceptions with increasing age. Gender has also been investigated, for example Beringer (2000) and Gilbert (2004) found differences in bushfire knowledge between genders. Men tended to have a better understanding of bushfire, and this was statistically significant in Beringer's (2000) study, and he suggested that a lack of knowledge may lead to females perceiving the bushfire to be a greater threat. Anderson-Berry (2003) linked level of education with risk perception; people with a higher education are likely to have a more accurate perception of risk because they more readily understand the scientific complexities of hazards, and they are likely to be better skilled at searching for and acquiring information. Fothergill and Peek (2004) reviewed the literature concerning the affect of socioeconomic status on risk perceptions; it appears that people of lower socioeconomic status may perceive higher levels of risk possibly because poorer people have little control over their lives and hold little power in the world. However occupation may affect risk perception, people of lower socioeconomic status tend to work in more hazardous occupations which can moderate risk perceptions (Fothergill \& Peek, 2004). Fisek, Yeniceri, Muderrisoglu and Ozkarar (2002) alternatively suggested that socioeconomic status does not affect risk perception; for example income had no effect on overall risk perception. These studies strongly suggest that while demographics and socioeconomic factors can influence risk perceptions, the resultant effect is largely unpredictable.

\section{Expectation of the impact of a bushfire event}

Most people are well aware of the potential major impacts of bushfire, the effects are often experienced through mass media coverage, and many periurban people understand that they live in a fire-prone area. However it appears that there is an overwhelming majority of people who do not expect a bushfire event to occur where they live, or at least whilst they are living there. Considering the high fire risk in most peri-urban areas, most people participating in various studies spoke about "if" a fire comes rather than 
"when" (Monroe \& Nelson, 2004; Nelson, Monroe \& Fingerman J ohnson, 2004). People tend to consign rare events to the distant future and do not consider that "some time" could be tomorrow (Kerry, Kelk, Etkin, Burton, \& Kalhok, 1999). If a fire did come however, there were various expectations of the event, and expectations were often based on the perception of bushfire as an uncontrollable or controllable event. Those people who perceive fire as uncontrollable thus expect random and significant destruction where suppression efforts are futile. These expectations were voiced during focus group discussions in Winter and Fried's (2000) study. Participants characterised wildfire as an awesome, uncontrollable force where destruction is inevitable. The participants however, had experienced wildfire either directly or indirectly, and many saw dramatic examples of fire behaviour, examples that contradicted expectations such as houses with a 300-ft-wide defensible space destroyed and wood sheds left standing despite being directly exposed to the flames. It is apparent that these participants did not have an understanding of the impact of embers on buildings. Participants who had directly experienced the fire held stronger beliefs that destruction was inevitable. The authors suggested that such an attitude helps them cope with the issue of personal responsibility for their loss. In the absence of hazard experience, similar expectations of random or total destruction can also be formed by vicarious experiences through the mass media, which tends to focus on destruction and loss of life (Paton, 2003). There are also many misconceptions about bushfire in circulation, which could also lead a person to believe that bushfire is an uncontrollable event. For example, there is the expectation that bushfires are so severe that only houses built especially to withstand bushfire will survive, or that houses explode in bushfires (Ramsay \& Rudolph, 2003).

In contrast, there are people who perceive bushfire as a controllable event and thus expect controlled and insignificant damage, and particularly do not expect their homes or property to be damaged, wholly or even partially. Such expectations may be based on a lack of knowledge, misinformation, or due to beliefs or experience based on successful fire suppression and controlled damage in the past (Kumagai et al., 2004a). It is also likely that these people are most at risk in a bushfire due to a probable lack of preparedness, and late evacuation in the instance where bushfire threatens their home. There were a number of people in Brennan's (1998) study who did not expect that the fire would come near their property, but if the fire did happen to approach, and they felt threatened, they presumed that they would be able to evacuate safely. One respondent said they would "make a spilt-second decision on whether to stay or go and consult with my neighbour [when the fire reached the house next door]" (Brennan, 1998, p. 16), which would have been a very dangerous survival strategy had the fire reached next door. Discussions with respondents indicated that they did not consider what conditions would be 
like when evacuating as the fire approached. Furthermore, residents were more ready to accept that the fire was under control than the fire fighters who were concerned about a wind change. Similarly, during the Ash Wednesday fires there were many people watching the fire front, not expecting to find themselves in the path of the fire and thus not taking any precautions, until the wind changed (Lazarus \& Elley, 1984; Krusel \& Petris, 1992). A lack of knowledge of fire behaviour and conditions, leading to such unfounded expectations, is life threatening. A large proportion of deaths during the Ash Wednesday fires were due to late evacuations, and deliberately entering the fire area, because people did not recognise the real threat to their safety (Krusel \& Petris, 1992). The extreme wind change that occurred on Ash Wednesday, which was unexpected by the majority of people, was associated with most deaths. A respondent in Holden et al.'s (2000) study expressed concern about the general lack of understanding "If there is a fire down the bottom, you've only got 3 minutes. They have absolutely no idea" (p. 3). Additionally, the loss of electricity and water during a bushfire event is in many cases unexpected. Water is obviously a crucial element in fighting fires, and there is a heavy reliance on mains water supply and electricity for water pumps, however these services do often fail because of bushfire. There were a number of examples during the Ash Wednesday bushfires where the fire could have been controlled, and houses saved, if there was water (Lazarus \& Elley, 1984).

The expectation that fire can be controlled on the other hand, may be based on a good understanding of bushfire and mitigative measures. In this instance, expectations of the bushfire event and potential impacts are more realistic. For example, respondents in Nelson, Monroe, Fingerman J ohnson and Bowers (2004) and Monroe and Nelson's (2004) studies, who seemed to have a good understanding of bushfire, did not believe that bushfire events were out of their hands, they "had a healthy respect for the damage that a wildfire can do" (Nelson et al., 2004, p. 423). While there was the general expectation that houses prepared for bushfire would withstand the event, they understood that houses and property could be lost, including houses that were prepared, if certain climatic conditions existed.

The Colorado Office of Community Services (Burns, Porter-Norton, Mosher \& Richard, 2003) undertook focus group discussions consisting of 275 people from 29 Western Colorado communities. While it was noted that the participants were not necessarily representative residents of their communities, they were chosen for their good understanding of their respective communities and because they had some awareness of, and interest in bushfire. The participants also had a very good understanding of the direct and indirect impacts of bushfire. Although discussions centred on participants' ideas and concerns about bushfire issues (i.e., did not 
necessarily reflect what the respondents actually expected would happen to themselves or their community), respondents acknowledged that wildfire would impact on the cultural, social and economic fabric of a community. They mentioned the cumulative effects and the negative consequences for the economic health of the region, quality of life and scenic beauty of the area, for example, and the social costs such as neighbourhood relations and other values that cannot be easily reconstructed. This study indicates that there are a considerable number of people who do have realistic expectations, or at least ideas, of bushfire and associated potential impacts. However, through various accounts given by people after experiencing a bushfire, it appears that regardless of a person's understanding, knowledge and expectations of a bushfire event, when a bushfire actually occurs, for many people, the bushfire was not only unexpected but many events that unfolded were unexpected, and pre-conceived expectations were often not met.

Indirect costs, particularly social costs, are difficult to measure, and are often omitted in official loss statistics complied in the aftermath of a natural disaster, and thus do not reflect the true costs of a disaster (David, Baish \& Hearn Morrow, 1999). Therefore, unless one has experienced a disaster, it is difficult to actually know what to expect, and given that people generally do not expect a bushfire to occur, they perceive a low risk of damage to their homes (Holden et al., 2000) and are over-confident in their ability to cope in the event of a bushfire (Odgers \& Rhodes, 2002), it is not surprising that they are shocked when a bushfire does occur. For example, from Halvorson's (2002) investigation into the 2000 Bitter Root Valley (Montana) fires, people described finding themselves "living in harms way", some respondents expressed disbelief or even denial that bushfires were burning close enough to threaten communities. Everyone in the area felt affected, and many were significantly traumatised by the event and experienced multiple anxieties. Various comments from respondents indicate that the magnitude of the event was completely unexpected as were the short and long term psychological, economic and environmental effects. People often do not expect that their basic needs can be compromised (Debelle, 1993), and that it takes such a long time to get back to normal. The 2003 fires in Canberra particularly highlight the latter point, The Age newspaper (Rising from the ashes, 2004) interviewed residents who were affected by bushfire one year after the event, and revealed that very few had rebuilt their homes. This was partly due to planning delays, under insurance and a shortage of builders, but also because of the enormity of the situation, not only rebuilding a home but also lives, which has been overwhelming for some people and impossible for others. 


\section{Expectation of themselves}

What people expect of themselves before, during and after a natural hazard, such as in preparation, protecting property and recovering from disaster, is related to perceptions of who is responsible. Responsibility can be linked with property rights to the hazard. For example, if the risk is regarded as public (i.e., the magnitude of risk an individual faces depends on the actions of others), then the individual perceives him or herself as having little responsibility in reducing the risk and/or dealing with the consequences, if the risk is regarded as private (i.e., an individual's own behaviour determines the magnitude of risk), then the individual perceives him or herself as having primary responsibility. Bushfire risk can be viewed as having both public and private components because various people (e.g., residents and public land managers) contribute to the risk and share, to varying degrees, in the consequences. Perceived responsibility, in particular will play a role in determining which risks are ultimately reduced, and by whom (Winter \& Fried, 2000).

\section{Preparedness and mitigation}

Recent studies investigating bushfire preparedness and mitigation have indeed found that people do perceive some level of personal responsibility. For example, Winter and Fried (1997, cited in Winter \& Fried, 2000, pp. 3637) found that most respondents (80\%) in their Michigan study considered wildfire protection to be either an equally shared responsibility between homeowners and the government (54\%) or primarily a responsibility of the homeowner (26\%). Very few (6\%) saw the government as solely responsible for protection. Furthermore, in accepting some responsibility, most homeowners in Michigan were willing to pay for wildfire protection: willing to pay for protection activities undertaken by the state and/or by the individual (Fried, Winter \& Gilless, 1999); and willing to pay US\$57 per year for a 50\% reduction in risk (Winter \& Fried, 2001). Winter and Fried (2000) investigated which fire protection activities Michigan homeowners viewed as their own responsibility, and found that responsibilities were generally limited to being careful with fire and protecting their own property from wildfire damage, as well as maintaining insurance coverage on their home and personal property. However, because many respondents held the view that fire is an uncontrollable force that burns indiscriminately across ownerships, some declared that fire protection is simply everyone's responsibility. Common fire protection activities cited throughout the literature that people expect themselves to undertake, or are at least aware of, include clearing and removing vegetation around the house (e.g., tree limbs, understorey, grass, leaves), keeping appropriate equipment on hand (e.g., water pumps, hoses, sprinklers), mowing the property, removing 
flammable rubbish, insuring the house and using fire retardant building materials (Monroe, Jacobson \& Marynowski, 1999; Holden et al., 2000; Odgers \& Rhodes, 2002; Nelson et al., 2004). Despite the general perception of personal responsibility and the various activities people know and expect themselves to undertake to fulfil their responsibilities, many people do not actually take action to prepare themselves or their property for bushfire. Taking action can be moderated by several factors. In particular, if a person does not perceive the bushfire risk it is unlikely that they will participate in fire protection activities. In addition, many people who perceive there is a bushfire risk, and even knowing what actions to take to reduce the risk, still do not always undertake fire protection activities (McCaffrey, 2004). For example, a focus group participant in Holden et al.'s (2000) study commented on the distance between awareness and action succinctly; "People are aware of quite a lot of things these days, but few things are put into action. Like my neighbour who is a fire fighter. His property is full of scrub and fallen palm leaves, but he hasn't done anything about it. If anyone is aware, he is; but he hasn't done anything about it" (Holden et al., 2000, p. 4).

According to McCaffrey (2004), in considering mitigation measures, people engage in two types of evaluation: cost-benefit and implementation feasibility. Cost-benefit analysis involves weighing the financial costs against the expected return of the investment over a relevant time frame. Many fire protection measures are costly (e.g., building modifications and removal of large trees), and there is significant uncertainty in estimating the benefit because there is no guarantee of protection from bushfire. "People do not exert any effort "for nothing"; they need to feel that their efforts will pay off" (Kumagai et al., 2004a, p. 30). It is also difficult for people to continually exert resources and effort for long periods of time (Kumagai et al., 2004a). This is particularly true for people on low income (or perhaps restrained by other socioeconomic factors) where costs are proportionately greater than for those on a high income. Turner, Nigg and Paz (1986, cited in Fothergill \& Peek, 2004, p. 92) found that disaster preparedness increases steadily with income levels. Fisek, Yeniceri, Muderrisoglu and Ozkarar (2002) also found that income was an important predictor of behavioural as well as psychological preparedness. A person who does not own their home is also likely to assume higher costs than expected returns because of the shorter time frame typical of renters. Making a relatively large investment for a probable short period of time, and for someone else's property, can certainly be perceived as doing something for nothing. Indeed Beringer (2000) found that non-property owners were less likely than property owners to make even small investments in fire protection, such as cleaning guttering, reading bushfire literature and discussing what their family should do in the event of a fire. Furthermore, people who perceive bushfire as an uncontrollable force 
will be less likely to invest in protection measures because of the expectation that their efforts will be futile (Winter \& Fried, 2000; Nelson et al., 2004)

The feasibility of implementing an intervention includes consideration of the environmental and technical viability of a fire protection activity: how well it fits with the area and current land use, and the availability of skills and resources. It also includes socio-cultural and personal considerations such as whether the activity conforms to personal beliefs, community, mores and laws (McCaffrey, 2004). A significant problem in protecting houses against bushfire is its perceived incompatibility with values about landscape forms, and other beliefs and values about the natural environment. Environmental values are fundamental to "our human identity and fulfilment depend(s) to a great extent on the satisfactory expression of these values... reflect(ing) a profound human craving for affiliating with nature and wildlife" (Kellert, 1996, cited in Nelson et al., 2004, p. 414), or as simply stated by a respondent in Winter, Vogt and Fried's (2002) study; 'We live in the woods... because we want to live in the woods" (p. 19). Removing or modifying vegetation around the house is generally seen as sacrificing the closeness to nature, the scenic beauty of the property, privacy, and the conservation of energy afforded through shade trees (Monroe, Long \& Marynowski, 2003b; Nelson et al., 2004; Nelson, Monroe \& Fingerman Johnson, 2005). A resident said that it would affect her emotionally to cut down trees (Nelson et al., 2005), and some felt so strongly about maintaining naturalness that they believed that if a fire did come it should take their house as well as the trees (Nelson et al., 2004), indicating that some people simply value the forest more than their house. On the other hand, in line with different people's values (and also the ecosystem in which they live), whilst valuing nature, some residents also value a well maintained yard with a lawn for example. Therefore in this instance, while not always intentional, people are creating a defensible space to match their particular landscape values (Nelson et al., 2005); "The landscape of any farm is the owner's portrait of himself" (Leopold, 1939, cited in Nelson et al., 2005, p. 323). Although there is evidence that activities and modifications undertaken on one's property need to be "within reason", as determined by the social norm of the community. Respondents in Monroe and Nelson's (2004) study reported social norms about fire preparedness in their communities, however the degree varied from certainty that their neighbours would disapprove of defensible space to equal certainty that their neighbours would not care what they did on their land. The Institute of Medicine (2002) considers such social norms as one of the significant factors in predicting willingness to adopt appropriate safety measures.

McCaffrey (2004) also explained that the lack of action in undertaking bushfire protection activities is additionally due to the fact that people live 
busy and complicated lives, which often means that natural hazards have low salience compared to other concerns. People's judgements about preparation include reasoning about their permanence and their ease of adoption, thus fire protection measures that require little investment in time and effort both initially and over time, are favoured. Through investigating which preparation activities people have and have not undertaken, Odgers and Rhodes (2002) found that the activities actually undertaken were most likely to have been done for reasons other than bushfire, such as cutting back and removing vegetation from around the house and mowing the lawn, which also fulfils the desire for a tidy yard. Similarly, sprinklers and hoses are also installed for the purpose of watering gardens. Odgers and Rhodes (2002) also identified that activities least commonly adopted are those that are deliberate and specific to bushfire risk such as having a non-electric pump and a written plan. This pattern is mirrored throughout the literature and indicates that people in fire-prone areas are generally under-prepared. Furthermore, people who have experienced fire and even indicate their intentions to prepare themselves for a future event do not necessarily take action. For example, Hamer (2001) discussed his neighbour's experience with bushfire which burned the (unmanaged) forest on his property and would have spread to houses along the street if not for a neighbour who stayed behind to fight the fire. After the fire the person cleared the grass under his trees and trimmed the limbs, however in time, with the fire no longer front-page news and new activities and issues needing attention, weeds were neglected and the forest was returning to its pre-fire hazardous state. Hamer (2001) on the other hand, who actually lost his house in the fire, is moving to another peri-urban area, building a fire-proof home, and defying community norms by creating defensible space. Although, experience with bushfire inconsistently influences individual preparedness in the same manner that it influences risk perception, there are a number of examples where people who have lost their homes to bushfire, rebuild fireproof homes (Gilbert, 2004; Thistleton, 2004).

\section{Response and recovery}

The literature clearly indicates that in the event of a fire, a person's first priority is to protect themselves and their family, and, where possible, to protect their property. Families with young children and other dependent persons tend to evacuate, younger people ( $<40$ years) are also more likely to evacuate because of young children and little bushfire experience (Beringer, 2000). However there is a large proportion of people who intend to stay with their house, most of whom are male [67\% in Beringer's (2000) study and $62 \%$ in Odgers and Rhodes' (2002) study] because women tend to evacuate with dependents, and because women may perceive a higher risk due to a lack of knowledge (Beringer, 2000). Those people who intend to stay with 
their homes, expect that they will be able to do so and thus not be forced to evacuate or be stopped by roadblocks on their way home. There are a number of accounts where people have defied the authorities, risking arrest, to get to their homes (Lazarus \& Elley, 1984). People who were prevented from staying with their homes later expressed much anger from the distress that it caused (Beringer, 2000; Odgers \& Rhodes, 2002). Although remaining with the house in a bushfire event significantly increases house survival, and thus will protect people providing they remain inside the house as the fire front passes (Krusel \& Petris, 1992), people with unrealistic expectations of the event and themselves, will be at risk.

Thus, there are many people living in high fire risk areas who do not perceive the risk, do not adequately understand bushfire and the impacts and underinvest in fire protection measures. Despite this, there is a general expectation that they will be able to cope when faced with the danger of bushfire (Odgers, 2002). However when a bushfire event actually occurs many of these people come to realise that they expected too much of themselves. In Brennan's (1998) study, of 43 people or households who had planned to stay with their house during a fire event, only 15 were fully committed (being prepared and confident). The uncommitted households were those who were likely to leave the house at some stage during the fire, despite the intention of staying, which is a dangerous survival strategy. It seems that those who were uncommitted suffered stress from the experience of being alone waiting for the fire, were not confident even when fairly well prepared, or understood that they were not prepared and relied heavily on the fire fighting services. One person's experience during the Ash Wednesday fires describes the physical and psychological stress a bushfire can have on a person; "[we] worked like mad for a couple of hours [preparing the house]... spent half an hour in the pool setting up the reserve pipe to the filter, but I forgot that the electricity was off. I wasn't thinking clearly" (Lazarus \& Elley, 1984, p. 12). To the inexperienced person, it is not always obvious that being prepared for a bushfire involves much more than physical preparations: a person must be fully aware of and perceive the risk of bushfire; understand how bushfires behave; how people and houses survive in bushfires and what to expect during a bushfire; they need to have a comprehensive household plan consisting of what each household member's role will be; and be psychologically ready (Odgers \& Rhodes, 2002). The latter points it seems are most commonly neglected, which leads people to evacuate at the last minute and risk their lives.

People also tend to be overconfident in their ability to recover from bushfire (Odgers, 2002), but various reports investigating people after they have been affected by fire indicate that recovery for many people is not an easy process; it is a stressful and long process. The Sydney Morning Herald (Marriner \& 
Holder, 2004) reported that it took six months for a woman to face returning to the site of her old home and one year after the Canberra fires, which had burnt her home, she finally felt that she was ready to move on. Similarly, a man spoke to Peter Harris (2004) about the year in limbo after the Canberra fires burnt his home, and his struggle to move away from the "bushfire victim" mentality. He wanted everything to return to normal, and in the beginning he thought that it would be possible; they were insured, and possessions could be replaced, and he had his family. However, he and his wife came to realise that they could not return to their prior life, they had lost more than a home, they had lost part of themselves. Furthermore, another couple who also lost their home to the Canberra fires described the struggle with an avalanche of unexpected and unwanted decisions concerning their house and their lives (Campbell, 2003). Even those people who had not lost their homes experienced a traumatic year after the Canberra fires: "The fires have had a big impact on the people who stayed behind... We're living in a very desolate environment, the ambience of the area has gone" (Rising from the ashes, 2004, p. 1). and "The wind blows and it's louder than it ever was before... You don't hear the kids anymore" (Rising from the ashes, 2004, p. 1). There are some instances, however seemingly very few, where the situation has not been so dire. For example, a couple who moved into temporary accommodation (a townhouse) after losing their home to the Canberra fires found that they loved the new lifestyle and living with less, and being free from clutter (Rising from the ashes, 2004).

People who have a strong sense of community or societal commitment, and are generally well prepared and/or in a better position than others for example, feel compelled and that it is their responsibility to lend their support to others during and after a bushfire event. For example, Lazarus and Elley (1984) identified people who, after preparing their own house, helped others to prepare, and people who had equipment to fight the fires protecting their own house as well as neighbours'. One respondent explained that she would not have known what to do if her neighbour had not come and helped her. People in the Bitter Root Valley fires used existing formal and informal social networks and organisations to rally together to help others prepare their houses, and after the fires, to help people affected by the fire to recover; and to "do the right thing". Some people were frustrated when they were not able to do anything to help (Halvorson, 2002). Furthermore, many people, particularly young people, want to be directly involved in fighting fires with the fire brigade; $66 \%$ of the 18 to 25 year old respondents were involved in fire fighting in Beringer's (2000) study, and according to Beringer this perhaps reflects the number of young people who are involved in the local fire brigades. 


\section{Expectation of neighbours and community}

There are some important community characteristics that can determine the resilience of a community, and the individuals living within it, to natural disasters. Buckle, Marsh and Smale (2000) listed a number of factors that support individuals, families and communities to minimise the consequences of disasters including: shared community values; aspirations and goals; established social infrastructure; positive social and economic trends; sustainability of social and economic life; partnerships (between agencies, between community groups and between commercial enterprises); communities of interest (where a geographically diverse group shares a common interest, skill or expertise); established networks; and resources and skills. Similarly, Jakes et al. (2002) highlighted the importance of social capital, human capital and cultural capital in community preparedness for bushfire, and Anderson-Berry (2003) simply stated that "closer-knit communities tend to be more resilient" (p. 226).

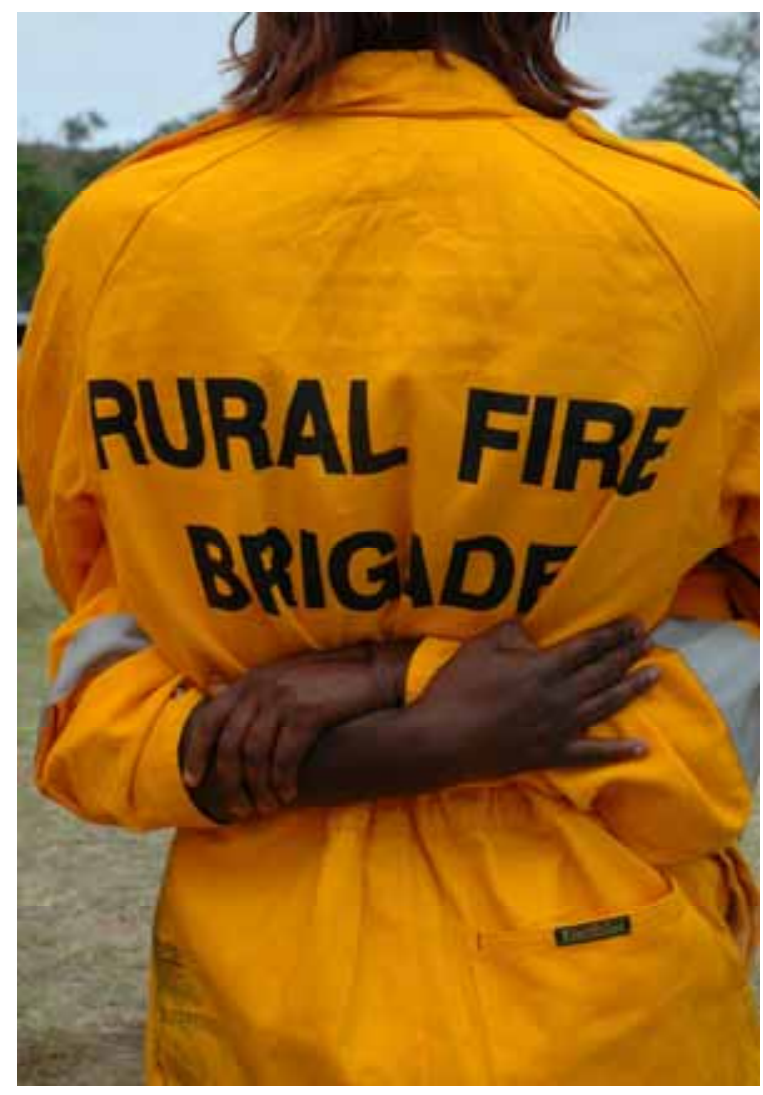

Figure 11.1 Rural Fire Brigade member and cohesiveness 
Being part of a community that is cohesive and rich with the above social characteristics will compel individuals and groups to assist fellow community members in need, as was described in the previous section. It will also mean that community members in need of assistance will look for support from their community. Furthermore, the community will be more likely to act as an organised collective group in preparing for, responding to and recovering from natural disasters. The importance of social responses (e.g., decision making, management and support), together with structural responses (e.g., building materials, defensible space and insurance), to bushfire threats was recently highlighted by Steelman and Kunkel (2004). They noted that social responses will be unique to individual communities: social responses operate at the local community level and consequently take diverse forms in different communities; and the social capacity of a community to respond is strongly dependant on its characteristics leading to vast differences across communities.

\section{Preparedness and mitigation}

A community with the social capacity to respond to a bushfire threat can encourage its individuals and equip them with the necessary skills and resources to undertake measures to protect their home. McGee and Russell (2003) investigated the link between social cohesion and bushfire preparedness and found a positive relationship; there were extensive social networks within the long-term resident community that addressed bushfire preparedness, newcomers however were generally not part of this network and were found to be less prepared for the event of a fire. There is also evidence that individuals in this community are self-sufficient and confident in the face of the bushfire threat because of the strong social network of support. Larsson and Enander (1997) have also suggested that how a person perceives the views of other members of their community to disaster preparations may influence an individual's actions. Although this is an area that needs to be developed more, it is likely that people within a cohesive community that has a positive attitude toward bushfire preparedness, such as in McGee and Russell's (2003) study, will be motivated to undertake fire protection measures because of an expectation of a positive reaction from others. On the other hand, if undertaking fire protection measures is expected to create negative reactions, such as defensible space in a community that values naturalness, it is unlikely that the measures will be undertaken. Hamer (2001) for example, was concerned about the bushfire threat in his neighbourhood and considered creating defensible space around his home, however in a discussion with a neighbour he realised that the action could create considerable negative reaction. He therefore did not create defensible space (perhaps consequently, Hamer's house was later destroyed by bushfire). Flint and Luloff (2005) have explained that a 
community will not take action and mobilise resources, and thus support individual fire protection measures, unless there is a shared community perception of risk. Furthermore, a fire protection measure that requires collective action is also unlikely to be undertaken by an individual unless others in the neighbourhood take action (Paton, 2003). However, in the instance where a community has collectively taken action to reduce the risk of bushfire, there are high expectations that all others in the community will do the same. For example, when "appropriate defensible actions" are not undertaken by residents, this inaction is viewed as personal apathy or irresponsibility (Burns, Porter-Norton, Mosher \& Richard, 2003). In many cases, those who do not join in fire protection activities are newcomers and/or people without a strong connection the community in question, respondents in a number of studies have voiced their concern or frustration with the lack of participation of newcomers in particular (Halvorson, 2002; Gilbert, 2004).

\section{Response and recovery}

Family and community cohesion is an important predictor of an individual's response to a natural hazard; social ties tend to increase the probability of an effective response (Krusel \& Petris, 1992; Anderson-Berry, 2003). Social ties are an important informal communication network. The reception of information during a bushfire is particularly important to enable people to make informed decisions about what actions should be undertaken and when. During the Bitter Root Valley fires, residents responded to the general confusion of whether to evacuate or not by monitoring various conditions to judge the level of risk and then disseminating this information, which was tailored to the needs of others in the community, through various information networks (Halvorson, 2002). Bitter Root Valley is a good example of a community with the social capacity to respond effectively to bushfires, and community members, particularly those born and raised there and thus closely affiliated with the community, rely on this social capacity for support and, as a community, to be independent from outside groups. For example, many evacuated residents did not utilise the Red Cross shelter because they sought accommodation with friends and family, or camped with other families by the river (Halvorson, 2002).

In the bushfire aftermath there was a similar "pulling together" within the Bitter Root Valley community. As discussed previously, community members established formal and informal support networks to help bushfire victims. A strong sense of community emerged both during the bushfire and after, and the experience of dealing with the fire hazard seemed to give an additional sense of identity to the communities (Halvorson, 2002). Kumagai et al. (2004a) explained that "a community's disaster recovery processes reflect 
the community's pre-disaster social and physical conditions" (p. 31). Indeed the Bitter Root Valley communities were well prepared for disaster and were thus able to deal effectively with the aftermath; it appeared that the majority of people in need of assistance and support received assistance and support from fellow community members. Halvorson (2002) did identify victims who were not well established or connected to the local community, and these people fell outside of the community networks, however, critical financial and moral support was provided by external aid, the efforts of which were enhanced by the community support networks. Without such a strong sense of community and informal and formal community support networks, preparedness, response and recovery efforts would have proceeded incrementally and haphazardly (Halvorson, 2002). The existence of active community leadership has also been identified as an important component of hazard mitigation, response and recovery (Petterson, 1999; Reddy, 2000). There is a need, if not an expectation, for somebody, particularly existing community leaders, to activate and organise the community and its resources to respond to hazards effectively. Most research shows that such leadership does indeed emerge in the situation of a hazard (Petterson, 1999; Reddy, 2000). Despite the expectations of fellow community members that a person may have in times of crises, it appears that people are nevertheless amazed and heartened by the level of support that was actually received. Even people from the Bitter Root Valley communities expressed amazement: "The community pulling together was amazing for me" (Halvorson, 2002, p. 7).

Many studies investigating the weeks or months after a disaster have reported the pulling-together of communities, even communities that were not cohesive pre-disaster (Moore, Daniel, Linnan, Campbell, Benedict \& Meier, 2004). Such collective moments are termed "altruistic or therapeutic communities", however this is not a long-term effect. Participants in Moore et al.'s (2004) study described the later phases (after experiencing the therapeutic community) of the Hurricane Floyd flood disaster in North Carolina as being characterised by a general lack of concern on the part of fellow residents (and governmental authorities). As a community begins to recover and the effects of the disaster become less apparent, memories fade, people are less willing to help and other issues and problems begin to take priority. For many, a period of disillusionment and anger entails the experiences and perceptions of high levels of trust, social cohesion, or collective efficacy, possibly leading to changes in the way these people view their community and their place in it (Moore et al., 2004). Hoffman (2000) also described the dichotomy of a community following the Oakland Berkeley Firestorm in 1991. "At first the outside community saw us with sympathy. Eventually, when recovery took longer than the day, week or month they envisioned, they came to view us as greedy whiners and 
undeserving receivers of pots of gold" (p. 60). Driven by jealousy, the disaster victims thus became targets of wanton envy, they were viewed as "lucky" because they had all new things and would eventually have new houses. In response, disaster victims withdrew from the outside community and adopted equally separating, and in due course dehumanising, conceptualisations to mark them.

A human-caused or "technological" disaster can also set the stage for anger and conflict as victims blame what they perceive to be the responsible party and disagree over remediation measures (Carroll, Cohn, Seesholtz \& Higgins, 2005). Bushfires have elements of both technological and natural disasters. Bushfires are a natural occurrence in many parts of the world, however, they can also be started by a deliberate or accidental human act. Technology also plays a role in suppression and management of bushfire. Carroll, Cohn, Seesholtz and Higgins (2005) investigated bushfire as a galvanising and fragmenting influence in three Arizona communities and found that although the disaster literature is replete with examples of communities suffering internal conflict in the aftermath of disaster events, there was little within-community tension and conflict in the communities studied. Rather, the communities pulled together. However, much of the disaster literature in this area does not address bushfire, therefore further investigation is warranted. Tension and conflict were apparent, but most of the blaming behaviour in these communities was directed at outside agencies, which will be discussed in later sections. Kumagai, Bliss, Daniels and Carroll (2004b) suggested that it should not be assumed that community responses to bushfire events are simple or predictable.

\section{Expectations of Organisations}

The public perceive the primary responsibility of fire and emergency services to be fire suppression and protecting people and property, and, in most cases, the fire services in particular are perceived to fulfil their roles effectively. Holden et al.'s (2000) study suggested that regardless of a person's awareness or knowledge of fire brigades, most people highly value the fire brigade that services their area, even people who are not sure about which type of brigade actually services their area. Furthermore, Gilbert (2004) revealed that there is a general high level of confidence in local brigades. Such positive views may be attributed to a number of factors: fire fighters are often depicted at the front line of a bushfire, risking their lives to save others and are thus often viewed as heroes; and local brigades in particular are usually part of the community with family and friends volunteering and working for the community. As a result local fire brigades are viewed as distinct from government agencies. 


\section{Preparedness and mitigation}

Efforts made by fire brigades and their community schemes such as Community Fireguard (CFA, Victoria), to communicate with the local community appear to be well appreciated. There is an expectation that the information received by the local brigades is accurate and tailored to local conditions, and is thus perceived as credible. Participants in McGee and Russell's (2003) study indicated their preference for information from the local fire brigade, above other information sources. It was also suggested that most people in this community prefer to actively seek such information themselves, however, these people also tended to accept much of the responsibility to respond to the bushfire threat. People in other communities generally do not perceive themselves as having such a high level of responsibility, and are less resourceful, and consequently rely on others to provide information. The opinion that fire brigades adequately liaise with the general public appears closely related to whether residents have had contact with the local fire brigade since living in the area. For example $67 \%$ of residents in Beringer's (2000) study had had contact with the local fire brigade and $67 \%$ felt there was sufficient liaison between the CFA and the general public. Therefore, although people highly regard and prefer information received from their fire brigade, there does not appear to be an expectation that fire brigades will be visibly active and have regular contact with residents to provide information. Holden et al.'s (2000) study revealed that only $5 \%$ of respondents thought that information delivered through door knocks and one-on-one meetings would be effective, the majority indicated that literature in the form of a pamphlet, booklet or leaflet (65\%) and television (15\%) would be the best delivery mode. Furthermore, in Odgers and Rhodes' (2002) study, respondents believed that fire brigades should assign a higher priority to bushfire hazard reduction than educating the public. Similarly, Holden et al.'s (2000) respondents thought that fire brigades should take a more active role in prevention, however; it was perceived that brigades are constrained by a lack of resources and sometimes authority.

\section{Response and recovery}

During a bushfire event there is a huge reliance on fire brigades and emergency services, as would be expected. However, it is clear throughout the literature that a majority of people expect too much of these services, in particular many people expect that fire fighters will be available to protect their homes and that they will be specifically warned and told when to evacuate (Beringer, 2000; Gilbert, 2004). These expectations are based on a lack of awareness; indeed emergency service priorities are to protect people and property, but in a major fire event these services are often overwhelmed 
and not able to meet such expectations. Furthermore, front line fire fighters do not always have the most accurate and up-to-date information (Brennan, 1998), and, possibly as a result, actions taken by fire and emergency personnel are not always the most appropriate. For example, there are a number of instances where people have been evacuated, from their otherwise safe homes, during the height of the fire (Braun, 2002).

Newcomers and those who have not experienced a bushfire, who are more likely to rely heavily on emergency services, are most often astonished by the fires and the alleged lack of emergency services (Halvorson, 2002). Carroll, Findley, Blatner, Mendez, Daniels and Walter (2000) also mentioned that people's emotional reactions tend to be equal to the fire's magnitude and intensity. One community in their Washington study appeared to be more emotionally charged and more likely to give rise to conflict than the other two communities because a section of this community experienced some serious direct impacts that the other communities did not. Although such astonishment and conflict may lead to blaming behaviour, it is more likely that the government and its agencies, including federal fire services, will be blamed rather than local fire brigades (see next section). After experiencing a bushfire, the community in Odgers and Rhodes' (2002) study praised the fire services despite an overall opinion that they could have been better prepared, the local government was generally viewed as ineffective and criticised for its lack of action.

There is obviously a great reliance on emergency aid organisations after a major bushfire, particularly for those people who do not have strong social connections to the community. However, it would appear that there is also a large perception gap between what fire victims expected and what occurred. Two major themes surfaced from Carroll et al.'s (2005) study: individuals expected both a better organised and more effective distribution of financial resources and a more sympathetic and caring response; and a more equalised distribution of resources between the three communities affected by the bushfires. This resulted in considerable tension between the communities and the American Red Cross to the point that the organisation was picketed by locals. Furthermore, the unequal distribution of resources created considerable conflict between the three communities. Unequal distribution of aid appears to be a common occurrence post-disaster, but is nevertheless unexpected (David et al., 1999; Moore et al., 2004), and people of lower socioeconomic status are often further marginalised (Fothergill \& Peek, 2004). 


\section{Expectation of government}

Because bushfire risk has a considerable public component, and bushfires are commonly perceived as a technological hazard, all levels of government are perceived to be responsible to some extent to mitigate bushfire and its impacts. However, although there is the general expectation that governments need to take action, which actions and to what extent can vary considerably from person to person and area to area. Much of the literature investigating people's reactions to or acceptability of mitigative measures has been based on the Theory of Reasoned Action, which suggests that beliefs are a strong predictor of attitudes and attitudes are a strong predictor of behaviour (Bright, Vaske, Kneeshaw \& Absher, 2002; Vogt, Winter \& Fried, 2002; Vogt, Winter \& Fried, 2005).

Preparedness and mitigation

People's knowledge and perceptions of fire and fire policies are becoming more sophisticated. Thirty to 40 years ago people generally believed that fire was bad and thus supported aggressive suppression. As people became more knowledgeable about the beneficial effects of fire, attitudes changed and support for suppression-only policies gave way to fire management (Cortner, Gardner \& Taylor, 1990). In most instances, fire management on public land is expected, but opinion on how this should be done varies. Prescribed burning and mechanical fuel reduction, the major fuel reduction techniques, have both been the subject of controversy. For example, in the USA mechanical fuel reduction has been broadly supported but environmentalists are suspicious because fire more closely mimics natural disturbance patterns, and they have accused the federal forest agencies of using fuel reduction as an excuse for logging. The timber industry and many foresters are equally suspicious of prescribed burning, which they consider as wasteful, and dangerous because of the risk of the fire getting out of control. Similarly, grazing as a fuel management technique has attracted debate (Brunson \& Shindler, 2004). Peri-urban resident opinion has also led to controversy over fire management techniques, however, judgements of acceptability can be based on a variety of factors. For example, using a Theory of Reasoned Action approach, Bright, Vaske, Kneeshaw and Absher (2002) identified six basic belief dimensions that may influence a person's perception of bushfire management: anthropocentric; biocentric; responsibility; capable/trust; freedom; and benefit/harm. Knowledge, experience and personal importance are also entwined with acceptability judgements.

A study undertaken by Daniel, Weidemann and Hines (2002) in northern Arizona has suggested that people who value the beauty of forested areas, or 
value nature for what it provides humans (i.e., the anthropocentric belief dimension), are less supportive of fuel management strategies that compromise aesthetic values. Prescribed burning and bare fuel breaks in particular do not protect aesthetic values. However, there was evidence that people in the above study would support other fire management strategies that address the safety-aesthetic value trade-off. Newcomers to peri-urban areas are perceived to be more anthropocentric. Participants in Monroe et al.'s (2003a) study, including various government, non-government and industry representatives as well as homeowners representing 13 southern US states, indicated that newcomers were viewed as not connected to the land and environmentally irresponsible because they planted exotic species and complained about bushfire smoke. On the other hand, people who valued 'naturalness', leaving forested areas as natural as possible (i.e., the biocentric belief dimension), were more supportive of prescribed burning because it reflects a natural ecosystem process (Nelson et al., 2004; Nelson et al., 2005).

The perception of who is responsible for reducing the bushfire risk can influence the acceptability of fire management strategies. As previously discussed, a person who regards the bushfire risk as public will perceive the government as primarily responsible for reducing the risk and will thus expect institutional intervention, consequently leading to institutional legitimacy (Winter \& Fried, 2000). Much of the literature suggests that people are more in favour of fire management policies that require the government to take action rather than themselves (Gardner et al., 1987; Blanchard \& Ryan, 2004). However, with regard to private property, many people do perceive themselves as responsible for protecting their own house. They are not supportive of any policies that require homeowners to take steps to reduce the risk themselves, because such policies would also impinge on perceived rights to freedom. Therefore reducing the fire risk on public land is perceived as government responsibility primarily, and fire management policies that address the risk on public land are supported, if not expected, particularly when homeowners are implementing fire protection measures on their own property. A lack of action on public land nearby can also moderate private landholder mitigation measures (Kent et al., 2003; Anonymous, 2004). However, once again, which specific policies will be supported and by whom, will vary.

Trust has emerged as an important factor influencing public opinion of fire management strategies (Vogt, Winter \& Fried, 2002; Winter, 2002; Vogt, Winter \& Fried, 2005). Trust in the government to implement a fire management strategy is closely related to the perceived competence of the government to implement the strategy successfully. For example, there are a number of instances where prescribed burning became out of control and 
threatened people and properties, therefore the government agency is viewed as incompetent and consequently is not trusted to undertake prescribed burning safely. As a result people have intensely rejected prescribed burning as a fire management strategy (Winter \& Fried, 2000; Vogt et al., 2005).

There is an emphasis on individuality and self-reliance in the western world, and the right to free choice is an important concept (McCaffrey, 2004; Bright et al., 2002). Therefore government actions that restrict or dictate what is done on private property or affect private property values may be resisted. Indeed, homeowners are not supportive of policies that affect the way they manage their property. Participants in Winter and Fried's (2000) study were not supportive of building codes, safety ordinances, zoning and regulations to modify vegetation on their own property. They wanted the opportunity for voluntary compliance and thought that such policies would be unnecessary because of existing and potential insurance markets, and that it would detract from aesthetic and convenience aspects of their homes. Blanchard and Ryan (2004) suggested that local residents may support land-use regulations, including building codes, for new developments because it would not impinge their own property rights. Residents in the Burns et al. (2003) study, who appeared to have a good understanding of the fire risk and the importance of mitigation, were in full support of land-use planning and building codes. New residents may also be supportive because there is still an element of free choice: they can choose to live in a lower fire risk area if they do not agree with such regulations.

A belief that bushfire is harmful to nature may lead a person to not support management strategies such as prescribed burning. However, an increase in knowledge of bushfire and its effects can influence such beliefs. Cortner et al. (1990) discussed the general increase in people's knowledge of the effects of fire over the last four decades and an increasing positive attitude toward fire (e.g., bushfire is beneficial to nature). Loomis, Blair and Gonzalez-Caban (2001) investigated the effect of knowledge on attitudes toward prescribed burning and found that Florida residents' attitudes were more supportive of prescribed burning as knowledge increased. Therefore an increase in knowledge may change a person's perception of bushfire, which may then lead to the acceptance of prescribed burning. Indeed, knowledge has been found to be an important consideration in reactions to fire management issues (Winter, 2002). Blanchard and Ryan (2004) revealed that respondents in their south-eastern Massachusetts study who have a high level of knowledge about a specific fire hazard reduction strategy were more likely to support the use of that strategy. It has therefore been suggested that the public be educated about fire management issues (Winter, 2002; Blanchard \& Ryan, 2004). Loomis, Blair and Gonzalez-Caban's (2001) study suggested that educational information can increase knowledge leading to 
attitudes that support prescribed burning. However, once again, the effectiveness of public education programs in influencing attitudes or knowledge, and behaviour, has been questioned (Cortner et al., 1990). Although, it seems that the public expects to receive educational material, participants in Winter and Fried's (2000) study were overwhelmingly favourable toward educational programs designed to reduce fire ignitions. However this was because of a belief that human action, mainly that of newcomers and visitors who are viewed as ignorant of the fire danger, is the cause of most forest fires. Participants in other studies have indicated their desire for information on other bushfire issues such as bushfire awareness and preparing homes (Gilbert, 2004). Furthermore, there is particular demand for more innovative and community-based information, for example information that details how to protect homes from bushfire whilst maintaining aesthetic values (Creighton, Baumgartner \& Gibbs, 2002), and more specific information that assists people to purchase fire protection products that are appropriate to their needs and budget (Odgers, 2002).

The effect of personal experience with bushfire on attitudes toward fire management strategies is also questionable. Vogt (2002) investigated seasonal and permanent homeowners' past experiences and approval of fuel reduction and found that seasonal homeowners had less experience with bushfire and fuel reduction techniques, however, there was general support from both seasonal and permanent homeowners for prescribed burning and mechanical fuel reduction. J abobson, Monroe and Marynowski (2001) and Vogt et al. (2005) similarly found no significant effect of past experience with bushfire on attitudes toward fire management. On the other hand Blanchard and Ryan (2004) suggested that past experience with bushfire can increase the level of support for prescribed burning because people who have witnessed fires in the past may have become more comfortable with them. Although it may depend on the type of experience; participants in Winter and Fried's (2000) study who witnessed significant destruction due to an escaped prescribed burn were suspicious of prescribed burning and generally not supportive of it as a fuel reduction strategy. Additionally, because the past experience with bushfire led many to believe that it was an uncontrollable force, investment in suppression infrastructure was considered pointless, although it was acknowledged that the government needs to respond to bushfires that do occur and ensure that fire fighters are well equipped for their own safety.

Vogt et al. (2005) investigated the effect of personal importance (or personal relevance to fuel management techniques) on homeowner's approval of fuel management techniques. They found that personal importance was a good predictor of approval. For example, from the same study, Winter, Vogt and Fried (2002) indicated that if vegetation amenity is important to a person, 
defensible space compliance will likely be disapproved, if property rights are important, any ordinances impinging on such rights will likely be disapproved, and if smoke sensitivity is an issue, prescribed burning will also likely be disapproved. However, Vogt et al. (2005) also highlighted the wide range of factors in addition to personal importance, including belief dimension(s), knowledge and experience discussed above, and also social and environmental factors associated with where a person lives (e.g., demographics, political traditions and ecosystem type), that are intricately linked leading to great variations in opinions and acceptability of fire management practices between and within locations. Brunson and Shindler (2004) found such differences in their western USA study suggesting that government policies addressing bushfire management need to be adaptive to the local situation at hand.

\section{Response and recovery}

With increasing knowledge, people's expectations of how the government should respond to a bushfire are changing (Cortner et al., 1990). For example, people do not necessarily expect a fire to be immediately suppressed, however, this depends on a number of factors. For example, Kneeshaw, Vaske, Bright \&Absher (2004) investigated situational influences of acceptable wildland fire management actions, they found that fire origin was one of the most important factors for "put the fire out" and one of the least important factors for "let the fire burn"; if the fire was ignited through lightning there was support for letting the fire burn, and conversely if the fire was ignited through human carelessness there was support for putting the fire out. Furthermore the relative importance of risk of private property damage and forest recovery was consistently high in influencing acceptability of management actions; if the fire posed a risk to private property and if forest recovery were to take many years there was support for putting the fire out. The relative importance of air quality was minor but there was general support for putting the fire out if air quality became poor. The relative importance of outdoor recreation was lowest, if a recreational area was closed due to the fire, recreating in another area nearby may be an acceptable substitute. Past experience with bushfire is also an important factor, however once again the effect will vary depending on the type of experience.

In the USA, federal fire services have been criticised in their efforts to collaboratively fight fires with local services. Federal fire services focus on the big picture of the fire as a generalised event whereas local services have a more place-specific view. Some people view this as depersonalisation, which grates on local residents and fire fighters whose particular homes and special places are at risk (Carroll et al., 2005). This was the underlying cause of 
much of the post-fire conflict in the communities of Carroll et al.'s (2005) study. It appears that local fire fighters expected that their knowledge, skills and commitment would have been better valued, and utilised. They also felt too constrained by the rules and decisions made at higher levels, and this led to local fire fighters and homeowners defying the instructions of the Incident Command System. Federal services were also accused of putting the majority of their resources into fighting fires in one community, leading to intercommunity conflict. Carroll et al. (2005) explained that "the relative inflexibility of rational, bureaucratic systems was seen as unable to adapt to quickly-changing conditions, something at which the spontaneous creation of local helping systems seemed more adept" (p. 316). This highlights the importance of the government and its policies to become more attuned to local situations, and the importance of communities to become more organised and better prepared to be able to respond to bushfire. This would lead to effective collaborative efforts that significantly increase the resilience of the community.

The government however, is often blamed in the event of a bushfire. Blaming behaviour has been well documented among people affected by disaster, and this phenomenon can create much hostility toward the organisation or institution that was supposed to protect people from disaster (Kumagai et al., 2004a), namely the government and its agencies responsible for some aspect of fire protection. Just 33.8\% of respondents in Odgers and Rhodes' (2002) study felt that the local government was effective in responding to bushfires, compared with $92 \%$ of respondents indicating that the fire service was effective, and although reasons were not given, there appears to be a general public opinion that governments are ineffective in their efforts to mitigate bushfire. Blaming behaviour can be the result of whether property damage was incurred, whether or not a person maintained a sense of control, and/ or whether the bushfire was perceived as primarily natural or technological (Kumagai, Bliss, Daniels \& Carroll, 2004b). Participants in Kumagai et al.'s (2004b) study who incurred property damage from the Butte Complex Fires in Nevada in 1999 attributed the damage to "others actions", specifically backfires started by the California Department of Forestry and Fire Protection (CDF) in spite of the fact that there was no public evidence of such backfires. The study also indicated that people who had lost their sense of control tended to attribute damage to factors associated with fire fighters and the CDF. Losing one's sense of control was associated with a belief that their property did not receive adequate attention from fire fighters, and not being able to obtain up-to-date information during the bushfire. Participants who viewed the fires as the result of nature (rather than technology) were less likely to blame others, one respondent acknowledged the build up of fuel as a contributing factor to fire magnitude but said that humans can not do 
anything about events that "are totally the act of God" (Kumagai et al., 2004b, p. 120).

The primary expectation of all levels of governments post-disaster is the provision of assistance, and in many cases actual assistance received falls short of what was expected. Controversy about government assistance after the Canberra bushfires was well documented throughout the media (Government must do more, 2003); \$5000 per rebuilding household was considered miserly and not enough to rebuild social capital and address the social issues following a disaster. Years after Hurricane Floyd in North Carolina, families were still waiting for promised assistance, and for authorised repair and replacement units, which affects the trust that residents have in their local government (Moore et al., 2004). Communities rely on external assistance to mitigate the economic impact associated with natural disaster, and indeed, with such assistance, disaster can result in economically positive impacts on a stricken community (Kumagai et al, 2004a). However, there are a number of issues concerning disaster assistance, primarily the issue of equity. As previously discussed it is not uncommon that assistance, from both government and non-government organisations, does not adequately address those most in need (David et al., 1999; Fothergill \& Peek, 2004). Secondly, because of disaster assistance, the costs of disaster are borne not only by those affected, but also by the community, all levels of government and the general population (Cortner et al., 1990). Thirdly, there is evidence that people may not undertake preventative measures, such as home insurance, in view of the existence of disaster recovery programs (Cortner et al., 1990; McKee et al., 2004). Because people expect that they can live where they wish, continually putting themselves in dangerous situations and thus creating such economic problems, Sowell (2004) has suggested phasing out state and federal disaster relief and relying more heavily on prevention and mitigation activities, particularly insurance. After a disaster there is an expectation of government that actions will be taken to prevent another disaster. For example, after Hurricane Floyd, people were sceptical about whether their counties' had learned anything from the disaster, respondents mentioned that, since the flood, counties had not done a good job of keeping drainage ditches free of debris and that bridges were not high enough to surmount future flood levels (Moore et al., 2004). Disaster prevention, however, such as relocating and redesigning infrastructure, can be influenced by a communities' desire to "return to normalcy" as quickly as possible, which does not create a positive environment for orderly, well-planned reconstruction processes (Petterson, 1999). Similarly, recovery planning can become thwarted by old perceptions and mental pictures of the community as it was before the disaster (Petterson, 1999). Furthermore, in terms of encouraging homeowner participation in preventative measures, policies are not well accepted. 
However, respondents in a number of studies have indicated that they support citizen involvement in developing fire hazard reduction programs (Blanchard \& Ryan, 2004), which is important because such programs and policies need public input to be able to deal with the realities of public expectations as well as the realities of the biophysical environment (Cortner et al., 1990).

\section{Expectation of the media}

Prevention and mitigation

The media has a significant influence on public knowledge, perceptions and opinions. Many studies have linked respondent knowledge and perceptions of bushfire and opinions of bushfire management with information disseminated by the media. For example, Cortner et al. (1990) reported that the news media, second to experience, was a way in which people were made aware of the bushfire hazard. Jacobson et al. (2001) found that public opinion about the benefits of prescribed fire closely matched the benefits identified by the media, and similarly Loomis et al. (2001) suggested that media coverage of bushfires in Florida contributed to Florida respondents' knowledge and support of prescribed burning. There is also evidence that people prefer bushfire information to be delivered via the media; respondents in Holden et al. (2000) indicated that television, second to literature (e.g., pamphlet, booklet), is the best delivery method for bushfire information. However, Monroe and Nelson's (2004) study has suggested that the media is not always a trusted source, and indeed in the USA for example, there has been cause to distrust the media because of conflicting messages (Cortner et al., 1990; Burns et al., 2003). Respondents in Monroe and Nelson's study (2004) indicated that written news and televised interviews with experts are better trusted. Focus groups discussions in the Burns et al. (2003) study revealed that people believe the media should be more proactive, not only by providing more accurate and objective information but by discussing the complexity of bushfires and the benefits of prescribed burning, and explaining "why" mitigation action should be taken, rather than providing mere informational messages. "The well functioning of a modern society is based on the good and fast circulation of information. This is even more relevant in the case of a society vulnerable to natural hazards" (Anonymous, 1998, p. 21). Information (collection, production and dissemination) and communication media are a crucial link in the chain of sound prevention measures and awareness-raising (Anonymous, 1998). 


\section{Response and recovery}

In a bushfire event people rely heavily on and need information to make effective decisions, and although emergency services remain responsible for the communication of risk (Krusel \& Petris, 1992), the media plays a crucial role. Often the media is the only potential source of information during a fire. From Lazarus and Alley's (1984) study, it appears that many people during the Ash Wednesday fires could not use phones, lived a significant distance from neighbours and/ or had no contact with emergency services, however, they did have access to a radio and/or television but there were reports that the media did not provide adequate information. As a likely consequence, some of these people did not know the fire was in their area until it reached their house. There are a number of reports suggesting that the media could have done a better job of warning people of an impending hazard (Moore et al., 2004). Furthermore, Odgers and Rhodes' (2002) study suggested that people would like the media to provide more specific information during a fire event, such as the location, severity and direction of the bushfire.

The media can also influence the recovery cycle of a community after a disaster. For example, the 2002 Rodeo-Chediski fire in northern Arizona highlighted the influence of media coverage during and after the fires on the magnitude of recovery assistance received by a community. One community, of three affected by the fire, received the most media coverage and as a result received the most help offers from ordinary people and helping organisations wanting to contribute money and other resources to aid in recovery. This inequity contributed to the tension and conflict observed in the aftermath (Carroll et al., 2005).

\section{Expectation of insurance agencies}

Insurance agencies are obviously depended on for money to rebuild homes, however, often a person's insurance policy does not cover 100\% of the loss, which is commonly unexpected because people may not realise that they live in a fire-prone area or forget to update their policy, for example. However, there are also unanticipated disputes between fire victims and their insurers. For example, in the aftermath of the Canberra fires a woman claimed that her insurance agency was unreasonable in offering to pay only two-thirds of her home insurance, because it did not cover the concrete slab, which had been compromised according to an engineer, and the assessment excluded part of the house (Morris, 2002). Although it is primarily the responsibility of the person buying insurance, there is a need for insurance agencies to undertake an awareness raising role concerning people's insurance policies, which, if effective, would lessen the financial repercussions. 
Cortner et al. (1990) revealed that people in a fire-affected community who did not update their policies were provided an economic advantage because they were able to apply for a low interest loan, which effectively provided the resources to rebuild bigger and better homes than their neighbours who had updated their policies. There is also perhaps a need for insurance agencies to play a role in promoting homeowner bushfire preparedness, via mechanisms such as a reduction in home insurance premiums if a house is constructed of fire resistant materials, as was suggested by a respondent in Winter and Fried's (2000) study.

\section{Conclusion}

This review of community expectations of bushfires and the impact of bushfires on communities shows quite clearly that there are considerable differences between and within communities in terms of bushfire awareness, perceptions of bushfires, expectations of what happens during a bushfire, the impact on individuals and communities, and expectations of the roles of various organisations. The implications of this are substantive and fraught with difficulties for service delivery and applied social research. Locality clearly remains important and it often falls to the local service providers to understand the expectations and beliefs held by the communities they serve. There is a clear need to identify effective strategies for service providers to understand and engage with their communities. The challenge for applied social researchers is to identify and develop appropriate strategies or models for engagement. 


\section{References}

\section{Chapter 1}

Anderson, C. (1983). Aborigines and tin mining in North Queensland: A case study in the anthropology of contact history. Mankind, 13, 473-498.

Anderson, C. (1984). The political economic basis of Kuku-Yalangi social history. Unpublished $\mathrm{PhD}$ thesis, University of Queensland, Brisbane.

Bell, C. \& Newby, H. (1971). Community studies: An introduction to the sociology of the local community. London: Allen and Unwin.

Buckle, P. (1999). Re-defining community and vulnerability in the context of emergency management. The Australian Journal of Emergency Management, 13(4), 21-26.

Cahnman, W.J. \& Heberle, R. (Eds.). (1971). Ferdinand Toennies on sociology: Pure, applied and empirical. Chicago: University of Chicago Press.

Cohen, A.P. (1985). The symbolic construction of community. Chichester, Sussex: Ellis Horwood.

Cottrell, A., Cunliffe, S., King, D. \&Anderson-Berry, L. (2001). Awareness and preparedness for natural hazards in a remote community: Bloomfield River Region and Rossville. Townsville: Centre for Disaster Studies. J ames Cook University. Retrieved November 1, 2005, from <http:// www.tesag.jcu.edu.au/CDS/ reports/ Bloomfield2001.pdf>.

Hall, R.R., Thorns, D.C. \&Willmott, W.E. (1984), Community class and kinship - bases for collective action within localities. Environment and Planning D: Society and Space, 2(2), 201-215.

Hillery, G.A. Jr. (1955). Definitions of community: Areas of agreement. Rural Sociology, 20(2), 111-123.

Marsh, G. \& Buckle, P. (2001). Community: The concept of community in the risk and emergency management context. The Australian J ournal of Emergency Management, 16(1), 5-7.

Martinez-Brawley, E.E. (1990). Perspectives on the small community: Humanistic views for practitioners. Washington, DC: NASW Press.

Milofsky, C. (1988). Community organizations. New York: Oxford University Press.

Neuman, W.L. (1997). Social research methods: Qualitative and quantitative approaches. Boston: Allyn and Bacon.

Nisbet, R.A. (1970). The sociological tradition. London: Heinemann.

Nisbet, R.A. (1974). The social philosophers: Community and conflict in western thought. London: Heinemann. 
Périer, P. (1998). Le Play and his followers: Over a century of achievement. International Social Science J ournal, 50(157), 343-348.

Sullivan, M. (2003). Communities and their experience of emergencies. The Australian J ournal of Emergency Management, 18(1), 19-26.

Tindall, D.B. \& Wellman, B. (2001). Canada as social structure: Social network analysis and Canadian sociology. Canadian Journal of Sociology, 26(3), 265-308.

Warren, R.L. (1963). The community in America. Chicago: Rand McNally.

Wellman, B. (1988). The community question re-evaluated. In M.P. Smith (Ed.), Power, community and the city. (pp. 81-107). New Brunswick: Transaction Books.

Wellman, B. (2001). Physical place and cyberplace: The rise of personalized networking. International J ournal of Urban and Regional Research, 25(2), 227-252.

\section{Chapter 2}

Alexander, C. (1966). A city is not a tree. Architectural Forum, April 1966; reprinted in Design, No. 6 February 1966. Revised (1986) for Zone 1/2, New York; revised version reprinted in Thakara, J. (1988). Design after modernism. London: Thames and Hudson.

Benini, A.A. (1999). Network without centre?: A case study of an organizational network responding to an earthquake. Journal of Contingencies and Crisis Management, 7(1), 38-47.

Britton, N.R. (2001). A new emergency management for the new millennium? The Australian Journal of Emergency Management, $16(4), 44-54$.

Cliffe, L. (2000). What happens to the state in conflict?: Political analysis as a tool for planning humanitarian assistance. Disasters, 24(4), 291314.

Comfort, L.K., Sungu, Y., J ohnson, D. \& Dunn, M. (2001). Complex systems in crisis: Anticipation and resilience in dynamic environments. J ournal of Contingencies and Crisis Management, 9(3), 144-158.

Crondstedt, M. (2002). Prevention, preparedness, response, recovery: An outdated concept. The Australian Journal of Emergency Management, 17(2), 10-13.

Douglas, R. (1999). Administrative law and response to emergencies. The Australian J ournal of Emergency Management, 14(2), 1-10.

Duffield, M. (2001). Governing the borderlands: Decoding the power of aid. Disasters, 25(4), 308-320. 
Edwards, M. \& Hulme, D. (2002a). NGO performance and accountability: Introduction and overview. In M. Edwards \& A. Fowler (Eds.), The earthscan reader on NGO management. London: Earthscan Publications.

Edwards, M. \& Hulme, D. (2002b). Beyond the magic bullet?: Lessons and conclusions. In M. Edwards \&A. Fowler (Eds.), The earthscan reader on NGO management. London: Earthscan Publications.

Emergency Management Australia. (1998). Australian emergency manuals series: Part 1: The fundamentals: Manual 3: Australian emergency management glossary. Canberra: Author.

Emergency Management Division. (2000). Overview of the integrated management system. State of Washington: Author. Retrieved

September 13, 2006, from <http:/ / emd.wa.gov/ 3-

pet/ ent/ courses/cse-presents/g-230-12-01/g-230-condef.ppt\#257,2,Objectives>.

Fahey, C. (2003). Working with communities to build social capital: Reflecting on old and new thinking about volunteers. The Australian J ournal of Emergency Management, 18(4), 12-17.

Fowler, A. (2002). NGO futures: Beyond aid: NGDO values and the fourth position. In M. Edwards \& A. Fowler (Eds.), The earthscan reader on NGO management. London: Earthscan Publications.

Fox, F. (2001). New humanitarianism: Does it provide a moral banner for the 21st century? Disasters, 25(4), 275-289.

Harvey P. (1998). Rehabilitation in complex political emergencies: Is rebuilding civil society the answer? Disasters, 22(3), 200-217.

Hilhorst, D. (2002). Being good at doing good?: Quality and accountability of humanitarian NGOs. Disasters, 26(3), 193-212.

J uratowitch, D.M., Daly, K.L. \& Smith, N.J . (2002). Reduction of stress and trauma in the delivery of disaster recovery services: The users decide: An exploratory study of the effects of delivering disaster recovery services. The Australian J ournal of Emergency Management, 17(1), $50-54$.

King, D. (2002). Post disaster surveys: Experience and methodology. The Australian J ournal of Emergency Management, 17(3), 1-13.

Keen, D. (1998). Aid and violence, with special reference to Sierra Leone. Disasters, 22(4), 318-327.

Loosemore, M. \& Hughes, W.P. (2001). Confronting social defence mechanisms: Avoiding disorganisation during crises. Journal of Contingencies and Crisis Management, 9(2), 73-87.

Macrae, J . \& Leader, N. (2001). Apples, pears and porridge: The origins and impact of the search for 'coherence' between humanitarian and political responses to chronic political emergencies. Disasters, 25(4), 290-307. 
Norman, S. \& Coles, E. (2003). Order out of chaos?: A critical review of the role of central, regional, and local government in emergency planning in London. The Australian Journal of Emergency Management, 18(2), 98-107.

Palmer, M. (2001). Doing it by the book: A paradox in disaster management. The Australian J ournal of Emergency Management, 16(3), 40-44.

Prater, C. \& Wu, J-Y. (2002). The politics of emergency response and recovery: Preliminary observations on Taiwan's 921 earthquake. The Australian J ournal of Emergency Management, 17(3), 48-59.

Queensland Government. (2003). Disaster Management Act 2003. Brisbane: Author.

Reno, W. (1997). Humanitarian emergencies and warlord economies in Liberia and Sierra Leone. Helsinki: UNU World Institute for Development Economics Research.

Richards, P. (1996). Fighting for the rainforest: War, youth \& resources in Sierra Leone. Oxford: J ames Currey.

Silberbauer, G. (2003). Structural and personal social processes in disaster. The Australian J ournal of Emergency Management, 18(3), 29-36.

Spillan, J.E. (2003). An exploratory model for evaluating crisis events and managers' concerns in non-profit organisations. Journal of Contingencies and Crisis Management, 11(4), 160-169.

Sullivan, M. (2003). Integrated recovery management: A new way of looking at a delicate process. The Australian Journal of Emergency Management, 18(2), 4-27.

Woodward, S.L. (2001). Humanitarian war: A new consensus? Disasters, 25(4), 331-344.

Yates, J . (1999). Improving the management of emergencies: Enhancing the ICS. The Australian J ournal of Emergency Management, 14(2), 1824.

\section{Chapter 3}

Adger, W.N., Hughes T.P., Folke C., Carpenter S.R. \& Rockstrom, J . (2005). Social-ecological resilience to coastal disasters. Science, 309, 12 August 2005, 1036-1039.

Anderson-Berry L, King, D. \& Crane, G. (2002). Assessment of the effectiveness of various methods of delivery of public awareness information on tropical cyclones to Queensland coastal communities. Report on Project 05/2001 for Emergency Management Australia. Townsville: Centre for Disaster Studies, James Cook University. Retrieved September 21, 2005, from <http:// www.tesag.jcu.edu.au/CDS/ reports/ Warnings_Report2003. doc $>$. 
Anderson-Berry, L. \& King, D. (2005). Mitigation of the impact of tropical cyclones in northern Australia through community capacity enhancement. Mitigation and Adaptation Strategies for Global Change, 10(3), 367-392.

Bankoff, G. (2003). Constructing vulnerability: The historical, natural and social generation of flooding in metropolitan Manila. Disasters, 27(3), 224-238.

Betts, R. (2003). The missing links in community warning systems: Findings from two Victorian community projects. The Australian J ournal of Emergency Management, 18(3), 37-45.

Blatt, F. (2001). The Lassing Mine disaster: A retrospective. The Australian J ournal of Emergency Management, 16(4), 38-43.

Comstock, R. D. \& Mallonee, S. (2005). Comparing reactions to two severe tornadoes in one Oklahoma community. Disasters, 29(3), 277-287.

Finnis, K., Standring, S., Johnston, D. \& Ronan, K. (2004). Children's understanding of natural hazards in Christchurch, New Zealand. The Australian J ournal of Emergency Management, 19(2), 11-20.

Gordon, R. (2004). The social system as site of disaster impact and resource for recovery. The Australian J ournal of Emergency Management, 19(4), 16-22.

Haig, J . (2004). Establishment of the international post cyclone database:

Review and collation of post cyclone reports world wide which study the physical, social, economic, psychological and environmental impact of tropical cyclones including response and meteorological reports. Centre for Disaster Studies, Townsville: J ames Cook University and Emergency Management Australia.

Retrieved September 21, 2005, from $<$ http:// www.tesag.jcu.edu.au/CDS/reports/ FinalReport_EMA26. pdf>.

Handmer, J . \& Hillman, M. (2004). Economic and financial recovery from disaster. The Australian J ournal of Emergency Management, 19(4), 44-50.

Izadkhah, Y.O. \& Hosseini, M. (2005). Towards resilient communities in developing countries through education of children for disaster preparedness. International J ournal of Emergency Management, 2(3), 138-148.

J ohnes, M. (2000). Aberfan and the management of trauma. Disasters, 24(1), 1-17.

Jonkman, S.N. \& Kelman, I. (2005). An analysis of the causes and circumstances of flood disaster deaths. Disasters, 29(1), 75-97.

Kano Megumi, M.P.H., Siegel, J.M. \& Bourque, L.B. (2005). First-aid training and capabilities of the lay public: A potential alternative source of emergency medical assistance following a natural disaster. Disasters, 29(1), 58-74. 
Kendra, J.M. \& Wachtendorf, T. (2003). Elements of resilience after the World Trade Center disaster: Reconstituting New York City's emergency operations centre. Disasters, 27(1), 37-53.

Keys, C. (2005). The great Labe-Elbe river flood of 2002. The Australian J ournal of Emergency Management, 20(1), 53-54.

King, D. (2002). Post disaster surveys: Experience and methodology. The Australian J ournal of Emergency Management, 17(3), 39-47.

King, D. \& Gurtner, Y. (2005). After the wave: A wake up warning for Australian coastal locations. The Australian J ournal of Emergency Management, 20(1), 4-9.

O'Neil, P. (2004, May 18). Why don't they listen: Developing a risk communication model to promote community safety behaviour. The International Emergency Management Society 11th Annual Conference Proceedings. Melbourne: TIEMS.

Paton, D., J ohnston, D.M., Bebbington, M.S., Lai, C-D \& Houghton, B.F. (2000). Direct and vicarious experience of volcanic hazards: Implications for risk perception and adjustment adoption. The Australian J ournal of Emergency Management, 15(4), 58-63.

Pfister, N. (2002). Community response to flood warnings: The case of an evacuation from Grafton, March 2001. The Australian J ournal of Emergency Management, 17(2), 19-29.

Prater, C. \& Wu, J-Y. (2002). The politics of emergency response and recovery: Preliminary observations on Taiwan's 921 earthquake. The Australian J ournal of Emergency Management, 17(3), 48-59.

Shaw, R., \& Goda, K. (2004). From disaster to sustainable civil society: The Kobe experience. Disasters, 28(1), 16-40.

Skertchly, A. \& Skertchly, K. (2000). Human aspects of the Katherine-Daly flood disaster. The Australian J ournal of Emergency Management, 15(1), 47-52.

Thomalla, F \& Schmuck, H. (2004). 'We all knew that a cyclone was coming': Disaster preparedness and the cyclone of 1999 in Orissa, India. Disasters, 28(4), 373-387.

Wachtendorf, T. (2000). When disasters defy borders: What can we learn from the Red River flood about transnational disasters?, The Australian J ournal of Emergency Management, 15(3), 36-41.

Winchester, P. (2000). Cyclone mitigation, resource allocation and postdisaster reconstruction in South India: Lessons from two decades of research. Disasters, 24(1), 18-37.

Yates, L., \& Anderson-Berry, L. (2004). The societal and environmental impacts of Cyclone Zoë and the effectiveness of the tropical cyclone warning systems in Tikopia and Anuta Solomon Islands: December 26- 29, 2002. The Australian Journal of Emergency Management, 19(1), 16-20. 


\section{Chapter 4}

Australian Bureau of Statistics. (2002). Census of population and housing, 2001. Canberra: Author.

Drabek, T.E. (1994). Disaster evacuation and the tourist industry. Program on environment and behaviour monograph 57. Boulder: University of Colorado.

Goudie, D.D. (1996). Early evacuation to billets in Cairns above 10 metres, ahead of land-based and cyclone tide flooding. In D. King (Ed.), Flood management workshop proceedings: Proceedings, 04-06 November 1996. Cairns: Centre for Disaster Studies, James Cook University.

King, D. \& Goudie, D. (1998). Breaking through the disbelief: The March 1997 flood at Cloncurry: Even the duck swam away. The Australian J ournal of Emergency Management, 12(4), 29-33.

Lourensz, R.S. (1977). Tropical cyclones in the Australian region: J uly 1909 to J une 1975. Canberra: Australian Government Publishing Service.

Minnery, J.R. \& Smith, D.I. (1994). Climate change, flooding and urban infrastructure. Australian-New Zealand Conference on Climate Change. Greenhouse 94. Canberra: Centre for Resource and Environmental Studies, Australian National University.

Smith, D.I. (1995). Vertical evacuation and storm surge: A literature review and commentary. Centre for Resource and Environmental Studies, Australian National University.

James Cook University of North Queensland. (1972). Cyclone "Althea": Vol.2. Storm surges and coastal effects. Townsville: Author.

\section{Chapter 5}

Abramovitz, J .N. (2001). Averting unnatural disasters. In L.R. Brown, C. Flavin, \&

H. French. (Eds.). State of the World 2001. (pp. 123-142, 236-243). London: Earthscan Publications.

Anonymous. (1989). A shaken world. New Scientist, 124(1688), 2.

Berry, L.J . (2002). Community vulnerability to landfalling tropical cyclones and storm surges. Unpublished $\mathrm{PhD}$ thesis, James Cook University, Cairns.

Asian Development Bank. (2002). Risk management. Manilla: Author.

Blaikie, P., Cannon, T., Davis, I. \& Wisner, B. (1994). At risk: Natural hazards, people's vulnerability, and disasters. London: Routledge.

Department of Emergency Services (2001). State planning policy on landuse planning for natural hazard mitigation and development assessment. Brisbane: Author. 
Deutsche Gesellschaft für Technische Zusammenarbeit (GTZ) GmbH (2002). Disaster risk management: Working concept. Eschborn, Frankfurt: Author. Retrieved from <http:// search.gtz.de/ > .

Drabek, T. E. (1995). Disaster planning and response by tourist business executives. Cornell Hotel and Restaurant Administration Quarterly, 36(3), 86-96.

Evans, A. F. (1996). Insurance, reinsurance and catastrophe protection in the Caribbean. New York: Organization of American States, Unit for Sustainable Development and Environment. Retrieved from $<$ http:// www.oas.org/ cdmp/ document/insuranc.htm>.

Freeman, P.K. (1999). Infrastructure, natural disasters, and poverty. In Proceedings of the EuroConference on Global Change and Catastrophic Risk Management: Flood Risks in Europe. International Institute of Applied Systems Analysis, 6-9 J une 1999, Laxenburg, Austria. Retrieved from <http:// www.iiasa.ac.at/ Research/CAT/ publications.html>.

Glaesser, D. (2003). Crisis management in the tourism Industry. Oxford, Butterworth Heinemann.

Granger, K. (2000). An information infrastructure for disaster management in Pacific island countries. The Australian Journal of Emergency Management, 15(1), 20-32.

Guha-Sapir, D., Hargitt, D. \& Hoyois, P. (2004). Thirty years of natural disasters 1974-2003: The numbers. Brussels: Centre for Research on the Epidemiology of Disasters, Université Catholique de Louvain.

Heathcote, R.L. (1979). The threat from natural hazards in Australia. In R.L. Heathcote \& B.G. Thom. (Eds.). Natural Hazards in Australia: Proceedings of a symposium. (pp. 3-12). Canberra: Australian Academy of Science.

Inskeep, E. (1998). Guide for local authorities on developing sustainable tourism. Madrid: World Tourism Organization. Retrieved from <http:// pub.world-tourism.org >.

J ones, B.G. (1992). Population growth, urbanization and disaster risk and vulnerability in metropolitan Areas: A conceptual framework. In A. Kreimer, \&M. Munasinghe (Eds.). Environmental management and urban vulnerability, World Bank Discussion Paper, No 168. Washington DC: The World Bank.

Kippo News. (1996, March 26). Kankeiren to promote three summer festivals. Retrieved from <http:// www.kippo.or.jp/ kansaiwindowhtml/ news/ 1996e/ 19960326 NEWS.HTML>.

Kishore, K. (2003). Disaster risk management in Asia and possible linkages with adaptation to climate change. Geneva: UN, United Nations Institute for Training and Research. Retrieved from <http:// www.ccpunitar.org/ $>$. 
Kreimer, A. \&Arnold, M. (Eds.). (2000). Managing disaster risk in emerging economies. Washington DC: The World Bank. Retrieved from <http:/ / www-wds.worldbank.org/ >.

Kuehlbrandt, E. (2000). Tropical cyclone awareness and preparedness amongst backpacker accommodation providers and backpackers in Cairns. Townsville: Centre for Disaster Studies, J ames Cook University. Retrieved from $<$ <ttp:// www.tesag.jcu.edu.au/ CDS/ Pages/ Report.htm>.

Kunreuther, H. (1996). Mitigating disaster losses through insurance. J ournal of Risk and Uncertainty, 12(2), 171-187.

Linnerooth-Bayer, J . (1999). Who pays for catastrophes? Risk Analysis: Facing the New Millennium. Rotterdam: Society for Risk Analysis.

Mileti, D.S. (1999). Disasters by design: A reassessment of natural hazards in the United States. Washington, DC: J oseph Henry Press.

Munich Re. (1998). World map of natural hazards. Munich: Munich Reinsurance Company. Retrieved from $<\mathrm{http}: / /$ www.munichre.com/ >.

Munich Re. (1999). Topics 2000: Natural catastrophes - the current position. Munich: Munich Reinsurance Company. Retrieved from <http:// www.munichre.com/ >.

Munich Re. (2000). The reinsurance of natural catastrophe risks. Munich: Munich Reinsurance Company.

Murphy, P.E. \& Bayley, R. (1989). Tourism and disaster planning. Geographical Review, 79(1), 36-46.

Office of Foreign Disaster Assistance. (1990). Significant data on major disasters worldwide. Washington, DC: Author.

Quarantelli, E.L. (1993). Community crises: An exploratory comparison on the characteristics and consequences of disasters and riots. J ournal of Contingencies and Crisis Management 1(2), 67-78.

Quarantelli, E.L. (1999). Implications for programs and policies from future disaster trends. Risk Management: An International J ournal, 1, 9-19.

Salter, J . (1995). Disasters as manifestations of vulnerability. The Australian J ournal of Emergency Management, 10(1), 9-10.

Smith, S.L.J. (1995). Tourism analysis: A Handbook. Harlow, UK: Longman.

Swiss Re. (1998). Questions of reinsurance: A short guide. Zurich: Author.

Swiss Re. (2003). Natural catastrophes and man-made disasters in 2002: High flood loss burden. Zurich: Author. Retrieved from <http:// www.swissre.com/ >.

United Nations Environment Program. (2003). Weather related natural disasters in 2003 cost the world billions. Belarus: UNEP. Retrieved from <http:/ / un.by/ en/ news/ world/ 2003/ 15-12-03-4.html>. 
Wilks, J . \& Moore, S. (2003). Tourism risk management for the Asia Pacific region: An authoritative guide for managing crises and disasters.

Gold Coast, Queensland: CRC for Sustainable Tourism.

World Tourism Organization (2001). Tourism after 11 September 2001: Analysis, remedial actions and prospects. Madrid: Author. Retrieved from <http:// pub.world-tourism.org>.

World Tourism Organization. (2002). Tourism satellite account in depth: Analysing tourism as an economic activity. Madrid: Author. Retrieved from <http:/ / unuto.org/ statistiques/tsa_in_depth/index.htm>.

\section{Chapter 6}

Bali Recovery Group. (2002). Bali Recovery Group. Retrieved November 20, 2002, from <http:// 209.164.26.114/index.asp>.

Bali SOS (2003). Bali Emergency Network. Retrieved J anuary 6, 2003, from $<\mathrm{http}: / /$ www.balisos.com/ pages/SOS.html>.

Bar-On, R.R. (1996). Measuring the effects on tourism of violence and of the promotion following violent acts. In A. Pizam \& Y. Mansfield. (Eds.), Tourism, crime and international security issues. (pp. 159-174). England: J ohn Wiley and Sons Ltd.

Beirman, D. (2003). Restoring tourism destinations in crisis: A strategic marketing approach. Sydney: Allen and Unwin.

Bloom, J. (1996). A South African perspective of the effects of crime and violence on the tourism industry. In A. Pizam \&Y. Mansfield. (Eds.), Tourism, crime and international security issues. (pp. 91-102). England: J ohn Wiley and Sons Ltd.

BPS Statistics Indonesia (2003). Tourism Statistics. Retrieved April 5, 2003 from <http:// www.bps.go.id/ sector/ tourism/index.html>.

Cavlek, N. (2002). Tour operators and destination safety. Annals of Tourism Research, 29(2), 478-496.

Cuny, F. (1983). Disasters and development. Oxford: Oxford University Press.

Faulkner, B. (2001). Towards a framework for tourism disaster management. Tourism Management, 22(2), 135-147.

Gee, C.Y. \& Gain, C. (1986). Coping with crisis. Travel and Tourism Analyst, June 1986, 3-12.

Glaesser, D. (2003). Crisis management in the tourism industry. Oxford: Butterworth-Heinemann.

Hitchcock, M. \& Darma Putra, I.N. (2005). The Bali bombings: Tourism crisis management and conflict avoidance. Current Issues in Tourism, 8(1), 62- 76 . 
International Strategy for Disaster Reduction. (2004). Terminology: Basic terms of disaster risk reduction. Geneva: ISDR. Retrieved August 4, 2006, from <http:// www.unisdr.org/ eng/library/lib-terminologyeng.htm>.

Kalla, J . (2003). Mitigating against the social and economic costs of the terrorist attack on Bali. Twelfth meeting of the Consultative Group of Indonesia, Promoting Equitable Growth, Investment and Poverty Reduction, Bali, 21-22 J anuary 2003. Retrieved from <http:/ / www.worldbank.or.id/ eap/ eap.nsf/ CountryOffice/ Indonesia / A8F409DF5AADF66E47256D39003A88CB?OpenDocument>.

Karyadi, N. (2003) Restoring faith: Social and economic mitigation in postbomb Bali. Twelfth meeting of the Consultative Group of Indonesia, Promoting Equitable Growth, Investment and Poverty Reduction, Bali, 21-22 J anuary 2003. Retrieved from $<$ http:/ /nweb18.worldbank.org/ eap/ eap.nsf/ Attachments/ 01210312CGI-O-Ngurah+Karyadi/ \$File/ 12CGI-O-Ngurah+Karyadi.pdf>.

McIntosh, R.W. \& Goeldner, C.R. (1986). Tourism: Principles, practices, philosophies. New York: J ohn Wiley \& Sons.

Pacific Asia Travel Association. (2003). Crisis: It won't happen to us. Bangkok: PATA. Retrieved from <http:// www.pata.org/ patasite/ fileadmin/ docs/general/Crisis.pdf>.

Pizam, A. \& Mansfield, Y. (Eds.). (1996) Tourism, crime and international security issues. West Sussex: J ohn Wiley and Sons.

Quarantelli, E.L. (1998). What is a disaster?: Perspectives on the question. New York: Routledge.

Robert, B. \& Lajtha, C. (2002). A new approach to crisis management. J ournal of Contingencies and Crisis Management, 10(4), 181-191. $<\mathrm{http}: / /$ www.blackwell-synergy.com/toc/jccm/10/4>.

Ritchie, B.W. (2004). Chaos, crises and disasters: a strategic approach to crisis management in the tourism industry. Tourism Management, 25(6), 669-683.

Shaluf, I.M., Ahmadun, F. \& Said, A.M. (2003). A review of disaster and crisis. Disaster Prevention and Management, 12(1), 24-32.

Sonmez, S.F., Apostolopoulos, Y. \& Tarlow, P. (1999) Tourism in crisis: Managing the effects of terrorism. J ournal of Travel Research, 38(1), 13-18.

United Nations Environment Program. (2003). Tourism: Sustainable development of tourism. Paris: UNDP. Retrieved J anuary 29, 2004, from <http:// www.uneptie.org/ pc/ tourism/ sust-tourism/ >. 
United Nations Development Program. (2003). Bali: Beyond the tragedy: Impact and challenges for tourism-led development in Indonesia. Denpasar: Consultative Group on Indonesia, UNDP-World Bank. Retrieved August 26, 2006, from $<$ http:// www.undp.or.id/ programme/ conflict/ documents/ bali\%20b eyond\%20the\%20tragedy en.pdf>.

World Health Organization/ Emergency Humanitarian Action. (2002). Disaster and emergencies: Definitions: Training package. Addis Ababa: WHO/EHA. Retrieved J anuary 29, 2004, from $<$ http:// www.who.int/ disasters/ repo/ 7656.pdf>.

World Bank. (2003). Confronting crisis: Impacts and response to the Bali tragedy. Twelfth meeting of the Consultative Group of Indonesia, Promoting Equitable Growth, Investment and Poverty Reduction, Bali, 21-22 J anuary 2003. Retrieved from $<$ http:/ / lnweb18.worldbank.org/ eap/ eap.nsf/ Attachments/ 01210312CGI-Bali/ \$File/CGI_BaliUpdate.pdf>.

World Tourism Organisation. (2002). Tourism activities. Madrid: WTO. Retrieved September 1, 2006, from <http:// worldtourism.org/newsroom/ campaign/ menu.htm>.

World Tourism Organisation. (2003). Crisis guidelines for the tourism Industry. Madrid: WTO. Retrieved J uly 3, 2003, from $<$ http:/ / www.worldtourism.org/market_research/Crisis\%20and\%20Disaster\%20Manag ement\%20Guidelines.pdf>.

World Tourism Organisation. (2004). Sustainable development of tourism. Madrid: WTO. Retrieved August 31, 2006, from <http:// www.worldtourism.org/ frameset/ frame sustainable.html>.

World Travel and Tourism Council. (2003). Travel and tourism security action plan. London: WTTC. Retrieved July 3, 2003, from $<\mathrm{http://} \mathrm{www.wttc.org/} \mathrm{publications/} \mathrm{pdf/} \mathrm{SecurityActionPlanFINAL \%}$ 2004apr03mth2.pdf>.

World Travel and Tourism Council. (2005). World travel and tourism: Sowing the seeds of growth. London: WTTC. Retrieved September 8, 2006, from <http:// www.wttc.org/mediaCentre/ speeches/HVS\%20China.pdf>.

\section{Chapter 7}

Dixon, R.M.W. (1991). Words of our country: Stories, place names and vocabulary in Yidiny, the Aboriginal language of the Cairns-Yarrabah region. Brisbane: University of Queensland Press.

Ellis, J.A. (1991). From the dreamtime: Australian Aboriginal legends. Melbourne: Collins Dove. 
Greene G., Tramacchi J . \& Gill L. (1992). Roughtail: The dreaming of the roughtail lizard and other stories told by the Kukatja. Broome: Magabala Books.

Larrakia (2001). Saltwater people: Larrakia stories from around Darwin. Casuarina, Northern Territory: Larrakia Nation Aboriginal Corporation.

Moyle, A.M. (n.d.). Introductory notes to songs from Yarrabah. Canberra: Australian Institute of Aboriginal Studies.

Murphy, K. (1984). Big blow up north: A history of tropical cyclones in Australia's Northern Territory. Darwin: University Planning Authority.

Napurrurlarlu, N.O. \& J akamarrarlu, N.P. (1988). Ngawarra-Kurlu: The flood. Darwin: Yuendumu Bilingual Resources Development Unit.

Nunkiarry, G. (1996). Gurliliyin, gayiliyin mitim traibul lo: Law from the south meets law from the north. In A. Hunter \& R. Bin Salleh (Eds.), Moola Bulla: In the shadow of the mountain. (pp. 10-12). Broome: Magabala Books.

Roth, W.E. (1897). Ethnological studies among the north-west-central Queensland Aborigines. Brisbane: E. Gregory, government printer.

Roth, W.E. (1903). North Queensland ethnography: Bulletin No. 5: Superstition, magic, and medicine. Brisbane: Home Secretary's Department.

Tjeemairee, K. (1968). The flood and the bird-men. In R. Robinson (Ed.), Aboriginal myths and legends. (pp. 85-90). Melbourne :Sun Books.

Trezise, P. (1993). Dream road: A journey of discovery. St Leonards: Allen \& Unwin.

Umbagai, E. (1980). The spirit water. In Mowanjum Mission (Ed.), Visions of Mowanjum: Aboriginal writings from the Kimberley. (p. 77). Adelaide: Rigby.

Unaipon, D. (2001). The flood and its result: Berrwerina tribe, Darling River. In S. Muecke \& A. Shoemaker (Eds.), David Unaipon: Legendary tales of the Australian Aborigines. (pp. 25-41). Melbourne: Melbourne University Press.

Utemorrah, D. (1980). How the people were all drowned. In Mowanjum Mission (Ed.), Visions of Mowanjum: Aboriginal writings from the Kimberley. (pp. 46-48). Adelaide: Rigby.

Utemorrah, D. (2000a). Maambulbarda: Eye-of-the-sea (M. Clendon, Trans.). In Kimberley Language Resource Centre (Ed.), Worrorra Lalai: Worrorra Dreamtime stories. (pp. 95-114). Halls Creek, Western Australia: Kimberley Language Resource Centre.

Utemorrah, D. (2000b). Dumbi: The owl (M. Clendon, Trans.). In Kimberley Language Resource Centre (Ed.), Worrorra Lalai: Worrorra Dreamtime stories. (pp. 5-12). Halls Creek, Western Australia: Kimberley Language Resource Centre. 
Wungunyet, J. 1980). The woman who destroyed the old world. In Mowanjum Mission (Ed.), Visions of Mowanjum: Aboriginal writings from the Kimberley. (pp. 90-91). Adelaide: Rigby.

\section{Chapter 8}

Ahern, A. (2002). Paint up: Amanda Ahern and the Mornington Island elders. St Lucia: University of Queensland Press.

Binnion, J. (1987). The Lardil people of Mornington Island: Student handbook. Port Adelaide: Aboriginal Community College.

Callaghan, J . (2004). Known tropical cyclone impacts in the Gulf of Carpentaria. Retrieved October 12, 2006, from $<\mathrm{http}$ // australiasevereweather.com/ cyclones/impacts-gulf.pdf>.

Memmott, P. \& Horsman, R. (1991). A changing culture: The Lardil Aborigines of Mornington Island. Wentworth Falls, NSW: Social Science Press.

McKnight, D. (1999). People, countries, and the rainbow serpent: Systems of classification among the Lardil of Mornington Island. New York: Oxford University Press.

Skertchly, A. \& Skertchly, K. (1999). Traditional Aboriginal knowledge and sustained human survival in the face of severe natural hazards in the Australian monsoon region: Some lessons from the past for today and tomorrow. The Australian J ournal of Emergency Management, 15(3), 36-41.

Sinatra, J \& Murphy, P. (1999). Listen to the people, listen to theland. Carlton: Melbourne University Press.

Trezise, P. (1993). Dream road: A journey of discovery. St Leonards: Allen \& Unwin.

\section{Chapter 9}

Abrahams, H., Mulvaney, M., Glasco, D. \& Bugg, A. (1995). Areas of conservation significance on Cape York Peninsula. Brisbane and Canberra: Cape York Peninsula Land Use Strategy, Office of the Coordinator General of Queensland and Australian Heritage Commission.

Anderson, C. (1988). All bosses are not created equal. Anthropological Forum, 5(1), 507-522.

Anyango, D. (1997). Towards a better fire management strategy in the savannas of northern Australia: The potential of Landsat thematic mapper satellite images and GIS. Unpublished Master of Applied Science dissertation, J ames Cook University, Townsville. 
Australian Bureau of Statistics. (2002). Census of population and housing, 2001. Canberra: Author.

Cape York Peninsula Development Association (2003). Cape York Fire Management Project Cairns: Author. Retrieved from $<\mathrm{http}: / /$ www.cypda.com.au/ >.

Chase, A.K. (1980). Which way now?: Tradition, continuity and change in a north Queensland Aboriginal community. Unpublished $\mathrm{PhD}$ thesis, University of Queensland, Brisbane.

Commonwealth of Australia. (1993). Native Title Act 1993. Canberra: Author.

Commonwealth of Australia. (1998). Native Title Amendment Act 1998. Canberra: Author.

Cowlishaw, G. (1987). Colour, culture and the Aboriginalists. Man, 22(2), 221-237.

Freier, P.L. (1999). Living with the Munpitch: The history of Mitchell River Mission, 1905-1967. Unpublished Ph.D. thesis, J ames Cook University, Townsville.

Gribble, E.R.B. (1933). A despised race: The vanishing Aboriginals of Australia. Sydney: Australian Board of Mission.

Kidd, R. (1997). The way we civilise: Aboriginal affairs - The untold story. St Lucia: University of Queensland Press.

Lane, M.B. \& Chase, A. (1996). Resource development on Cape York Peninsula: Marginalisation and denial of indigenous perspectives. In R. Howitt, J. Connell \& P Hirsch (Eds.), Resources nations and indigenous peoples: Case studies from Australasia, Melanesia and Southeast Asia. (pp. 172-183). Oxford: Oxford University Press.

Loos, N. (1982). Invasion and resistance: Aboriginal-European relations on the north Queensland frontier. Canberra: ANU Press.

McConnel, U.H. (1930). The Wik-Munkan tribe of Cape York Peninsula: Part 1. Oceania, (1)1, 97- 104.

Monaghan, J . (2001). An atlas of the wetlands in the Kowanyama DOGIT and a preliminary assessment of their Value to the Kowanyama community. Report to Kowanyama Land and Natural Resource Management Office. Kowanyama: Author.

Monaghan, J . (2003a). Landscape mapping of the traditional country of the people of Pormpuraaw. Report to the Pormpuraaw Aboriginal Council and the West Coast of Cape York Peninsula Traditional Landowners Association. Pormpuraaw: Author.

Monaghan, J . (2003b). Kowanyama: Sea and saltwater country: A report for the Northern Regional Marine Plan Scoping Study. Report to Kowanyama Land and Natural Resource Management Office. Kowanyama: Author. 
Monaghan, J . (2003c). Landscape mapping of the traditional country of the people of Kowanyama. Report to Kowanyama Land and Natural Resource Management Office. Kowanyama: Author.

Monaghan, J . (2005). 'Our way': Social space and the geography of land allocation practice on the southern gulf lowlands of Cape York Peninsula. Unpublished $\mathrm{PhD}$ thesis, James Cook University, Townsville.

Monaghan, J . \& Taylor, J .C. (2003). Natural disaster risk mitigation plan for the Pormpuraaw community. Report to the Pormpuraaw Community Council and Queensland State Emergency Services.

Retrieved J une 12, 2004 from $<$ <ttp:// www.tesag.jcu.edu.au/ CDS/ Pages/ Report.htm>.

Norris, V. (2003). Kowanyama natural resource management plan. Kowanyama: Kowanyama Land and Natural Resource Management Office.

Queensland Government. (1984). Aboriginal Communities (Justice and Land Matters) Act 1984. Brisbane: Author.

Queensland Government. (1985). Aborigines and Torres Strait Islanders (Land Holding) Act 1985. Brisbane: Author.

Queensland Government. (1997). Integrated Planning Act 1997. Brisbane: Author.

Queensland Government. (1991). Aboriginal Land Act 1991. Brisbane: Author.

Roth, W.E. (1907). North Queensland Ethnography, Volume 1 Bulletin No.18, Social and individual nomenclature. In K.F. MacIntyre. (1984). (Ed.). The Queensland Aborigines. (pp. 79-106). Carlisle, WA: Hesperian Press.

Rowse, T. (1992). Remote possibilities: The Aboriginal domain and the administrative imagination. Darwin: North Australia Research Unit, ANU.

Sharp, L. (1937). The social anthropology of a totemic system in north Queensland, Australia. Unpublished PhD. thesis, Harvard University, Cambridge, MA.

Smith, B.R. (2000). Between places: Aboriginal decentralisation, mobility and territoriality in the region of Coen, Cape York Peninsula (Queensland, Australia). Unpublished $\mathrm{PhD}$ thesis, London School of Economics, University of London.

Stanner, W.E.H. (1965). Aboriginal territorial organisation: Estate, range, domain and regime. Oceania, 36(1), 1-26.

Strang, V. (1994). Uncommon ground: Concepts of landscapes and humanenvironmental relations in far north Queensland. Unpublished $\mathrm{PhD}$ thesis, Oxford University, Oxford.

Sutton, P. (1996). The robustness of Aboriginal land tenure systems: Underlying and proximate customary titles. Oceania, 67(1), 7-29. 
Sutton, P. (1998). Native title and the descent of rights. Perth: National Native Title Tribunal.

Taylor, J. (1979). Housing programs at Edward River and Mitchell River Aboriginal reserves. In M. Heppell (Ed.), A black reality: Aboriginal camps and housing in remote Australia. (pp. 207-228). Canberra: Australian Institute of Aboriginal Studies.

Taylor, J.C. (1984). Of acts and axes: An ethnography of socio-cultural change in an Aboriginal community, Cape York Peninsula. Unpublished PhD thesis, J ames Cook University, Townsville.

Taylor, J.C. (1999). Indigenous traditional affiliations to land in the Kowanyama deed of grant in trust area. Report to the Kowanyama Aboriginal Council and the Queensland Department of Natural Resources. Kowanyama: Author.

\section{Chapter 10}

Australasian Fire Authorities Council. (2005). Position paper on bushfires and community safety. Melbourne: AFAC. Retrieved October 26, 2006, from

$<\mathrm{http}$ // www.afac.com.au/awsv2/publications/guidelines_information .htm>.

Beckingsale, D. (1994). Community fireguard and the rural-urban interface. Fire Management Quarterly, 10, 1-8.

Boura, J. (1999). Community fireguard: Creating partnerships with the community. CFA Occasional Paper No. 2. Mt Waverley, Victoria: Country Fire Authority. Retrieved October 26, 2006, from <http:// www.cfa.vic.gov.au/ documents/ occ-02-boura.pdf>.

Cohen, J.D. (1999). Reducing the wildland fire threat to homes: Where and how much? USDA Forest Service Pacific Southwest Research Station Gen. Tech. Rep. PSW-GTR-173. Albany, CA. Retrieved October 26, 2006, from

<http:/ / www.firelab.org/ old/ fbp/ fbppubs/ fbppdf/ cohen/ reducingwlfire .pdf>.

Cottrell, A. (2005). Communities and bushfire hazard in Australia: More questions than answers. Environmental Hazards, 6(2), 109-114.

DeGrosky, M.T. (2003, October). Facilitating community-based solutions. Paper presented at the $3^{\text {rd }}$ International Wildland Fire Conference and Exhibition, Sydney.

Doyle, M.(2001). How to Make Meetings Work. New York. J ove Books.

Ellis, S., Kanowski, P. \& Whelan, R. (2004). National Inquiry on bushfire mitigation and management. Canberra: Council of Australian Governments. Retrieved September 13, 2006, from $<\mathrm{http}$ :// www.coagbushfireenquiry.gov.au/ findings.htm>. 
Ellis, S.J. (2003, October) Summary and analysis of review into operational response - Lessons for the future - ACT fires J anuary 2003. Paper presented at the $3^{\text {rd }}$ International Wildland Fire Conference and Exhibition, Sydney.

Firewise Communities. (2003) .Firewise Communities USA. Quincy, Massachusetts: National Fire Protection Association. Retrieved December 18, 2003, from <http:// www.firewise.org/ usa/ index.htm>.

Frank, F. \& Smith, A. (1999). The community development handbook: A tool to build community capacity. Quebec: Human Resources Development Canada (HRDC).

Frentz, I.C., Farmer, F.L., Guldin, J .M. \& Smith, K.G. (2004). Public lands and population growth. Society and Natural Resources, 17(1), 57-68.

Gledhill, J.B. (2003, October). Community self-reliance during bushfires: The case for staying at home. Paper presented at the $3^{\text {rd }}$ International Wildland Fire Conference and Exhibition, Sydney.

Hamilton, L. (2003, October). Social considerations of reducing fuels in the wildland-urban interface in the western United States. Paper presented at the $3^{\text {rd }}$ International Wildland Fire Conference and Exhibition, Sydney.

Helling, A. (1998). Collaborative visioning: Proceed with caution!: Results from evaluating Atlanta's vision 2020 project. Journal of the American Planning Association, 64(3), 335-350.

Ingalsbee, T. (2003). Home losses in the Cerro Grande/Los Alamos Fire: Fire protection efforts begin at home. Eugene, Oregon: Author. Retrieved December 2, 2003, from <http:// www.fire-ecology.org/ >.

J urie, J .D. (2000). Building capacity: Organizational competence and critical theory. J ournal of Organizational Change Management, (13)3, 264274.

Koperberg, P. (2003, October). The politics of fire management. Paper presented at the $3^{\text {rd }}$ International Wildland Fire Conference and Exhibition, Sydney.

Leonard, J.E. \& Bowditch, P.A. (2003, October). Findings of studies of houses damaged by bushfire in Australia. Paper presented at the $3^{\text {rd }}$ International Wildland Fire Conference and Exhibition, Sydney.

Lipnack, J . \& Stamps, J . (1997). Virtual teams: reaching across space, time, and organizations with technology. New York: J ohn Wiley \& Sons.

Margerum, R.D. (2002). Evaluating collaborative planning: Implications from an empirical analysis of growth management. Journal of the American Planning Association, 68(2), 179-193.

McKinney, M. (1998). Resolving public disputes: A handbook on building consensus. Helena, Montana: Montana Consensus Council. 
McLeod, R. (2003). Inquiry into the operational response to the J anuary 2003 bushfires in the ACT. Canberra: Australian Capital Territory Government. Retrieved J anuary 25, 2007, from $<$ www.cmd.act.gov.au/mcleod_inquiry/ Documents/Final/ McLeodInq uiry.pdf $>$.

Miller, S.I., Carter, W. \& Stephens, R.G. (1984). Report of the bushfire review committee on bushfire preparedness in Victoria, Australia, following the Ash Wednesday Fires 16 February 1983. Melbourne: Victorian Government.

National Interagency Fire Center. (2001). Fire protection in the wildland/urban interface: Everyone's responsibility. Boise, Idaho: NIFC. Retrieved December 5, 2003, from <http:/ / www.nifc.gov>.

Nicholson, J . (1995). Key elements of major fire prevention and suppression: The role of fire management agencies in reducing the threat from major bushfires. Draft report to the Australian Fire Authorities Council Rural Land Management Consultative Committee.

Queensland Fire and Rescue Service. (2004). Structural protection in the iZone. Brisbane: Queensland Government.

Rhodes, A.N. (2003, October). Understanding community response to wildfire. Paper presented at the $3^{\text {rd }}$ International Wildland Fire Conference and Exhibition, Sydney.

Rohrmann, B. (1999). Community-based fire preparedness programmes: An empirical evaluation. The Australasian Journal of Disaster and Trauma Studies, 1999, 1, 1-21.

Scott Waldron, G. (2001). Looking for local solutions to the wildland-urban interface problem. In Public Entity Risk Institution (Ed.). Reducing the risk of wildland-urban interface fires. Fairfax, Virginia: Public Entity Risk Institute. Retrieved J une 2, 2003, from <http:// www.eriskcenter.org/ uploaded/ wildlandurbaninterfacefires.pdf>.

Smalley, J . (2003, October). Firewise communities: Recasting the future of the wildland-urban interface. Paper presented at the $3^{\text {rd }}$ International Wildland Fire Conference and Exhibition, Sydney.

Smith, E. \& Adams, G. (1991). Incline Village/ Crystal Bay defensible space handbook. Reno: University of Nevada.

Tasmania Fire Service. (1994). Community fireguard. Hobart: Tasmania Fire Service.

Department of Transport and Regional Services. (2004). Natural disasters in Australia: Reforming mitigation, relief and recovery arrangements. Canberra: Council of Australian Governments. Retrieved September 13, 2006, from <http:// www.dotars.gov.au/ disasters/ research/ coag_report/ index.a $\mathrm{spx}>$. 


\section{Chapter 11}

Anderson-Berry, L.J . (2003). Community vulnerability to tropical cyclones: Cairns, 1996-2000. Natural Hazards, 30(2), 209-232.

Anonymous. (1998). United Nations 1998 world disaster reduction campaign - prevention begins with information: Natural disaster prevention and the media. The Australian J ournal of Emergency Management, 13(2), 21.

Anonymous. (2004). Community wildfire protection plans from four angles. J ournal of Forestry, 102(6), 4-7.

Beringer, J . (2000). Community fire safety at the urban/rural interface: The bushfire risk. Fire Safety J ournal, 35(1), 1-23.

Blanchard, B. \& Ryan, R.L. (2003). Community perceptions of wildland fire risk and fire hazard reduction strategies at the wildland-urban interface in the northeastern United States. In Proceedings of the 2003 Northeastern Recreation Research Symposium (pp. 284-294). Retrieved October 25, 2005, from $<$ http:// www.fs.fed.us/ne/ newtown_square/publications/technical_r eports/pdfs/2004/317papers/ blanchard317.pdf>.

Boughton, G. (1998). The community: Central to emergency risk management. The Australian J ournal of Emergency Management, 13(2), 2-5.

Braun, K. (2002). Bushfire threat to homeowners. In Proceedings of the Symposium: Fire in Ecosystems of South-west Western Australia: Impacts and management: Volume 2 Community perspectives about fire (pp. 64-72). Retrieved October 21, 2005, from $<$ http:// science.calm.wa.gov.au/ articles/2003-0604/ fire proceedings day3.pdf $>$.

Brennan, P. (1998). Bushfire threat: Response in a small community. Melbourne: Centre for Environmental Safety and Risk Engineering, Victoria University of Technology. Retrieved December 14, 2006, from <http:/ / www.ema.gov.au/ agd/ ema/ emaInternet.nsf/ Page/ RWPDDC1 BC77D1B61ECFCA256C8100178D18?OpenDocument>.

Bright, A.D., Vaske J J ., Kneeshaw, K. \& Absher, J.D. (2002). Scale development of wildfire management basic beliefs. In Proceedings of the Ninth International Symposium on Society and Management: Homeowners, Communities, and Wildfire: Science Findings from the National Fire Plan (pp. 18-25). Retrieved October 25, 2005, from $<$ http:// ncrs.fs.fed.us/ pubs/gtr/ gtr nc231.pdf>.

Brunson, M.W. \& Shindler, B.A. (2004). Geographic variation in social acceptability of wildland fuels management in the western United States. Society and Natural Resources, 17(8), 661-678. 
Buckle, P., Marsh, G. \& Smale, S. (2000). New approaches to assessing vulnerability and resilience. The Australian J ournal of Emergency Management, 15(2), 8-14.

Burns, S., Porter-Norton, M, Mosher, M \& Richard, T (2003). People and fire in western Colorado: Focus group attitudes, beliefs, opinions and desires regarding wildfire in the wildland-urban interface of Colorado's west slope. Durango, Colorado: Fort Lewis College, Office of Community Services. Retrieved November 6, 2006, from <http:/ / www.southwestcoloradofires.org/ default.asp>.

Campbell, A. (2003, April 1). Dark days disappear as family decides new direction. The Canberra Times, p. 14.

Carroll, M.S., Findley, A.J ., Blatner, K.A., Mendez, S.R., Daniels, S.E. \& Walter, G.B. (2000). Social assessment for the Wenatchee National Forest wildfires of 1994: Targeted analysis for the Leavenworth, Entiat, and Chelan Ranger Districts. Portland, Oregon: U.S. Department of Agriculture, Forest Service, Pacific Northwest Research Station. Retrieved October 25, 2005, from <http:// www.fs.fed.us/pnw/ pubs/ gtr 479.pdf>.

Carroll, M.S., Cohn, P.J., Seesholtz, D.N. \& Higgins, L.L. (2005). Fire as a galvanising and fragmenting influence on communities: The case of the Rodeo-Chediski fire. Society and Natural Resources, 18(4), 301320.

Canadian Forest Service. (2004). Challenges and solutions. Edmonton: Author. Retrieved October 25, 2005, from $<$ http:// fire.cfs.nrcan.gc.ca/research/management/ wui//challenges_e. $\mathrm{htm}>$.

Cortner, H.J ., Gardner, P.D. \& Taylor, J .G. (1990). Fire hazards at the urbanwildland interface: What the public expects. Environmental Management, 14(1), 57-62.

Cottrell, A. (2005). Communities and bushfire hazard in Australia: More questions than answers. Environmental Hazards, 6(2), 109-114.

Creighton, J .H., Baumgartner, D.M. \& Gibbs, S.D. (2002). Fire prevention in the rural/ urban interface: Washington's backyard forest stewardship/ wildfire safety program. J ournal of Extension, 40(2). Retrieved October 21, 2005, from $<$ ¿ttp:// www.joe.org/joe/ 2002april/iw5.html>.

Cunningham, C. \& Kelly, S. (n.d.). Attrition of community knowledge of bushfire hazards: A case study of the Blue Mountains, New South Wales, Australia. Westfield, Massachusetts: Department of Geography and Regional Planning, Westfield State College. Retrieved October 21, 2005, from <http:// www.wsc.ma.edu/ garp/ faculty/ sk/ australia.htm>. 
Daniel, T.C., Weidemann, E. \& Hines, D. (2002). Assessing public tradeoffs between fire hazard and scenic beauty in the wildland-urban interface. In Proceedings of the Ninth International Symposium on Society and Management: Homeowners, Communities, and Wildfire: Science Findings from the National Fire Plan (pp. 18-25). Retrieved October 25, 2005, from <http://ncrs.fs.fed.us/pubs/gtr/ gtr_nc231.pdf>.

David, S.D., Baish, S. \& Hearn Morrow, B. (1999). Uncovering the hidden costs of coastal hazards. Environment, 41(8), 10-19.

Debelle, P. (1993, February 6). When a town burns. The Age, p. 1.

De Cicco, P.R. (1990). Fire hazard: Historical perspectives. In A.S. Nowak \& T.V. Galambos (Eds.). Making buildings safer for people during hurricanes, earthquakes and fires. (pp. 84-103). New York: Van Nostrand Reinhold.

Fisek, G.O., Yeniceri, N., Muderrisoglu, S. \&Ozkarar, G. (2002). Risk perception and attitudes towards mitigation. In Proceedings from the Second Annual IIASA-DPRI Meeting Integrated Disaster Risk Management: Megacity Vulnerability and Resilience. Retrieved October 21, 2005, from <http:// www.iisa.ac.at/ Research/ RMS/ dpri2002/ Papers/ fisek.pdf>.

Flint, C.G. \&Luloff, A.E. (2005). Natural resource-based communities, risk, and disaster: An intersection of theories. Society and Natural Resources, 18(5), 399-412.

Fothergill, A. \& Peek, L.A. (2004). Poverty and disasters in the United States: A review of recent sociological findings. Natural Hazards, 32(1), 89110.

Fried, J .S., Winter, G.J . \& Gilless, J.K. (1999). Assessing the benefits of reducing fire risk in the wildland-urban interface: A contingent valuation approach. International J ournal of Wildland Fire, 9(1), 920.

Gardner, P.D., Cortner, H.J . \&Widaman, K. (1987). The risk perceptions and policy response toward wildland fire hazards by urban home-owners. Landscape and Urban Planning, 14, 163-172.

Gilbert, J.B. (2004). The bushfire risk: Community awareness and perception on the rural-urban fringe of Melbourne. London: Unit Dissertation, University College. Retrieved August 4, 2005, from

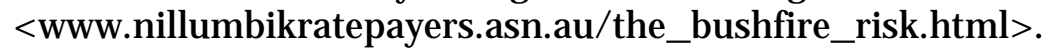

Gough, J . (2000). Perceptions of risk from natural hazards in two remote New Zealand communities. The Australasian J ournal of Disaster and Trauma Studies, 2000-2, 1-12. Retrieved November 3, 2006, from <http:// www.massey.ac.nz/ \%7Etrauma/ issues/ 2000-2/ gough.htm>. Government must do more for fire victims. (2003, September 17). The Canberra Times, p. 16. 
Halvorson, S.J . (2002). The fires of 2000: Community response and recovery in the Bitter Root Valley, Western Montana. Boulder, Colorado: Natural Hazards Research and Applications Information Centre, University of Colorado. Retrieved October 21, 2005, from <http:// www.colorado.edu/ hazards/ qr/ qr/ 151/ qr151.html>.

Hamer, N. (2001). Can we increase the public perception of danger in the urban-wildland interface? In Public Entity Risk Institution (Ed.). Reducing the risk of wildland-urban interface fires. Fairfax, Virginia: Public Entity Risk Institute. Retrieved October 21, 2005, from $<$ http:/ / www.eriskcenter.org/ uploaded/ wildlandurbaninterfacefires.pdf>.

Harris, P. (2004, J anuary 17). A kinder spark rekindled. The Age, p. 3. Haswell, D. \& Brown, N. (2002). Approaches to community safety and bushfires in southwestern Australia. In Proceedings of the Symposium: Fire in Ecosystems of South-west Western Australia: Impacts and management: Volume 2 Community perspectives about fire (pp. 47-57). Retrieved October 21, 2005, from <http:// science.calm.wa.gov.au/ articles/2003-0604/ fire proceedings_day3.pdf>.

Hoffman, S.M. (2000). Eve and Adam among the embers: Gender patterns after the Oakland Berkeley Firestorm. In E. Enarson \& B.H. Morrow. (Eds.), The gendered terrain of disaster: Through women's eyes, (pp. 55-61). Westport, Connecticut: Greenwood Publishing.

Holden, S., J ones, M. \& Gabler, J . (2000). Perceptions of fire risk in potential bushfire hazard areas. Unpublished Gold Coast City Council Survey.

Hugo, G. (2002). Changing patterns of population distribution in Australia. A J oint Special Issue of the J ournal of Population Research and the New Zealand Population Review, 1-23.

Institute of Medicine. (2002). Speaking of health: Assessing health communication strategies for diverse populations. Washington DC: Institute of Medicine of the National Academies. Retrieved November 3, 2006, from <http:// www.iom.edu/ Object.File/ Master/ 15/ 432/ speakingofhealth8pgFI NAL.pdf $>$.

Jacobson, S.K., Monroe, M.C. \&Marynowski, S. (2001). Fire at the wildland interface: The influence of experience and mass media on public knowledge, attitudes, and behavioural intentions. Wildlife Society Bulletin, 29(3), 929-937. 
Jakes, P.J ., Nelson, K., Lang, E., Monroe, M., Agrawal, S., Kruger, L. \& Sturtevant, V. (2002). A model for improving community preparedness for wildfire. In Proceedings of the Ninth International Symposium on Society and Management: Homeowners, Communities, and Wildfire: Science Findings from the National Fire Plan (pp. 4-9). Retrieved October 25, 2005, from <http:// ncrs.fs.fed.us/ pubs/ gtr/ gtr_nc231.pdf>.

J ohnston, D.M., Bebbington, M.S., Lai, C-D., Houghton, B.F. \& Paton, D. (1999). Volcanic hazard perceptions: Comparative shifts in knowledge and risk. Disaster Prevention and Management, 8(2), 118-126.

Kent, B., Gebert, K., McCaffrey, S., Martin, W., Calkin, D., Schuster, E., Martin, I., Wise Bender, H., Alward, G., Kumagai, Y., Cohn, P.J ., Carroll, M., Williams, D. \&Ekarius, C. (2003). Social and economic issues of the Hayman fire. Fort Collins, Colorado: U.S. Department of Agriculture, Forest Service, Rocky Mountain Research Station. Retrieved October 25, 2005, from <http:// www.fs.fed.us/rm/pubs/rmrs_gtr114/rmrs_gtr114_6.pdf>.

Kerry, M., Kelk, G., Etkin, D., Burton, I. \& Kalhok, S. (1999). Glazed over: Canada copes with the ice storm of 1998. Environment, 41(1), 6-11, 2832.

Kneeshaw, K., Vaske, J .J ., Bright, A.D. \&Absher, J.D. (2004). Situational influences of acceptable wildland fire management actions. Society and Natural Resources, 17(6), 477-489.

Krusel, N. \& Petris, S.N. (1992). A study of civilian deaths in the 1983 Ash Wednesday bushfires Victoria, Australia. CFA Occasional Paper No 1. Mount Waverley: Country Fire Authority. Retrieved November 6, 2006, from <http:// www.cfa.vic.gov.au/ publications/ casestudykrusel.htm>.

Kumagai, Y., Carroll, M.S. \& Cohn, P. (2004a). Coping with interface wildfire as a human event: Lessons from the disaster/hazards literature. J ournal of Forestry, 102(6), 28-32.

Kumagai, Y., Bliss, J .C., Daniels, S.E. \& Carroll, M.S. (2004b). Research on causal attribution of wildfire: An exploratory multiple-methods approach. Society and Natural Resources, 17(2), 113-127.

Larsson, G. \& Enander, A. (1997). Preparing for disaster: Public attitudes and actions. Disaster Prevention and Management, 6(1), 11-21.

Lazarus, G. \&Elley, J . (1984). A study of the effect of household occupancy during Ash Wednesday bushfire in upper Beaconsfield, Victoria, February 1983. National Centre for Rural Fire Research Technical Paper No. 3. Caulfield East: Chisholm Institute of Technology.

Loomis, J .B., Blair, L.S. \& Gonzalez-Caban, A. (2001). Prescribed fire and public support: Knowledge gained, attitudes changed in Florida. J ournal of Forestry, 99(11), 18-22. 
Lupton, D. \& Tulloch, J . (2002). Risk is part of your life': Risk epistemologies among a group of Australians. Sociology, 36(2), 317334.

Marsh, G. (2001). Community: The concept of community in the risk and emergency management context. The Australian J ournal of Emergency Management, 16(1), 5-7.

Marriner, C. \& Holder, S. (2004, J anuary 19). On a clear day, fire-ravaged capital looks to rebuild. The Sydney Morning Herald, p. 3.

McCaffrey, S. (2004). Thinking of wildfire as a natural hazard. Society and Natural Resources, 17(6), 509-516.

McGee, T.K. \& Russell, S. (2003). “It's just a natural way of life...”: An investigation of wildfire preparedness in rural Australia. Environmental Hazards, 5(1), 1-12.

McKee, M., Berrens, R.P., J ones, M., Helton, R. \& Talberth, J . (2004). Using experimental economics to examine wildfire insurance and averting decisions in the wildland-urban interface. Society and Natural Resources, 17(6), 491-507.

Meacham, B.J . (2004). Understanding risk: Quantification, perceptions, and characterization. J ournal of Fire Protection Engineering, 14(3), 199227.

Monroe, M.C., Long, A.J. \& Marynowski, S. (2003b). Wildland fire in the southeast: Negotiating guidelines for defensible space. J ournal of Forestry, 101(3), 14-19.

Monroe, M.C. \& Nelson, K.C. (2004). The value of assessing public perceptions: Wildland fire and defensible space. Applied Environmental Education and Communication, 3(2), 109-117.

Monroe, M., J acobson, S. \& Marynowski, S. (1999). Needs assessment report: Awareness and attitudes about fire in Florida. Florida: School of Forest Resources and Conservation, University of Florida. Retrieved October 25, 2005, from $<$ http:// www.sfrc.ufl.edu/Extension/ needsurv.htm>.

Monroe, M.L., Bowers, A.W. \&Hermansen, L.A. (2003a). The moving edge: Perspectives on the southern wildland-urban interface. Asheville, North Carolina: U.S. Department of Agriculture, Forest Service, Southern Research Station. Retrieved October 25, 2005, from $<$ http:// www.srs.fs.usda.gov/ pubs/gtr/ gtr_srs063.pdf>.

Montz, B.E. (1993). Hazard area disclosure in New Zealand: The impacts on residential property values in two communities. Applied Geography, 13(3), 225-242.

Moore, S., Daniel, M., Linnan, L., Campbell, M., Benedict, S. \& Meier, A. (2004). After Hurricane Floyd passed: Investigating the social determinants of disaster preparedness and recovery. Family and Community Health, 27(3), 204-217. 
Morris, L. (2002, March 9). Bushfire victim gutted by insurance shortfall. The Sydney Morning Herald, p.13.

National Interagency Fire Centre (2003). Wildland fire statistics. Boise, Idaho: National Interagency Fire Centre. Retrieved October 25, 2005, from <http:// www.nifc.gov/ stats/index.html>.

Nelson, K.C., Monroe, M.C., Fingerman J ohnson, J . \& Bowers, A. (2004). Living with fire: Homeowner assessment of landscape values and defensible space in Minnesota and Florida, USA. International J ournal of Wildland Fire, 13(4), 413-425.

Nelson, K.C., Monroe, M.C. \& Fingerman J ohnson, J . (2005). The look of the land: Homeowner landscape management and wildfire preparedness in Minnesota and Florida. Society and Natural Resources, 18(4), 321336.

Odgers, P. (2002). Bushfire threat and community perception. In Proceedings of the Symposium: Fire in Ecosystems of South-west Western Australia: Impacts and management: Volume 2 Community perspectives about fire (pp. 58-63). Retrieved October 21, 2005, from $<\mathrm{http://} \mathrm{science.calm.wa.gov.au/} \mathrm{articles/2003-06-}$ 04/ fire proceedings day3.pdf $>$.

Odgers, P. \& Rhodes, A. (2002). Community response to the New South Wales bushfires 2001-2002. Melbourne: The Australasian Fire Authorities Council.

Paton, D. (2003). Disaster preparedness: A social-cognitive perspective. Disaster Prevention and Management, 12(3), 210-216.

Petterson, J . (1999). A review of the literature and programs on local recovery from disaster. Fairfax, Virginia: Public Entity Risk Institute. Retrieved November 6, 2006, from <http:/ / www.eriskcenter.org/ assets/ pdfs/GR04-GG.pdf>.

Ramsay, C. \& Rudolph L. (2003). Landscape and building design for bushfire areas. Melbourne: CSIRO Publishing.

Reddy, S.D. (2000). Factors influencing the incorporation of hazard mitigation during recovery from disaster. Natural Hazards, 22(2), 185-201.

Rising from the ashes. (2004, J anuary 17). The Age, p. 1.

Rohrmann, B. (1999). Community-based fire preparedness programmes: An empirical evaluation. The Australasian J ournal of Disaster and Trauma Studies, 1999-1, 1-19. Retrieved 6 November 2006 from $<$ <ttp:/ / www.massey.ac.nz/ \%7Etrauma/ issues/ 19991/rohrmann.htm>.

Rohrmann, B. (2000a). Critical assessment of information on bushfire preparedness for residents. The Australian J ournal of Disaster Management, 15(1), 14-19. 
Rohrmann, B. (2000b). A socio-psychological model for analysing risk communication processes. The Australian J ournal of Disaster and Trauma Studies 2000-2, 1-14.

Sowell, T. (2004, September 13). Should taxpayers pay for hurricane damage? Human Events, 60(31), 7.

Steelman, T.A. \& Kunkel, G.F. (2004). Effective community responses to wildfire threats: Lessons from New Mexico. Society and Natural Resources, 17(8), 679-699.

Thistleton, J . (2004, November 23). Residents steel themselves for future bushfires. The Canberra Times, p. 4.

Vogt, C. (2002). Seasonal and permanent home owners' past experiences and approval of fuels reduction. In Proceedings of the Ninth International Symposium on Society and Management: Homeowners, Communities, and Wildfire: Science Findings from the National Fire Plan (pp. 63-72). Retrieved October 25, 2005, from $<\mathrm{http}: / /$ ncrs.fs.fed.us/pubs/gtr/gtr_nc231.pdf>.

Vogt, C., Winter, G. \& Fried, J . (2002). Antecedents to attitudes toward prescribed burning, mechanical thinning, and defensible space fuel reduction techniques. In Proceedings of the Ninth International Symposium on Society and Management: Homeowners, Communities, and Wildfire: Science Findings from the National Fire Plan (pp. 4-9). Retrieved October 25, 2005, from $<\mathrm{http}: / /$ ncrs.fs.fed.us/pubs/gtr/gtr_nc231.pdf>.

Vogt, C.A., Winter, G. \& Fried, J .S. (2005). Predicting homeowners' approval of fuel management at the wildland-urban interface using the theory of reasoned action. Society and Natural Resources, 18(4), 337-354.

Weichselgartner, J . (2001). Disaster mitigation: The concept of vulnerability revisited. Disaster Prevention and Management, 10(2), 85-95.

Whittaker, J . \& Mercer, D. (2004). The Victorian bushfires of 2002-03 and the politics of blame: A discourse analysis. Australian Geographer, 35(3), 259-287.

Willis, M. (2004). Bushfire arson: A review of the literature. Canberra: Australian Institute of Criminology, Australian Government. Retrieved October 25, 2005, from <http:// www.aic.gov.au/publications/rpp/61/06_part2.html>.

Winter, P.L. (2002). Californian's opinions on wildland and wilderness fire management. In Proceedings of the Ninth International Symposium on Society and Management: Homeowners, Communities, and Wildfire: Science Findings from the National Fire Plan (pp. 84-92). Retrieved October 25, 2005, from $<\mathrm{http}: / /$ ncrs.fs.fed.us/pubs/gtr/gtr_nc231.pdf>.

Winter, G. \& Fried, J .S. (2000). Homeowner perspectives on fire hazard, responsibility, and management strategies at the wildland-urban interface. Society and Natural Resources, 13(1), 33-49. 
Winter, G. \& Fried, J .S. (2001). Estimating contingent values for protection from wildland fire using a two-stage decision framework. Forest Science, 47(3), 349-360.

Winter, G., Vogt, C. \& Fried, J .S. (2002). Fuel treatments at the wildlandurban interface: Common concerns in diverse regions. J ournal of Forestry, 100(1), 15-21.

Young, E. (1998). Dealing with hazards and disasters: Risk perception and community participation in management. The Australian J ournal of Emergency Management, 13(2), 14-16. 


\section{Contributors}

Luke Balcombe was an Environmental Science Masters degree student at James Cook University, and scholar with the Bushfire CRC during 20042006. Luke researched the "Tamborine Mountain Bushfire Awareness Case Study" with Dr Alison Cottrell of J CU and Judy Newton of the Queensland Fire and Rescue Service. The case study was part of the Bushfire CRC "Understanding Communities" project and especially researched the social construction of risk of communities and fire service providers. Luke had previous experience as a Park Ranger at Tamborine Mountain and as an international forester researching fire management issues based at the World Forest Institute in Portland, Oregon.

Sally Bushnell was a Research Officer in the Bushfire CRC in the Centre for Disaster Studies at JCU. Sally completed her Master of Applied Science Degree in Natural Resource Management at JCU in 2005. This degree incorporated research into the effectiveness of faunal underpasses and revegetation corridors in mitigating the effects of habitat fragmentation. Other projects have included developing a monitoring strategy for the 'Central Eastern Rainforest Reserves of Australia' World Heritage Area, and investigating the social impacts of artificial reefs, in the Great Barrier Reef. Other research undertaken included Bushfire CRC Understanding Communities projects investigating the attitudes, values and expectations of people who live in bushfire-prone areas.

Alison Cottrell is a senior lecturer in the Centre for Disaster Studies in the School of Earth and Environmental Sciences at JCU. Alison's research focus is communities and their relationships with hazards. Perceptions of risk, vulnerability and resilience at the individual, household and community levels are of prime concern. Previous research in hazards has covered issues of women's experiences preparing for floods and community participation in flood mitigation activities. Current research includes a project with the Bushfire CRC on understanding the relationships between government policy, planning, service delivery and community responses to bushfires. This research is linked to an assessment of appropriate community based strategies for enhancing community resilience to hazards in general. Alison's teaching activities include cultural aspects of environmental issues, disaster studies, community studies and qualitative social research methods. 
Scott Cunliffe is a consultant to government and the private sector throughout the Asian region, specialising in strategic planning and risk management for sustainable tourism whilst living in South East Asia, the USA and Europe for the last fifteen years. Scott's PhD research at JCU was completed in 2005 and focused on tourism risk management for coastal tropical areas, which developed a comprehensive approach to sustainable tourism with risk management at the core. Milestone projects include: the introduction of the Main Street urban revitalization process to community and business development in Australia; cultural heritage and conservation planning for the ancient city of Angkor in Cambodia; Team Leader for the Asian Development Bank long-term tourism development plan for the Greater Mekong Sub-region, and tourism development strategies in more than a dozen Asian countries and regions for the World Tourism Organization. Initially trained as an architect and urban planner, Scott's first project for the United Nations Children's Fund (UNICEF) in Vietnam in 1985 nurtured a growing interest in risk management, strategic planning and long-term forecasting. Scott's current professional activities are focused on introducing risk management methodologies to mitigate the impacts of disaster and catastrophes affecting communities and tourism businesses in coastal areas.

Douglas Goudie has a biological science degree from Melbourne University, majoring in genetics and evolution. Douglas commenced postgraduate research at J CU in planning and sustainability in 1993. By 2001 Douglas had a MSc. in planning and psychology, and a $\mathrm{PhD}$ in sustainability and urban transport. From 1994 Douglas conducted consultancies on disaster impact mitigation, planning and public involvement and has modelled transport and evacuation issues for a cyclone surge over the lowlying areas of Cairns in northern Queensland; conducted post-flood survey studies for Queensland Emergency Services, and has conducted three disaster risk management studies for local governments in Queensland. At the national level, Douglas has completed a three-year post doctoral study, in collaboration with the Australian Bureau of Meteorology. The chapter on Indigenous weather knowledge in this book results from a collaborative national research project with the Bureau. Douglas is an adjunct lecturer at JCU and has recently commenced an additional post-doctoral study with a unit of the Bushfire CRC at the University of Tasmania.

Yetta Gurtner is a $\mathrm{PhD}$ candidate and researcher with the Centre for Disaster Studies at JCU. With a background in Southeast Asian studies Yetta's current research is focused on crisis recovery in tourist dependant destinations, including Bali and Phuket, and facilitating greater tourism sustainability through proactive community mitigation strategies. Yetta has also conducted extensive fieldwork in the post-disaster context. Further 
areas of interests include all phases of disaster management, the social and economic impacts of tourism in developing nations and exploring efforts towards more sustainable development.

David King is an Associate Professor of Geography in the School of Earth and Environmental Sciences at JCU, and is both Director of the Centre for Disaster Studies, and the Centre for Tropical Urban and Regional Planning. David has worked in northern Queensland for fifteen years and was formerly at the University of Papua New Guinea. David's research specialises in social impact and evaluation in areas including planning, natural hazard vulnerability and resilience, disaster mitigation and recovery, as well as the social impact of mining projects, third world development, and Census analysis.

Eddie McLachlan is a research student with the Centre for Disaster Studies and the School of Indigenous Australian Studies at JCU. Eddie is researching natural hazard vulnerability awareness and mitigation strategies for remote Indigenous communities in northern Australia.

Jim Monaghan was based at the Kowanyama Land and Natural Resource Management Office. Jim has a PhD in geography from J CU specialising in the use of natural and cultural space and has many years experience working in both the Kowanyama and Pormpuraaw areas of northern Queensland. 


\section{Glossary}

\section{Catastrophic Disaster}

An extreme natural hazard event which impacts on a community, or communities resulting in widespread, devastating, economic, social and environmental consequences.

\section{Dreamtime}

Dreamtime is most often used to refer to the 'time before time', or 'the time of the creation of all things', while Dreaming is often used to refer to an individual's or group's set of beliefs or spirituality.

\section{Mitigation}

Measures taken in advance of, or after, a disaster aimed at decreasing or eliminating its impact on society and environment.

\section{Normalisation bias}

Persons without event experience are more reluctant to personalise risk and respond to pre-event warnings, whereas those with experience are more apt to respond. Also, the judgment that if the first event did not affect oneself negatively, then subsequent events will also be avoided.

\section{One hundred year flood}

A flood having a 1 per cent chance of occurring in any one year.

\section{Optimistic bias}

The judgment that negative events are less likely to happen to oneself than to other people.

\section{PPRR}

Emergency management can be identified as having four phases:

Preparedness, Prevention, Response and Recovery (PPRR). The activities in an emergency management plan that support these phases are not necessarily sequential, with elements frequently taking place concurrently. 


\section{Relief}

The provision of immediate shelter, life support and human needs of persons affected by, or responding to, an emergency. It includes the establishment, management and provision of services to emergency relief or recovery centres.

\section{Risk management}

The systematic application of management policies, procedures and practices to the tasks of identifying, analysing, evaluating, treating and monitoring risk.

\section{Sustainable development}

Development which meets the following sustainability principles: intergenerational and intra-generational equity; integration of the economy and the environment; dealing cautiously, yet anticipatory with risk, uncertainty and irreversibility; conservation of biological diversity; and recognition of the global dimension.

\section{The Dry}

In northern Australia between May and September the Dry Season features low humidity and rainfall brought on by dry southeast winds.

\section{Theory of Reasoned Action}

The Theory of Reasoned Action suggests that a person's behaviour is determined by his/her intention to perform the behaviour and that this intention is, in turn, a function of his/ her attitude toward the behaviour and his/ her subjective norm (Ajzen and Fishbein, 1980).

\section{The Wet}

In northern Australia between October and April the Wet Season features warm, moist monsoonal northwest winds which bring high humidity and high rainfall.

\section{Vulnerability}

The degree of susceptibility and resilience of the community and the environment to hazards. 


\section{Index}

A

Aboriginal Communities (J ustice and Land Matters) Act 1984 158, 270

Aborigines and Torres Strait Islanders (Land Holding) Act 1985 161,270

Aboriginal Coordinating Council 159

Aboriginal Land Act 1991 160, 162, 193

Accountability 30, 92, 97, 257

Agencies 170, 184, 185, 188, 191, 202, 207-210, 212-213, 216, 218, 221, 238, 242, 244-245, 250, 253-254

Alice Springs 157

Altruistic/ therapeutic community 241

Annual fire planning 183

Ant 122145

Aquaculture 167, 188

Ash Wednesday 216, 230, 236, 253

Asia Pacific region 31

Attitudes 212, 213, 219, 245, 247248, 276-279, 281, 283

Aurukun 158

Australia 160, 162, 172, 174, 182$185,190,193,194,197,202-$ 203, 205-206, 208, 211, 214217

Australian Aborigine 102

Australian Broadcasting Commission 150
B

Balgo Hills 116, 122

Bali 35-36, 69, 82, 93-101

Bali bombing 3, 35

Balūmbanda 127

Basic belief dimensions 245

Behaviour 12, 22, 35-37, 40, 4344, 57, 118-119, 138, 157, 170, $188,190,204,212-213,229-$ 230, 232, 242, 244-245, 248, 250

Bentinck Island 132-133, 146

Billet brokers 52, 58-59, 62

Billiluna 112-113, 122

Black-tip shark 171

Blaming behaviour 242, 244, 250

Borroloola 157

Bushfire 119, 136, 173-174, 179, 183-184, 187, 192, 194, 197198, 201-208, 211-214, 216254

Bushfire management 214, 219, 245, 249, 252

Bushfire preparedness 232, 239, 254

C

Cairns 8, 36-39, 48, 50, 52-62, 67, 103-104, 106, 119, 157, 191

Camp sites 162, 171

Canberra 197, 204-206, 214, 231, 237, 251

Capacity building 48, 100

Cape York Peninsula 35, 38, 121, $126,140,144,158,161,171-$ $172,187,190$

Catastrophic events 64, 66, 69, $71,73,127$ 
Cattle 6, 39, 130, 161, 164, 167, 171-174, 183, 188

CDEP 151, 167, 185

Children 45, 103, 105, 108, 116$118,127,129,134,137-138$, $151,155,165,170,184,189$, 235

Chillagoe 157

Civil society 28, 31

Cloncurry 36, 39, 50-51, 60

Coastal tropical areas 64, 70-71, $73,79,284$

Coen 157

Collaboration 91, 101, 208, 209, 215

Commitment 11, 25, 57, 91, 96, 98-99, 206, 208-210, 213, 215, 237, 250

Communication 100, 116, 240, 252-253

Communication of risk 253

Communities 9-18, 20, 22, 24, 29-39, 42-44, 46-47, 54, 61, 63-64, 66, 70, 72-74, 83, 86, 91, 93, 97, 102, 116, 119, 121, $129,148,156-162,171,183-$ 184, 186-188, 190-192, 194, 198-214, 219-253

Community 6-254

Community as network 10

Community as typology 12

Community cohesion 49, 224, 226, 240

Community Fireguard 210-211, 243

Community norm 235

Complex human disasters 1

Controlled burning 172

Cooperation 24, 76, 88, 209, 212

Cosmology 171

Cost-benefit analysis 233

Councils 158, 160, 162, 185, 187, 192

Creation of firebreaks 183
Crisis management 38, 82, 8689, 91-92, 94, 100

Crisis management continuum 87

Crisis recovery 91, 284

Cyclone 22, 35, 37-40, 42, 45, 48, 52, 54-55, 57-59, 61-62, 67, $84,107-108,119-121,125,129$ 140, 142-156, 166

Cyclone Bernie 154

Cyclone J ustin 37

Cyclone Ted 130-133, 136, 142, 148-149, 152-153

Cyclone Tracy 24, 139-141

Cyclone Zoe 23, 27

CYPDA 172, 178

CYPLUS 191

D

Darwin 35-36, 139-140, 142, 153, 157

Defence forces 23-24

Defining community 9, 15

Denham Island 140-141

Department of Communities 159

Department of Natural Resources 271

Destructive winds 119, 134

Developing countries 23, 25, 7581

Development 8, 13, 24, 27, 29-31, $42,48,54,60-61,65,70-7174-$ 77, 79, 82-85, 88-89, 91-92, 94, 160-161, 188, 194, 197, 201-202, 215, 247

Dingo 114-115

Dinner camps 162-164, 171

Djigūrrumbanda 127

Disabled 61

Disaster subculture 226

DOGIT 8, 158, 160, 162, 178, 183, 185 
Dreamtime 102, 108, 112-113, 116, 119, 125

\section{$\mathbf{E}$}

Earthquake 35, 42-44, 46, 48-49, $63,65,68,73-74,84,202-203$

East Timor 31

Education 33, 42-46, 49, 56, 61$62,71,89,92,98,125,160$, $170,186,198,206,211,213$ 225, 228, 248

Edward River Mission 188

Effective communications 61

Eidsvold 118

Elderly 8, 61

EMA 19-20, 23

Emergency management 18-21, 23-29, 32-34, 42, 45, 49, 63, 78

Emergency response 94

Empirical community 12, 15

Equal 14, 23, 74, 234, 244

Evacuation 21, 36, 38-39, 41, 43, 48-49, 52, 54-58, 60-62, 67, $85,89,202-204,229$

Evacuation layers 56-57

Evaluation 84, 88, 210-211, 213214,233

Extreme weather impacts 102

$\mathbf{F}$

FEMA 19

Fiji 24

Fire 60, 65, 104, 106, 108, 119, 147, 157, 162-164, 172-183, 190, 194-195, 197-198, 201254

Firebreaks 175, 182-183, 218

Fire hazard management 157

Fire regimes 174, 182
Fire services 201, 207, 214, 242, 244, 249

Fishing permits 171

Flammability 197

Flood 21-22, 36, 38-40, 42-43, 48-62, 84, 103-105, 107-119, 126, 241, 251

Floodplain 54

Flood points 52-53, 55, 58

Flowering 121, 124

G

Grass Clan 173

Gulf of Carpentaria 39, 106, 126, $130,143,150,171$

Gununa 127, 129-130, 135-136, 139-140, 143-145, 148, 150151, 154

$\mathbf{H}$

Halls Creek 112, 114, 122-123

Hazard 6, 9, 16, 32-33, 35, 40-41, $43,45-47,49,63-66,71,74$, $80,82,84-85,88,94,129$, 173-174, 183, 192, 203, 218219, 221-222, 224, 227-228, 235, 241, 252

Hazard reduction 201, 243, 247, 252

Hinterland 160, 162-163, 171, 193

Homeland 127, 155, 164, 167, 170, $183,187-190,192-193$

Homeowners 80, 202, 214, 218, $223,225,232,246-248,250$ 251, 254

Hope Vale 158, 193

Hurricane Floyd 241 
Implementation feasibility 233 Indigenous 37-39, 102, 119, 121, 124-127, 129-132, 134, 143, $145,147,151,153,183-184$

Individuals 26

Indonesia 31, 69, 93, 100

Infirm 61, 66

Inquiry 198

Insurance policy 253

Insured loss 68-69, 78

Integrated Planning Act 1997 160

Interface zones 201, 204, 215

I'ygow 166

i-Zone 197-198

\section{J}

Jamaica 178

Jaum 122

Jimberan Bay 99

$\mathbf{K}$

Kalkadoon Aboriginal people 105

Kalumburu 122

Kiaidilt Aboriginal people 132

Kimberley 102, 108, 115-116, 118, 121-124

Kobe disaster 44, 63-64

Kokoberra Aboriginal people 164, 167

Kokomunjen Aboriginal people 164

Kowanyama 157-158, 161-169, $171,174,180,182-186,188-$ 192

Kuku-Yalangi people 6

Kup murri 163-164

Kunjen country 166
Kununurra 122

Kuta 93-94, 97

Kuuk Thaayore country 169, 188

$\mathbf{L}$

Lagoons 164

Lake Gregory 110, 112-113, 115

Landslide 49, 65, 73, 84, 94

Lardil Aboriginal people 106-107, 126-129, 131-134, 136-139, 142-146, 150-151, 154-155

Larūmbanda 127

Lee-a-lin 142

Leelūmbanda 127

Lightning strikes 122, 172, 205

Lizard 106, 111, 117-118, 124

Local environment 103

\section{M}

Magnetic Island 36, 50, 52, 60-61

Maintenance of fire 172

Maximise tourist safety 60

Military 95, 99

Minimise loss 48, 57, 73

Mission 8, 108, 128-129, 133-135, $152,155,161,170,188$

Mission Bay 106

Mitchell River 166

Mitchell River Mission 188

Mitigation 16-17, 19-22, 27, 29, 33-34, 41-42, 70-71, 73-74, 76-77, 80, 87-89, 173, 179, $192,198,206-208,210-$ 211, 232-233, 239, 241, $243,245-247,251-252$

Mobile or fixed sirens 52, 60, 62

Monsoon 119, 121, 139, 151

Moral community 12-14 
Moral story 118

Mornington Island 36-37, 105106, 108, 126-131, 136, 141, 143-155

Mornington Shire Council 128

Mount Isa 105, 126

Mowanjum Mission 108, 110, 116

Mulan 114-116, 122-123

Mulung 142

$\mathbf{N}$

Native Title Act 1993 160, 162, 193

Native Title Amendment Act 1998 $160,162,193$

Natural and anthropogenic hazards 63, 65, 71

Natural Disaster Risk Mitigation 173, 179

New Orleans 47

New South Wales 211, 216, 226

Ngarjaia 108

Nhulunbuy 143

Normalisation bias 222

Normanton 36, 157

Northern Territory 35, 110, 136, $139,144,148,157$

North Queensland 6, 48, 50, 62, 103-104, 106, 119, 157

$\mathbf{O}$

Old people 103, 133, 137, 145-147, 165

Oombulgurri 122, 124

Optimistic bias 222

Outstations 6, 127, 161-162, 166$167,170,182-183$

Own community 103
$\mathbf{P}$

Palm Beach 106

Palm Island 120, 158

Paruku 110, 115

Perceptions 9, 37-38, 84, 86, 90, 97, 183, 219, 221-224, 226$228,232,241,245,251252$, 254

Peri-urban area 157, 160, 174, 217-219, 223-224, 226-228, 235, 246

Peri-urban community 226

Peri-urban landscapes 157, 162, 170,187

Philippines 31, 42, 46

PNG 23-24, 31

Pormpuraaw 157-158, 161-162, 170-171, 173-174, 178-179, 182192

Post-disaster studies 22, 34-36, 38-39, 43

Precautionary 48-49, 52, 57, 60, $62,102,182$

Preparations 22, 38, 46, 105, 151, $184,203,205,236,239$

Preparedness 19, 87

Prescribed burning 245-249, 252

Prevention 18-20, 24, 33, 49, 76, 87, 205-207, 218, 243, 251-252

Promotion and marketing 100, 161

Public education 49, 58, 61, 89, 98, 213, 248

Public involvement 57-58, 210, 284

Public risk 90 
Quartz 105

Queensland 6, 7, 24, 35, 38, 48, 50, 60-62, 103-106, 118-119, $121,148,157-162,183$

Question 6, 9, 12, 187, 206, 240

$\mathbf{R}$

Readiness 87

Recovery 87-92, 94-97, 99-100, 172, 206, 235-236, 240-241, $243,249,251,253$

Reduction 44, 48, 63, 70-73, 7677, 80, 86-89, 97, 103, 174175, 182, 201, 206, 218, 226, $232,243,245,247-248,252$, 254

Relief 24-25, 27-31, 34, 43, 64, 75, 79, 85, 87, 89, 250

Remote Aboriginal communities 157, 183, 187, 190

Resolution 92

Response 19, 87

Responsibility 8, 22, 24, 27, 34, $44,60,66,71,99,173,202-$ 204, 207-208, 210-211, 218, $229,232-233,237,240,242-$ 243, 245-246, 253

Ringer Soak 121, 122

Risk 97-99, 103, 118, 155, 162, 172-175, 179, 182-184, 187, 190, 192, 194, 197-198, 201, 203-204, 206-207, 209, 211, $214,217-254$

Risk management 64-66, 71-74, 76-77, 79, 81, 88, 118, 183184, 187, 190, 192, 197, 206

Risk perception87, 90, 98, 218, 221-228, 235

Risk reduction 87

Risk treatment options 179
Road network 204

\section{$\mathbf{S}$}

Safety and security $81,87,89-90$, 96, 99-100

Safety weather warnings 103, 125

Salmon 142-143, 171

Self-reliance 247

SES 8, 27, 61, 183

Severe restrictions 54

Shelter 22, 48-49, 54, 57-58, 60$62,64,103,112,121,131,133-$ 134, 140, 144-145, 147, 164, 203, 240

Social/community norm 235

Social organisation 160-161, 171, 185-186, 188, 191

Solomon Islands $23,27,31,36$, 41

South Australia 211, 216

Stakeholders 20, 72, 82-83, 86, 88, 90-92, 96, 99, 101, 206, 209-210, 215

Strathgordon 173, 178

Strong political support 58

Sturt Creek 113-116

Survey techniques 15

Sustainable development 48, 84, 91

Sustainable urban development 54

$\mathbf{T}$

Tasmania 207, 211

Terrorism 31, 36, 69, 73, 81, 85, 95, 97-100,

Theory of Reasoned Action 245 
The Dry 106, 119, 123-124, 126, 161-165, 172-174, 183

The Wet 8, 9, 39, 60, 106, 119, $121-124,126,142,160,163,171$

Tourism crisis $82,86-88,92-93$, 96, 101

Tourism disasters 74

Tourism risk management65, 81

Tourist-reliant destinations 8283

Tourists and tourism 42

Townsville 36-37, 39, 51-52, 120 , 157, 191

Tsunami 23, 35-36, 41-42, 46, 48-49, 65, 84, 98, 105, 109, 203

$\mathbf{U}$

Understanding 12, 29, 33-34, 4344, 46, 66-67, 72, 75, 92,127, $151,185,191,206-208,218-$ 223, 226-231, 247

Upheaval 154

Urban 157, 160, 174, 191, 205-206

USA 245, 249, 252

$\mathbf{V}$

Victoria 43, 210-211, 216, 223224

Vulnerability $33,35,38,41-42$, 44, 46, 49, 52, 63-65, 70-75, 77, 79, 82, 84-86, 88, 91-93, 101, 222-223, 225

Vulnerability of individuals 49

Vulnerability reduction 63,70 $73,77,86$

Vulnerable communities 44,54 , 61, 102

\section{W}

Wandjina 108, 116-118

Weather warnings 103, 118, 125

Weipa 140-141, 143

Wellesley Island 126, 146

Western Australia 108, 110, 157, 194

Wik Aboriginal people 188

Woorabindah 158

World Trade Center 44, 69, 96

Wyndham 114, 122

\section{$\mathbf{Y}$}

Yarrabah 104-105, 119-120, 158

Yir Thangedl country 168-169

Yir Yoront country 164, 169, 188 


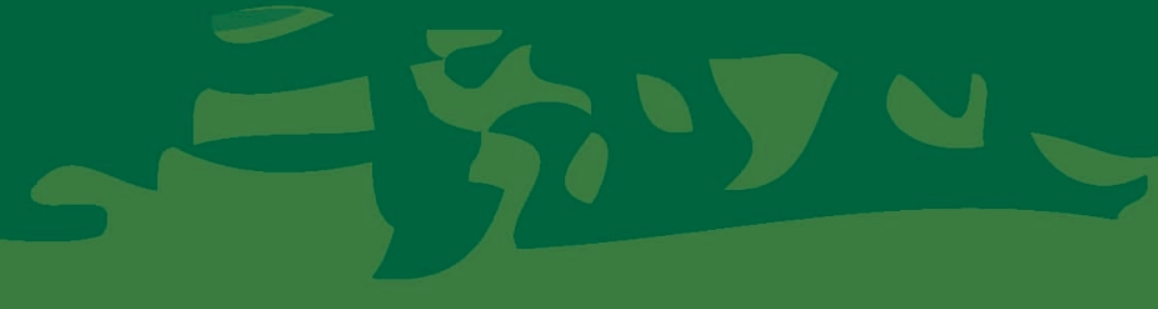

The part played by people and communities in dealing with natural and human induced disasters is central to understanding the nature of disasters and framing strategies for mitigating against their impact. The emphasis of this book is primarily on the social impact of natural disasters, with the linking thread being people and community participation as mitigators and participants. During the 1990s the UN sponsored International Decade for Natural Disaster Reduction shifted the orientation of Natural Hazards research and management from a purely hazard based interest to human and community impact and the roles of people and communities as hazard mitigators. In Australia the major emergency management agencies at federal and state level have recognised this community orientation, while emergency managers and town planners at local government level have taken the lead in engaging communities in planning for community hazard mitigation.

In recognition of twenty five years of research through the Centre for Disaster Studies, this book presents a range of the hazards, communities and events that centre members have investigated. Participation in many disasters both within Australia as well as overseas in the Asia Pacific region, provides a wealth of experience, both theoretical and practical, that is expressed from the point of view of the communities that live alongside hazards. 